\title{
Jean-Jacques Rousseau
}

\author{
Lettres
}

$(1728-1778)$

Un document produit en version numérique par Mme Diane Brunet, collaboratrice bénévole

Courriel: brunet_diane@hotmail.com

Dans le cadre de la collection: "Les classiques des sciences sociales" dirigée et fondée par Jean-Marie Tremblay, professeur de sociologie au Cégep de Chicoutimi

Site web: http://www.uqac.uquebec.ca/zone30/Classiques_des_sciences_sociales/index.html

Une collection développée en collaboration avec la Bibliothèque

Paul-Émile-Boulet de l'Université du Québec à Chicoutimi

Site web: http://bibliotheque.uqac.uquebec.ca/index.htm 
Cette édition électronique a été réalisée par Diane Brunet, bénévole, brunet_diane@hotmail.com

à partir de :

\section{Jean-Jacques Rousseau}

Lettres (1728-1778) Présentation, choix et notes de Macel Raymond. Lausanne : La Guilde du livre, 1959, 337 pp.

Polices de caractères utilisée :

Pour le texte: Times, 12 points.

Pour les citations : Times 10 points.

Pour les notes de bas de page : Times, 10 points.

Édition électronique réalisée avec le traitement de textes Microsoft Word 2001 pour Macintosh.

Mise en page sur papier format

LETTRE (US letter), 8.5'” x 11'’)

Édition complétée le 3 septembre 2004 à Chicoutimi, Québec.

\section{G Fait avec}




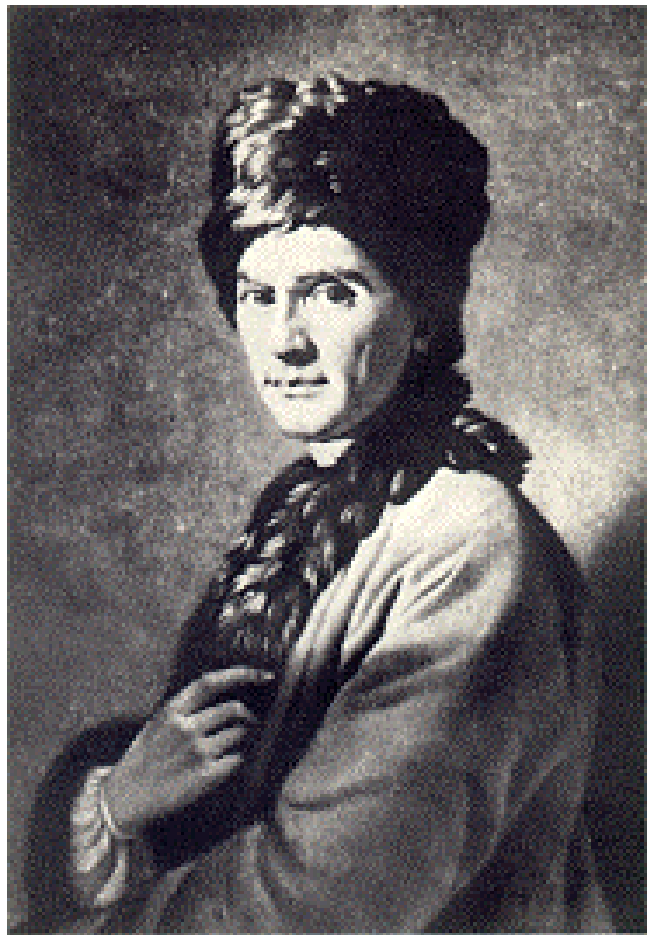

\section{Illustration 1}

\section{Jean-Jacques Rousseau} peint par Ramsay

$\underline{\text { Retour à la table des matières }}$ 


\section{Table des matières}

Introduction

I - Jeunesse irrégulière

Lettre 1: À un cousin [1728]

Lettre 2: À Mlle Giraud à Annecy [Neuchâtel, été 1731]

Lettre 3: À Isaac Rousseau, son père, à Nyon [Neuchâtel, été 1731]

Lettre 4: À Mme de Warens, à Chambéry [le 29 juin 1733]

Lettre 5: À Mme la baronne de Warens, à Chambéry [À Cluses, le 31 août 1733]

Lettre 6: À Isaac Rousseau à Nyon] [Chambéry, fin de 1735]

Lettre 7: À Mlle La Bussière, à Lyon [1735-I742]

Lettre 8: À Mme de Warens à Chambéry [À Grenoble, le 13 septembre 1737]

Lettre 9: A Mme de Warens, à Chambéry [le 23 octobre 1737]

Lettre 10: À M. (X***) [Vers I739]

Lettre 11: À Mme de Warens, à Chambéry [Charmettes, 18 mars 1739]

\section{II - $\quad \underline{\text { Les années difficiles }}$}

Lettre 12: À Mme de Warens, à Chambéry À Lyon, \}le 1er mai 1740]

Lettre 13: À M. Dupin [Paris, le 10 avril 1743]

Lettre 14: À M. de Conzié [comte des Charmettes, À Venise, ce 21 septembre 1743]

Lettre 15: À M. du Theil [À Paris, le 11 octobre 1744]

Lettre 16: À M. de Voltaire [À Paris, le 11 novembre I745]

Lettre 17: À M. Altuna [Å Paris, le 30 juin 1748]

Lettre 18: À M. de Valmalette [Maître d'Hôtel du Roi, à Paris] (fragment), Vers 1749-1751]

Lettre 19: À M. de Voltaire [À Paris, le 30 janvier 1750]

\section{III - La réforme intérieure}

Lettre 20: À Mme de Francueil [À Paris, le 20 avril 1751]

Lettre 21: À Mme de Créqui [À Paris, le 9 octobre 1751]

Lettre 22: À Mme [la marquise de Créqui] [Paris] Ce samedi [Vers 1752]

Lettre 23: A Mme de Warens, [née baronne de la Tour, à Chambéry, À Paris, le 13 février 1753]

Lettre 24: À Mme d'Epinay [Ce dimanche matin, mai 1754

Lettre 25: À Mme Goncerut [née Rousseau, à Nyon, À Genève, le 11 Juillet 1754] 
Lettre 26: À Mme Dupin [rue Plâtrière, à Paris, À Genève, le 20 juillet $1754]$

Lettre 27: À M. de Lastic [À Paris, le 20 décembre 1755]

Lettre 28: À Mme Dupin [Ce lundi matin, 1755 ?]

Lettre 29: À M. Perdriau [ministre du saint Évangile et pasteur à Genève, À Paris, le 20 février 1755

Lettre 30: À M. Jacob Vernes [ministre du saint Évangile, à la Cité, à Genève. À Paris le 2 avril 1755]

Lettre 31: À Voltaire [À Paris, le 10 septembre 1755]

Lettre 32: À Mme d'Epinay [Vers mars 1756]

Lettre 33: À Mme d'Epinay, [à Paris, Le 16 ou le 17 mars 1756]

Lettre 34: À Mme d'Epinay, [à Paris, ce mardi [22 mars ( ?) 1756]

IV - Le démon de midi

Lettre 35: À Mme d'Epinay [L'Ermitage, 12 avril I756]

Lettre 36: À Mme d'Epinay, [à Paris, ce samedi 1er mai [1756]

Lettre 37: À Mme d'Epinay, [à Epinay, de l'Ermitage, avant le 17 septembre 1756]

Lettre 38: À Mme d'Epinay, [rue Saint-Honoré, vis-à-vis les Capucins, à Paris. Ce mercredi, etc. (sic), fin novembre ou début décembre 1756]

Lettre 39: A Mme d'Epinay, [rue Saint-Honoré, vis-à-vis les Capucins, à Paris. À l'Ermitage, le 13 mars [1757]

Lettre 40: À Mme d'Epinay, [rue Saint-Honoré, vis-à-vis les Capucins, à Paris. Ce jeudi soir, 17 mars 1757]

Lettre 41: À Mme [d'Epinay, ce samedi 26 mars 1757]

Lettre 42: À M. Diderot [26 mars 1757]

Lettre 43: À Mme d'Epinay [Ce dimanche matin. 29 mai 1757]

Lettre 44: À Mme d'Houdetot [Début de juillet 1757]

Lettre 45: À Sophie [Mme d'Houdetot, vers le 15 octobre 1757]

Lettre 46: À M. de Saint-Lambert [À l'Ermitage, le 29 octobre 1757]

Lettre 47: À Mme la comtesse d'Houdetot [Â l'Ermitage, le ler novembre 1757]

Lettre 48: À Mme d'Houdetot, [Ce 2 novembre jour de deuil et d'affliction, 1757]

Lettre 49: À Mme d'Houdetot, [Le 3 novembre 1757]

Lettre 50: À Mme d'Houdetot, [À l'Ermitage, le 10 novembre 1757]

Lettre 51: À Mme d'Epinay [À l'Ermitage, le 23 novembre 1757|

\section{V - $\quad$ Le commerce des Grands}

Lettre 52: À Mme d'Houdetot [Ce 5 janvier 1758]

Lettre 53: À Mme d'Houdetot [À Montmorency, le 10 janvier 1758]

Lettre 54: À Mme la comtesse d'Houdetot [Le 11 janvier 1758]

Lettre 55: À M. Diderot [Le 2 mars 1758]

Lettre 56: À un jeune homme [Printemps 1758]

Lettre 57: À M. d'Alembert [Ầ Montmorency, le 25 juin 1758]

Lettre 58: À M. M.-M. Rey [libraire à Amsterdam, à Montmorency, le 8 juillet 1758]

Lettre 59: À M. Romilly [étudiant à Genève À Montmorency, le 6 février 1759] 
Lettre 60: Au maréchal de Luxembourg [À Montmorency, le 30 avril 1759]

Lettre 61: A M. [le maréchal de Luxembourg] Au petit Château, le 27 mai 1759

Lettre 62: À Mme [la maréchale de Luxembourg] À Montmorency, le 29 octobre 1759

Lettre 63: À Mme de Verdelin [à Paris, mercredi 12 mars 1760]

Lettre 64: À M. Lenieps [À Montmorency, le 15 mai 1760]

Lettre 65: À M. de Voltaire [À Montmorency, le 17 juin 1760]

Lettre 66: À Mme de Luxembourg [Ce dimanche 26 octobre (1760)]

Lettre 67: À Mme la marquise de Verdelin [À Montmorency, le 5 novembre 1760]

Lettre 68: À M. Coindet [chez MM. Thelusson et Necker, rue Michelle-Comte à Paris, ce lundi matin, 19 janvier 1761]

Lettre 69: À Mme de Luxembourg [À Montmorency, le 12 juin 1761]

Lettre 70: À M. Du Parc [Dom Deschamps, à Montmorency, le 25 Juin 1761]

Lettre 71: A Jacqueline Danel [À Montmorency, le 22 juillet 1761]

Lettre 72: À M. Du Parc [Dom Deschamps], À Montmorency, le 12 septembre 1761

Lettre 73: À M. Moultou [À Montmorency, le 23 décembre 1761]

Lettre 74: À M. Roustan [ministre du saint Évangile, à Genève. À Montmorency, le 23 décembre 1761]

Lettre 75: À M. [de Malesherbes], À Montmorency, le 23 décembre 1761

Lettre 76: À M. [de Malesherbes]. À Montmorency, le 4 janvier 1762

Lettre 77: À M. de Malesherbes [À Montmorency, le 12 janvier 1762]

Lettre 78: À M. de Malesherbes [ À Montmorency, le 26 janvier 1762]

Lettre 79: À M. [de Malesherbes]. À Montmorency, le 28 janvier 1762

Lettre 80: À Mme la marquise de Créqui [À Montmorency, le 7 juin 1762]

VI - $\quad$ L'exil: 1762-1765

Môtiers, l'Île de Saint-Pierre

Lettre 81: Au maréchal de Luxembourg [À Yverdon, le 15 juin 1762]

Lettre 82: À Mlle le Vasseur [Yverdon, le 17 juin 1762]

Lettre 83: À Mylord Maréchal [Vitam impendere vero. Vers le 11 juillet 1762]

Lettre 84: Au Roi de Prusse [vers le 11 juillet 1762]

Lettre 85: À Môtiers-Travers, [Au roi de Prusse, Frédéric II], le 1er novembre 1762

Lettre 86: À Mlle Duchesne, sœur de l'Hôtel-Dieu de Montmorency. Môtiers, le 16 janvier 1763

Lettre 87: Au maréchal de Luxembourg [Môtiers, le 20 janvier 1763]

Lettre 88: À M. le maréchal de Luxembourg [Môtiers le 28 janvier $1763]$

Lettre 89: A M. Jacob [Favre premier syndic de la République de Genève]. À Môtiers-Travers, le 12 mai 1763

Lettre 90: À M. Grumet [curé d'Ambérieu. Môtiers-Travers, le 21 août 1763

Lettre 91: À Mme Boy de la Tour [À Môtiers, le 19 novembre 1763] 
Lettre 92: À M. Séguier de Saint-Brisson [22 juillet 1764]

Lettre 93: À M. Jean-André De Luc [banquier, rue de la Cité. À

Môtiers-Travers, à Genève le 20 octobre 1764]

Lettre 94: À M. Du Peyrou [à Neuchâtel. À Môtiers, le 4 novembre 1764

Lettre 95: A M. Duclos [Môtiers, le 13 janvier 1765]

Lettre 96: À M. Du Peyrou [à Neuchâtel, ce vendredi 12 avril 1765]

Lettre 97: A M. de Voltaire [31 mai 1765]

Lettre 98: À M. Guy [chez Mme la veuve Duchesne, rue SaintJacques, à Paris. À Môtiers-Travers, le 7 septembre 1765]

Lettre 99: À M. Guy, libraire à Paris. À l'île Saint-Pierre, au lac de Bienne, le ler octobre 1765

Lettre 100: Â M. Du Peyrou [à Neuchâtel. À l'île, ce 17 octobre 1765]

Lettre 101: À M. de Graffenried [bailli de Nidau. À l'île Saint-Pierre, le 20 octobre 1765]

Lettre 102: À M. Du Peyrou [Fin octobre 1765]

\section{VII - L'exil: L'Angleterre}

Lettre 103: À David Hume [Strasbourg, le 4 décembre 1765]

Lettre 104: À Mme de Verdelin [À Wootton, le 9 avril 1766]

Lettre 105: À Mme de Luze-Warney [Neuchâtel, en Suisse. À

Wootton, le 10 mai 1766]

Lettre 106: À M. de Mirabeau [(fragments) Vers le 25 mars 1767]

Lettre 107: À M. Davenport [Â Wootton, le 30 avril 1767]

Lettre 108: To Richd Davenport Esqr., at Wootton, Ashburnbag, Derbyshire. [Turn at Stilton. A Spalding en Lincolnshire, le 11 mai 1767 (lundi)]

Lettre 109: Au général Conway [Douvres, vers le 18 ou 19 mai 1767]

\section{VIII - La vie cachée: Trye - Bourgoin - Monquin}

Lettre 110: À M. de Mirabeau [Ce vendredi 19 juin 1767]

Lettre 111: À M. Coindet [Hôtel le Blanc, rue de Cléry, à Paris. À Gisors, le 27 juin au soir 1767]

Lettre 112: A M. Coindet, à l'Hôtel le Blanc, rue de Cléry, à Paris, ce 28 juin 1767]

Lettre 113: À Mme [la marquise de Verdelin] Au Château de Trye, le 22 juillet 1767

Lettre 114: Au prince de Conti [À Trye, le 19 novèmbre 1767]

Lettre 115: À M. d'Ivernois [négociant à Genève. À Trye, le 29 janvier 1768]

Lettre 116: Au prince de Conti [Trye-le-Château, (18?) juin 1768]

Lettre 117: À M. Du Peyrou [Lyon, le 20 juin 1768]

Lettre 118: À Mlle le Vasseur [sous le nom de Mle Renou. Grenoble, ce 25 juillet 1768, à trois heures du matin]

Lettre 119: À Mme de Lessert [née Boy de la Tour, à Lyon. À Bourgoin, fin août 1769]

Lettre 120: À M. Laliaud [À Bourgoin, le 28 novembre 1768]

Lettre 121: À M. Tissot [professeur en médecine, à Lausanne. À Bourgoin, janvier 1769]

Lettre 122: À Mme Rousseau [Monquin, ce samedi 12 août 1769] 
Lettre 123: À Mme Boy de la Tour [née Roguin, à Lyon. À Monquin, le 19 septembre 1769]

Lettre 124: Ầ Mme Boy de la Tour [née Roguin, à Lyoné À Monquin, le 6 octobre 1769]

Lettre 125: À Mme de Lessert [née Boy de la Tour, rue Piset, à Lyon. A Monquin, le 3 novembre 1769]

Lettre 126: À M. Laliaud [À Monquin, le 30 novembre 1769]

Lettre 127: À Mme Boy de la Tour [née Roguin, à Lyon. À Monquin, le 2 janvier 1770]

Lettre 128: À Mme de Berthier [À Monquin, le 17 janvier 1770]

Lettre 129: À Mme B. [de Berthier]. Monquin, le 16 mars 1770

IX La vie cachée: Paris

Lettre 130: À M. Dusaulx [Paris, ce 4 de janvier 1771]

Lettre 131: À M. Bernardin de Saint-Pierre [Ce vendredi 3 août 1771]

Lettre 132: À M. Linné [Paris, le 21 septembre 1771]

Lettre 133: À Mme [Delessert, à Lyon]. À Paris, le 6 décembre 1771]

Lettre 134: À Mme la comtesse d'Egmont [Vers 1771]

Lettre 135: À Mme la marquise de Créqui [Août (?) 1773]

Lettre 136: À Glück [Paris, le 17 avril 1774]

Lettre 137: Au prince Beloselski [À Paris, le 27 mai 1775]

Lettre 138: À Mme de Corancez [À Paris, le 9 janvier 1778]

Lettre 139: À M. [le comte Duprat]. À Paris, le 3 février 1778

$\underline{\text { Table des illustrations }}$ 


\section{Table des illustrations}

Retour à la table des matières

1. Jean-Jacques Rousseau. Portrait fait par A. Ramsay en 1766, gravé par J.E. Nochez en 1769.

2. Habitation de Jean-Jacques Rousseau aux Charmettes. Près Chambéry. Signée : J. Werner del. Lith. J. Perrin Libr. Edit. à Chambéry.

3. Planche représentant l'Ermitage de Montmorency signée à gauche : Guyot del, au milieu : Aubert aqua forti, à droite : Gossard, sculp. (Une petite planche analogue avait été dessinée en 1819 par C. Bourgeois.)

4. 12e figure de Gravelot pour la Nouvelle Héloüse gravée par J. Folkéma pour une édition qui parut à Amsterdam, en 1761, chez Marc-Michel Rey, en 6 volumes in-12.

5. Môtiers-Travers, habitation de Jean-Jacques Rousseau, dessiné et gravé par Sigismond Himely (1801-1872).

6. Vue de l'Isle de Rousseau, prise à l'Isle des Lapins. Signée Lorig fc. C'est la 8e planche de l'opuscule de Sigismond Wagner paru vers 1814 à Berne chez G. Lory et C. Rheiner, peintres, sous le titre: «L'île de St. Pierre dite l'Ile de Rousseau, dans le lac de Bienne. »

7. Vue du Donjon de Trye-le-Château. Grande planche folio dessinée par Villeneuve en 1820 ; et lithographiée par F. Delpech.

8. La ferme de Monquin en son état actuel.

Ces estampes, qui appartiennent à la Bibliothèque Publique et Universitaire de Genève, ont été photographiées par Jean Artaud, à Genève. 


\section{Jean-Jacques Rousseau Lettres (1728-1778)}

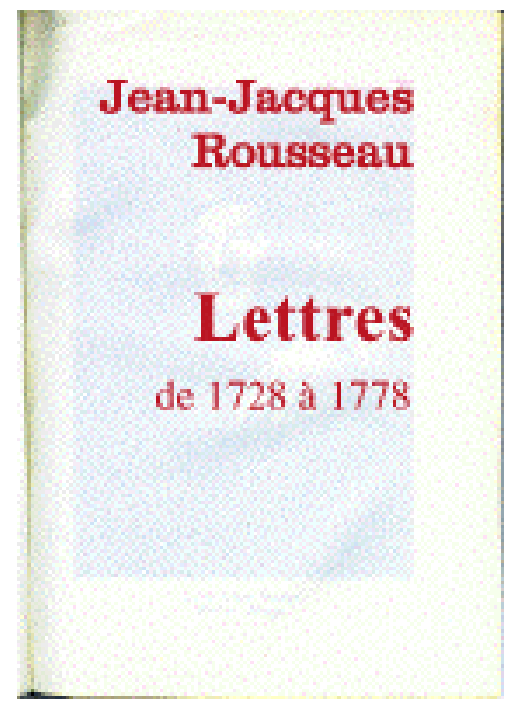

Présentation, choix et notes de Macel Raymond.

Lausanne : La Guilde du livre, 1959, 337 pp. 


\title{
Introduction
}

\author{
Par Marcel Raymond
}

\section{$\underline{\text { Retour à la table des matières }}$}

« Dans un siècle où il n'est presque personne qui ne soit grand écrivain et qui n'écrive avec une maîtrise aisée et heureuse, Rousseau est le premier à écrire avec ennui, mauvaise conscience et le sentiment d'une faute qu'il lui faut aggraver sans cesse pour s'efforcer d'y échapper. » De cette phrase si judicieuse de Maurice Blanchot ${ }^{1}$, rapprochons cette autre où il remarque, après Jean Starobinski ${ }^{2}$, que Rousseau « inaugure ce genre d'écrivain que nous sommes tous plus ou moins devenus, acharné à écrire contre l'écriture... puis s'enfonçant dans la littérature par espoir d'en sortir, puis ne cessant plus d'écrire parce que n'ayant plus la possibilité de rien communiquer. » Il y a chez Rousseau un drame de l'écriture, qui se rattache à son drame personnel: comment se connaître soi-même, comment se faire reconnaître pour ce qu'on est ? Et il y a d'abord un paradoxe de l'écriture et de toute espèce de langage parlé, la parole trahissant nécessairement (moins cependant que le mot sur la page) ce qu'exprimerait un langage plus pur: le chant, ou encore ce langage premier, naturel, qui se révèle dans l'intonation et surtout dans le geste corporel, dans le jeu de la physionomie, dans le regard.

À dix reprises, Rousseau assure qu'écrire et penser le fatigue, que son tempérament trop ardent l'éblouit, l'égare, et qu'il a besoin d'attendre, avant de saisir sa plume, que les idées s'arrangent dans sa tête, ce qu'elles ne font

N.R.F. du 1er juin 1958: Jean-Jacques et la Littérature.

Jean-Jacques Rousseau, la Transparence et l'Obstacle, Plon, 1958. 
«qu'avec la plus incroyable difficulté » ${ }^{3}$. Au reste, le papier blanc le glace. Souvent, il compose durant ses insomnies, dictant au matin à la mère de Thérèse ce qu'il a retenu de son travail nocturne. Plus souvent et avec plus de bonheur, il écrit à la promenade. À la fin de sa vie, il a toujours sur lui quelques tablettes ou des cartes à jouer qu'il couvre de phrases crayonnées, dont un certain nombre sont conservées à Neuchâtel.

Mais là où il réussit le moins, c'est aux ouvrages « qui veulent être faits avec une certaine légèreté, dit-il, comme les lettres » ${ }^{4}$. Le ton du genre lui est étranger, à ce qu'il prétend : " Je n'écris point de lettres sur les moindres sujets qui ne me coûtent des heures de fatigue, ou si je veux écrire de suite ce qui me vient, je ne sais ni commencer ni finir, ma lettre est un long et confus verbiage... » Il est certain que sa timidité, l'irrégularité de son régime nerveux, l'incapacité qui est la sienne de se situer dans le monde, de préciser sa relation à son prochain, et encore la sourde plainte d'une conscience de soi trop exigeante, tout cela contribue à «enlacer» une âme qui ne rêve que de s'épancher, de se dégager. Vers le 25 mars 1767, dans un brouillon de lettre au marquis de Mirabeau, Rousseau note : «... Vos lettres me plaisent et me font du bien ; mais écrire me fait un mai extrême ; écrire est un devoir qui me tue ; je ne puis me soumettre à ce devoir que par la plus forte nécessité. Dans tous mes projets de béatitude temporelle, n'avoir ni montre ni écritoire a toujours été mon article favori. »

Toutefois, la correspondance générale, quoique incomplète, occupe vingt volumes in-octavo, y compris, il est vrai, celles qu'on possède parmi les lettres des correspondants de Rousseau. En réalité, peu d'hommes ont pris plus au sérieux le "devoir d'écrire », de répondre aux inconnus mêmes qui sollicitaient appui et conseil. Peu ont eu un plus grand souci de s'expliquer, de justifier leur conduite et parfois au prix d'une dialectique périlleuse, vertigineuse - insupportable. Allons plus loin : qui dira que les lignes qui précèdent, à l'adresse de Mirabeau, ne sont pas bien venues, qu'elles n'atteignent pas leur but, que l'auteur n'y suit pas au plus près le mouvement de sa pensée ? C'est qu'il y est question de lui-même. Quand l'occasion s'offre de glisser à la confidence, de se découvrir, de laisser voir le fond de son cœur, mais à un ami véritable, en qui il a mis sa confiance, Moultou, Malesherbes, le maréchal de Luxembourg - cette confiance qu'il se croira presque toujours, à l'épreuve, dans l'obligation douloureuse de reprendre - Rousseau s'exprime sans gêne, sa parole coule de source, il invente le tour le plus adroit ou le plus ferme. Que la passion l'anime, ou le dépit, ou la « félicité » qu'engendre l'amour ou l'amitié, son langage acquiert soudain une immédiateté qui enchante. Écrit-il à Thérèse, à un homme du peuple, c'est comme il parle. Plus de détours, de préciosité ou d'afféterie, aucune de ces contorsions que fait naître l'intention de plaire, ou seulement le souci de la politesse chez un être qui a « des sociétés au-dessus de sa condition ». Et il faut bien admettre que Rousseau, une fois levés les obstacles et les inhibitions qui, d'ordinaire, liaient sa langue, pouvait se montrer d'une éloquence spontanée singulièrement prenante. Un témoin de sa vieillesse, le latiniste Dusaulx (et ce témoin manque le plus souvent de bienveillance !), déclare : "J'ose dire qu'il ne se connaissait pas lui-même, lorsqu'il prétendait que la nature lui avait refusé le talent de la parole : la

Confessions, livre Ill.

Confessions, livre III. 
solitude sans doute avait concentré ce talent en lui-même; mais dans ses moments d'abandon, et lorsque rien ne l'offusquait, il débordait comme un torrent impétueux à qui rien ne résiste. » ${ }^{5}$ Les vertus de l'orateur, de l'écrivain, sont bien en lui des données premières. Mais ces vertus ne trouvent leur plein emploi que lorsque l'occasion et les circonstances le permettent. Ou bien c'est par le patient détour d'un effort raisonné, qui brise mille contraintes, que se conserve, dans le discours volontaire, quelque chose de la force originelle.

Ainsi, on aurait tort de chercher, dans les lettres de Rousseau, le ton et le style d'un grand épistolier. On n'y sentira ni « la pétulance militaire » (je cite Baudelaire) qui caractérise l'auteur de Candide, ni la pulsation vitale et le continuo des lettres de Diderot à Sophie Volland, ni les emportements et les exaltations de minuit d'un Flaubert, toutes portes closes et la page de prose parachevée. Ce qu'on y rencontre, plutôt qu'un philosophe, plutôt qu'un écrivain même, c'est un homme ; un homme habile et compliqué, mais que le métier d'écrire n'a pas sérieusement entamé, qui a de surprenantes réserves de simplicité, de délicatesse, d'innocence, en qui le travail de la réflexion n'a pas étouffé l'esprit d'enfance.

Beaucoup de ces lettres, de celles qui sont postérieures au séjour à Venise (1743-1744), sont d'un malade constamment occupé par des maux physiques qui paraissent dépendre d'une malformation congénitale et sur lesquels la correspondance fournit de-ci de-là, à l'adresse d'un intime ou d'un médecin, toutes les précisions désirables. Mais Rousseau est persuadé qu'il a «gagné la bonne santé en marchant », que ses promenades, si elles ne l'ont pas guéri, ont du moins apaisé ses souffrances. Il est de fait que, par un effet curieux de suppléance, le persécuté qu'il est devenu après la condamnation de l'Émile et du Contrat social (1762) semble mobiliser pour sa défense toutes ses puissances d'attention, après celles d'une imagination noire. Désormais, les maux physiques demeurent à la périphérie du champ de la conscience. Le mai moral, au contraire, avec l'idée fixe de la persécution, réelle ou imaginaire, se fait de plus en plus envahissant. Si nous avons écarté de ce Choix la lettre à M. de Saint-Germain, du 26 février 1770, où Rousseau décrit le «système » qui l'enserre - tel du moins qu'il l'entrevoit à cette date, dans les ténèbres, car sa pensée ne cesse pas d'échafauder de nouvelles hypothèses - c'est qu'elle est d'une ampleur démesurée. Il en est de même de la lettre à David Hume, du 10 juillet 1766, acte d'accusation dont chaque terme demanderait examen. On lira, en revanche, la longue lettre au prince de Conti, où Rousseau rapporte à son protecteur ce qui s'est passé entre Du Peyrou et lui, au château de Trye, dans la nuit du 9 au 10 novembre 1767, « fatale nuit, la plus terrible de [sa] vie ». Peu de pages jettent une lumière plus vive, plus meurtrière, sur les plaies d'un esprit malade, forcé par son démon à tout interpréter dans le sens du pire.

Pourtant, le récit fait au prince se poursuit sans une faiblesse stylistique, sans la moindre défaillance d'une pensée inexorablement présente à son mal, et maîtresse de son expression. Car il faut mettre en évidence, chez Rousseau, outre le phénomène des «intermittences du cœur», qui le fait différer si souvent de lui-même, d'un instant à l'autre - c'est ce qu'on a nommé son

5 De mes Rapports avec Jean-Jacques Rousseau, et de notre Correspondance, Paris, 1798. 
psychisme à renversement - celui du partage et de la quasi-autonomie des pouvoirs du moi, à un moment donné, qui laissent, après une première erreur d'aiguillage, l'intelligence intacte. Et on s'étonnera à bon droit de la cœxistence de la paranoïa et d'une pensée solide, capable d'argumenter avec force et clarté sur des matières de littérature, de morale et même de politique. Capable aussi de s'oublier, je veux dire d'oublier comme par enchantement tout ce qui l'assiège et menace de la détruire, le vent ayant tourné ; alors, JeanJacques ne parle plus que de chansons ou de fleurs. Sans doute, personne, passant d'un correspondant à l'autre, ne demeure le même homme. On cache ou on dévoile telle part de soi-même. Les uns semblent faits, pour accueillir les soupirs, les plaintes, pour apaiser l'angoisse. Devant d'autres figures, le respect humain joue son rôle. C'est ainsi qu'aux environs du 18 juin 1768, Rousseau jette au prince de Conti le cri de son honneur outragé. Mais deux jours après, avec un calme affecté, il écrira à Du Peyrou qu'il a pris la décision de quitter Trye pour chercher « dans un peu de voyages et d'herborisations » des amusements et des distractions. Une autrefois, alors qu'il semble au plus fort de son délire, il notera que, pour remettre d'aplomb sa tête, il aurait besoin de franchir les Alpes et d'aller à Turin « entendre de la bonne musique ».

Jean-Jacques a-t-il été heureux ? Certes, il a vécu pour le bonheur. Toujours, il a attendu l'heure où il entrerait enfin dans l'existence solitaire, passive, " oiseuse » pour laquelle il se sentait né. Rejeté toujours au-delà, il a essayé de rendre présents, par le jeu de l'imagination et de la mémoire affective, les moments si courts, si «fugitifs » où il avait cru respirer une odeur de paradis et qui lui donnaient le sentiment d'avoir vécu. Rien ne remplace, à cet égard, si l'on veut retrouver les étapes de cette quête, la lecture des Confessions, des Dialogues, des Rêveries. Mais ces ouvrages posthumes, médités et rédigés dans l'âge mûr et la vieillesse, sont une sorte de construction mythologique. C'est son propre mythe que Rousseau élabore et qui plonge ses racines dans son arrière-pensée, vérité et mensonge mêlés et tous deux révélateurs (à des degrés divers), puisque aussi bien le mensonge, le plus souvent indélibéré, et la poésie manifestent ici le sens et l'intensité du désir et du regret. Et quelle plus profonde vérité que celle du désir et du regret ?

La vérité de la correspondance est nécessairement à plus courte vue, elle tient compte de tous les accidents de l'existence, elle enregistre les secousses sismiques qui bouleversent quotidiennement un être hypersensible. L'éclairage y est parfois très différent, et le fait avait frappé Jean Guéhenno dès le commencement de son travail de biographe : «Sa vie fut en réalité plus sombre », dit-il dans l'introduction de son grand ouvrage ${ }^{6}$. Il entend plus sombre dans la réalité prise au jour le jour, telle qu'elle se reflète dans les lettres, que dans la peinture transposée que nous livrent les écrits autobiographiques. Hanté dans l'âge mûr par l'idée du complot dont il est la victime et par celle de la trahison de ses amis, Rousseau s'est retourné vers ses années de jeunesse avec une complaisance accrue. Dès l'hiver 1757-1758, il assure à Mme d'Houdetot qu'il «ne vit plus que dans sa vie passée », qu'il tient

6 Jean-Jacques, en marge des Confessions, 3 vol., Paris, Plon et Gallimard. 
désormais de son passé «tout son être » ${ }^{7}$. La dixième et dernière Promenade («Aujourd'hui jour de Pâques fleuries, il y a précisément cinquante ans de ma première connaissance avec Mme de Warens ») nous conduit au point le plus haut de cette recréation. Car nous savons maintenant que le plein bonheur des Charmettes n'a duré qu'une, peut-être deux saisons ${ }^{8}$. Et il est singulier, quoique explicable, que dans la troisième des lettres à Malesherbes (de janvier 1702), Rousseau n'en fasse nulle mention et s'arrête à la date de son arrivée à l'Ermitage (1756) comme au premier temps de son bonheur.

On peut se demander toutefois si, à partir de son exil à Môtiers et malgré les tempêtes de Wootton, de Trye, de Bourgoin, où il lui arrive d'être tout à fait conscient que «sa tête s'altère », que son esprit bat la campagne, Rousseau n'a pas souffert, je ne dis pas moins douloureusement, mais de façon moins continue que ne le laisseraient supposer ses écrits autobiographiques, et même sa correspondance. Combien de fois n'a-t-il pas affirmé : "Ici commence le court bonheur de ma vie »? Le bonheur résidant essentiellement pour lui en ce qui est proche de l'origine, tous ces commencements le ramenaient chaque fois à la source de sa vie, rendaient à son être une joie et une jeunesse qui coupaient court à sa «mélancolie » et le dépaysaient assez pour qu'il lui fût possible de changer d'âme. Sa recette, il l'a donnée : il faut «boire l'eau d'oubli »! Ceux qui l'ont fréquenté, au temps de son dernier séjour à Paris, vantent son naturel, sa gaieté. « De beaux sons, un beau ciel, un beau paysage » suffisaient à le tirer de l'ornière et «perçaient jusqu'à son cœur ». Un rafraîchissement continuel lui venait de ses sensations, dont s'emparait bien vite la rêverie. «On n'est jamais si heureux ni si malheureux qu'on l'imagine », a dit La Rochefoucauld. Propos désabusé d'un homme qui juge, comme Pascal, que l'imagination est « une maîtresse d'erreur et de fausseté ». Mais on peut admettre au contraire que dans le bonheur subjectif (en existe-t-il un autre ?) la part de la réalité et celle de l'imagination ne sont pas discernables, ou mieux que la réalité ne vaut que par la puissance de l'image, plus ou moins pénétrante et suggestive, qu'on est capable de s'en faire. L'âge d'or de l'humanité, pour Rousseau, c'est celui qu'il évoque dans son Discours sur l'inégalité, non point «état de nature » mais âge intermédiaire qu'il définit par cette formule heureuse : «L'espèce était déjà vieille, et l'homme restait toujours enfant. » 9

\section{MARCEL RAYMOND}

7 Correspondance générale, tome III, p. 362.

8 Voir le commentaire des Écrits autobiographiques, tome I des CEuvres complètes de Jean-Jacques Rousseau, collection de la Pléiade, 1959.

9 Tout choix est arbitraire et suppose une optique particulière. Par ce travail, qui n'avait jamais été fait, sauf erreur, en pays de langue française, c'est l'homme, les aspects si différents de sa nature, les principaux moments de sa destinée, que nous avons tenté d'éclairer. Peu ou pas de lettres «philosophiques », «théologiques »; nous avons renoncé aussi à mettre en évidence la part que prit Rousseau aux affaires politiques de Genève ; mais nous avons retenu quelquefois des billets où la façon de dire est plus significative que le contenu ; et nous avons groupé en deux ou trois occasions des billets qui se suivent et laissent voir le flux et le reflux d'une pensée, ses repentirs. Les notes qui accompagnent les lettres ne visent qu'à les rendre compréhensibles. C'est par la relecture des Confessions et par la connaissance de l'ensemble de l'œuvre de Rousseau qu'on se prépare à goûter vraiment sa correspondance. 
Jean-Jacques Rousseau, Lettres (1728-1778)

\section{Première partie}

Jeunesse irrégulière

$1728-1739$

\section{$\underline{\text { Retour à la table des matières }}$}

Orphelin de mère, Jean-Jacques Rousseau fut élevé à Genève par une tante qui lui laissa de «fortes impressions» et qui lui donna le goût de la musique. Le père est un personnage fantasque, horloger, maître à danser et grand liseur de romans. À Bossey, au pied du Salève, où il fut mis en pension avec son cousin, chez un pasteur, l'enfant fut heureux - jusqu'au jour oùune punition imméritée lui découvre l'injustice : « Nous restâmes à Bossey quelques mois. Nous y fûmes comme on nous représente le premier homme dans le Paradis terrestre, mais ayant cessé d'en jouir... »(Confessions, livre I). Avant qu'il eût treize ans, on fit de lui un apprenti-graveur, et il passa trois années mauvaises sous un maître difficile. Enfin, le 14 mars 1728, un dimanche soir, à son retour de promenade, Rousseau, trouvant fermées les portes de la ville, décide de quitter Genève.

Alors commence une adolescence semi-vagabonde, dans une Savoie sarde, adolescence qui se prolongera longtemps. A Annecy, un jour de Pâques fleuries, Jean-Jacques fait la connaissance de Mme de Warens: «Un visage pétri de grâces, de beaux jeux bleus pleins de douceur »(Confessions, livre II). On l'envoie à Turin s'instruire dans la religion catholique Le voici laquais, 
jalousé par ses compagnons, impatient, mécontent de lui-même. Il retraverse les Alpes : de 1729 à 1740, la maison de sa protectrice, à Annacy puis à Cbambéry, sera pour lui un havre de grâce. Tour à tour séminariste, pensionnaire à la maîtrise de la Cathédrale d'Annecy, plus tard employé au cadastre de Savoie, maître de musique (sachant peu de musique), interprète au service d'un faux archimandrite quêtant pour le rétablissement du Saint-Sépulcre, il ne s'éloigne guère de Mme de Warens qu'avec le désir de la rejoindre, ou parce qu'il sait qu'elle l'accueillera toujours. Dans une lettre de 1735, il supplie son père d'agréer qu'il passe auprès d'elle « le reste de ses jours ». S'il n'envisage qu'une vie brève, c'est que sa santé lui cause déjà de fréquentes alarmes, comme l'inquiète le personnage d'amant que Mme de Warens a choisi pour lui contre son gré afin de parfaire, pense-t-elle, son éducation virile. En 1735 ou en 1736, se place le premier séjour aux Charmettes, qui sera suivi de plusieurs autres. Retraite d'amour perdue ? Elle le fut fort peu de temps, «Maman » s'étant trouvé un autre «protégé », le maître valet Wintzenried (1737). Les Charmettes sont bien plutôt le lieu de la première expérience de la vie intérieure, des longs loisirs coupés par les travaux aimables et par de grandes lectures, des rêveries dans la nature, d'un bonheur qui s'illuminera peu à peu dans la mémoire ; mais c'est aussi le lieu des regrets : "Insensiblement je me sentis isolé et seul dans cette même maison dont auparavant j'étais l'âme » (Confessions, livre VI). Nouvelle chute dans la mélancolie, nouvel exil : à vingt-neuf ans, Jean-Jacques part pour Lyon en qualité de précepteur chez Mme de Mably. 


\section{Lettre 1}

\section{À [un cousin, à Turin]}

[1728 ?]

$\underline{\text { Retour à la table des matières }}$

Mon cher cousin,

Quoique tu m'écrives de la façon que tu écrirais à un étranger, je ne laisse pas de te répondre à notre manière accoutumée ; c'est donc sur ce ton que je tâcherai de t'éclaircir sur les reproches que tu me fais dans ta lettre. Premièrement tu peux voir par la preuve de mon amitié que tu tiens de ma main et que je te prie de ne jamais abandonner jusqu'à ce que je t'en puisse donner une plus évidente et sensible, si mon amitié est une amitié fardée et peu sincère comme tu me le marques, fondé sur ce que je n'ai fait paraître aucun déplaisir de ton éloignement, mais tu sais toi-même que nous en étions demeurés d'accord ensemble et que tu m'y avais sollicité, afin de [me] mettre à couvert du soupçon d'être d'intelligence avec toi, et Dieu sait si je n'ai pas cherché avec tout l'empressement possible à apprendre ton adresse à Turin afin de t'y faire tenir un papier parlant venant de ma main Par la voie d'un de mes amis qui est parti pour ce pays-là il y a quelques jours, qui est le fils de M. Dassier ; je te prie de le bien saluer de ma part si tu le vois; par tout cela tu peux connaître le caractère maudit de celui qui t'a incité à me faire ces reproches parce que je n'avais pas voulu le défrayer de la moitié du port de ta lettre ; je lui ai rendu l'argent des médailles, il a bien eu l'insolence de demander à ma tante Fazi l'argent que tu lui devais et a écrit deux fois à ton père pour ce sujet ; au reste c'est le garçon le plus intéressé que j'aie vu de ma vie, jusqu'à me mettre en trousse ses amis, des fils de bouchers, pour se faire payer 10 sous de Genève que je lui devais, et encore lorsqu'il savait que je n'avais point d'argent. À ce portrait reconnais l'indignité de son procédé et reviens des faux préjugés où tu es tombé à mon égard; quoi qu'il en soit, mon cher cousin, sois persuadé que rien ne saurait jamais m'empêcher d'être à ton égard le plus fidèle ami qui fut jamais. 


\section{Lettre 2}

\section{À [Mlle Giraud à Annecy]}

[Neuchâtel, été 1731]

$\underline{\text { Retour à la table des matières }}$

. . . . . . . serai bien certain de votre adresse et que vous m'apprendrez que vous avez reçu cette lettre, je ne doute pas que (vous) n'ayez conservé pour moi cette mểme bonté que vous m'avez témoignée jusqu'à présent ; ainsi je vous écris avec une certaine confiance que vous me pardonnerez, je crois, facilement. Ici répondons à votre chère lettre.

Je suis très sensible à la bonté que veut bien avoir Mme de Warens de se ressouvenir encore de moi. Cette nouvelle m'a donné une consolation que je ne saurais vous exprimer, et je vous proteste que jamais rien ne m'a plus violemment affligé que d'avoir encouru sa disgrâce. J'ai eu déjà l'honneur de vous dire, Mademoiselle, que j'ignorais les fautes qui avaient pu me rendre coupable à ses yeux, mais jusqu'ici la crainte de lui déplaire m'a empêché de prendre la liberté de lui écrire pour me justifier ou du moins pour obtenir par mes soumissions un pardon qui serait dû à ma profonde douleur, quand même j'aurais commis les plus grands crimes. Aujourd'hui, Mademoiselle, si vous voulez bien vous employer pour moi, l'occasion est favorable et, à votre sollicitation, elle m'accordera sans doute la permission de lui écrire, car c'est une hardiesse que je n'oserais prendre de moi-même. C'était me faire injure que demander si je voulais qu'elle eût mon adresse : puis-je avoir rien de caché pour une personne à qui je dois tout ? Je ne mange pas un morceau de pain que je ne reçoive d'elle ; sans les soins de cette charitable dame, je serais peut-être déjà mort de faim, et si j'ai vécu jusqu'à présent, c'est aux dépens d'une science qu'elle m'a procurée. Hâtez-vous donc, Mademoiselle, je vous 
en supplie, intercédez pour moi et tâchez de m'obtenir la permission de me justifier.

J'ai bien reçu votre lettre datée du 21 novembre adressée à Lausanne ; j'avais donné de bons ordres, et elle me fut envoyée sur-le-champ. L'aimable demoiselle de Graffenried est toujours dans mon cœur et je brûle d'impatience de recevoir de ses nouvelles ; faites-moi le plaisir de lui demander, au cas qu'elle soit encore à Annecy, si elle agréerait une lettre de ma main. Comme j'ai ordre de m'informer de M. Venture, je serais fort aise d'apprendre où il est actuellement. Il a eu grand tort de ne point écrire à $M$. son père qui est fort en peine de lui ; j'ai promis de donner de ses nouvelles dès que j'en saurais moimême ; si cela ne vous fait pas de la peine, accordez-moi la grâce de me dire s'il est toujours à Annecy et son adresse à peu près. Comme j'ai beaucoup travaillé depuis mon départ d'auprès de vous, si vous agréez pour vous désennuyer que je vous envoie quelques-unes de mes pièces, je le ferai avec joie, toutefois sous le sceau du secret, car je n'ai pas encore assez de vanité pour vouloir porter le nom d'auteur; il faut auparavant que je sois parvenu à un degré qui puisse me faire soutenir ce titre avec honneur. Ce que je vous offre, c'est pour vous dédommager, en quelque sorte, de la compote de curiosité qui n'est pas encore mangeable. Passons à votre dernier article qui est le plus important. Je commencerai par vous dire qu'il n'était point nécessaire de préambule pour me faire agréer vos sages avis, je les recevrai toujours en bonne part et avec beaucoup de respect et je tâcherai d'en profiter. Quant à celui que vous me donnez, soyez persuadée, Mademoiselle, que ma religion est profondément gravée dans mon âme et que rien n'est capable de l'en effacer. Je ne veux pas ici me donner beaucoup de gloire de la constance avec laquelle j'ai refusé de retourner chez moi ; je n'aime pas prôner des dehors de piété qui souvent trompent les yeux et ont de tout autres motifs que ceux que montrent [les] apparences ; enfin, Mademoiselle, ce n'est pas par divertissement que j'ai changé de nom et de patrie et que je risque à chaque instant d'être regardé comme un fourbe et peut-être un espion. Finissons une trop longue lettre; c'est assez vous ennuyer; je vous prie de vouloir bien m'honorer d'une prompte réponse parce que je ne ferai peut-être pas long séjour dans cette [ville]; mes affaires sont ici dans une fort mauvaise crise ; je suis déjà fort endetté et je n'ai qu'une seule écolière. Tout [le monde] est [en] campagne ; je ne sais comment sortir, je ne sais comment rester, parce que je ne sais point faire de bassesses. Gardez-vous de rien dire de ceci à Mme de Warens ; j'aimerais mieux la mort qu'elle crût que je suis dans la moindre indigence, et vous-même, tâchez de l'oublier, car je me repens de vous l'avoir dit. Adieu, Mademoiselle, je suis toujours avec autant d'estime que de reconnaissance [etc.]. 


\section{Lettre 3}

\section{À [Isaac Rousseau, son père, à Nyon]}

[Neuchâtel, été 1731]

$\underline{\text { Retour à la table des matières }}$

Mon cher père,

Malgré les tristes assurances que vous m'avez données que vous ne me regardiez plus pour votre fils, j'ose encore recourir à vous comme au meilleur de tous les pères, et quels que soient les justes sujets de haine que vous devez avoir contre moi, le titre de fils malheureux et repentant les efface dans votre cœur, et la douleur vive et sincère que je ressens d'avoir si mal usé de votre tendresse paternelle me remet dans les droits que le sang me donne auprès de vous ; vous êtes toujours mon cher père et quand je ne ressentirais que le seul poids de mes fautes, je suis assez puni dès que je suis criminel. Mais, hélas ! il est bien encore d'autres motifs qui feraient changer votre colère en une compassion légitime, si vous en étiez pleinement instruit; les infortunes qui m'accablent depuis longtemps n'expient que trop les crimes dont je me sens coupable, et s'il est vrai que les fautes sont énormes, la pénitence les surpasse encore.

Triste sort que celui d'avoir le cœur plein d'amertume et de n'oser même exhaler sa douleur par quelques soupirs, triste sort que d'être abandonné d'un père dont on aurait pu faire les délices et la consolation, mais plus triste sort de se voir forcé d'être à jamais ingrat et malheureux en même temps et d'être obligé de traîner par toute la terre sa misère et ses remords. Vos yeux se chargeraient de larmes si vous connaissiez à fond ma véritable situation, l'indignation ferait bientôt place à la pitié, et vous ne pourriez vous empêcher 
de ressentir quelque peine des malheurs dont je me vois accablé. Je n'aurais osé me donner la liberté de vous écrire si je n'y avais été forcé par une nécessité indispensable. J'ai longtemps balancé dans la crainte de vous offenser encore davantage ; mais enfin j'ai cru que dans la triste situation où je me trouve, j'aurais été doublement coupable si je n'avais fait tous mes efforts pour obtenir de vous des secours qui me sont absolument nécessaires. Quoi que j'aie à craindre de votre refus, je ne m'en flatte pas moins de quelque espérance ; je n'ai point oublié que vous êtes bon père, et je sais que vous êtes assez généreux pour faire du bien aux malheureux, indépendamment des lois du sang et de la nature qui ne s'effacent jamais dans les grandes âmes. Enfin, mon cher père, il faut vous l'avouer, je suis à Neuchâtel dans une misère où mon imprudence a donné lieu ; comme je n'avais point de talent que la musique qui pût me tirer d'affaire, je crus que je ferais bien de la mettre en usage si je le pouvais ; et voyant bien que je n'en savais pas encore assez pour l'exercer dans des pays catholiques, je m'arrêtai à Lausanne où j'ai enseigné pendant quelques mois, d'où étant venu à Neuchâtel, je me vis dans peu de temps, par des gains assez considérables joints à une conduite fort réglée, en état d'acquitter quelques dettes que j'avais à Lausanne ; mais étant sorti d'ici un peu inconsidérément après une longue suite d'aventures que je me réserve l'honneur de vous détailler de bouche, si vous voulez bien le permettre, je suis revenu, mais le chagrin que je puis dire sans vanité que mes écolières conçurent de mon départ a bien été payé à mon retour par les témoignages que j'en reçois qu'elles ne veulent plus recommencer, de façon que, privé de secours nécessaires, j'ai contracté ici quelques dettes qui m'empêchent d'en sortir avec honneur et qui .......

[C'est à de] pareils bienfaits que le Ciel réserve ses récompenses. Que ferais-je si vous me refusiez ? De quelle confusion ne serais-je pas couvert ? Faudra-t-il, après avoir si longtemps vécu sans reproche, malgré les vicissitudes d'une fortune inconstante, que je déshonore aujourd'hui mon nom par une indignité ? Non, mon cher père, j'en suis [sûr], vous ne le permettrez pas. Ne craignez point que je vous fasse jamais une semblable prière ; je puis enfin par le moyen d'une science que je cultive incessamment vivre sans le secours d'autrui ; je sens combien il pèse d'avoir obligation aux étrangers et je me vois en état, après des soins continuels, de subsister par moi-même ; je ne ramperai plus et ce métier est indigne de moi. Si j'ai refusé plusieurs fois une fortune éclatante, c'est que j'estime mieux une obscure liberté qu'un esclavage brillant. Mes souhaits vont être accomplis et j'espère que je vais bientôt jouir d'un sort doux et tranquille sans dépendre que de moi-même et d'un père dont je veux toujours respecter et suivre les ordres. Pour me voir en cet état, il ne me manque que d'être hors d'ici où je me suis témérairement engagé ; j'attends ce dernier bienfait de votre main avec une entière confiance.

Honorez-moi, mon cher père, d'une réponse de votre main, ce sera la première lettre que j'aurai reçue de vous dès ma sortie de Genève, accordezmoi le plaisir de baiser au moins ces chers caractères. Faites-moi la grâce de vous hâter, car je suis dans une crise très pressante. Mon adresse est ici jointe, vous devinerez aisément les raisons qui m'ont fait prendre un nom supposé ; votre prudente discrétion ne vous permettra pas de rendre publique cette lettre ni de la montrer à personne qu'à ma chère mère que j'assure de mes très humbles respects et que je supplie les larmes aux yeux de vouloir bien me 
pardonner mes fautes et me rendre sa chère tendresse. Pour vous, mon cher père, je n'aurai jamais de repos que je n'aie mérité le retour de la vôtre, et je me flatte que le jour viendra encore où vous vous ferez un vrai plaisir de m'avouer pour,

mon cher père,

votre très humble

et très obéissant

serviteur et fils. 


\section{Lettre 4}

\section{À Mme la baronne de Warens, à Chambéry}

À Besançon, le 29 juin [1733]

$\underline{\text { Retour à la table des matières }}$

Madame,

J'ai l'honneur de vous écrire dès le lendemain de mon arrivée à Besançon. J'y ai trouvé bien des nouvelles auxquelles je ne m'étais pas attendu et qui m'ont fait plaisir en quelque façon. je suis allé ce matin faire ma révérence à M. l'abbé Blanchard, qui nous a donné à dîner, à $M$. le comte de Saint-Rieux et à moi. Il m'a dit qu'il partirait dans un mois pour Paris, où il va remplir le quartier de M. Campra, qui est malade ; et, comme il est fort âgé, M. Blanchard se flatte de lui succéder en la charge d'intendant, premier maître de quartier de la musique de la chambre du Roi et conseiller de Sa Majesté en ses Conseils. Il m'a donné sa parole d'honneur qu'au cas que ce projet lui réussisse, il me procurera un appointement dans la chapelle, ou dans la chambre du Roi, au bout du terme de deux ans, le plus tard. Ce sont là des postes brillants et lucratifs, qu'on ne peut assez ménager : aussi l'ai-je très fortement remercié, avec assurance que je n'épargnerai rien pour m'avancer de plus en plus dans la composition, pour laquelle il m'a trouvé un talent merveilleux. je lui rends à souper ce soir avec deux ou trois officiers du régiment du Roi, avec qui j'ai fait connaissance au concert. M. l'abbé Blanchard m'a prié d'y chanter un récit de basse-taille, que ces messieurs ont eu la complaisance d'applaudir, aussi bien qu'un duo de Pyrame et Thisbé, que j'ai chanté avec M. Duroncel, fameux haute-contre de l'ancien Opéra de Lyon : c'est beaucoup faire pour un lendemain d'arrivée. 
J'ai donc résolu de retourner dans quelques jours à Chambéry, où je m'amuserai à enseigner pendant le terme de deux années, ce qui m'aidera toujours à me fortifier, ne voulant pas m'arrêter ici, ni passer pour un simple musicien, ce qui me ferait quelque jour un tort considérable. Ayez la bonté de m'écrire, Madame, si j'y serai reçu avec plaisir et si l'on m'y donnera des écoliers. Je me suis fourni de quantité de papiers et de pièces nouvelles d'un goût charmant, et qui sûrement ne sont pas connus à Chambéry ; mais je vous avoue que je ne me soucie guère de partir que je ne sache au vrai si l'on se réjouira de m'avoir : j'ai trop de délicatesse pour y aller autrement. Ce serait un trésor, et en même temps un miracle, de voir un musicien en Savoie : je n'ose ni ne puis me flatter d'être de ce nombre; mais en ce cas je me vante toujours de produire en autrui ce que je ne suis pas moi-même. D'ailleurs, tous ceux qui se serviront de mes principes auront lieu de s'en louer, et vous en particulier, Madame, si vous voulez bien encore prendre la peine de les pratiquer quelquefois. Faites-moi l'honneur de me répondre par le premier ordinaire ; et au cas que vous voyiez qu'il n'y ait pas de débouché pour moi à Chambéry, vous aurez, s'il vous plaît, la bonté de me le marquer; et comme il me reste encore deux partis à choisir, je prendrai la liberté de consulter le secours de vos sages avis sur l'option d'aller à Paris en droiture avec l'abbé Blanchard, ou à Soleure auprès de M. l'ambassadeur. Cependant, comme ce sont là de ces coups de partie qu'il n'est pas bon de précipiter, je serai bien aise de ne rien presser encore.

Tout bien examiné, je ne me repens point d'avoir fait ce petit voyage, qui pourra dans la suite m'être d'une grande utilité. J'attends, Madame, avec soumission, l'honneur de vos ordres, et suis avec une respectueuse considération, Madame [etc.]. 


\section{Lettre 5}

\section{À Mme la baronne de Warens, à Chambéry}

À Cluses, le 31 août 1733

$\underline{\text { Retour à la table des matières }}$

Madame,

L'on dit bien vrai que brebis galeuse, le loup la mange. J'étais à Genève, gai comme un pinson, pensant terminer quelque chose avec mon père, et, d'ici, avoir maintes occasions de vous assurer de mes profonds respects ; mais, Madame, l'imagination court bien vite, tandis que la réalité ne la suit pas toujours. Mon père n'est point venu, et m'a écrit, comme dit le Révérend Père une lettre de vrai Gascon, et qui pis est, c'est que c'est bien moi qu'il gasconne : vous en verrez l'original dans peu : ainsi rien de fait ni à faire pour le présent, suivant toutes les apparences. L'autre cas est que je n'ai pu avoir l'honneur de vous écrire aussi tôt que je l'aurais voulu, manque d'occasions, qui sont bien claires dans ce pays-ci, et seulement une fois la semaine.

Si je voulais, Madame, vous marquer en détails toutes les honnêtetés que j'ai reçues du Révérend Père et que j'en reçois actuellement tous les jours, j'aurais pour longtemps à dire ; ce qui rangé sur le papier par une main aussi mauvaise que la mienne, ennuie quelquefois le bénévole lecteur. Mais, Madame, j'espère me bien dédommager de ce silence gênant la première fois que j'aurai l'honneur de vous faire la révérence. 
Tout cela est parfaitement bien jusqu'ici ; mais sa Révérence, ne vous en déplaise, me retient ici un peu plus longtemps qu'il ne faudrait, par une espèce de force, un peu de sa part, un peu de la mienne : de sa part par les manières obligeantes et les caresses avec lesquelles il a la bonté de m'arrêter; et de la mienne, parce que j'ai de la peine à me détacher d'une personne qui me témoigne tant de bonté. Enfin, Madame, je suis ici le mieux du monde ; et le Révérend Père m'a dit qu'il ne prétend que je m'en aille que quand il lui plaira et que je serai bien et dûment lactifié.

Je fais, Madame, bien des vœux pour la conservation de votre santé. Dieu veuille vous la rendre aussi bonne que je le souhaite et que je l'en prie. J'ai l'honneur d'être avec un profond respect, Madame, votre très humble et très obéissant serviteur. 


\section{Lettre 6}

\section{À [Isaac Rousseau à Nyon]}

[Chambéry, fin de 1735]

$\underline{\text { Retour à la table des matières }}$

Monsieur et très cher Père,

Dans la dernière lettre que vous avez eu la bonté de m'écrire le 5e courant, vous m'exhortez à vous communiquer mes vues au sujet d'un établissement. Je vous prie de m'excuser si j'ai tardé de vous répondre; la matière est importante ; il m'a fallu quelques jours pour faire mes réflexions et pour les rédiger clairement afin de vous en faire part.

Je conviens avec vous, mon très cher père, de la nécessité de faire à bonne heure le choix d'un établissement et de s'occuper à suivre utilement ce choix ; j'avais déjà compris cela, mais je me suis toujours vu jusqu'ici hors de la supposition absolument nécessaire en pareil cas, et sans laquelle l'homme ne peut agir, qui est la possibilité.

Supposons par exemple que mon génie eût tourné naturellement du côté de l'étude soit pour l'Église, soit pour le barreau. Il est clair qu'il eût fallu des secours d'argent, soit pour ma nourriture, soit pour mon habillement, soit encore pour fournir aux frais des études. Mettons le cas aussi que le commerce eût été mon but ; outre mon entretien, il eût fallu payer un apprentissage, et enfin trouver un fonds convenable pour m'établir honnêtement. Les frais n'eussent pas été beaucoup moindres pour le choix d'un métier ; il est vrai que je savais déjà quelque chose de celui de graveur, mais outre qu'il n'a jamais été de mon goût, il est certain que je n'en savais pas à beaucoup près assez pour 
pouvoir me soutenir et qu'aucun maître ne m'eût reçu sans payer les frais d'un assujettissement.

Voilà suivant mon sentiment le cas de tous les différents établissements dont je pouvais raisonnablement faire choix. Je vous laisse juger à vousmême, mon cher père, s'il a dépendu de moi d'en remplir les conditions.

Ce que je viens de dire ne peut regarder que le passé ; à l'âge où je suis, il est trop tard pour penser à tout cela et telle [est] ma misérable condition que quand j'aurais pu prendre un parti solide, tous les secours nécessaires m'ont manqué, et quand j'ai lieu d'espérer de me voir quelque avance, le temps de l'enfance, ce temps précieux d'apprendre, se trouve écoulé sans retour.

Voyons donc à présent ce qu'il conviendrait de faire dans la situation où je me trouve. En premier lieu, je puis pratiquer la musique que je sais assez passablement pour cela ; secondement un peu de talent que j'ai pour l'écriture (je parle du style) pourrait m'aider à trouver un emploi de secrétaire chez quelque grand seigneur ; enfin, je pourrais dans quelques années et avec un peu plus d'expérience servir de gouverneur à des jeunes gens de qualité.

Quant au premier article, je me suis toujours assez applaudi du bonheur que j'ai eu de faire quelque progrès dans la musique, pour laquelle on me flatte d'un goût assez délicat et voici, mon cher père, comment j'ai raisonné.

La musique est un art de peu de difficulté dans sa pratique, c'est-à-dire que par tout pays, on trouve facilement à l'exercer. Les hommes sont faits de manière qu'ils préfèrent assez souvent l'agréable à l'utile : il faut les prendre par leurs faibles et en profiter quand on peut le faire sans injustice ; or qu'y at-il de plus juste que de tirer une contribution honnête de son travail ? La musique est donc de tous les talents que je puis avoir, non pas peut-être à la vérité celui qui me fait le plus d'honneur, mais au moins le plus sûr quant à la facilité, car vous conviendrez qu'on ne trouve pas toujours aisément l'entrée des maisons considérables, et pendant qu'on cherche et qu'on se donne des mouvements, il faut vivre et la musique peut toujours servir d'expectative.

Voilà la manière dont j'ai considéré que la musique pourrait m'être utile. Voici pour le second article qui regarde le poste de secrétaire.

Comme je me suis déjà trouvé dans le cas, je connais à peu près les divers talents qui sont nécessaires dans cet emploi : un style clair et bien intelligible, beaucoup d'exactitude et de fidélité ; de la prudence à manier les affaires qui peuvent être de notre ressort et, par-dessus tout, un secret inviolable ; avec ces qualités, on peut faire un bon secrétaire. Je puis me flatter d'en posséder quelques-unes, je travaille chaque jour à l'acquisition des autres et je n'épargnerais rien pour y réussir.

Enfin, quant au poste de gouverneur d'un jeune seigneur, je vous avoue naturellement que c'est l'état pour lequel je me sens un peu de prédilection ; vous allez d'abord être surpris ; différez, s'il vous plaît, un instant de décider.

Il ne faut pas que vous pensiez, mon cher père, que je me sois donné si parfaitement à la musique, que j'aie négligé toute autre espèce de travail. La 
bonté qu'a eue Mme de Warens de m'accorder chez elle un asile m'a procuré l'avantage de pouvoir employer mon temps utilement, et c'est ce que j'ai fait avec assez de soin jusqu'ici. D'abord, je me suis fait un système d'étude que j'ai divisé en deux chefs principaux : le premier comprend tout ce qui sert à éclairer l'esprit et à l'orner de connaissances utiles et agréables, et l'autre renferme les moyens de former le cœur à la sagesse et à la vertu. Mme de Warens a la bonté de me fournir des livres et j'ai tâché de faire le plus de progrès qu'il était possible et de diviser mon temps de manière que rien n'en restât inutile.

De plus, tout le monde peut me rendre justice sur ma conduite ; je chéris les bonnes mœurs et je ne crois pas que personne ait rien à me reprocher de considérable contre leur pureté ; j'ai de la religion, et je crains Dieu ; d'ailleurs, sujet à d'extrêmes faiblesses et rempli de défauts plus qu'aucun autre homme au monde, je sens combien il y a de vices à corriger chez moi. Mais enfin les jeunes gens seraient heureux s'il tombaient toujours entre les mains de personnes qui eussent autant que moi de haine pour le vice et d'amour pour la vertu.

Ainsi, pour ce qui regarde les sciences et les belles lettres, je crois d'en savoir autant qu'il en faut pour l'instruction d'un jeune gentilhomme, outre que ce n'est point précisément l'office d'un gouverneur d'en donner les leçons, mais seulement d'avoir attention qu'elles se prennent avec fruit, et effectivement il est nécessaire qu'il sache sur toutes les matières plus que son élève ne doit apprendre.

Je n'ai rien à répondre à l'objection qu'on me peut faire sur l'irrégularité de ma conduite passée ; comme elle n'est pas excusable, je ne prétends pas l'excuser. Aussi, mon cher père, je vous ai dit d'abord que ce ne serait que dans quelques années et avec plus d'expérience que j'oserais entreprendre de me charger de la conduite de quelqu'un : c'est que j'ai dessein de me corriger entièrement et que j'espère d'y réussir.

Sur tout ce que je viens [de] dire, vous pourrez encore m'opposer que ce ne sont point des établissements solides, principalement quant aux premier et troisième articles, et là-dessus, je vous prie de considérer que je ne vous les propose point comme tels, mais seulement comme les uniques ressources où je puisse recourir dans la situation où je me trouve en cas que les secours présents vinssent à me manquer. Mais il est temps de vous développer mes véritables idées et d'en venir à la conclusion. Vous n'ignorez pas, mon cher père, les obligations infinies que j'ai à Mme de Warens; c'est sa charité qui m'a tiré plusieurs fois de la misère et qui s'est constamment attachée depuis huit ans à pourvoir à tous mes besoins et même bien au delà du nécessaire. La bonté qu'elle a eue de me retirer dans sa maison, de me fournir des livres, de me payer des maîtres, et par-dessus tout, ses excellentes instructions et son exemple édifiant m'ont procuré les moyens d'une heureuse éducation et de tourner au bien mes mœurs alors encore indécises. Il n'est pas besoin que je relève ici la grandeur de tous ces bienfaits, la simple exposition que j'en fais à vos yeux suffit pour vous en faire sentir le prix au premier coup d'œil : jugez, mon cher père, de tout ce qui doit se passer dans un cœur bien fait en reconnaissance de tout cela; la mienne est sans borne, et voyez jusqu'où s'étend mon bonheur : je n'ai de moyen pour la manifester que le seul qui peut 
me rendre parfaitement heureux. J'ai donc dessein de supplier Mme de Warens de vouloir bien agréer que je passe le reste de mes jours auprès d'elle, et que je lui rende jusqu'à la fin de ma vie tous les services qui seront en mon pouvoir. Je veux lui faire goûter autant qu'il dépendra de moi par mon attachement à elle et par la sagesse et la régularité de ma conduite les fruits des soins et des peines qu'elle s'est donnés pour moi. Ce n'est point une manière frivole de lui témoigner ma reconnaissance ; cette sage et aimable dame a des sentiments assez beaux pour trouver de quoi se payer de ses bienfaits par ses bienfaits mêmes et par l'hommage continuel d'un cœur plein de zèle, d'estime, d'attachement et de respect pour elle.

J'ai lieu d'espérer, mon cher père, que vous approuverez ma résolution et que vous la seconderez de tout votre pouvoir ; par là, toutes difficultés sont levées, l'établissement est tout fait, assurément le plus solide et le plus heureux qui puisse être au monde, puisque outre les avantages qui en résultent en ma faveur, il est fondé de part et d'autre sur la bonté du cœur et sur la vertu. $\mathrm{Au}$ reste, je ne prétends pas trouver par là un prétexte honnête de vivre dans la fainéantise et dans l'oisiveté ; il est vrai que le vide de mes occupations journalières est grand, mais je l'ai entièrement consacré à l'étude, et Mme de Warens pourra me rendre la justice que j'ai suivi assez régulièrement ce plan, et jusqu'à présent elle ne s'est plainte que de l'excès. Il n'est pas à craindre que mon goût change; l'étude a un charme qui fait que quand on l'a une fois goûtée, on ne peut plus s'en détacher, et d'autre part, l'objet en est si beau qu'il n'y a personne qui puisse blâmer ceux qui sont assez heureux pour y trouver du goût et pour s'en occuper.

Voilà, mon cher père, l'exposition de mes vues. Je vous supplie très humblement d'y donner votre approbation, d'écrire à Mme de Warens et de vous employer auprès d'elle pour les faire réussir ; j'ai lieu d'espérer que vos démarches ne seront pas infructueuses et qu'elles tourneront à notre commune satisfaction. Je suis [etc.]... 


\section{Lettre 7}

\section{À Mlle La Bussière, à Lyon}

[1735-I742]

$\underline{\text { Retour à la table des matières }}$

J'ose à peine vous avouer, Mademoiselle, la circonstance à laquelle je dois le bonheur de vous avoir vue, et le tourment de vous aimer. Le hasard a commencé, l'amour a terminé cet événement. Mais que dis-je, le hasard ? Non, l'amour a tout opéré, dès l'instant que votre voix enchanteresse s'est fait entendre. C'est par lui qu'elle a pénétré jusqu'à mon cœur ; c'est lui qui a excité en moi la plus indiscrète curiosité ; c'est lui qui a étalé à mes avides regards des trésors dangereux ; c'est lui qui, depuis les bains du 20 de ce mois, trouble ma raison ; c'est lui qui m'a dicté cette lettre.

Mais pourquoi vous taire ici le plus redoutable de ses pièges, et celui sans lequel j'eusse peut-être échappé à tous les autres ? je ne craindrai point de le dire, Mademoiselle : il doit nous faire honneur à tous les deux. Oui, ce sont moins ces yeux dont la douceur égale la vivacité ; c'est moins cette fraîcheur et ces lys répandus avec tant de profusion sur toute votre personne; c'est moins cette taille svelte et légère, qui ne perd rien par la nudité ; c'est moins cette forme élégante, ces gracieux contours, qu'il me serait aussi téméraire de vouloir décrire qu'il me l'a été d'oser les voir ; c'est moins, dis-je, le détail et l'ensemble de tant de charmes qui m'ont séduit, que cette rougeur aimable, fille de la pudeur et de l'ingénuité, dont j'aperçus votre front se couvrir, dès que je m'offris à votre vue, après vous avoir démasqué trop malignement mon indiscrétion par un couplet que je chante Dieux ! que vous étiez belle, tant il est vrai que la vertu est le fond le plus séduisant de la beauté ! Que ne puis-je vous rendre tout ce qui se passa dans mon âme, à l'aspect de votre confusion ! Je n'eus pas le courage de vous fixer longtemps ; il me sembla, dans vos yeux, 
que vous me reprochiez d'avoir ajouté la méchanceté à la licence ; et ces reproches me paraissaient moins inspirés par le courroux que par le regret de me trouver si coupable. Oh! combien je détestai ma cruelle plaisanterie ! Combien je me serais estimé heureux de pouvoir me précipiter à vos genoux pour en obtenir le pardon ! Et maintenant encore, presque sans espoir d'être à jamais connu de vous, je sens qu'il importe à ma tranquillité que vous me l'accordiez.

La crainte d'aggraver mes torts, en paraissant jouir des alarmes de votre pudeur, m'éloigna promptement du rivage. Je me retirai tout rempli de vos traits, désolé d'avoir pu vous causer quelque peine, de ne vous laisser qu'une opinion désavantageuse de moi, et désespéré de ne voir aucuns moyens de réparer ma faute. Cette cruelle idée m'a tellement bourrelé l'esprit que vingt fois j'ai formé le dessein de vous voir et de vous parler ; vingt fois ma timidité m'a retenu.

C'est de votre bouche même que j'ai appris votre nom, tandis que vous accoutumiez le jeune enfant qui vous accompagnait au bain à le répéter en diverses manières et avec les plus agréables diminutifs ; mon oreille attentive se prêtait aux douces inflexions de votre voix, et ce nom chéri se gravait en traits de feu dans ma mémoire. Quelques indices m'ont informé de votre demeure : j'ai osé porter mes pas de ce côté. Mon cœur sut bientôt vous démêler parmi les personnes avec qui vous étiez. J'étais déjà troublé ; mais dans l'instant où vos yeux rencontrèrent les miens, mes genoux chancelants, ma vue obscurcie, me permirent à peine de poursuivre mon chemin. Vous n'avez jamais sans doute éprouvé ces effets. Votre jeunesse, votre innocence m'en sont de sûrs garants. Puissiez-vous toujours les ignorer; mais heureux celui pour qui vous les ressentirez ! Un peu remis de mon émotion, je revins sur mes pas, à peu près comme l'aiguille aimantée revient sur son pôle. Vous aviez prévu sûrement ce retour. Vos beaux yeux obstinément baissés rendirent encore vaine, cette fois, l'espérance que j'avais d'y lire mon pardon. Enfin découragé par mille obstacles, par mille inconvénients que ma raison s'est efforcée de grossir et de multiplier, j'ai voulu vous oublier ; j'ai tout tenté pour vous chasser de mon cœur. Efforts impuissants! Je me sens capable de souffrir tout, hors l'idée de votre haine, et malheureusement elle m'occupe sans cesse. Tranquillisez-moi sur cet article, Mademoiselle, ne fût-ce que par pitié : je [ne] me crois point en droit d'exiger d'autre sentiment; mais celui-ci est innocent ; il est l'apanage des belles âmes, il ne peut manquer d'avoir une place dans la vôtre. Quant à moi, peu vous importe quel sentiment m'anime : votre délicatesse n'en reçoit aucune atteinte. Si c'est un crime, il est à moi seul, et vous n'y avez d'autre part que le talent involontaire d'être aimable. Permettez-moi cependant de vous donner un avis : n'allez plus au bain, Mademoiselle, ou prenez-y plus de précautions ; à la fin, vous ne seriez plus tout à fait si excusable. Vous ne manqueriez pas de curieux indiscrets dévoués à un sort pareil au mien : il y aurait de l'inhumanité à abuser de la magie de vos attraits, pour allumer dans le cœur de ces malheureux des incendies que vous ne voudriez point éteindre. Ce sont de ces manèges barbares dont il faut abandonner l'usage aux coquettes : je vous crois trop sensible pour l'être.

Je ne me ferai point connaître, Mademoiselle : cette réserve est aussi essentielle pour moi qu'elle l'est peu pour vous. Si toutefois, ce dont je ne me flatte point, vous preniez à moi un intérêt assez vif pour le désirer, nous 
aviserions aux moyens de vous satisfaire d'une manière décente et sans manquer à ce que vous devez à vous-même. Je ne vous demande ici qu'un mot de consolation, une simple assurance que vous ne m'en voulez pas. C'est peu de chose pour vous, ce sera tout pour moi.

Je suis, Mademoiselle, l'homme qui vous aime et qui vous estime le plus.

Il vous sera facile de me témoigner vos dispositions par la même voie qui vous fait parvenir cette lettre. Soyez assurée du secret et de la discrétion des personnes.

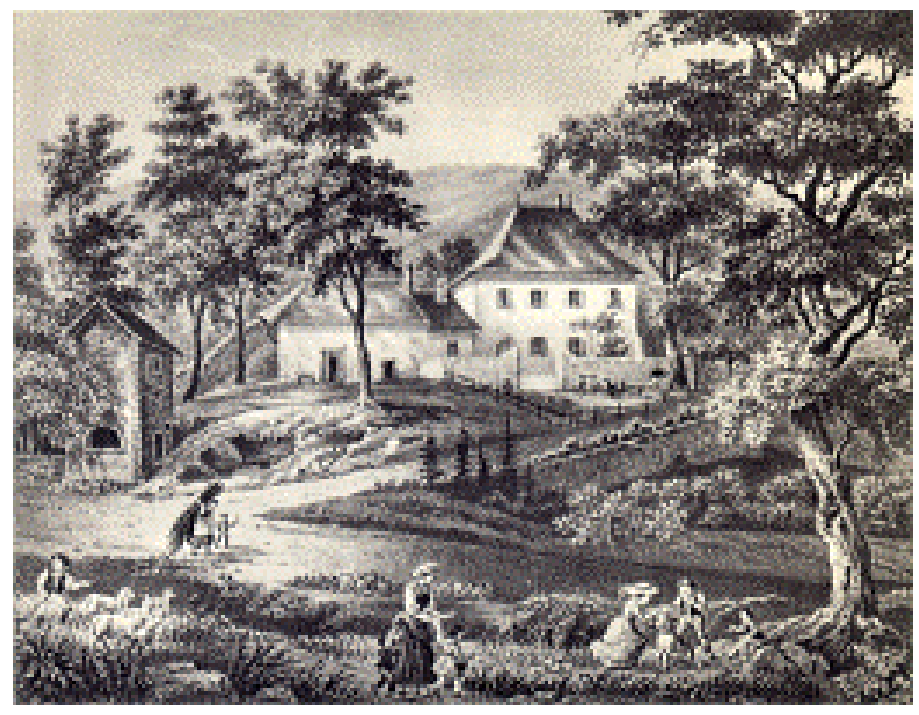

Illustration 2

L'habitation de J.-J. Rousseau, aux Charmettes

$\underline{\text { Retour à la table des matières }}$ 


\section{Lettre 8}

\section{À Mme de Warens à Chambéry}

À Grenoble, le 13 septembre 1737

$\underline{\text { Retour à la table des matières }}$

Madame,

Je suis ici depuis deux jours ; on ne peut être plus satisfait d'une ville que je le suis de celle-ci. On m'y a marqué tant d'amitiés et d'empressements que je croyais, en sortant de Chambéry, me trouver dans un nouveau monde. Hier M. Micoud me donna à dîner avec plusieurs de ses amis, et le soir, après la comédie, j'allai souper avec le bonhomme Lagère.

Je n'ai vu ni Mme la Présidente, ni Mme d'Eybens, ni M. le président de Tencin : ce seigneur est en campagne. Je n'ai pas laissé de remettre la lettre à ses gens. Pour Mme de Bardonnanche, je me suis présenté plusieurs fois sans pouvoir lui faire la révérence ; j'ai fait remettre la lettre, et j'y dois dîner ce matin, où j'apprendrai des nouvelles de Mme d'Eybens.

Il faut parler de M. de l'Orme. J'ai eu l'honneur, Madame, de lui remettre votre lettre en main propre. Ce monsieur, s'excusant sur l'absence de $\mathrm{M}$. l'Évêque, m'offrit un écu de six francs : je l'acceptai par timidité ; mais je crus devoir en faire présent au portier. Je ne sais si j'ai bien fait; mais il faudra que mon âme change de moule avant que de me résoudre à faire autrement. J'ose croire que la vôtre ne m'en démentira pas. 
J'ai eu le bonheur de trouver pour Montpellier, en droiture, une chaise de retour : j'en profiterai. Le marché s'est fait par l'entremise d'un ami et il ne m'en coûte pour la voiture qu'un louis de vingt-quatre francs : je partirai demain matin. Je suis mortifié, Madame, que ce soit sans recevoir ici de vos nouvelles ; mais ce n'est pas une occasion à négliger.

Si vous avez, Madame, des lettres à m'envoyer, je crois qu'on pourrait les faire tenir ici à M. Micoud qui les ferait partir ensuite pour Montpellier à l'adresse de M. Lazerne. Vous pouvez aussi les envoyer de Chambéry en droiture. Ayez la bonté de voir ce qui convient le mieux ; pour moi, je n'en sais rien du tout.

Il me fâche extrêmement d'avoir été contraint de partir sans faire la révérence à $M$. le marquis d'Antremont, et lui présenter mes très humbles actions de grâces ; oserais-je, Madame, vous prier de vouloir suppléer à cela ?

Comme je compte de pouvoir être à Montpellier mercredi au soir, le $18 \mathrm{du}$ courant, je pourrai donc, Madame, recevoir de vos précieuses nouvelles dans le cours de la semaine prochaine, si vous preniez la peine d'écrire dimanche ou lundi matin. Vous m'accorderez, s'il vous plaît, la faveur de croire que mon empressement jusqu'à ce temps-là ira jusqu'à l'inquiétude.

Permettez encore, Madame, que je prenne la liberté de vous recommander le soin de votre santé. N'êtes-vous pas ma chère Maman ? N'ai-je pas le droit d'y prendre le plus vif intérêt ? Et n'avez-vous pas besoin qu'on vous excite à tout moment à y donner plus d'attention?

La mienne fut fort dérangée hier soir au spectacle. On représenta Alzire ; mal, à la vérité, mais je ne laissai pas d'y être ému jusqu'à perdre la respiration ; mes palpitations augmentèrent étonnamment, et je crains de m'en sentir quelque temps.

Pourquoi, Madame, y a-t-il des cœurs sensibles au grand, au sublime, au pathétique, pendant que d'autres ne semblent faits que pour ramper dans la bassesse de leurs sentiments ? La fortune semble faire à tout cela une espèce de compensation; à force d'élever ceux-ci, elle cherche à les mettre de niveau avec la grandeur des autres; y réussit-elle ou non ? Le public et vous, Madame, ne serez pas du même avis. Cet accident m'a forcé de renoncer désormais au tragique jusqu'au rétablissement de ma santé. Me voilà privé d'un plaisir qui m'a bien coûté des larmes dans ma vie. J'ai l'honneur d'être avec un profond respect, Madame, [etc.]... 


\section{Lettre 9}

\section{À Mme de Warens, à Chambéry}

À Montpellier, le 23 octobre 1737

$\underline{\text { Retour à la table des matières }}$

Madame,

Je ne me sers point de la voie indiquée de M. Barillot, parce que c'est faire le tour de l'École; vos lettres et les miennes passant toutes par Lyon, il faudrait avoir une adresse à Lyon.

Voici un mois passé de mon arrivée à Montpellier sans avoir pu recevoir aucune nouvelle de votre part, quoique j'aie écrit plusieurs fois et par différentes voies. Vous pouvez croire que je ne suis pas fort tranquille, et que ma situation n'est pas des plus gracieuses ; je vous proteste cependant, Madame, avec la plus parfaite sincérité que ma plus grande inquiétude vient de la crainte qu'il ne vous soit arrivé quelque accident. Je vous écris cet ordinaire-ci par trois différentes voies, savoir par MM. Vèpres, M. Micoud, et en droiture ; il est impossible qu'une de ces trois lettres ne vous parvienne; aussi j'en attends la réponse dans trois semaines au plus tard. Passé ce tempslà, si je n'ai point de nouvelles, je serai contraint de partir dans le dernier désordre et de me rendre à Chambéry comme je pourrai. Ce soir la poste doit arriver et il se peut qu'il y aura quelque lettre pour moi. Peut-être n'avez-vous pas fait mettre les vôtres à la poste les jours qu'il fallait : car j'aurais réponse depuis quinze jours si les lettres avaient fait chemin dans leur temps. Vos lettres doivent passer par Lyon pour venir ici ; ainsi c'est les mercredis et 
samedis de bon matin qu'elles doivent être mises à la poste : je vous avais donné précédemment l'adresse de ma pension; il vaudrait peut-être mieux les adresser en droiture où je suis logé, parce que je suis sûr de les recevoir exactement. C'est chez M. Marcellon, huissier de la Bourse, en rue Basse, proche du Palais. J'ai l'honneur d'être avec un profond respect, Madame, [etc.]...

Si vous avez quelque chose à m'envoyer par la voie des marchands de Lyon et que vous écriviez, par exemple, à MM. Vèpres par le même ordinaire qu'à moi, je dois, s'ils sont exacts, recevoir leur lettre en même temps que la vôtre.

J'allais fermer ma lettre quand j'ai reçu la vôtre, Madame, du 12e du courant. Je crois n'avoir pas mérité les reproches que vous m'y faites sur mon peu d'exactitude. Depuis mon départ de Chambéry, je n'ai point passé de semaine sans vous écrire. Du reste, je me rends justice et, quoique peut-être il dût me paraître un peu dur que la première lettre que j'ai l'honneur de recevoir de vous ne soit pleine que de reproches, je conviens que je les mérite tous. Que voulez-vous, Madame, que je vous dise ? Quand j'agis, je crois faire les plus belles choses du monde, et puis il se trouve au bout que ce ne sont que sottises : je le reconnais parfaitement bien de moi-même. Il faudra tâcher de se raidir contre sa bêtise à l'avenir, et faire plus d'attention sur sa conduite, c'est ce que je vous promets avec une forte envie de l'exécuter. Après cela, si quelque retour d'amour-propre voulait encore m'engager à tenter quelque voie de justification, je réserve à traiter cela de bouche avec vous, Madame, non pas s'il vous plaît à la Saint-Jean, mais à la fin du mois de janvier ou au commencement du suivant.

Quant à la lettre de M. Arnauld, vous savez, Madame, mieux que moimême ce qui me convient en fait de recommandation. je vois bien que vous vous imaginez que, parce que je suis à Montpellier, je puis voir les choses de plus près et juger de ce qu'il y a à faire ; mais, Madame, je vous prie d'être bien persuadée que, hors ma pension et l'hôte de ma chambre, il m'est impossible de faire aucune liaison, ni de connaître le terrain le moins du monde à Montpellier, jusqu'à ce qu'on m'ait procuré quelque arme pour forcer les barricades que l'humeur inaccessible des particuliers et de toute la nation en général met à l'entrée de leurs maisons. Oh ! qu'on a une idée bien fausse du caractère languedocien, et surtout des habitants de Montpellier à l'égard de l'étranger ! Mais pour revenir, les recommandations dont j'aurais besoin sont de toutes les espèces. Premièrement pour la noblesse et les gens en place, il me serait très avantageux d'être présenté à quelqu'un de cette classe, pour tâcher à me faire connaître et à faire usage du peu de talents que j'ai, ou du moins à me donner quelque ouvrage qui pût m'être utile dans la suite, en temps et lieu. En second lieu, pour les commerçants, afin de trouver quelque voie de communication plus courte et plus facile, et pour mille autres avantages que vous savez que l'on tire de ces connaissances-là. Troisièmement, parmi les gens de lettres, savants, professeurs, par les lumières qu'on peut acquérir avec eux et les progrès qu'on y pourrait faire ; enfin, généralement pour toutes les personnes de mérite avec lesquelles on peut du moins lier une honnête société, apprendre quelque chose, et couler quelques heures prises sur la plus rude et la plus ennuyeuse solitude du monde. J'ai l'honneur de vous écrire cela, Madame, et non à M. l'abbé Arnauld, parce qu'ayant la lettre, vous 
verrez mieux ce qu'il y aura à répondre, et que si vous voulez bien vous donner cette peine vous-même, cela fera encore un meilleur effet en ma faveur.

Vous faites, Madame, un détail si riant de ma situation à Montpellier qu'en vérité je ne saurais mieux rectifier ce qui peut n'être pas conforme au vrai qu'en vous priant de prendre tout le contrepied. Je m'étendrai plus au long dans ma prochaine, sur l'espèce de vie que je mène ici. Quant à vous, Madame, plût à Dieu que le récit de votre situation fût moins véridique ! Hélas, je ne puis, pour le présent, faire que des vœux ardents pour l'adoucissement de votre sort : il serait trop envié s'il était conforme à celui que vous méritez. Je n'ose espérer le rétablissement de ma santé, car elle est encore plus en désordre que quand je suis parti de Chambéry ; mais, Madame, si Dieu daignait me la rendre, il est sûr que je n'en ferai d'autre usage qu'à tâcher de vous soulager de vos soins, et à vous seconder en bon et tendre fils, et en élève reconnaissant. Vous m'exhortez, Madame, à rester ici jusqu'à la Saint-Jean : je ne le ferais pas quand on m'y couvrirait d'or. Je ne sache pas d'avoir vu, de ma vie, un pays plus antipathique à mon goût que celui-ci, ni de séjour plus ennuyeux, plus maussade que celui de Montpellier. Je sais bien que vous ne me croirez point, vous êtes encore remplie des belles idées que ceux qui y ont été attrapés en ont répandues dehors pour attraper les autres. Cependant, Madame, je vous réserve une relation de Montpellier qui vous fera toucher les choses au doigt et à l'œil, je vous attends là pour vous étonner. Pour ma santé, il n'est pas étonnant qu'elle ne s'y remette pas : Premièrement les aliments n'y valent rien, mais rien, je dis rien et je ne badine point. Le vin y est trop violent, et incommode toujours ; le pain y est passable, à la vérité ; mais il n'y a ni bœuf, ni vache, ni beurre; on n'y mange que de mauvais mouton, et du poisson de mer en abondance, le tout toujours apprêté à l'huile puante. Il vous serait impossible de goûter de la soupe ou des ragoûts qu'on nous sert à ma pension, sans vomir. Je ne veux pas m'arrêter davantage là-dessus, car si je vous disais les choses précisément comme elles sont, vous seriez en peine de moi bien plus que je ne le mérite. En second lieu l'air ne me convient pas ; autre paradoxe encore plus incroyable que les précédents, c'est pourtant la vérité. On ne saurait disconvenir que l'air de Montpellier ne soit fort pur et en hiver assez doux. Cependant le voisinage de la mer le rend à craindre pour tous ceux qui sont attaqués de la poitrine : aussi y voit-on beaucoup de phtisiques. Un certain vent, qu'on appelle ici le marin, amène de temps en temps des brouillards épais et froids, chargés de particules salines et âcres qui sont fort dangereuses : aussi j'ai ici des rhumes, des maux de gorge et des esquinancies plus souvent qu'à Chambéry. Ne parlons plus de cela quant à présent, car si j'en disais davantage vous n'en croiriez pas un mot. je puis pourtant protester que je n'ai dit que la vérité. Enfin, un troisième article, c'est la cherté. Pour celui-là je ne m'y arrêterai pas parce que je vous en ai parlé précédemment et que je me prépare à parler de tout cela plus au long en traitant de Montpellier. Il suffit de vous dire qu'avec l'argent comptant que j'ai apporté et les $200 £$ que vous avez eu la bonté de me promettre, il s'en faudrait beaucoup qu'il m'en restât actuellement autant devant moi, pour prendre l'avance, comme vous dites, qu'il en faudrait laisser en arrière pour boucher les trous. Je n'ai encore pu donner un sou à la maîtresse de pension, ni pour le louage de ma chambre ; jugez, Madame, comment me voilà joli garçon, et pour achever de me peindre, si je suis contraint de mettre quelque chose à la presse, ces honnêtes gens-ci ont la charité de ne prendre que douze sols par 
écu de six francs, tous les mois. À la vérité, j'aimerais mieux tout vendre que d'avoir recours à un tel moyen. Cependant, Madame, je suis si heureux, que personne ne s'est encore avisé de me demander de l'argent, sauf celui qu'il faut donner tous les jours pour les eaux, bouillons de poulet, purgatifs, bains ; encore ai-je trouvé le secret d'en emprunter pour cela sans gage et sans usure ; et cela du premier cancre de la terre. Cela ne pourra pas durer pourtant, d'autant plus que le deuxième mois est commencé depuis hier ; mais je suis tranquille depuis que j'ai reçu de vos nouvelles, et que je suis assuré d'être secouru à temps. Pour les commodités, elles sont en abondance. Il n'y a point de bon marchand à Lyon qui ne tire une lettre de change sur Montpellier. Si vous en parlez à M. C., il lui sera de la dernière facilité de faire cela. En tout cas, voici l'adresse d'un que paie un de nos messieurs de Belley, et de la voie duquel on peut se servir: M. Parent, marchand drapier à Lyon, au Change. Quant à mes lettres, il vaut mieux les adresser chez M. Barcellon, ou plutôt Marcellon, comme l'adresse est à la première page : on sera plus exact à me les rendre. Il est deux heures après minuit, la plume me tombe des mains, cependant je n'ai pas écrit la moitié de ce que j'avais à écrire. La suite de la relation et le reste, etc., sera renvoyé pour lundi prochain. C'est que je ne puis faire mieux, sans quoi, Madame, je ne vous imiterais certainement pas à cet égard. En attendant, je m'en rapporte aux précédentes et présente mes respectueuses salutations aux Rds PP. jésuites, le R. P. Hemet et le R. P. Coppier. Je vous prie bien humblement de leur présenter une tasse de chocolat, que vous boirez ensemble, s'il vous plaît, à ma santé. Pour moi, je me contente du fumet, car il ne m'en reste pas un misérable morceau.

J'ai oublié de finir, en parlant de Montpellier et de vous dire que j'ai résolu d'en partir vers la fin de décembre et d'aller prendre le lait d'ânesse en Provence, dans un petit endroit fort joli, à deux lieues du Saint-Esprit. C'est un air excellent ; il y aura bonne compagnie, avec laquelle j'ai déjà fait connaissance en chemin, et j'espère de n'y être pas tout à fait si chèrement qu'à Montpellier. Je demande votre avis là-dessus. Il faut encore ajouter que c'est faire d'une pierre deux coups, car je me rapproche de deux journées.

Je vois, Madame, qu'on épargnerait bien des embarras et des frais si l'on faisait écrire par un marchand de Lyon à son correspondant d'ici de me compter de l'argent quand j'en aurai besoin, jusqu'à la concurrence de la somme destinée, car ces retards me mettent dans de fâcheux embarras, et ne vous sont d'aucun avantage. 


\section{Lettre 10}

\section{AM. $\left(\mathrm{X}^{* * *}\right)$}

[Vers I739]

$\underline{\text { Retour à la table des matières }}$

Vous voilà donc, Monsieur, déserteur du monde et de ses plaisirs ; c'est, à votre âge et dans votre situation, une métamorphose bien étonnante, quand un homme de 22 ans, galant, aimable, poli, spirituel comme vous l'êtes, et d'ailleurs point rebuté de la fortune se détermine à la retraite par simple goût et sans y être excité par quelque mauvais succès dans ses affaires ou dans ses plaisirs. On peut s'assurer qu'un fruit si précieux du bon sens et de la réflexion n'amè[ne]ra pas après lui de dégoût ni de repentir. Fondé sur cette assurance, j'ose vous faire à l'égard [de] votre retraite un compliment qui ne vous sera pas répété par bien des gens ; je vous en félicite : sans vouloir trop relever ce qu'il y a de grand et peut-être d'héroïque dans votre résolution, je vous dirai franchement que j'ai souvent regretté qu'un esprit aussi juste et une âme aussi belle que la vôtre ne fussent faits que pour la galanterie, les cartes, et le vin de champagne; vous étiez né, mon très cher Monsieur, pour une meilleure occupation ; le goût un peu passionné mais délicat qui vous entraîne vers les plaisirs vous a bientôt fait démêler la fadeur des plus brillants, vous éprouverez avec étonnement que les plus simples et les plus modestes n'en ont ni moins d'attraits ni moins de vivacité ; vous connaissez désormais les hommes, vous n'avez plus besoin de les tant voir pour apprendre à les mépriser; il sera bon maintenant que vous vous consultiez un peu pour savoir à votre tour quelle opinion vous devez avoir de vous-même. Ainsi, en même 
temps que vous essaierez d'un autre genre de vie, vous ferez en même temps sur votre intérieur un petit examen dont le fruit ne sera pas inutile à votre tranquillité.

Je ne voudrais pas, Monsieur, que vous donnassiez dans l'excès sans ménagement, vous n'avez pas sans doute absolument renoncé à la société, ni au commerce des hommes ; comme vous vous êtes déterminé de pur choix et sans qu'aucun fâcheux revers vous y ait contraint, vous n'aurez garde d'épouser les fureurs atrabilaires des misanthropes, ennemis mortels du genre humain ; permis à vous de le mépriser à la bonne heure, vous ne serez pas le seul ; mais vous devez l'aimer toujours ; les hommes quoi qu'on dise sont nos frères, en dépit de nous et d'eux, frères fort durs à la vérité, mais nous n'en sommes pas moins obligés de remplir à leur égard tous les devoirs qui nous sont imposés ; à cela près, il faut avouer qu'on ne peut se dispenser de porter la lanterne dans la quantité pour s'établir un commerce et des liaisons, et quand malheureusement la lanterne ne montre rien, c'est bien une nécessité de traiter avec soi-même, et de se prendre, faute d'autre, pour ami et pour confident. Mais ce confident, et cet ami, il faut aussi un peu le connaître et savoir comment et jusqu'à quel point on peut se fier à lui, car souvent l'apparence nous trompe, même jusque sur nous-même. Or le tumulte des villes et le fracas du grand monde ne sont guère propres à cet examen, les distractions des objets extérieurs y sont trop longues et trop fréquentes. On ne peut y jouir d'un peu de solitude et de tranquillité. Sauvons-nous à la campagne, allons y chercher un repos et un contentement que nous n'avons pu trouver au milieu des assemblées et des divertissements. Essayons de ce nouveau genre de vie, goûtons un peu de ces paisibles douceurs dont Horace, un fin connaisseur s'il en fut, faisait un si grand cas.

Voilà, Monsieur, comment je soupçonne que vous avez raisonné. 


\section{Lettre 11}

\section{À Mme de Warens, à Chambéry}

Charmettes, 18 mars 1739

$\underline{\text { Retour à la table des matières }}$

Ma très chère Maman,

J'ai reçu, comme je le devais, le billet que vous m'écrivîtes dimanche dernier, et j'ai convenu sincèrement avec moi-même que, puisque vous trouviez que j'avais tort, il fallait que je l'eusse effectivement; ainsi, sans chercher à chicaner, j'ai fait mes excuses de bon cœur à mon frère, et je vous fais de même ici les miennes très humbles. Je vous assure aussi que j'ai résolu de tourner toujours du bon côté les corrections que vous jugerez à propos de me faire, sur quelque ton qu'il vous plaise de les tourner.

Vous m'avez fait dire qu'à l'occasion de vos Pâques, vous voulez bien me pardonner. Je n'ai garde de prendre la chose au pied de la lettre, et je suis sûr que, quand un cour comme le vôtre a autant aimé quelqu'un que je me souviens de l'avoir été de vous, il lui est impossible d'en venir jamais à un tel point d'aigreur qu'il faille des motifs de religion pour le réconcilier. Je reçois cela comme une petite mortification que vous m'imposez en me pardonnant et dont vous savez bien qu'une parfaite connaissance de vos vrais sentiments adoucira l'amertume.

Je vous remercie, ma très chère Maman, de l'avis que vous m'avez fait donner d'écrire à mon père. Rendez-moi cependant la justice de croire que ce n'est ni par négligence, ni par oubli, que j'avais retardé jusqu'à présent. Je 
pensais qu'il aurait convenu d'attendre la réponse de M. l'abbé Arnauld, afin que si le sujet du mémoire n'avait eu nulle apparence de réussir, comme il est à craindre, je lui eusse passé sous silence ce projet évanoui. Cependant, vous m'avez fait faire réflexion que mon délai était appuyé sur une raison trop frivole, et, pour réparer la chose le plus tôt qu'il est possible, je vous envoie ma lettre que je [vous] prie de prendre la peine de lire, de fermer et de faire partir si vous le jugez à propos.

Il n'est pas nécessaire, je crois, de vous assurer que je languis depuis longtemps dans l'impatience de vous revoir. Songez, ma très chère Maman, qu'il y a un mois, et peut-être au delà, que je suis privé de ce bonheur. Je suis du plus profond du cœur, et avec les sentiments du fils le plus tendre, ma très chère Maman, [etc.]... 
Jean-Jacques Rousseau, Lettres (1728-1778)

\title{
Deuxième partie
}

\section{Les années difficiles}

\author{
$1740-1750$
}

Retour à la table des matières

À Lyon, Rousseau fait effort pour s'humaniser, il se veut « honnête homme », il s'essaye à la poésie. Toutefois, son année de préceptorat s'achève par un échec. Il ne savait employer, avoue-t-il dans les Confessions (livre VI), «que trois instruments toujours inutiles et souvent pernicieux auprès des enfants, le sentiment, le raisonnement, la colère ». En juillet 1742, le voici sur la route de Paris avec, dans sa poche, de quoi faire fortune : un nouveau projet de notation musicale ! Mais l'Académie des sciences l'accueille sans chaleur. On l'introduit dans le monde de la haute finance : pour Mme Dupin, la femme du fermier général, il fait d'immenses lectures et des extraits. Cependant il s'occupe de chimie et il laisse sur cette matière un manuscrit de près de 1200 pages.

N'est-ce pas la fortune : au début de l'été 1743, l'ambassadeur de France à Venise, M. de Montaigu, l'engage comme secrétaire. Dans les Confessions (livre VII), le récit de l'aventure vénitienne est d'un homme qui sait faire fi de la fausse humilité : mais il est prouvé que Rousseau a rédigé, outre la plus grande partie des dépêches, les mémoires que l'ambassadeur adressait au Sénat de la République sérénissime. À Venise, il fit son devoir, en un lieu, en un temps où le devoir était chose diffjcile. Puis la mésentente s'établit entre le 
patron et son secrétaire. Pour finir, on le chasse et on l'accuse stupidement d'avoir vendu le chiffre des dépêches. Accusé à tort, Rousseau s'effarouche, il réclame justice, mais on ne lui rend pas Justice

De retour à Paris, il tente de se faire parisien, et il se contorsionne, incapable de flatter sans gaucherie. L'opéra des Muses galantes est un demiéchec ; avec les Fêtes de Ramire, il se juge frustré de son travail. Les comédies qu'il broche pour les Dupin ne passent guère le niveau de divertissements de société. Son mal congénital, l'incontinence d'urine due au rétrécissement de l'urètre, s'est réveillé, il l'accompagnera jusqu'à sa mort, « le tenant éloigné des cercles » (selon Mme d'Epinay). Un sourd malaise l'empoisonne : dans cet effort pour parvenir, pour «primer en quelque chose » (Confessions, livre VII), tous ses gestes ne trahissent-ils pas sa vraie nature ? Voici qu'il cherche auprès d'une jeune lingère, Thérèse Levasseur, « un amusement » (idem) : un enfant naît, en 1746, on le porte à l'hospice, comme c'est l'usage. Quatre autres subiront le même sort, si l'on en croit Rousseau (mais est-il bien le père de tous ces enfants ?) et Thérèse sera la compagne de sa vie. C'est aussi le temps où il devient l'intime de l'éblouissant Diderot qui sera, durant quelques années, son maître, et un ami tyrannique. 


\section{Lettre 12}

\section{À Mme la baronne de Warens, à Chambéry}

À Lyon, le 1er mai 1740

Retour à la table des matières

Madame et très chère Maman,

Me voici enfin arrivé chez M. de Mably. Je ne vous dirai point encore précisément quelle y sera ma situation, mais ce qu'il m'en paraît déjà n'a rien de rebutant. M. de Mably est un très honnête homme à qui un grand usage du monde, de la Cour et de ses plaisirs ont appris à philosopher de bonne heure, et qui n'a pas été fâché de me trouver des sentiments assez concordants aux siens ; jusqu'ici je n'ai qu'à me louer des égards qu'il m'a témoignés ; il entend que j'en agisse chez lui sans façon, et que je ne sois gêné en rien. Vous devez juger qu'étant ainsi livré à ma discrétion, je m'en accorderai en effet d'autant moins de libertés ; les bonnes manières peuvent tout sur moi et si M. de Mably ne se dément point, il peut être assuré que mon cœur lui sera sincèrement attaché. Mais vous m'avez appris à ne pas courir à l'extrême sur de premières apparences et à ne jamais compter plus qu'il ne faut sur ce qui dépend de la fantaisie des hommes. Savoir, à présent, comment on pense sur mon compte, c'est ce qui n'est pas entièrement en mon pouvoir ; ma timidité ordinaire m'avait fait jouer le premier jour un assez sot personnage, et si M. de Mably avait été Savoyard, il aurait porté là-dessus son redoutable jugement sans espérance d'appel ; je ne sais si au travers de cet air embarrassé, il a démêlé en 
moi quelque chose de bon ; ce qu'il y a de sûr, c'est que ses manières polies et engageantes m'ont entièrement rassuré, et qu'il ne tient plus qu'à moi de me montrer à lui tel que je suis. Il écrit au Rd P. de la Coste qui ne manquera point de vous communiquer sa lettre ; vous pourrez juger là-dessus de ce qu'il pense sur mon compte. J'ose vous prier, ma très chère Maman, de vouloir bien faire agréer mes très humbles respects aux RR. PP. jésuites. Quant à mon petit élève, on ne saurait lui refuser d'être très aimable, mais je ne saurais encore vous dire s'il aura le cœur également bon, parce que souvent, ce qui paraît à cet âge des signes de méchanceté, n'[en] sont en effet que de vivacité et d'étourderie. J'ai rempli ma lettre de minuties, mais daignez, ma très chère maman, m'éclaircir au plus tôt de ce qui m'est uniquement important, je veux dire de votre santé et de la prospérité de vos affaires, que font les Charmettes, les kiki et tout ce qui m'intéresse tant. Mon adresse est chez M. de Mably, prévôt général du Lyonnais, rue Saint-Dominique. J'ai l'honneur d'être avec une vive reconnaissance et un profond respect, Madame, votre très humble et très obéissant serviteur et fils. 


\section{Lettre 13}

\section{À M. Dupin}

[Paris] le 10 avril 1743

$\underline{\text { Retour à la table des matières }}$

Monsieur,

Permettez, Monsieur, que j'emploie les moments qu'une légère indisposition m'empêche de passer près de vous, à vous ouvrir mon cœur derechef. Je sais combien ces sortes de récidives sont importunes, mais je crois nécessaire d'y venir encore une fois, pour n'y revenir jamais.

Je ne suis ni assez aveugle ni assez vain pour m'imaginer que j'eusse jamais pu être d'une grande utilité dans votre maison.

Quand Mme Dupin et vous, Monsieur, m'avez fait l'honneur de m'y admettre, j'ai senti que vous ne le faisiez que par un principe d'humanité, et j'ai proportionné ma reconnaissance à ce sentiment. Vous pouviez, cependant, avoir fondé sur mes faibles talents quelques espérances, que j'ai sans doute mal soutenues ; ce sont les indices qu'il me paraît d'en avoir et la justice que je suis forcé de me rendre qui m'engagent aujourd'hui à m'en éclaircir avec vous. je vois, Monsieur, que vous en conservez toujours la même bonté pour moi ; mais, dans les cœurs aussi bien faits que le vôtre, les bontés ne tirent guère à conséquence pour le mérite de celui qui les reçoit. Il est étrange qu'avec tant de zèle et de bonne volonté, je ne me sois montré jusqu'à présent que par des endroits défectueux. Sans doute, il n'est pas possible que l'amour pour le bien n'ait produit en moi quelques bonnes qualités ; malheureusement, elles y sont offusquées par tant de défauts qu'elles ne sauraient percer les premières, et 
l'impression étant déjà faite quand elles viendraient à paraître, c'est rarement par elles qu'on peut juger de moi. Quoi qu'il en soit, le dégoût visible de Mme Dupin m'annonce un malheur qui me cause plus d'affliction que d'étonnement, et je dois prévoir le vôtre assez tôt pour ne vous pas laisser le désagrément de me le témoigner, ni à moi le désespoir de déplaire à un bienfaiteur pour qui tous les mouvements de mon cœur sont des sentiments de respect, de reconnaissance et d'attachement.

Je m'étais flatté, Monsieur, du bonheur de vous appartenir pour le reste de mes jours, et je puis jurer que cette idée est le premier et le seul vrai sentiment de plaisir qui m'ait touché. L'espoir de mériter votre estime et votre affection, joint à l'amour de l'étude et du repos, m'en faisait un avenir charmant, auquel j'ai sacrifié avec joie toute autre vue. Bien loin de prétendre me prévaloir aujourd'hui d'un tel sacrifice, je conviens le premier que je ne suis point digne de ce bonheur, et quand je n'aurais contre moi d'autre motif d'exclusion que l'ardeur avec laquelle je le souhaite, je connais trop la triste fatalité qui me poursuit, pour compter sur un bien capable de me rendre heureux. Un triste penchant à prévoir tous les malheurs que je crains, et une cruelle exactitude du sort à justifier toutes mes craintes, me rend le mien comme assuré, et c'est pour vous supplier de confirmer ou de détruire ce doute, une bonne fois, que j'ai l'honneur de vous écrire aujourd'hui. Je n'ai ni assez de talents, ni assez de mérite, ni assez de sagesse, pour me croire digne de votre protection et de vos bontés. À prendre la chose dans ce sens-là, j'ai cent motifs de craindre, et je n'en ai aucune de me rassurer. Si Mme Dupin et vous, Monsieur, n'êtes qu'équitables, mon sort n'est plus douteux, et il en faudra subir la triste influence. Sur ce pied-là, mon parti est pris, et, sans faire le désespéré, vous connaîtrez par ma conduite si mon zèle était sincère, et si j'ai porté dans l'avenir des vues au delà de votre disgrâce. J'espère que vous conviendrez aussi que la durée des bienfaits ne fixe point en moi celle du respect et de la reconnaissance.

Rempli de travers et de défauts, je sais du moins les haïr. Il est des retours sur nos fautes qui valent mieux que de n'en avoir point commis. Si les erreurs d'un tel caractère vous paraissent dignes de quelque indulgence, j'implore la vôtre et celle de Mme Dupin ; il suffira que ma vue ne lui soit pas odieuse à un certain point pour que je travaille avec succès à devenir supportable. Mes talents sont extrêmement bornés, je l'avoue ; mais il est d'autres endroits par lesquels un honnête homme peut se faire aimer, estimer, et même se rendre utile ; j'en ferai mon unique étude. Sans ambition, sans intérêt et sans désir de briller, je ne ferai consister mon bonheur qu'à mériter votre confiance, vos bontés et celles de Mme Dupin. Je ne vous dis rien qui ne soit une image fidèle de ce qui se passe au fond de mon âme. jugez-moi là-dessus et daignez m'accorder un mot de réponse.

J'ai l'honneur d'être avec respect, Monsieur, votre très humble et très obéissant serviteur. 


\section{Lettre 14}

\section{À. M. [de Conzié, comte des Charmettes]}

À Venise, ce 21 septembre 1743

\section{$\underline{\text { Retour à la table des matières }}$}

Je connais si bien, Monsieur, votre générosité naturelle, que je ne doute point que vous ne preniez part à mon désespoir, et que vous ne me fassiez la grâce de me tirer de l'état affreux d'incertitude où je suis. Je compte pour rien les infirmités qui me rendent mourant, au prix de la douleur de n'avoir aucune nouvelle de Mme de Warens, quoique je lui aie écrit, depuis que je suis ici, par une infinité de voies différentes. Vous connaissez les liens de reconnaissance et d'amour filial qui m'attachent à elle, jugez du regret que j'aurais à mourir sans recevoir de ses nouvelles. Ce n'est pas sans doute vous faire un grand éloge que de vous avouer, Monsieur, que je n'ai trouvé que vous seul, à Chambéry, capable de rendre un service par pure générosité ; mais c'est du moins vous parler suivant mes vrais sentiments que de vous dire que vous êtes l'homme du monde de qui j'aimerais mieux en recevoir. Rendez-moi, Monsieur, celui de me donner des nouvelles de ma pauvre maman; ne me déguisez rien, Monsieur, je vous en supplie, je m'attends à tout, je souffre déjà tous les maux que je peux prévoir, et la pire de toutes les nouvelles pour moi, c'est de n'en recevoir aucune. Vous aurez la bonté, Monsieur, de m'adresser votre lettre sous le pli de quelque correspondant de Genève, pour qu'il me la fasse parvenir, car elle ne viendrait pas en droiture. 
Je passai en poste à Milan, ce qui me priva du plaisir de rendre moi-même votre lettre que j'ai fait parvenir depuis. J'ai appris que votre aimable marquise s'est remariée il y a quelque temps. Adieu, Monsieur, puisqu'il faut mourir tout de bon, c'est à présent qu'il faut être philosophe. Je vous dirai une autre fois quel est le genre de philosophie que je pratique. J'ai l'honneur d'être, avec le plus sincère et le plus parfait attachement, Monsieur [etc.]. 


\section{Lettre 15}

\section{À M. [du Theil]}

À Paris, le 11 octobre 1744

$\underline{\text { Retour à la table des matières }}$

Monsieur,

Voici la dernière fois que je prendrai la liberté de vous écrire jusqu'à ce qu'il vous ait plu de me faire parvenir vos ordres. Je sens combien mes lettres doivent vous importuner, et ce n'est qu'avec beaucoup de respect que je me vois réduit à un métier si contraire à mon caractère ; mais, Monsieur, je ne pouvais en conséquence de ce que j'ai eu l'honneur de vous écrire précédemment me dispenser de vous informer de mon arrivée à Paris, et de plus, je reconnais que le ton de mes lettres demanderait bien des explications que la discrétion m'oblige, cependant, d'abandonner en partie et que je réduirai à une seule exposition du motif qui me les a fait écrire.

Si vous daignez, Monsieur, faire prendre quelques explications sur ma conduite et sur mon caractère, soit à Venise, soit à Gênes où j'ai l'honneur d'être connu de M. de Jonville, soit à Lyon, soit à Genève ma patrie, j'espère que vous n'apprendrez rien qui n'aggrave l'injustice des violences dont $\mathrm{M}$. le comte de Montaigu a jugé à propos de m'accabler. Les traitements qu'il m'a faits sont de ceux contre lesquels un honnête homme ne se précautionne point. Avec les devoirs que je me suis imposés, et les sentiments dont je me suis nourri, je m'étais cru assez supérieur à de semblables accidents pour n'avoir point à chercher dans mes principes de règles de conduite en de pareils cas. Le 
zèle et l'exactitude avec lesquels je me suis acquitté de l'emploi que S.E. m'avait confié n'ont pas dû m'inspirer plus de défiance : peut-être serai-je assez heureux pour que vous en puissiez entendre parler par quelqu'un qui soit en état d'en juger, et qui n'ait point d'intérêt à me calomnier. S'il m'est donc arrivé, Monsieur, de vous écrire quelque chose d'irrégulier, je vous supplie de le pardonner au trouble affreux et au désespoir où m'ont jeté de si étranges traitements. Connaît-on rien de plus triste pour un honnête homme que de se voir indignement diffamer aux yeux du public, et en péril de sa propre vie, sans ombre de prétexte, pour de misérables discussions d'intérêt, sans qu'il lui soit permis de se défendre ni possible de se justifier! Inutilement ai-je senti que je m'allais donner du ridicule et que l'inférieur aurait toujours tort vis-àvis de son supérieur, puisque je n'ai point vu d'autre voie que de justes et respectueuses représentations pour soutenir mon honneur outragé. Ce ne sont point les traitements de M. le comte de Montaigu qui me touchent en euxmêmes. J'ai lieu de ne le pas croire assez connaisseur en mérite pour faire un cas infini de son estime : mais, Monsieur, que pensera le public qui, content de juger sur les apparences, se donne rarement la peine d'examiner si celui qu'on maltraite l'a mérité ? C'est aux personnes qui aiment l'équité, et qui sont en droit d'approfondir les choses, de réparer en cela l'injustice du public et d'y rétablir l'honneur d'un honnête homme qui compte sa vie pour rien quand il a perdu sa réputation. Rien n'est si simple que cette discussion à mon égard ; s'agit-il de l'intérêt ? Le compte que j'aurai l'honneur de vous remettre écrit de la propre main de M. le comte de Montaigu est un témoignage sans réplique qui ne fera pas honneur à sa bonne foi. S'agit-il de l'honneur ? Tout Venise a vu avec indignation les traitements honteux dont il m'a accablé. je suis déjà instruit de quelles couleurs S.E. sait peindre les personnes qu'elle a prises en haine : si donc on l'en croit sur sa parole, je ne doute point, à la vérité, que je ne sois perdu et déshonoré ; mais qu'on daigne prendre quelques informations et vérifier les choses, et j'ose croire que M. le comte de Montaigu m'aura sans y penser rendu service en me faisant connaître.

Je ne prétends point, Monsieur, exiger de satisfaction de M. l'Ambassadeur. Je n'ignore pas, quelque juste qu'elle fût, les raisons qui doivent s'y opposer. Je ne demande que d'être puni rigoureusement si je suis coupable : mais si je ne le suis point, et que vous trouviez mon caractère digne de votre estime et mon sort de quelque pitié, j'ose implorer, Monsieur, votre protection et quelque marque de bonté de votre part qui puisse me réhabiliter aux yeux du public. Peut-être y regagnerai-je plus que je n'aurai perdu : mais je sens que le zèle qui me porterait à m'en rendre digne laisserait un jour en doute si vous avez exercé envers moi plus de générosité que de justice.

J'ai l'honneur d'être avec un profond respect, Monsieur, votre très humble et très obéissant serviteur

à l'Hostel d'Orléans, rue du Chantre, près le Palais Royal. 


\section{Lettre 16}

\section{À M. [de Voltaire]}

À Paris, le 11 novembre I745

$\underline{\text { Retour à la table des matières }}$

Monsieur,

Il y a quinze ans que je travaille pour me rendre digne de vos regards et des soins dont vous favorisez les jeunes Muses en qui vous découvrez quelque talent. Mais, pour avoir fait la musique d'un opéra, je me trouve, je ne sais comment, métamorphosé en musicien. C'est, Monsieur, en cette qualité que M. le duc de Richelieu m'a chargé de scènes dont vous avez lié vos Divertissements de la Princesse de Navarre ; il a même exigé que je fisse dans les canevas les changements nécessaires pour les rendre convenables à votre nouveau sujet. J'ai fait mes respectueuses représentations ; M. le Duc a insisté, j'ai obéi ; c'est le seul parti qui convienne à l'état de ma fortune. M. Ballod s'est chargé de vous communiquer ces changements. Je me suis attaché à les réduire au moins de mots qu'il était possible. C'est le seul mérite que je pouvais leur donner. Je vous supplie, Monsieur, de vouloir les examiner, ou plutôt d'en substituer de plus dignes de la place qu'ils doivent occuper. Quant aux récitatifs, j'espère aussi, Monsieur, que vous voudrez bien les juger avant l'exécution, et m'indiquer les endroits où je me serai écarté du beau et du vrai, c'est-à-dire de votre pensée. Quel que soit pour moi le succès de ces faibles essais, ils me seront toujours glorieux, s'ils me procurent l'honneur d'être connu de vous, et de vous montrer l'admiration et le profond respect avec lesquels j'ai l'honneur d'être, Monsieur, votre très humble et très obéissant serviteur. 


\title{
Lettre 17
}

\author{
À M. Altuna
}

À Paris, le 30 juin 1748

Retour à la table des matières

Votre lettre du 7 de ce mois, mon cher et bon ami, est venue bien à propos pour ma consolation, au milieu des terribles attaques d'un mal dont je n'avais pas eu jusqu'ici le moindre soupçon. Une violente rétention d'urine a été suivie d'une indication déclarée de gravelle, et enfin d'une colique néphrétique, la plus effroyable qu'on ait jamais sentie. Après quinze jours de souffrance, grâce à Dieu, les douleurs sont un peu calmées ; mais la difficulté d'uriner continue toujours au même degré. J'ai pris les bains qui ne m'ont rien fait, et après avoir employé tous les secours de l'art qui étaient à la portée de mes facultés, j'ai trouvé que la patience et la résignation étaient les seuls remèdes à mon mal, de manière que je vais recommencer de sortir et de vaquer à mes affaires, me remettant du reste à la volonté de Dieu. Je tire un favorable augure des épreuves amères qu'il lui plaît de m'envoyer. J'ai tant mérité de châtiments que je n'ai pas le droit de me plaindre de ceux-ci, et puisqu'il commence par la justice, $\mathrm{j}$ 'espère qu'il finira par la miséricorde.

À quelle rude épreuve mettez-vous ma vertu, en me rappelant sans cesse un projet qui faisait l'espoir de ma vie ? J'aurais besoin plus que jamais de son exécution pour la consolation de mon pauvre cœur accablé d'amertumes et pour le repos que demanderaient mes infirmités ; mais, quoi qu'il en puisse arriver, je n'achèterai point ma félicité par un lâche déguisement envers mon ami. 
Vous connaissez mes sentiments sur un certain point ; ils sont invariables ; car ils sont fondés sur l'évidence et sur la démonstration qui sont, quelque doctrine qu'on embrasse, les seules armes qu'on ait pour l'établir. Car, quoique ma foi m'apprenne bien des choses qui sont au-dessus de ma raison, c'est premièrement ma raison qui m'a forcé de me soumettre à ma foi. Mais n'entrons point dans ces discussions. Vous pouvez parler, et je ne le puis pas : cela met trop d'avantage de votre côté. D'ailleurs vous cherchez, par zèle, à me tirer de mon état, et je me fais un devoir de vous laisser dans le vôtre, comme avantageux pour la paix de votre esprit, et également bon pour votre salut éternel, si vous y êtes de bonne foi, et que vous vous conduisiez toujours selon les divins et sublimes principes du christianisme. Vous voyez donc que de toutes manière la discussion sur ce point-là est interdite entre nous.

Du reste, ayez assez bonne opinion du cœur et de l'esprit de votre ami pour croire qu'il a réfléchi plus d'une fois sur les lieux communs que vous lui alléguez et que sa morale de principes, si ce n'est celle de sa conduite, n'est pas inférieure à la vôtre, ni certainement moins agréable à Dieu. Je suis donc intraitable sur ce point. Les plus affreuses douleurs, ni les approches de la mort, n'ont rien qui ne m'affermisse, rien qui ne me console dans l'espérance d'un bonheur éternel que j'espère partager avec vous dans le sein de mon Créateur.

Je m'aperçois que je ne vous parle que de moi. Mais puisque les grandes peines sont de mon côté, il est juste que la plus grande effusion de cœur y soit aussi. Du reste, soyez certain que vos peines et vos plaisirs seront toujours les miens.

Je fais des vœux ardents pour que le plus heureux mariage assure votre félicité. J'attends vos commissions pour y joindre les livres que vous me demandez, et je vous embrasse. À Dieu. 


\section{Lettre 18}

\section{À M. [de Valmalette, Maître d'Hôtel du Roi, à Paris] (fragment)}

[Vers 1749-1751]

$\underline{\text { Retour à la table des matières }}$

Quel long et injuste silence ! mon cher ami, mais j'étais malade et paresseux. Aujourd'hui que je suis malade, paresseux et libre, aujourd'hui que je me fous de tous vous autres gens de cour, aujourd'hui que tous les rois de la terre, avec toute leur morgue, tous leurs titres et tout leur or ne me feraient pas faire un pas... 


\section{Lettre 19}

\section{À M. [de Voltaire]}

À Paris, le 30 janvier 1750

Retour à la table des matières

Monsieur,

Un Rousseau se déclara autrefois votre ennemi de peur de se reconnaître votre inférieur ; un autre Rousseau, ne pouvant approcher du premier par le génie, veut imiter ses mauvais procédés. Je porte le même nom qu'eux, mais, n'ayant ni les talents de l'un, ni la suffisance de l'autre, je suis encore moins capable d'avoir leurs torts envers vous. Je consens bien de vivre inconnu, mais non déshonoré ; et je croirais l'être si j'avais manqué au respect que vous doivent tous les gens de lettres, et qu'ont pour vous tous ceux qui en méritent eux-mêmes.

Je ne veux point m'étendre sur ce sujet, ni enfreindre, même avec vous, la loi que je me suis imposée de ne jamais louer personne en face ; mais, Monsieur, je prendrai la liberté de vous dire que vous avez mal jugé d'un homme de bien en le croyant capable de payer d'ingratitude et d'arrogance la bonté et l'honnêteté dont vous avez usé envers lui au sujet des Fêtes de Ramire. Je n'ai point oublié la lettre dont vous m'honorâtes dans cette occasion. Elle a achevé de me convaincre que, malgré de vaines calomnies, vous êtes véritablement le protecteur des talents naissants qui en ont besoin. C'est en faveur de ceux dont je faisais l'essai que vous daignâtes me promettre de l'amitié : leur sort fut malheureux et j'aurais dû m'y attendre. Un solitaire 
qui ne sait point parler, un homme timide, découragé, n'ose se présenter à vous. Quel eût été mon titre ? Ce ne fut point le zèle qui me manqua, mais l'orgueil ; et n'osant m'offrir à vos yeux, j'attendis du temps quelque occasion favorable pour vous témoigner mon respect et ma reconnaissance.

Depuis ce jour, j'ai renoncé aux lettres et à la fantaisie d'acquérir de la réputation, et, désespérant d'y arriver comme vous à force de génie, j'ai dédaigné de tenter, comme les hommes vulgaires, d'y parvenir à force de manège ; mais je ne renoncerai jamais à mon admiration pour vos ouvrages. Vous avez peint l'amitié et toutes les vertus en homme qui les connaît et les aime. J'ai entendu murmurer l'envie, j'ai méprisé ses clameurs, et j'ai dit, sans crainte de me tromper : "Ces écrits qui m'élèvent l'âme et m'enflamment le courage ne sont point d'un homme indifférent pour la vertu. »

Vous n'avez pas non plus bien jugé d'un républicain, puisque j'étais connu de vous pour tel. J'adore la liberté ; je déteste également la domination et la servitude, et ne veux en imposer à personne. De tels sentiments sympathisent mal avec l'insolence ; elle est plus propre à des esclaves ou à des hommes plus vils encore, à de petits auteurs jaloux des grands.

Je vous proteste donc, Monsieur, que non seulement Rousseau de Genève n'a point tenu les discours que vous lui avez attribués, mais qu'il est incapable d'en tenir de pareils. Je ne me flatte point de mériter l'honneur d'être connu de vous, mais si ce bonheur m'arrive, ce ne sera, j'espère, que par des endroits dignes de votre estime.

J'ai l'honneur d'être avec un profond respect, Monsieur, votre très humble et très obéissant serviteur

J.-J. Rousseau, citoyen de Genève. 
Jean-Jacques Rousseau, Lettres (1728-1778)

\title{
Troisième partie
}

\section{La réforme intérieure}

\author{
$1751-1756$
}

\section{$\underline{\text { Retour à la table des matières }}$}

L'année 1749 est celle de la vocation. Barbarus hic ego sum, lit-on en tête du Discours sur les Sciences et les Arts. Dans un monde où chacun porte un masque, Rousseau sera le barbare. Qu'il paraisse, et les masques tomberont. De 1770 à 1755, il poursuit sa double carrière de musicien et d'écrivain : le Devin du Village (1752) marque le faîte de son activité de musicien, le Discours sur l'Origine de l'Inégalité (1755) le point culminant de sa révolte contre le mensonge social. Genève même a fêté le retour de l'enfant prodigue. Et Jean-Jacques se sent transformé (c'est là un aspect de sa vocation, qui est d'un écrivain révolutionnaire) : il se sent devenir l'homme de ses livres, le défenseur de la vertu et de la vérité. Vitam impendere veto, telle sera sa devise (celui qu'on appelle le Rousseau romain parle volontiers latin!). Vient alors le temps d'une difficile « réforme intérieure »: «... mes amis, mes connaissances ne me reconnaissaient plus. Je n'étais plus cet homme timide et plutôt honteux que modeste... Tout Paris répétait les âcres et mordants sarcasmes de ce même homme qui deux ans auparavant et dix ans après n'a jamais su trouver la chose qu'il avait à dire, ni le mot qu'il devait employer » (Confessions, livre IX). 
Mais ce révolté est un tendre, que hante le rêve d'une vie « oiseuse » où il retrouverait le bonheur perdu de l'enfance. C'est pourquoi il se décide à accepter l'invitation de son amie, Mme d'Epinay : avec Thérèse et sa mère, il ira habiter la maison de l'Ermitage, qu'on a aménagée pour lui dans le parc de la Chevrette, près de Montmorency. Cependant, Grimm et Diderot, très parisiens, et persuadés que Jean-Jacques ne pourra supporter cet exil, guettent le moment où sa volonté fléchira. 


\section{Lettre 20}

\section{À Mme de Francueil}

À Paris, le 20 avril 1751

\section{$\underline{\text { Retour à la table des matières }}$}

Oui, Madame, j'ai mis mes enfants aux Enfants-Trouvés ; j'ai chargé de leur entretien l'établissement fait pour cela. Si ma misère et mes maux m'ôtent le pouvoir de remplir un soin si cher, c'est un malheur dont il faut me plaindre, et non un crime à me reprocher. Je leur dois la subsistance; je la leur ai procurée meilleure ou plus sûre au moins que je n'aurais pu la leur donner moi-même ; cet article est avant tout. Ensuite, vient la déclaration de leur mère qu'il ne faut pas déshonorer.

Vous connaissez ma situation ; je gagne au jour la journée mon pain avec assez de peine ; comment nourrirais-je encore une famille. Et si j'étais contraint de recourir au métier d'auteur, comment les soucis domestiques et les tracas des enfants me laisseraient-ils, dans mon grenier, la tranquillité d'esprit nécessaire pour faire un travail lucratif ? Les écrits que dicte la faim ne rapportent guère et cette ressource est bientôt épuisée. Il faudrait donc recourir aux protections, à l'intrigue, au manège ; briguer quelque vil emploi ; le faire valoir par les moyens ordinaires, autrement il ne me nourrira pas, et me sera bientôt ôté ; enfín, me livrer moi-même à toutes les infamies pour lesquelles je suis pénétré d'une si juste horreur. Nourrir, moi, mes enfants et 
leur mère, du sang des misérables ! Non, Madame, il vaut mieux qu'ils soient orphelins que d'avoir pour père un fripon.

Accablé d'une maladie douloureuse et mortelle, je ne puis espérer encore une longue vie ; quand je pourrais entretenir, de mon vivant, ces infortunés destinés à souffrir un jour, ils payeraient chèrement l'avantage d'avoir été tenus un peu plus délicatement qu'ils ne pourront l'être où ils sont. Leur mère, victime de mon zèle indiscret, chargée de sa propre honte et de ses propres besoins, presque aussi valétudinaire, et encore moins en état de les nourrir que moi, sera forcée de les abandonner à eux-mêmes; et je ne vois pour eux que l'alternative de se faire décrotteurs ou bandits, ce qui revient bientôt au même. Si du moins leur état était légitime, ils pourraient trouver plus aisément des ressources. Ayant à porter à la fois le déshonneur de leur naissance et celui de leur misère, que deviendront-ils ?

Que ne me suis-je marié, me direz-vous ? Demandez à vos injustes lois, Madame. Il ne me convenait pas de contracter un engagement éternel, et jamais on ne me prouvera qu'aucun devoir m'y oblige. Ce qu'il y a de certain, c'est que je n'en ai rien fait, et que je n'en veux rien faire. «Il ne faut pas faire des enfants quand on ne peut pas les nourrir. » Pardonnez-moi, Madame, la nature veut qu'on en fasse, puisque la terre produit de quoi nourrir tout le monde ; mais c'est l'état des riches, c'est votre état qui vole au mien le pain de mes enfants. La nature veut aussi qu'on pourvoie à leur subsistance: voilà ce que j'ai fait ; s'il n'existait pas pour eux un asile, je ferais mon devoir et me résoudrais à mourir de faim moi-même plutôt que de ne pas les nourrir.

Ce mot d'Enfants-Trouvés vous en imposerait-il, comme si l'on trouvait ces enfants dans les rues, exposés à périr si le hasard ne les sauve ? Soyez sûre que vous n'auriez pas plus d'horreur que moi pour l'indigne père qui pourrait se résoudre à cette barbarie : elle est trop loin de mon cœur pour que je daigne m'en justifier. Il y a des règles établies ; informez-vous de ce qu'elles sont, et vous saurez que les enfants ne sortent des mains de la sage-femme que pour passer dans celles d'une nourrice. Je sais que ces enfants ne sont pas élevés délicatement : tant mieux pour eux, ils en deviennent plus robustes ; on ne leur donne rien de superflu, mais ils ont le nécessaire; on n'en fait pas des messieurs, mais des paysans ou des ouvriers. je ne vois rien, dans cette manière de les élever, dont je ne fisse choix pour les miens. Quand j'en serais le maître, je ne les préparerais point, par la mollesse, aux maladies que donnent la fatigue et les intempéries de l'air à ceux qui n'y sont pas faits. Ils ne sauraient ni danser ni monter à cheval ; mais ils auraient de bonnes jambes infatigables. Je n'en ferais ni des auteurs ni des gens de bureau; je ne les exercerais point à manier la plume, mais la charrue, la lime ou le rabot, instruments qui font mener une vie saine, laborieuse, innocente, dont on n'abuse jamais pour mal faire, et qui n'attire point d'ennemis en faisant bien. C'est à cela qu'ils sont destinés ; par la rustique éducation qu'on leur donne, ils seront plus heureux que leur père.

Je suis privé du plaisir de les voir, et je n'ai jamais savouré la douceur des embrassements paternels. Hélas ! je vous l'ai déjà dit, je ne vois là que de quoi me plaindre, et je les délivre de la misère à mes dépens. Ainsi voulait Platon que tous les enfants fussent élevés dans sa république; que chacun restât inconnu à son père, et que tous fussent les enfants de l'État. Mais cette 
éducation est vile et basse ! Voilà le grand crime ; il vous en impose comme aux autres ; et vous ne voyez pas que, suivant toujours les préjugés du monde, vous prenez pour le déshonneur du vice ce qui n'est que celui de la pauvreté. 


\section{Lettre 21}

\section{À Mme [la marquise de Créqui]}

À Paris, le 9 octobre 1751

$\underline{\text { Retour à la table des matières }}$

Je me flattais, Madame, d'avoir une âme à l'épreuve des louanges ; la lettre dont vous m'avez honoré m'apprend à compter moins sur moi-même, et s'il faut que je vous voie, voilà d'autres raisons d'y compter beaucoup moins encore. J'obéirai toutefois, car c'est à vous qu'il appartient d'apprivoiser les Monstres.

Je me rendrai donc à vos ordres, Madame, le jour qu'il vous plaira de me prescrire. Je sais que M. d'Alembert a l'honneur de vous faire sa cour; sa présence ne me chassera point ; mais ne trouvez pas mauvais, je vous supplie, que tout autre tiers me fasse disparaître.

Je suis avec un profond respect,

Madame,

Votre très humble et très obéissant serviteur 


\title{
Lettre 22
}

\section{À Mme [la marquise de Créqui]}

\author{
[Paris] Ce samedi [Vers 1752]
}

$\underline{\text { Retour à la table des matières }}$

J'ai travaillé huit jours, Madame, c'est-à-dire huit matinées. Pour vivre, il faut que je gagne quarante sols par jour : ce sont donc seize francs qui me sont dus, et dont je prie votre exactitude de différer le paiement jusqu'à mon retour de la campagne. Je n'ai point oublié votre ordre ; mais M. l'Ambassadeur était pressé, et vous m'avez dit vous-même que je pouvais également faire à loisir ma traduction sur la copie. À mon retour de Passy, j'aurai l'honneur de vous voir : le copiste recevra son paiement ; Jean-Jacques recevra, puisqu'il le faut, les compliments que vous lui destinez, et nous ferons, sur l'honneur que veut me faire M. l'Ambassadeur, tout ce qu'il plaira à lui et à vous. 


\section{Lettre 23}

\section{À Mme de Warens, née baronne de la Tour, à Chambéry}

À Paris, le 13 février 1753

\section{$\underline{\text { Retour à la table des matières }}$}

Vous trouverez ci-joint, ma chère Maman, une lettre de change de $240 £$. Mon cœur s'afflige également de la petitesse de la somme et du besoin que vous en avez. Tâchez de pourvoir aux besoins les plus pressants : cela est plus aisé où vous êtes qu'ici, où toutes choses et surtout le bois et le pain sont d'une cherté horrible. Je ne veux pas, ma bonne Maman, entrer avec vous dans le détail des choses dont vous me parlez, parce que ce n'est pas le temps de vous rappeler quel a toujours été mon sentiment sur vos entreprises. Je vous dirai seulement qu'au milieu de toutes vos infortunes, votre raison et votre vertu sont des biens qu'on ne peut vous ôter et dont le principal usage se trouve dans les afflictions.

Votre fils s'avance à grands pas vers sa dernière demeure. Le mal a fait un si grand progrès cet hiver que je ne dois plus m'attendre à en voir un autre. J'irai donc à ma destination avec le seul regret de vous laisser malheureuse.

On donnera le premier de mars la première représentation $d u$ Devin à l'Opéra de Paris ; je me ménage jusqu'à ce temps-là avec un soin extrême, afin d'avoir le plaisir de le voir. Il sera rejoué, aussi, le lundi gras au Château de Bellevue en présence du Roi, et Mme la marquise de Pompadour y fera un rôle. Comme tout cela sera exécuté par des seigneurs et dames de la Cour, je 
m'attends à être chanté faux et estropié, ainsi je n'irai point. D'ailleurs, n'ayant pas voulu être présenté au Roi, je ne veux rien faire de ce qui aurait l'air d'en rechercher de nouveau l'occasion. Avec toute cette gloire, je continue à vivre de mon métier de copiste qui me rend indépendant et qui me rendrait heureux, si mon bonheur pouvait se faire sans le vôtre et sans la santé.

J'ai quelques nouveaux ouvrages à vous envoyer et je me servirai pour cela de la voie de M. Léonard ou de celle de l'abbé Giloz, faute d'en trouver de plus directes.

Adieu, ma très bonne Maman, aimez toujours un fils qui voudrait vivre plus pour vous que pour lui-même. 


\section{Lettre 24}

\section{À Mme [d'Epinay]}

Ce dimanche matin [Mai 1754]

$\underline{\text { Retour à la table des matières }}$

Voilà mon maître et consolateur Plutarque. Gardez-le sans scrupule aussi longtemps que vous le lirez, mais ne le gardez pas pour n'en rien faire, et surtout ne le prêtez à personne, car je ne veux m'en passer que pour vous.

Si vous pouvez faire donner à Mlle le Vasseur l'argent de sa robe, vous lui ferez plaisir, car elle a de petites emplettes à faire avant notre départ.

Faites-moi dire si vous êtes délivrée de votre colique et de vos tracas domestiques, et comment vous avez passé la nuit.

Bonjour, ma dame et amie. 


\section{Lettre 25}

\section{À Mme Gonceru[t], née Rousseau, à Nyon}

À Genève, le 11 Juillet 1754

\section{$\underline{\text { Retour à la table des matières }}$}

Il y a quinze jours, ma très bonne et très chère tante, que je me propose, chaque matin, de partir pour aller vous voir, vous embrasser, et mettre à vos pieds un neveu qui se souvient, avec la plus tendre reconnaissance, des soins que vous avez pris de lui dans son enfance, et de l'amitié que vous lui avez toujours témoignée. Des soins indispensables m'ont empêché jusqu'ici de suivre le penchant de mon cœur, et me retiendront encore quelques jours ; mais rien ne m'empêchera de satisfaire mon empressement à cet égard le plus tôt qu'il me sera possible ; et j'aime encore mieux un retard qui me laissera le loisir de passer quelque temps près de vous, que d'être obligé d'aller et revenir le même jour. Je ne puis vous dire quelle fête je me fais de vous revoir, et de retrouver en vous cette chère et bonne tante que je pouvais appeler ma mère, par les bontés qu'elle avait pour moi, et à laquelle je ne pense jamais sans un véritable attendrissement. Je vous prie de témoigner à M. Gonceru le plaisir que j'aurai aussi de le revoir, et d'être reçu de lui avec un peu de la même bonté que vous avez toujours eue pour moi. je vous embrasse de tout mon cœur l'un et l'autre, et suis avec le plus tendre et le plus respectueux attachement, ma très chère et très bonne tante, votre très humble et très obéissant serviteur et neveu. 


\section{Lettre 26}

\section{À Mme Dupin, rue Plâtrière, à Paris}

À Genève, le 20 juillet 1754

\section{$\underline{\text { Retour à la table des matières }}$}

Me voici, Madame, contre toute espérance, heureusement arrivé dans ma patrie. Mon dessein n'était pas de partir sans recevoir vos ordres, et je me présentai en effet à votre porte la veille de mon départ, mais on me dit que vous étiez à la campagne chez $\mathrm{M}$. de Vernage et que vous ne reviendriez que le surlendemain ; de sorte que, ne m'étant déterminé que peu de jours avant mon départ, le temps qui me restait ne me laissa pas, à cet égard, celui de faire mon devoir.

Je ne puis vous dire, Madame, combien Genève m'a paru embelli sans que rien y soit changé ; il faut que le changement soit dans ma manière de voir. Ce qu'il y a de sûr, c'est que cette ville me paraît une des plus charmantes du monde, et ses habitants les hommes les plus sages et les plus heureux que je connaisse. La liberté y est bien affermie, le gouvernement tranquille, les citoyens éclairés, fermes et modestes, connaissant et soutenant courageusement leurs droits, mais respectant ceux d'autrui, et, par un traité que nous venons de conclure avec le roi de Sardaigne, notre souveraineté est enfin publiquement reconnue par le seul prince qui pourrait nous la disputer. J'ai pris hors de la ville un petit logement au bord du lac, et dans une situation délicieuse qui me rappelle celle de Chenonceaux. 
On ne peut rien ajouter aux bontés avec lesquelles j'ai été reçu : les caresses de mes concitoyens me laissent à peine quelques moments pour mon devoir et pour mes amis, et il faut nécessairement, au train de vie que je mène ici, que ma santé se rétablisse ou se détruise tout à fait ; on fait plus, on me sollicite de me fixer à Genève, et je vous avoue que le plaisir d'être désiré et bien voulu dans ma patrie me déterminerait peut-être à y rester, si des sentiments non moins forts et les promesses que j'ai faites à la bonne Mme le Vasseur ne me rappelaient à Paris, sans compter que la copie ferait la soupe fort maigre dans une aussi petite ville que celle-ci. J'espère donc, Madame, avoir l'honneur de vous revoir, sinon ce mois d'août comme j'avais compté, du moins avant la fin de septembre ; mais ce qu'il y a de très sûr, c'est que, dans quelque lieu que je vive, je garderai précieusement au fond de mon cœur l'éternel et touchant souvenir de vos bontés et de vos bienfaits.

Je suis avec respect, Madame, votre très humble et très obéissant serviteur.

Je vous supplie de vouloir bien assurer M. Dupin de mes obéissances, de même que M. et Mme de Chenonceaux.

Mlle le Vasseur prend la liberté de vous offrir ses très humbles respects. Elle travaille à mériter la continuation de vos bontés, par ample recueil de contes qui puissent égayer vos insomnies. 


\section{Lettre 27}

\section{À M. le comte de Lastic}

À Paris, le 20 décembre 1755

$\underline{\text { Retour à la table des matières }}$

Sans avoir l'honneur, Monsieur, d'être connu de vous, j'espère qu'ayant à vous offrir des excuses et de l'argent, ma lettre ne saurait être mal reçue.

J'apprends que Mlle de Cléry a envoyé de Blois un panier à une bonne vieille femme, nommée Mme le Vasseur, et si pauvre qu'elle demeure chez moi ; que ce panier contenait, entre autres choses, un pot de vingt livres de beurre ; que le tout est parvenu, je ne sais comment, dans votre cuisine ; que la bonne vieille, l'ayant appris, a eu la simplicité de vous envoyer sa fille, avec la lettre d'avis, vous redemander son beurre, ou le prix qu'il a coûté ; et qu'après vous être moqués d'elle, selon l'usage, vous et Mme votre épouse, vous avez, pour toute réponse, ordonné à vos gens de la chasser.

J'ai tâché de consoler la bonne femme affligée en lui expliquant les règles du grand monde et de la grande éducation; je lui ai prouvé que ce ne serait pas la peine d'avoir des gens, s'ils ne servaient à chasser le pauvre, quand il vient réclamer son bien; et, en lui montrant combien justice et humanité sont des mots roturiers, je lui ai fait comprendre, à la fin, qu'elle est trop honorée qu'un comte ait mangé son beurre. Elle me charge donc, Monsieur, de vous 
témoigner sa reconnaissance de l'honneur que vous lui avez fait, son regret de l'importunité qu'elle vous a causée, et le désir qu'elle aurait que son beurre vous eût paru bon.

Que si par hasard, il vous en a coûté quelque chose pour le port du paquet à elle adressé, elle offre de vous le rembourser, comme il est juste. Je n'attends là-dessus que vos ordres pour exécuter ses intentions, et vous supplie d'agréer les sentiments avec lesquels j'ai l'honneur d'être [etc.]... 


\section{Lettre 28}

\section{À Mme [Dupin]}

Ce lundi matin [1755 ?]

$\underline{\text { Retour à la table des matières }}$

Rousseau voudrait prier Mme Dupin de le prier à dîner ; non qu'il croie avoir besoin d'invitation, mais pour s'assurer qu'il ne trouvera point d'autre belle dame que la maîtresse de la maison, défaut que sa présence ne laisse pas oublier, mais que son entretien répare.

Raison ne sois point éperdue, Près d'elle tu gagnes toujours ;

Le sage te perd à sa vue,

Et te retrouve en ses discours.

Miséricorde ! Jean-Jacques faire des vers ! Pardon, Madame, et du secret, je vous supplie. Ils sont échappés malgré moi. 


\section{Lettre 29}

\section{À M. Perdriau, ministre du saint Évangile et pasteur à Genève}

À Paris, le 20 février 1755

Retour à la table des matières

Votre dernière lettre, Monsieur, m'a fait un plaisir d'autant plus sensible que j'étais fort inquiet de l'impression qu'aurait faite sur vous ma précédente. Votre amitié m'en est devenue plus chère après l'avoir trouvée à l'épreuve de ma franchise. Toutes vos observations sont très sages ; mais je m'assure que des intentions aussi pures que les rniennes ne laisseront à personne le courage d'en avoir d'autres en me lisant. Vous avez su le mauvais succès de mes négociations pour la Bible de Sixte Quint ; Mais vous n'avez pu savoir tout le chagrin qu'il m'a causé, et quoiqu'il n'y ait point eu de ma faute, je me reproche mon malheur dans cette circonstance comme je me reprocherais mon tort dans toute autre. Quant au manuscrit dont vous me parlez, il y a plus de six semaines que je l'ai remis à M. Vernes ; je souhaite qu'il ne se trouve pas indigne de la place qu'on veut bien lui accorder.

Vous regretterez ainsi que moi l'illustre Montesquieu. C'est à ceux qui ont une patrie et qui l'aiment à pleurer ce grand homme. Il n'avait pas besoin d'une si longue vie pour être immortel ; mais il eût dû vivre éternellement pour apprendre aux peuples leurs droits et leurs devoirs. J'étais à la campagne quand il mourut, et j'appris que de tous les gens de lettres dont Paris fourmille, 
le seul M. Diderot avait accompagné son convoi ; heureusement, c'était aussi celui qui laissait le moins apercevoir l'absence des autres.

J'ai eu, ce Carnaval, un spectacle bien agréable, mais qui ne suffit pas pour consoler de celui-là. C'est le bonhomme Fontenelle qui, chez Mme Helvétius, ouvrit le bal avec une jeune demoiselle de quatre ans. J'avais conseillé à la mère de ne pas manquer pour sa fille l'occasion de cette singularité ; je suis persuadé que ce sera pour la petite personne une anecdote mémorable qu'elle n'oubliera qu'à trente ans, comme de raison, niais qu'elle se rappellera dans sa vieillesse avec plaisir.

Si le froid a été vif à Genève, il ne l'a guère moins été à Paris ; mais il se tempère depuis quelques jours et j'espère que nous en voilà tout à fait quittes. Je traduirai d'autant plus volontiers le quatrième volume de Giannone que j'aurai le plaisir, en y travaillant, de songer que vous vous êtes occupé de moi. Je vous embrasse avec respect et de tout mon cœur.

Mille respects, je vous supplie, à M. Query. 


\title{
Lettre 30
}

\author{
À M. [Jacob] Vernes, \\ ministre du saint Évangile, \\ à la Cité, à Genève
}

À Paris,

le 2 avril 1755

$\underline{\text { Retour à la table des matières }}$

Pour le coup, Monsieur, voici bien du retard ; mais outre que je ne vous ai point caché mes défauts, vous devez songer qu'un ouvrier et un malade ne disposent pas toujours de leur temps comme ils aimeraient le mieux. D'ailleurs l'amitié se plaît à pardonner, et l'on n'y met guère la sévérité qu'à la place du sentiment. Ainsi je crois pouvoir compter sur votre indulgence.

Vous voilà donc, Messieurs, devenus auteurs périodiques. Je vous avoue que votre projet ne me rit pas autant qu'à vous : j'ai du regret de voir des hommes faits pour élever des monuments se contenter de porter des matériaux, et d'architectes se faire manœuvres. Qu'est-ce qu'un livre périodique ? Un ouvrage éphémère, sans mérite et sans utilité, dont la lecture négligée et méprisée par les gens lettrés, ne sert qu'à donner aux femmes et aux sots de la vanité sans instruction, et dont le sort, après avoir brillé le matin sur la toilette, est de mourir le soir dans la garde-robe. D'ailleurs, pouvez-vous vous résoudre à prendre des pièces dans les journaux et jusque dans le Mercure, et à compiler des compilations ? S'il n'est pas impossible qu'il s'y trouve par hasard quelque bon morceau, il est impossible que, pour le déterrer, vous n'ayez le 
dégoût d'en lire toujours une multitude de détestables. La philosophie du cœur coûtera cher à l'esprit, s'il faut le remplir de tous ces fatras. Enfin, quand vous auriez assez de zèle pour soutenir l'ennui de toutes ces lectures, qui vous répondra que votre choix sera fait comme il doit l'être, que l'attrait de vos vues particulières ne l'emportera pas souvent sur l'utilité publique, ou que, si vous ne songez qu'à cette utilité, l'agrément n'en souffrira point ? Vous n'ignorez pas qu'un bon choix littéraire est le fruit du goût le plus exquis, et qu'avec tout l'esprit et toutes les connaissances imaginables, le goût ne peut assez se perfectionner dans une petite ville pour y acquérir cette sûreté nécessaire à la formation d'un recueil. Si le vôtre est excellent, qui le sentira ? s'il est médiocre, et par conséquent détestable, aussi ridicule que le Mercure suisse, il mourra de sa mort naturelle, après avoir amusé durant quelques mois les caillettes du Pays de Vaud. Croyez-moi, Monsieur, ce n'est point cette espèce d'ouvrage qui vous convient. Des ouvrages graves et profonds peuvent nous honorer, tout le colifichet de cette petite philosophie à la mode nous va fort mal. Les grands objets, tels que la vertu et la liberté, étendent et fortifient l'esprit; les petits, tels que la poésie et les beaux-arts, lui donnent plus de délicatesse et de subtilité : il faut un télescope pour les uns, un microscope pour les autres ; et les hommes accoutumés à mesurer le ciel ne sauraient disséquer des mouches; voilà pourquoi Genève est le pays de la sagesse et de la raison, et Paris le siège du goût. Laissons-en donc les raffinements à ces myopes de la littérature, qui passent leur vie à regarder des cirons au bout de leur nez; sachons être plus fiers du goût qui nous manque, qu'eux de celui qu'ils ont ; et, tandis qu'il feront des journaux et des brochures pour les ruelles, tâchons de faire des livres utiles et dignes de l'immortalité.

Après vous avoir tenu le langage de l'amitié, je n'en oublierai pas les procédés, et, si vous persistez dans votre projet, je ferai de mon mieux un morceau tel que vous le souhaiterez pour y remplir un vide tant bien que mal.

Je me suis chargé depuis longtemps de vous faire pour M. Romilly mille remerciements de vos bontés pour son fils et je l'ai toujours oublié. Je vous prie de m'écrire désormais sous une enveloppe à l'adresse de $M$. de Fonvan, secrétaire de M. Dupin, fermier général à l'Hôtel des fermes, à Paris. Bien des respects, je vous prie, à MM. Vernet et Jalabert, et recevez les miens avec mes embrassements. 


\section{Lettre 31}

\section{À Voltaire}

À Paris, le 10 septembre 1755

$\underline{\text { Retour à la table des matières }}$

C'est à moi, Monsieur, de vous remercier à tous égards. En vous offrant l'ébauche de mes tristes rêveries, je n'ai point cru vous faire un présent digne de vous, mais m'acquitter d'un devoir et vous rendre un hommage que nous vous devons tous comme à notre chef. Sensible, d'ailleurs, à l'honneur que vous faites à ma patrie, je partage la reconnaissance de mes concitoyens, et j'espère qu'elle ne fera qu'augmenter encore, lorsqu'ils auront profité des instructions que vous pouvez leur donner. Embellissez l'asile que vous avez choisi ; éclairez un peuple digne de vos leçons; et, vous qui savez si bien peindre les vertus et la liberté, apprenez-nous à les chérir dans nos murs comme dans vos écrits. Tout ce qui vous approche doit apprendre de vous le chemin de la gloire.

Vous voyez que je n'aspire pas à nous rétablir dans notre bêtise, quoique je regrette beaucoup, pour ma part, le peu que j'en ai perdu. À votre égard, Monsieur, ce retour serait un miracle si grand à la fois et si nuisible, qu'il n'appartiendrait qu'à Dieu de le faire, et qu'au diable de le vouloir. Ne tentez donc pas de retomber à quatre pattes; personne au monde n'y réussirait moins que vous. Vous nous redressez trop bien sur nos deux pieds, pour cesser de vous tenir sur les vôtres. 
Je conviens de toutes les disgrâces qui poursuivent les hommes célèbres dans les lettres ; je conviens même de tous les maux attachés à l'humanité, et qui semblent indépendants de nos vaines connaissances. Les hommes ont ouvert sur eux-mêmes tant de sources de misères, que, quand le hasard en détourne quelqu'une, ils n'en sont guère moins inondés. D'ailleurs, il y a, dans le progrès des choses, des liaisons cachées que le vulgaire n'aperçoit pas, mais qui n'échapperont point à l'œil du sage, quand il y voudra réfléchir. Ce n'est ni Térence, ni Cicéron, ni Virgile, ni Sénèque, ni Tacite; ce ne sont ni les savants, ni les poètes, qui ont produit les malheurs de Rome et les crimes des Romains : mais sans le poison lent et secret qui corrompit peu à peu le plus vigoureux gouvernement dont l'histoire ait fait mention, Cicéron, ni Lucrèce, ni Salluste n'eussent point existé, ou n'eussent point écrit. Le siècle aimable de Lélius et de Térence amenait de loin le siècle brillant d'Auguste et d'Horace, et enfin les siècles horribles de Sénèque et de Néron, de Domitien et de Martial. Le goût des lettres et des arts naît chez un peuple d'un vice intérieur qu'il augmente ; et s'il est vrai que tous les progrès humains sont pernicieux à l'espèce, ceux de l'esprit et des connaissances, qui augmentent notre orgueil et multiplient nos égarements, accélèrent bientôt nos malheurs. Mais il vient un temps où le mal est tel que les causes même qui l'ont fait naître sont nécessaires pour l'empêcher d'augmenter ; c'est le fer qu'il faut laisser dans la plaie, de peur que le blessé n'expire en l'arrachant.

Quant à moi, si j'avais suivi ma première vocation, et que je n'eusse ni lu ni écrit, j'en aurais sans doute été plus heureux. Cependant, si les lettres étaient maintenant anéanties, je serais privé du seul plaisir qui me reste. C'est dans leur sein que je me console de tous mes maux : c'est parmi ceux qui les cultivent que je goûte les douceurs de l'amitié, et que j'apprends à jouir de la vie sans craindre la mort. Je leur dois le peu que je suis ; je leur dois même l'honneur d'être connu de vous. Mais consultons l'intérêt dans nos affaires et la vérité dans nos écrits. Quoiqu'il faille des philosophes, des historiens, des savants, pour éclairer le monde et conduire ses aveugles habitants, si le sage Memnon m'a dit vrai, je ne connais rien de si fou qu'un peuple de sages.

Convenez-en, Monsieur, s'il est bon que les grands génies instruisent les hommes, il faut que le vulgaire reçoive leurs instructions : si chacun se mêle d'en donner, qui les voudra recevoir? «Les boiteux, dit Montaigne, sont malpropres aux exercices du corps; et aux exercices de l'esprit, les âmes boiteuses. » Mais en ce siècle savant, on ne voit que boiteux vouloir apprendre à marcher aux autres.

Le peuple reçoit les écrits des sages pour les juger, non pour s'instruire. Jamais on ne vit tant de Dandins. Le théâtre en fourmille, les cafés retentissent de leurs sentences, ils les affichent dans les journaux, les quais sont couverts de leurs écrits; et j'entends critiquer l'Orphelin, parce qu'on l'applaudit, à tel grimaud si peu capable d'en voir les défauts, qu'à peine en sent-il les beautés.

Recherchons la première source des désordres de la société, nous trouverons que tous les maux des hommes leur viennent de l'erreur bien plus que de l'ignorance, et que ce que nous ne savons point nous nuit beaucoup moins que ce que nous croyons savoir. Or quel plus sûr moyen de courir d'erreurs en erreurs que la fureur de savoir tout ? Si l'on n'eût prétendu savoir que la terre ne tournait pas, on n'eût point puni Galilée pour avoir dit qu'elle 
tournait. Si les seuls philosophes en eussent réclamé le titre, l'Encyclopédie n'eût point eu de persécuteurs.

Si cent mirmidons n'aspiraient à la gloire, vous jouiriez en paix de la vôtre, ou du moins vous n'auriez que des rivaux dignes de vous.

Ne soyez donc pas surpris de sentir quelques épines inséparables des fleurs qui couronnent les grands talents. Les injures de vos ennemis sont les acclamations satiriques qui suivent le cortège des triomphateurs : c'est l'empressement du public pour tous vos écrits qui produit les vols dont vous vous plaignez: mais les falsifications n'y sont pas faciles, car le fer ni le plomb ne s'allient pas avec l'or. Permettez-moi de vous le dire, par l'intérêt que je prends à votre repos et à notre instruction : méprisez de vaines clameurs par lesquelles on cherche moins à vous faire du mal qu'à vous détourner de bien faire. Plus on vous critiquera, plus vous devez vous faire admirer. Un bon livre est une terrible réponse à des injures imprimées; et qui vous oserait attribuer des écrits que vous n'aurez point faits, tant que vous n'en ferez que d'inimitables?

Je suis sensible à votre invitation; et si cet hiver me laisse en état d'aller, au printemps, habiter ma patrie, j'y profiterai de vos bontés. Mais j'aimerais mieux boire de l'eau de votre fontaine que du lait de vos vaches; et quant aux herbes de votre verger, je crains bien de n'y en trouver d'autres que le lotos, qui n'est pas la pâture des bêtes, et le moly, qui empêche les hommes de le devenir.

Je suis de tout mon cœur et avec respect [etc.]... 


\section{Lettre 32}

\section{À Mme [d'Epinay]}

[Vers mars 1756]

$\underline{\text { Retour à la table des matières }}$

J'ai lu avec grande attention, Madame, vos lettres à M. votre fils ; elles sont bonnes, excellentes, mais elles ne valent rien pour lui. Permettez-moi de vous le dire avec la franchise que je vous dois. Malgré la douceur et l'onction dont vous croyez parer vos avis, le ton de ces lettres, en général, est trop sérieux ; il annonce votre projet; et, comme vous l'avez dit vous-même, si vous voulez qu'il réussisse, il ne faut pas que l'enfant puisse s'en douter. S'il avait vingt ans, elles ne seraient peut-être pas trop fortes, mais peut-être seraient-elles encore trop sèches. Je crois que l'idée de lui écrire est très heureusement trouvée, et peut lui former le cœur et l'esprit, mais il faut deux conditions : c'est qu'il puisse vous entendre et qu'il puisse vous répondre. Il faut que ces lettres ne soient faites que pour lui, et les deux que vous m'avez envoyées seraient bonnes pour tout le monde, excepté lui. Croyez-moi, gardez-les pour un âge plus avancé : faites-lui des contes, faites-lui des fables dont il puisse lui-même tirer la morale, et, surtout, qu'il puisse se les appliquer. Gardez-vous des généralités ; on ne fait rien que de commun et d'inutile en mettant des maximes à la place des faits ; c'est de tout ce qu'il aura remarqué, en bien ou en mal, qu'il faut partir. A mesure que ses idées commenceront à se développer, et que vous lui aurez appris à réfléchir, à comparer, vous proportionnerez le ton de vos lettres à ses progrès et aux facultés de son esprit. Mais si vous dites à $M$. votre fils que vous vous 
appliquez à former son cœur et son esprit, que c'est en l'amusant que vous lui montrerez la vérité et ses devoirs, il va être en garde contre tout ce que vous lui direz; il croira toujours voir sortir une leçon de votre bouche ; tout, jusqu'à sa toupie, lui deviendra suspect. Agissez ainsi, mais gardez-en bien le secret.

À quoi sert-il, par exemple, de l'instruire des devoirs de votre état de mère ? Pourquoi lui faire retentir toujours à l'oreille les mots soumission, devoirs, vigilance, raison ? Tout cela a un son effrayant à son âge. C'est avec les actions qui résultent de ces termes qu'il faut l'apprivoiser; laissez-lui ignorer leurs qualifications jusqu'à ce que vous puissiez les lui apprendre par la conduite qu'il aura tenue ; et encore faites-lui bien sentir, avant tout, l'avantage et l'agrément qu'il en aura recueillis, afin de lui montrer qu'un acte de soumission et de devoir n'est pas une chose si effrayante qu'il pourrait se l'imaginer.

Quant à la seconde lettre, si elle ne renferme pas des choses si contraires à votre but, elle est au moins remplie d'idées et d'images trop fortes, non seulement pour l'âge de $\mathrm{M}$. votre fils, mais même pour un âge beaucoup audessus du sien. Votre définition de la politesse est juste et délicate, mais il faut y penser à deux fois pour en sentir toute la finesse. Sait-il ce que c'est que l'estime, que la bienveillance ; est-il en état de distinguer l'expression volontaire ou involontaire d'un cœur sensible ? Comment lui ferez-vous entendre que le corps ne doit point courir après l'ombre, et que l'ombre ne peut exister sans le corps qui la produit ?

Prenez garde, Madame, qu'en présentant de trop bonne heure aux enfants des idées fortes et compliquées, ils sont obligés de recourir à la définition de chaque mot. Cette définition est presque toujours plus compliquée, plus vague que la pensée même; ils en font une mauvaise application, et il ne leur reste que des idées fausses dans la tête. Il en résulte un autre inconvénient, c'est qu'ils répètent en perroquets de grands mots auxquels ils n'attachent point de sens, et qu'à vingt ans, ils ne sont que de grands enfants ou de plats importants.

Vous m'avez demandé mon avis par écrit, Madame, le voilà. Je désire que vous vous en accommodiez, mais il ne m'est pas possible de vous en donner un autre. Si je ne me suis pas trompé sur votre compte, vous me pardonnerez ma brutalité, et vous recommencerez votre besogne avec plus de courage et de succès que jamais. 


\title{
Lettre 33
}

\section{À Mme d'Epinay,}

\author{
à Paris [Le 16 ou le 17 mars 1756]
}

$\underline{\text { Retour à la table des matières }}$

Il s'en faut beaucoup que mon affaire avec $\mathrm{M}$. Tronchin ne soit faite, et votre amitié pour moi y met un obstacle qui me paraît plus que jamais difficile à surmonter, mais vous avez plus consulté votre cœur que votre fortune et mon humeur dans l'arrangement que vous me proposez; cette proposition m'a glacé l'âme ; que vous entendez mal vos intérêts de vouloir faire un valet d'un ami, et que vous me pénétrez mal si vous croyez que de pareils raisons puissent me déterminer. Je ne suis point en peine de vivre ni de mourir : mais le doute qui m'agite cruellement, c'est celui du parti qui durant ce qui me reste à vivre peut m'assurer la plus parfaite indépendance. Après avoir tout fait pour elle, je n'ai pu la trouver à Paris. Je la cherche avec plus d'ardeur que jamais et ce qui m'afflige cruellement depuis près d'un an est de ne pouvoir démêler où je la trouverai la plus assurée. Cependant les plus grandes probabilités sont pour mon pays, mais je vous avoue que je la trouverais plus douce auprès de vous. La violente perplexité où je me trouve ne peut durer encore longtemps, mon parti sera pris dans sept ou huit jours, mais soyez bien sûre que ce ne seront pas des raisons d'intérêt qui me détermineront, parce que je n'ai jamais craint que le pain vînt à me manquer et qu'au pis-aller, je sais comment on s'en passe. 
Je ne refuse pas, au reste, d'écouter ce que vous avez à me dire pourvu que vous vous souveniez que je ne suis pas à vendre, et que mes sentiments audessus maintenant de tout le prix qu'on y peut mettre se trouveraient bientôt au-dessous de celui qu'on y aurait mis. Oublions donc l'un et l'autre qu'il ait même été question de cet article.

Quant à ce qui vous regarde personnellement, je ne doute pas que votre cœur ne sente le prix de l'amitié, mais j'ai lieu de croire que la vôtre m'est bien plus nécessaire qu'à vous la mienne, car vous avez des dédommagements qui me manquent et auxquels j'ai renoncé pour jamais.

Je vous prie de vouloir bien dire à $\mathrm{M}$. de Linant qu'il peut aller chez $\mathrm{M}$. Diderot, rue Tarannes vis-à-vis la rue Saint-Benoît, prendre la souscription et les volumes qu'il a désiré d'avoir et qu'il trouvera tout prêts. Pour trouver M. Diderot, il faut aller avant dix heures du matin.

Bonjour, Madame ; voilà encore un livre à vendre. Envoyez-moi mon opéra. 


\section{Lettre 34}

\section{À Mme d'Epinay, à Paris}

Ce mardi [22 mars ( ?) 1756]

\section{Retour à la table des matières}

Enfin, Madame, j'ai pris mon parti, et vous vous doutez bien que vous l'emportez. J'irai donc passer les fêtes de Pâques à l'Ermitage, et j'y resterai tant que je m'y trouverai bien et que vous voudrez m'y souffrir, mes projets ne vont pas plus loin que cela. Je vous irai voir demain et nous en causerons, mais toujours le secret, je vous en prie. Voilà maintenant un déménagement et des embarras qui me font trembler. Oh ! qu'on est malheureux d'être si riche. Il faudra que je laisse la moitié de moi-même à Paris, même quand vous n'y serez plus. Cette moitié sera des chaises, des tables, des armoires et tout ce qu'il ne faudra pas ajouter à ce que vous aurez mis à mon château. À demain. 
Jean-Jacques Rousseau, Lettres (1728-1778)

\section{Quatrième partie Le démon de midi}

$1756-1757$

$\underline{\text { Retour à la table des matières }}$

Le séjour de Rousseau à l'Ermitage (moins de vingt mois) s'est achevé par un drame, le drame de l'amour impossible et de l'amitié perdue, mais aussi celui de l'homme «qui avait cru s'être trouvé en épousant le personnage du témoin de la vérité » (Euvres complètes, t. I, collection de la Pléiade, commentaire, p. 1463). Seul à l'Ermitage, Jean-Jacques est ressaisi par ses chimères, les souvenirs de sa jeunesse descendent en lui, il s'écrit des lettres d'amour, dont il fera ensuite celles des héros de la Nouvelle Héloïse. Alors, au moment où sa vulnérabilité est extrême, Sophie d'Houdetot vient prendre dans sa vie la place que Julie occupait dans son imagination. Quelques mois à peine de passion brûlante, inassouvie : entre la comtesse et son «musicien extravagant » (selon le mot de Barrès), il y a l'ombre du marquis de SaintLambert.

À l'action principale se mêlent deux actions secondaires : Diderot (dans la préface du Fils naturel) a lancé une flèche à son ancien ami : «Il n'y a que le méchant qui soit seul »; du moins Jean-Jacques s'est-il senti visé par la sentence. Et puis Mme d'Epinay, jalouse de Sophie, sa jeune belle-sœur, a voulu mettre la main sur ses lettres, elle a tenté de dresser Thérèse et sa mère contre Rousseau : scènes, réconciliations imparfaites, larmes, griefs accumulés. Mme d'Houdetot se ressaisit et s'éloigne. Jean-Jacques, effrayé par la 
pensée du « crime » qu'il aurait souhaité commettre, essaye de se disculper par tous les moyens (jusqu'au mensonge), de reprendre le visage de conseiller vertueux (mais n'est-ce pas aussi un masque ?), de regagner le rivage de la bonne conscience et de la sagesse, du temps de sa « réforme intérieure » (mais cette sagesse était-elle sans alliage ?). Le voici désormais qui s'interroge, comme Saint-Preux dans son roman : «Suis-je celui que je pensais être ? et cette question, qui sort à peine de l'ombre, est au principe du délire d'angoisse de son âge mûr et de sa vieillesse. Sa réponse, sa défense, tiendra tout entière dans les mots qui figurent dans le préambule des Confessions : avec tous ses défauts, tous ses vices même, n'est-il pas le meilleur des hommes ? 


\title{
Lettre 35
}

\section{À Mme [d'Epinay]}

\author{
[L'Ermitage, 12 avril I756]
}

$\underline{\text { Retour à la table des matières }}$

Quoique le temps me contrarie depuis mon arrivée ici, je viens de passer les trois jours les plus tranquilles et les plus doux de ma vie. Ils le seront encore plus quand les ouvriers qu'occupe mon luxe ou votre sollicitude seront partis. Aussi, je ne serai proprement dans ma solitude que d'ici à deux ou trois jours ; en attendant je m'arrange, non selon la morale turque qui veut qu'on ne s'établisse ici-bas aucun domicile durable, mais selon la mienne, qui me porte à ne jamais quitter celui que j'occupe. Vous me trouverez rangé délicieusement à la magnificence près que vous y avez mise et qui toutes les fois que j'entre dans ma chambre me fait chercher respectueusement l'habitant d'un lieu si bien meublé. Au surplus, je ne vous conseille pas beaucoup de compter sur des compliments à notre première entrevue, je vous réserve, au contraire, une censure grave d'être venue malade et souffrante m'installer ici sans égard pour vous ni pour moi. Hâtez-vous de me rassurer sur les suites de cette indiscrétion, et souvenez-vous une fois pour toutes que je ne vous pardonnerai jamais d'oublier ainsi mes intérêts en songeant aux vôtres.

J'ai trouvé deux erreurs dans le compte joint à l'argent que vous m'avez remis ; toutes deux sont à votre préjudice et me font soupçonner que vous pourriez bien en avoir fait d'autres de même nature, ce qui ne vous réussirait pas longtemps. L'une est de 141 . en ce que vous payez sept mains de papier de Hollande à $51.5 \mathrm{~s}$. au lieu de $31.5 \mathrm{~s}$. qu'il m'a coûté et que je vous ai 
marquées ; l'autre est de 61 . pour un Racine que je n'ai jamais eu et que par conséquent vous ne pouvez avoir vendu à mon profit. Ce sont donc vingt francs dont vous êtes créditée sur ma caisse. Soit dit sur l'argent, et revenons à nous.

Je n'ai songé qu'à moi ces jours-ci, je savourais les beautés de mon habitation et les charmes d'une entière liberté. Mais en me promenant ce matin dans un lieu délicieux, j'y ai mis mon ancien ami Diderot à côté de moi et en lui faisant remarquer les agréments de la promenade, je me suis aperçu qu'ils s'augmentaient pour moi-même; je ne sais si je pourrai jamais jouir réellement de cette augmentation ; si cela peut se faire un jour, ce ne sera guère que par le crédit de mon ancien ami Grimm. Peut-être pourra-t-il et voudra-t-il bien me procurer une visite de l'ami que je lui ai procuré et partager avec moi le plaisir que j'aurai de le recevoir. Ce n'est pas encore le temps de parler de tout cela, mais vous, quand vous verra-t-on, vous en santé, et votre sauveur sans affaire, il m'a promis de venir et le fera sans doute; quant à vous, ma bonne amie, quelque envie que j'aie de vous voir, si vous venez sans lui, ne venez pas du moins sans sa permission. Bonjour ; malgré la barbe de l'ermite et la fourrure de l'ours, trouvez bon que je vous embrasse, et portez aux pieds du seigneur de la case les hommages de son très dévoué sujet et fontenier honoraire.

Les Gouverneuses veulent que je vous supplie d'agréer leurs très humbles respects. Elles s'accoutument ici presque aussi bien que moi et beaucoup mieux que mon chat. 


\section{Lettre 36}

\section{À Mme d'Epinay, à Paris}

Ce samedi 1er mai [1756]

$\underline{\text { Retour à la table des matières }}$

Je viens de courir les bois à la rosée et j'ai l'onglée, ainsi je ne vous écris qu'un mot pour vous dire que je suis bien aise que vous vous portiez bien, que je me porte passablement aussi, que nous vous remercions tous et que j'espère vous voir ici avant que vous receviez ce billet.

La petite-fille de Mme le Vasseur écrit à sa grand-mère comme si mon hôtesse n'avait pas encore été avertie que je quitte mon logement. Je vous prie, Madame, en ce cas, de vouloir bien la faire avertir avant le 13. 


\section{Lettre 37}

\section{À Mme d'Epinay, à Epinay}

[De l'Ermitage, avant le 17 septembre 1756]

\section{$\underline{\text { Retour à la table des matières }}$}

Je suis arrivé saucé, et à une heure de la nuit, mais du reste sans accident, et je vous remercie de votre inquiétude.

Votre jardinier a encore emporté ce matin des pêches au marché de Montmorency. On ne peut rien ajouter à l'effronterie qu'il met dans ses vols, et bien loin que ma présence ici le retienne, je vois très évidemment qu'elle lui sert de raison pour porter chez vous encore moins de fruits qu'à l'ordinaire. Il n'y aura de longtemps rien à faire à votre jardin, vous épargneriez les restes de votre fruit si vous lui donniez congé plus tôt que plus tard ; bien entendu que vous m'aurez fait avertir d'avance et que vous vous ferez rendre en même temps la clé de la maison. À l'égard du lit et de ce qui est dans sa chambre, comme j'ignore ce qui est à vous ou à lui, je ne lui laisserai rien emporter sans un ordre de votre part. Il est inutile que personne couche ici, et si cela est nécessaire, je pourrai y faire coucher quelqu'un du voisinage sur qui je compte et à qui d'ailleurs, je ne confierai pas la clé : en attendant, vous aurez le temps de faire chercher un jardinier. La seule précaution dont j'aurais besoin pour le repos des Gouverneuses, ce serait un fusil ou des pistolets pour cet hiver, mais je ne trouve personne qui m'en veuille prêter, et il ne serait pas raisonnable d'en acheter. Au fond, je vois que nous sommes ici en parfaite sûreté et sous la protection des voisins. 
Je suis obligé de vous écrire tout ceci, car il est difficile d'avoir de conversation tranquille dans les courts intervalles que j'ai à passer près de vous.

Bonjour, Madame, on va d'abord se mettre à votre ouvrage et il se fera sans interruption. Mes respects à Mme Desclavelles et mes amitiés au Tyran et à vos enfants.

Mon pied va mieux, malgré la fatigue. 


\section{Lettre 38}

\section{À Mme d'Epinay, rue Saint-Honoré, vis-à-vis les Capucins, à Paris}

Ce mercredi, etc. (sic)

[fin novembre ou début décembre 1756]

$\underline{\text { Retour à la table des matières }}$

Passe pour le cotillon, mais le sel ! jamais femme donna-t-elle à la fois de la chaleur et de la prudence. À la fin vous me ferez mettre mon bonnet de travers, et je ne le redresserai plus. N'avezvous pas assez fait pour vous ? faites maintenant quelque chose pour moi, et laissez-vous aimer à ma guise.

Oh ! que vous êtes bonne avec vos explications ! Ah ! ce cher rhumatisme ? Maintenant que vous m'avez expliqué votre billet, expliquez-moi le commentaire ; car cette glacière où je ne comprends rien y revient encore, et pour moi, je ne vous connais pas d'autre glacière qu'un recueil de musique française.

Enfin, vous avez vu l'homme. C'est toujours autant de pris ; car je suis de votre avis et je crois que c'est tout ce que vous en aurez : je me doute pourtant bien de ce qu'un ours musqué devrait vous dire, sur l'effet de ce premier entretien, mais quant à moi, je pense que le Diderot du matin voudra toujours vous aller voir et que le Diderot du soir ne vous aura jamais vue. Vous savez que le rhumatisme le tient aussi quelquefois, et quand il ne plane pas sur ses deux grandes ailes auprès du soleil on le trouve sur un tas d'herbe perclus des quatre pattes. Croyez-moi, si vous avez encore un cotillon de reste vous ferez 
bien de le lui envoyer. Je ne savais pas que le papa Gauffecourt fût malade et l'on m'a même flatté de le voir aujourd'hui ; ce que vous m'avez marqué fera que s'il ne vient pas j'en serai fort en peine.

Encore de nouveaux plans ? Diable soit fait des plans, et plan plan relantanplan. C'est sans doute une fort belle chose qu'un plan, mais faites des détails et des scènes théâtrales, il ne faut que cela pour le succès d'une pièce à la lecture, et même quelquefois à la représentation. Que Dieu vous préserve d'en faire une assez bonne pour cela.

J'ai relu votre lettre pour y chercher les fautes d'orthographe, et n'y en ai pas su trouver une, quoique je ne doute pas qu'elles n'y soient. Je ne vous sais pas mauvais gré de les avoir faites, mais bien de les avoir remarquées. Moi, j'en voulais faire exprès pour vous faire honte et n'y ai plus songé en vous écrivant.

Bonjour, mon amie du temps présent et bien plus encore du temps à venir. Vous ne me dites rien de votre santé, ce qui me fait augurer qu'elle est bonne.

À propos de santé, je ne sais pas s'il y a de l'orthographe dans ce chiffon, mais je trouve qu'il n'y a pas de grand sens ; ce qui me fait croire que je n'aurais pas mal fait de me faire de votre cotillon une bonne calotte bien épaisse au lieu d'un gilet; car je sens que le rhumatisme ne me tient pas au cœur, mais à la cervelle.

Je vous prie de vouloir bien demander au Tyran ce que signifie un paquet qu'il m'a fait adresser contenant deux écus de six francs. Cela me paraît un àcompte un peu fort sur les parties d'échecs qu'il doit perdre avec moi.

Diderot sort d'ici, je lui ai montré votre lettre et la mienne. Je vous l'ai dit, il a conçu une grande estime pour vous et ne vous verra point... Vous en avez assez fait ; même pour lui. Croyez-moi, laissez-le aller. La maman le Vasseur est de retour et se porte un peu mieux. 


\section{Lettre 39}

\section{À Mme d'Epinay, rue Saint-Honoré, vis-à-vis les Capucins, à Paris}

À l'Ermitage, le 13 mars [1757]

Retour à la table des matières

Ma chère amie, il faudra que j'étouffe si je ne verse pas mes peines dans le sein de l'amitié. Diderot m'a écrit une lettre qui m'a percé l'âme. Il m'y fait entendre que c'est par grâce qu'il ne me regarde pas comme un scélérat, et qu'il y aurait bien à dire là-dessus, ce sont ses termes; et cela, savez-vous pourquoi ? parce que Mme le Vasseur est avec moi. Eh ! bon Dieu, que diraitil de plus si elle n'y était pas ? Je les ai recueillis dans la rue, elle et son mari, dans un âge où ils n'étaient plus en état de gagner leur vie, elle ne m'a jamais rendu que trois mois de service; depuis dix ans, je m'ôte pour elle le pain de la bouche; je la mène dans un bon air où rien ne lui manque; je renonce pour elle au séjour de ma patrie : elle est sa maîtresse absolue, va, vient sans compte rendre, j'en ai autant de soin que de ma propre mère ; tout cela n'est rien, et je ne suis qu'un scélérat si je ne lui sacrifie encore mon bonheur et ma vie, et si je ne vais mourir de désespoir à Paris pour son amusement. Hélas, la pauvre femme ne le désire point ; elle ne se plaint point ; elle est très contente. Mais je vois ce que c'est ; $M$. Grimm ne sera pas content lui-même qu'il ne m'ait ôté tous les amis que je lui ai donnés. Philosophes des villes, si ce sont là vos vertus, vous me consolez bien de n'être qu'un méchant. J'étais heureux de ma retraite, la solitude ne m'est point à charge, je crains peu la misère, l'oubli 
du monde m'est indifférent, je porte mes maux avec patience ; mais aimer, et ne trouver que des cœurs ingrats, ah ! voilà le seul qui me soit insupportable! Pardon, ma chère amie, j'ai le cœur surchargé d'ennuis et les yeux gonflés de larmes qui ne peuvent sortir. Si je pouvais vous voir un moment et pleurer, que je serais soulagé ! Mais je ne remettrai de ma vie les pieds à Paris ; pour le coup, je l'ai juré.

J'oubliais de vous dire qu'il y a même de la plaisanterie dans la lettre du philosophe. Il devient barbare avec légèreté : on voit qu'il se civilise.

Marquez-moi, je vous prie, si vous avez fait quelque chose pour ce pauvre Romilly si du moins vous lui avez parlé, ou s'il faut que je lui écrive que je ne puis rien faire. 


\section{Lettre 40}

\section{À Mme d'Epinay, rue Saint-Honoré, vis-à-vis les Capucins, à Paris}

Ce jeudi soir [17 mars 1757]

$\underline{\text { Retour à la table des matières }}$

Mme le Vasseur doit vous écrire, ma bonne amie ; je l'ai priée de vous dire sincèrement ce qu'elle pense. Pour la mettre bien à son aise, je lui ai déclaré que je ne voulais pas voir sa lettre, et je vous prie de ne me rien dire de ce qu'elle contient.

Je n'enverrai pas la mienne à Diderot, puisque vous vous y opposez. Mais me sentant très grièvement offensé, il y aurait, à convenir d'un tort que je n'ai pas, une bassesse et une fausseté que je ne saurais me permettre et que vous blâmeriez vous-même sur ce qui se passe au fond de mon cœur. L'Évangile ordonne bien à celui qui reçoit un soufflet d'offrir l'autre joue, mais non de demander pardon. Vous rappelez-vous cet homme de la comédie qui crie au meurtre en donnant des coups de bâton, voilà le rôle du Philosophe.

N'espérez pas l'empêcher de venir par le temps qu'il fait : il serait très fâché qu'il fût plus beau. La colère lui donnera le loisir et les forces que l'amitié lui refuse. Et ce sera la première fois de sa vie qu'il sera venu le jour qu'il avait promis. Il s'excédera pour venir à pied me répéter les injures qu'il me dit dans ses lettres. Je ne les endurerai rien moins que patiemment ; il s'en retournera être malade à Paris, et moi, je paraîtrai à tout le monde un homme fort odieux. Patience ! il faut souffrir. N'admirez-vous pas la raison de cet 
homme qui me voulait venir prendre à Saint-Denis en fiacre, y dîner, et me ramener en fiacre, et à qui, huit jours après, sa fortune ne permet plus d'aller à l'Ermitage autrement qu'à pied ? Pour parler son langage, il n'est pas absolument impossible que ce soit là le ton de la bonne foi ; mais dans ce cas il faut qu'il soit arrivé d'étranges révolutions dans sa fortune. O la Philosophie !

Je prends part au chagrin que vous donne la maladie de Mme votre mère ; mais croyez que votre peine ne saurait approcher de la mienne, on souffre moins encore de voir malades les personnes qu'on aime qu'injustes et cruelles.

Adieu, ma bonne amie, voici la dernière fois que je vous parlerai de cette malheureuse affaire. Vous me parlez d'aller à Paris avec un sang-froid qui me réjouirait dans un autre temps. Je me tiens pour bien dites toutes les belles choses qu'il y aurait à dire là-dessus, mais avec tout cela je n'irai de ma vie à Paris, et je bénis le ciel de m'avoir fait ours, ermite, et têtu, plutôt que philosophe. 


\section{Lettre 41 \\ À Mme [d'Epinay]}

Ce samedi 26 [mars 1757]

$\underline{\text { Retour à la table des matières }}$

Diderot m'a écrit une troisième lettre en me renvoyant mes papiers. Quoique vous me marquiez par la vôtre que vous m'envoyez ce paquet, elle m'est parvenue plus tard et par une autre voie ; de sorte que quand je l'ai reçue, ma réponse à Diderot était déjà faite. Vous devez être aussi ennuyée de cette longue tracasserie que j'en suis excédé. Ainsi n'en parlons plus, je vous supplie.

Mais où avez-vous pris que je me plaindrai de vous aussi ? Si j'avais à m'en plaindre ce serait parce que vous usez de trop de ménagements avec moi et me traitez trop doucement. J'ai souvent besoin d'être plus gourmandé que cela, un ton de gronderie me plaît fort quand je le mérite ; je crois que je serais homme à le regarder quelquefois comme une sorte de cajolerie de l'amitié. Mais on querelle son ami sans le mépriser ; on lui dira fort bien qu'il est une bête, on ne lui dira pas qu'il est un coquin. Vous ne me ferez jamais entendre que vous me croyez faire grâce en pensant bien de moi, vous ne m'insinuerez jamais qu'en y regardant de près, il y aurait beaucoup d'estime à rabattre ; vous ne me direz pas : encore y aurait-il bien à dire là-dessus. Ce ne serait seulement pas m'offenser; ce serait vous offenser vous-même, car il ne convient pas à d'honnêtes gens d'avoir des amis dont ils pensent mal ; que s'il m'était arrivé de mal interpréter sur ce point un discours de votre part, vous vous hâteriez assurément de m'expliquer votre idée, et vous garderiez de soutenir durement ce même propos dans le mauvais sens où je l'aurais entendu. Comment, Madame, appelez-vous cela une forme, un extérieur ? 
J'ai envie, puisque nous traitons ce sujet, de vous faire ma déclaration sur ce que j'exige de l'amitié et sur ce que j'y veux mettre à mon tour. Reprenez librement ce que vous trouverez à blâmer dans mes règles : mais attendezvous à ne m'en pas voir départir aisément; car elles sont tirées de mon caractère que je ne puis changer.

Premièrement : je veux que mes amis soient mes amis, et non pas mes maîtres ; qu'ils me conseillent sans prétendre me gouverner ; qu'ils aient toutes sortes de droit sur mon cœur, aucun sur ma liberté. Je trouve très singulier les gens qui sous ce nom prétendent toujours se mêler de mes affaires, sans rien me dire des leurs.

Qu'ils me parlent toujours librement et franchement; ils peuvent me tout dire : hors le mépris, je leur permets tout. Le mépris d'un indifférent m'est indifférent ; mais si je le souffrais d'un ami, j'en serais digne. S'il a le malheur de me mépriser, qu'il ne me le dise pas; qu'il me quitte ; c'est son devoir envers lui-même. A cela près, quand il me fait ses représentations, de quelque ton qu'il les fasse, il use de son droit ; quand, après l'avoir écouté, je fais ma volonté, j'use du mien; et je trouve mauvais qu'on me rabâche éternellement sur une chose faite.

Leurs grands empressements à me rendre mille services dont je ne me soucie point, me sont à charge ; j'y trouve un certain air de supériorité qui me déplaît. D'ailleurs, tout le monde en peut faire autant ; j'aime mieux qu'ils m'aiment et se laissent aimer ; voilà ce que les amis seuls peuvent faire. Je m'indigne surtout quand le premier venu les dédommage de moi, tandis que je ne peux souffrir qu'eux au monde. Il n'y a que leurs caresses qui puissent me faire supporter leurs bienfaits. Mais quand je fais tant que d'en recevoir d'eux, je veux qu'ils consultent mon goût et non pas le leur : car nous pensons si différemment sur tant de choses que souvent ce qu'ils estiment bon me paraît mauvais. S'il survient une querelle, je dirais bien que c'est à celui qui a tort de revenir le premier : mais ce n'est rien dire, car chacun croit toujours avoir raison. Tort ou raison, c'est à celui qui a commencé la querelle à la finir. Si je reçois mal sa censure, si je m'aigris sans sujet, si je me mets en colère mal à propos, il ne doit pas s'y mettre à mon exemple, ou bien il ne m'aime pas. Au contraire, je veux qu'il me caresse bien, qu'il me baise bien ; entendez-vous, Madame. En un mot, qu'il commence par m'apaiser, ce qui sûrement ne sera pas long : car il n'y eut jamais d'incendie au fond de mon cœur qu'une larme ne pût éteindre. Alors, quand je serai attendri, calmé, honteux, confus, qu'il me gourmande bien, qu'il me dise bien mon fait, et sûrement il sera content de moi. S'il est question d'une minutie qui ne vaille pas l'éclaircissement, qu'on la laisse tomber; que l'agresseur se taise le premier, et ne fasse pas un sot point d'honneur d'avoir toujours l'avantage. Voilà ce que je veux que mon ami fasse envers moi et que je suis toujours prêt à faire envers lui dans le même cas.

Je pourrais vous citer là-dessus une espèce de petit exemple dont vous ne vous doutez pas quoiqu'il vous regarde. C'est au sujet d'un billet que je reçus de vous il y a quelque temps en réponse à un autre dont je vis que vous n'étiez pas contente et où vous n'aviez pas, ce me sembla, bien entendu ma pensée. Je fis une réplique assez bonne ou du moins elle me parut telle ; elle avait sûrement le ton de la véritable amitié, mais en même temps une certaine 
vivacité dont je ne puis me défendre, et je craignis, en la relisant, que vous n'en fussiez pas plus contente que de la première ; à l'instant, je jetai ma lettre au feu ; je ne puis vous dire avec quel contentement de cœur je vis brûler mon éloquence. Je ne vous en ai plus parlé, et je crois avoir acquis l'honneur d'être battu. Il ne faut quelquefois qu'une étincelle pour allumer un incendie. Ma chère et bonne amie, Pythagore disait qu'on ne devait jamais attiser le feu avec une épée ; cette sentence me paraît la plus importante et la plus sacrée des lois de l'amitié.

J'exige d'un ami bien plus encore que tout ce que je viens de vous dire ; plus même qu'il ne doit exiger de moi, et que je n'exigerais de lui, s'il était à ma place et que je fusse à la sienne. En qualité de solitaire, je suis plus sensible qu'un autre ; si j'ai quelque tort avec un ami qui vive dans le monde, il y songe un moment et mille distractions le lui font oublier le reste de la journée ; mais rien ne me distrait sur les siens ; privé de sommeil, je m'en occupe durant la nuit entière ; seul à la promenade, je m'en occupe depuis que le soleil se lève jusqu'à ce qu'il se couche ; mon cœur n'a pas un instant de relâche, et les duretés d'un ami me donnent dans un jour des années de douleurs. En qualité de malade j'ai droit aux ménagements que l'humanité doit à la faiblesse et à l'humeur d'un homme qui souffre ; quel est l'ami, quel est l'honnête homme qui ne doit pas craindre d'affliger un malheureux tourmenté d'une maladie incurable et douloureuse ? Je suis pauvre, et il me semble que cet état mérite encore des égards. Tous ces ménagements que j'exige, vous les avez eus sans que je vous en parlasse ; et sûrement jamais un véritable ami n'aura besoin que je les lui demande. Mais, ma chère amie, parlons sincèrement, me connaissez-vous des amis ? Ma foi, bien m'en a pris d'apprendre à m'en passer. Je connais force gens qui ne seraient pas fâchés que je leur en eusse obligation, et beaucoup à qui j'en ai en effet; mais des cœurs dignes de répondre au mien ; ah ! c'est bien assez d'en connaître un.

Ne vous étonnez pas si je prends Paris toujours plus en haine. Il ne m'en vient rien que de chagrinant, hormis vos lettres. On ne m'y reverra jamais. Si vous voulez me faire vos représentations là-dessus, et même aussi vivement qu'il vous plaira, vous en avez le droit. Elles seront bien reçues et inutiles; après cela, vous n'en ferez plus.

Faites tout ce que vous jugerez à propos au sujet du livre de M. d'Holbach, excepté de vous charger de l'édition. C'est une manière de faire acheter un livre par force, et de mettre à contribution ses amis. Je ne veux point de cela.

Je vous remercie du Voyage d'Anson; je vous le renverrai la semaine prochaine.

Pardonnez les ratures. Je vous écris au coin de mon feu où nous sommes tous rassemblés ; les Gouverneuses épousent avec le jardinier les histoires de tous les pendus du pays et la gazette d'aujourd'hui est si abondante que je ne sais plus du tout ce que je dis. Bonjour ma bonne amie. 


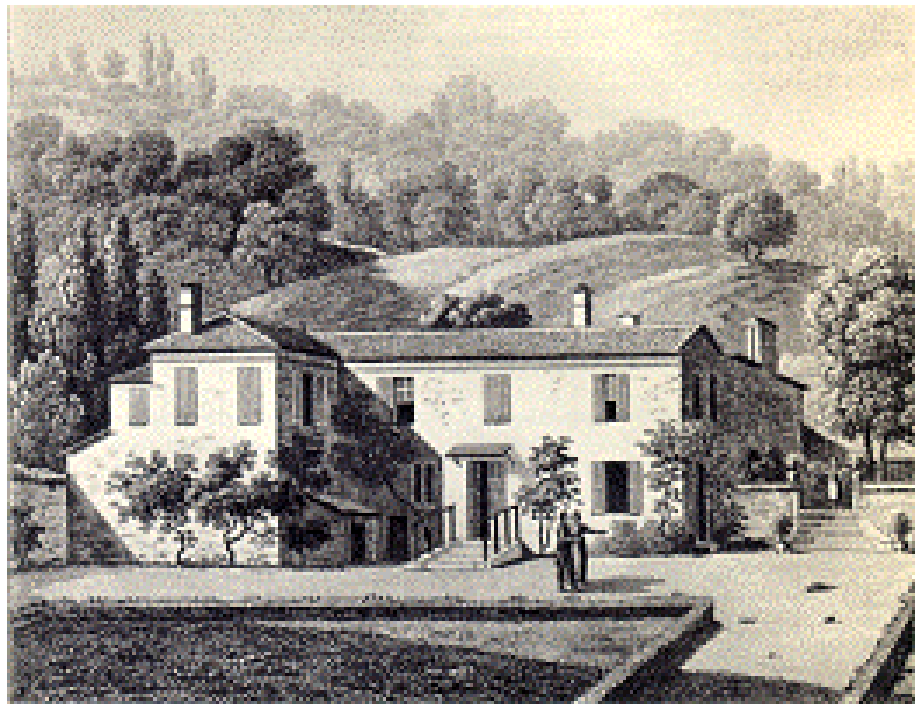

Illustration 3

L'Ermitage de J.-J. Rousseau, à Montmorency

$\underline{\text { Retour à la table des matières }}$ 


\section{Lettre 42}

\section{À M. [Diderot].}

[26 mars 1757]

$\underline{\text { Retour à la table des matières }}$

J'ai envie de reprendre en peu de mots l'histoire de nos démêlés. Vous m'envoyâtes votre livre. Je vous écrivis là-dessus un billet le plus tendre et le plus honnête que j'aie écrit de ma vie, et dans lequel je me plaignais, avec toute la douceur de l'amitié, d'une maxime très louche, et dont on pourrait me faire une application bien injurieuse. Je reçus en réponse une lettre très sèche, dans laquelle vous prétendez me faire grâce en ne me regardant pas comme un malhonnête homme; et cela uniquement parce que j'ai chez moi une femme de quatre-vingts ans; comme si la campagne était mortelle à cet âge, et qu'il n'y eût de femmes de quatre-vingts ans qu'à Paris. Ma réplique avait toute la vivacité d'un honnête homme insulté par son ami ; vous repartîtes par une lettre abominable. Je me défendis encore, et très fortement ; mais, me défiant de la fureur où vous m'aviez mis, et dans cet état même, redoutant d'avoir tort avec un ami, j'envoyai ma lettre à Mme d'Epinay, que je fis juge de notre différend. Elle me renvoya cette même lettre, en me conjurant de la supprimer, et je la supprimai. Vous m'en écrivez maintenant une autre dans laquelle vous m'appelez méchant, injuste, cruel, féroce. Voilà le précis de ce qui s'est passé dans cette occasion. 
Je voudrais vous faire deux ou trois questions très simples. Quel est l'agresseur dans cette affaire? Si vous voulez vous en rapporter à un tiers, montrez mon premier billet; je montrerai le vôtre.

En supposant que j'eusse mal reçu vos reproches, et que j'eusse tort dans le fond, qui, de nous deux, était le plus obligé de prendre le ton de la raison pour y ramener l'autre ? Je n'ai jamais résisté à un mot de douceur. Vous pouvez l'ignorer, mais vous pouvez savoir que je ne cède pas volontiers aux outrages. Si votre dessein, dans toute cette affaire, eût été de m'irriter, qu'eussiez-vous fait de plus?

Vous vous plaignez beaucoup des maux que je vous ai faits. Quels sont-ils enfin, ces maux ? Serait-ce de ne pas endurer assez patiemment ceux que vous aimez à me faire ; de ne pas me laisser tyranniser à votre gré, de murmurer quand vous affectez de me manquer de parole, et de ne jamais venir lorsque vous l'avez promis. Si jamais je vous ai fait d'autres maux, articulez-les. Moi, faire du mal à mon ami ! Tout cruel, tout méchant, tout féroce que je suis, je mourrais de douleur, si je croyais jamais en avoir fait à mon plus cruel ennemi autant que vous m'en faites depuis six semaines.

Vous me parlez de vos services ; je ne les avais point oubliés ; mais ne vous y trompez pas : beaucoup de gens m'en ont rendu qui n'étaient pas de mes amis. Un honnête homme qui ne sent rien, rend service et croit être ami : il se trompe, il n'est qu'honnête homme. Tout votre empressement, tout votre zèle pour me procurer des choses dont je n'ai que faire me touchent peu. Je ne veux que de l'amitié ; et c'est la seule chose qu'on me refuse. Ingrat, je ne t'ai point rendu de services, mais je t'ai aimé ; et tu ne me payeras de ta vie ce que j'ai senti pour toi durant trois mois. Montre cet article à ta femme, plus équitable que toi, et demande-lui si, quand ma présence était douce à ton coeur affligé, je comptais mes pas et regardais au temps qu'il faisait pour aller à Vincennes consoler mon ami. Homme insensible et dur ! deux larmes versées dans mon sein m'eussent mieux valu que le trône du monde ; mais tu me les refuses, et tu te contentes de m'en arracher. Eh bien! garde tout le reste, je ne veux plus rien de toi.

Il est vrai que j'ai engagé Mme d'Epinay à vous empêcher de venir samedi dernier. Nous étions tous deux irrités : je ne sais point mesurer mes paroles ; et vous, vous êtes défiant, ombrageux, pesant à la rigueur les mots lâchés inconsidérément, et sujet à donner à mille choses simples un sens subtil auquel on n'a pas songé. Il était dangereux en cet état de nous voir. De plus, vous vouliez venir à pied ; vous risquiez de vous faire malade, et n'en auriez pas, peut-être, été trop fâché. Je ne me sentais pas le courage de courir tous les dangers de cette entrevue. Cette frayeur ne méritait assurément pas vos reproches ; car, quoi que vous puissiez faire, ce sera toujours un lien sacré pour mon cœur que celui de notre ancienne amitié ; et, dussiez-vous m'insulter encore, je vous verrai toujours avec plaisir, quand la colère ne m'aveuglera pas.

À l'égard de Mme d'Epinay, je lui ai envoyé vos lettres et les miennes ; je serais étouffé de douleur sans cette communication ; et, n'ayant plus de raison, j'avais besoin de conseils. Vous paraissez toujours si fier de vos procédés dans cette affaire, que vous devez être fort content d'avoir un témoin qui les puisse 
admirer. Il est vrai qu'elle vous sert bien ; et, si je ne connaissais son motif, je la croirais aussi injuste que vous.

Pour moi, plus j'y pense, moins je puis vous comprendre. Comment, parce qu'à propos de je ne sais pas trop quoi vous avez dit que le méchant est seul, faut-il absolument me rendre méchant, et sacrifier votre ami à cette sentence ? Pour d'autres auteurs, l'alternative serait dangereuse ; mais vous ! D'ailleurs, cette alternative n'est point nécessaire ; votre sentence, quoique obscure et louche, est très vraie en un sens, et dans ce sens, elle ne me fait qu'honneur : car, quoi que vous en disiez, je suis beaucoup moins seul ici que vous au milieu de Paris. Diderot ! Diderot ! je le vois avec une douleur amère : sans cesse au milieu des méchants, vous apprenez à leur ressembler; votre bon cœur se corrompt parmi eux, et vous forcez le mien de se détacher insensiblement de vous. 


\section{Lettre 43 \\ À Mme[d'Epinay]}

Ce dimanche matin [29 mai 1757]

$\underline{\text { Retour à la table des matières }}$

Voilà, Madame, les prémices de votre Ermitage, à ce que dit le jardinier. Faites-moi dire, je vous supplie, des nouvelles de votre santé et de vos affaires, en attendant que les fêtes se passent, que les chemins s'essuyent et me permettent de vous aller voir. Je fus, mardi, dîner à Aubonne, et pris en revenant de la pluie et d'un dérangement qui l'un et l'autre n'ont pas cessé jusqu'ici. Bonjour, Madame, aimez-moi ermite comme vous m'aimiez ours ; autrement je quitte mon froc et je reprends ma peau. 


\section{Lettre 44}

\section{À Sophie [Mme d'Houdetot]}

[Début de juillet 1757]

$\underline{\text { Retour à la table des matières }}$

Je commence à ressentir l'effet des agitations terribles que vous m'avez si longtemps fait éprouver; elles ont épuisé mon cœur, mes sens, tout mon être, et, dans le supplice des privations les plus cruelles, j'éprouve l'accablement qui suit l'excès des plus doux plaisirs. Je sens à la fois le besoin de tous les biens, les douleurs de tous les maux; je suis malheureux, malade et triste ; votre vue ne m'anime plus, le mal et le chagrin me consument. Hé bien ! dans cet état d'anéantissement, mon cœur pense à vous encore, et ne peut penser qu'à vous. Il faut que je vous écrive, mais ma lettre se sentira de mes langueurs.

Vous souvient-il de m'avoir une fois reproché des cruautés bien raffinées? Ah ! si j'en juge par l'impression fatale que ces mots n'ont cessé de faire sur moi, c'est bien à vous qu'il faut reprocher ces cruautés. Je me garderai pour mon repos, de rechercher avec trop de soin le sens qu'ils purent avoir dans la circonstance où vous les prononçâtes; mais quelque signification qu'ils eussent, ils peuvent me rendre coupable, ils ne me rendront jamais séducteur.

Que je vous dise une fois ce que vous devez attendre, sur ce point difficile, de votre trop tendre et trop faible ami. Mes promesses n'ont jamais trompé personne : ce n'est pas par vous qu'elles commenceront. Vous avez assez vu de ma force à les tenir, vous m'avez assez vu me débattre dans leurs chaînes pour ne pas craindre que je puisse les briser. Ma passion funeste, vous la 
connaissez, il n'en fut jamais d'égale ; je n'ai rien senti de pareil à la fleur de mes ans; elle peut me faire oublier tout, et mon devoir même, excepté le vôtre. Cent fois elle m'eût déjà rendu méprisable, si je pouvais l'être par elle sans que vous le devinssiez aussi. Non, je le sens, la vertu même, près de vous, ne m'est pas assez sacrée pour me faire respecter, dans mes égarements, le dépôt d'un ami. Mais vous êtes à lui... Si vous êtes à moi, je perds, en vous possédant, celle que j'honore, ou je vous ôte à celui que vous aimez. Non, Sophie, je puis mourir de mes fureurs, mais je ne vous rendrai point vile. Si vous êtes faible, et que je le voie, je succombe à l'instant même ; tant que vous demeurerez à mes yeux ce que vous êtes, je n'en trahirai pas moins mon ami dans mon cœur, mais je lui rendrai son dépôt aussi pur que je l'ai reçu. Le crime est déjà cent fois commis par ma volonté. S'il l'est dans la vôtre, je le consomme, et je suis le plus traître et le plus heureux des hommes ; mais je ne puis corrompre celle que j'idolâtre. Qu'elle reste fidèle, et que je meure, ou qu'elle me laisse voir dans ses yeux qu'elle est coupable, je n'aurai plus rien à ménager. 


\section{Lettre 45}

\section{À Sophie [Mme d'Houdetot]}

[Vers le 15 octobre 1757]

Retour à la table des matières

Viens, Sophie, que j'afflige ton cœur injuste ; que je sois, à mon tour, sans pitié comme toi. Pourquoi t'épargnerais-je tandis que tu m'ôtes la raison, l'honneur, et la vie ? Pourquoi te laisserais-je couler de paisibles jours, à toi qui me rends les miens insupportables ? Ah ! combien tu m'aurais été moins cruelle si tu m'avais plongé dans le cœur un poignard au lieu du trait fatal qui me tue ! Vois ce que j'étais et ce que je suis devenu : vois à quel point tu m'avais élevé et jusqu'où tu m'as avili. Quand tu daignais m'écouter, j'étais plus qu'un homme; depuis que tu me rebutes (3), je suis le dernier des mortels : j'ai perdu le sens, l'esprit, et le courage ; d'un mot, tu m'as tout ôté. Comment peux-tu te résoudre à détruire ainsi ton propre ouvrage ? Comment oses-tu rendre indigne de ton estime celui qui fut honoré de tes bontés ? Ah ! Sophie, je t'en conjure, ne te fais point rougir de l'ami que tu as cherché. C'est pour ta propre gloire que je te demande compte de moi. Ne suis-je pas ton bien ? N'en as-tu pas pris possession ? tu ne peux plus t'en dédire, et, puisque je t'appartiens, malgré moi-même et malgré toi, laisse-moi du moins mériter de t'appartenir. Rappelle-toi ces temps de félicité qui, pour mon tourment, ne sortiront jamais de ma mémoire. Cette flamme invisible, dont je reçus une seconde vie plus précieuse que la première, rendait à mon âme, ainsi qu'à mes sens, toute la vigueur de la jeunesse. L'ardeur de mes sentiments m'élevait jusqu'à toi. Combien de fois ton cœur, plein d'un autre amour, fut-il ému des transports du mien! Combien de fois m'as-tu dit dans le bosquet de la 
cascade : Vous êtes l'amant le plus tendre dont j'eusse l'idée : non, jamais homme n'aima comme vous! Quel triomphe pour moi que cet aveu dans ta bouche ! Assurément il n'était pas suspect; il était digne des feux dont je brûlais de t'y rendre sensible en dépit des tiens, et de t'arracher une pitié que tu tereprochais si vivement. Eh ! pourquoi te la reprocher ? En quoidonc étais-tu coupable ? En quoi la fidélité était-elle offensée par des bontés qui laissaient ton cœur et tes sens tranquilles? Si j'eusse été plus aimable et plus jeune, l'épreuve eût été plus dangereuse ; mais, puisque tu l'as soutenue, pourquoi t'en repentir ? Pourquoi changer de conduite avec tant de raisons d'être contente de toi ? Ah ! que ton amant même serait fier de ta constance s'il savait ce qu'elle a surmonté ! Si ton cœur et moi sommes seuls témoins de ta force, c'est à moi seul à m'en humilier. Étais-je digne de t'inspirer des désirs ? Mais quelquefois ils s'éveillent malgré qu'on en ait, et tu sus toujours triompher des tiens. Où est le crime d'écouter un autre amour, si ce n'est le danger de le partager? Loin d'éteindre tes premiers feux, les miens semblaient les irriter encore. Ah ! si jamais tu fus tendre et fidèle, n'est-ce pas dans ces moments délicieux où mes pleurs t'en arrachaient quelquefois; où les épanchements de nos cœurs s'excitaient mutuellement ; où, sans se répondre, ils savaient s'entendre; où ton amour s'animait aux expressions du mien, et où l'amant qui t'est cher recueillait au fond de ton âme tous les transports exprimés par celui qui t'adore ? L'amour a tout perdu par ce changement bizarre que tu couvres de si vains prétextes. Il a perdu ce divin enthousiasme qui t'élevait à mes yeux au-dessus de toi-même ; qui te montrait à la fois charmante par tes ferveurs, sublime par ta résistance, et redoublait par tes bontés mon respect et mes adorations. Il a perdu, chez toi, cette confiance aimable qui te faisait verser dans ce cœur qui t'aime tous les sentiments du tien. Nos conversations étaient touchantes ; un attendrissement continuel les remplissait de son charme. Mes transports que tu ne pouvais partager, ne laissaient pas de te plaire, et j'aimais à t'entendre exprimer les tiens pour un autre objet qui leur était cher, tant l'épanchement et la sensibilité ont de prix, même sans celui du retour! Non, quand j'aurais été aimé, à peine aurais-je pu vivre dans un état plus doux, et je te défie de jamais dire, à ton amant même,rien de plus touchant que ce que tu me disais de lui mille fois le jour. Qu'est devenu ce temps, cet heureux temps ? La sécheresse et la gêne, la tristesse ou le silence, remplissent désormais nos entretiens. Deux ennemis, deux indifférents, vivraient entre eux avec moins de réserve que ne font deux cœurs faits pour s'aimer. Le mien, resserré par la crainte, n'ose plus donner l'essor aux feux dont il est dévoré. Mon âme intimidée se concentre et s'affaisse sur elle-même ; tous mes sentiments sont comprimés par la douleur. Cette lettre, que j'arrose de froides larmes, n'a plus rien de ce feu sacré qui coulait de ma plume en de plus doux instants. Si nous sommes un moment sans témoins, à peine ma bouche ose-t-elle exprimer un sentiment qui m'oppresse, qu'un air triste et mécontent le resserre au fond de mon cœur. Le vôtre, à son tour, n'a plus rien à me dire. Hélas ! n'est-ce pas me dire assez combien vous vous déplaisez avec moi, que ne me plus parler de ce que vous aimez ? Ah ! parlez-moi de lui sans cesse afin que ma présence ne soit pas pour vous sans plaisir.

Il vous est plus aisé de changer, ô Sophie, que de cacher ce changement à mes yeux. N'alléguez plus de fausses excuses qui ne peuvent m'en imposer. Les événements ont pu vous forcer à une circonspection dont je ne me suis jamais plaint ; mais tant que le cœur ne change pas, les circonstances ont beau 
changer, son langage est toujours le même ; et si la prudence vous force à me voir plus rarement, qui vous force de perdre avec moi le langage du sentiment pour prendre celui de l'indifférence ? Ah! Sophie, Sophie ! Ose me dire que ton amant t'est plus cher aujourd'hui que quand tu daignais m'écouter et me plaindre, et que tu m'attendrissais à mon tour, aux expressions de ta passion pour lui ! Tu l'adorais et te laissais adorer ; tu soupirais pour un autre, mais ma bouche et mon cœur recueillaient tes soupirs. Tu ne te faisais point un vain scrupule de lui cacher des entretiens qui tournaient au profit de ton amour. Le charme de cet amour croissait sous celui de l'amitié ; ta fidélité s'honorait du sacrifice des plaisirs non partagés. Tes refus, tes scrupules, étaient moins pour lui que pour moi. Quand les transports de la plus violente passion qui fut jamais t'excitaient à la pitié, tes yeux inquiets cherchaient dans les miens si cette pitié ne t'ôterait point mon estime ; et la seule condition que tu mettais aux preuves de ton amitié était que je ne cesserais point d'être ton ami.

Cesser d'être ton ami ! chère et charmante Sophie, vivre et ne plus t'aimer est-il, pour mon âme, un état possible ? Eh ! comment mon cœur se fût-il détaché de toi, quand aux chaînes de l'amour tu joignais les doux nœuds de la reconnaissance? J'en appelle à ta sincérité. Toi qui vis, qui causas ce délire, ces pleurs, ces ravissements, ces extases, ces transports qui n'étaient pas faits pour un mortel, dis, ai-je goûté tes faveurs de manière à mériter de les perdre ? Ah ! non ; tu t'es barbarement prévalue, pour me les ôter, des tendres craintes qu'elles m'ont inspirées. J'en suis devenu plus épris mille fois, il est vrai ; mais plus respectueux, plus soumis, plus attentif à ne jamais t'offenser. Comment ton bon cœur a-t-il pu se résoudre, en me voyant tremblant devant toi, à s'armer de ma passion contre moi-même, et à me rendre misérable pour avoir mérité d'être heureux?

Le premier prix de tes bontés fut de m'apprendre à vaincre mon amour par lui-même, de sacrifier mes plus ardents désirs à celle qui les faisait naître, et mon bonheur à ton repos. Je ne rappellerai point ce qui s'est passé ni dans ton parc, ni dans ta chambre; mais, pour sentir jusqu'où l'impression de tes charmes inspire à mes sens l'ardeur de te posséder, ressouviens-toi du MontOlympe, ressouviens-toi de ces mots écrits au crayon sur un chêne. J'aurais pu les tracer du plus pur de mon sang, et je ne saurais te voir ni penser à toi qu'il ne s'épuise et ne renaisse sans cesse. Depuis ces moments délicieux où tu m'as fait éprouver tout ce qu'un amour plaint, et non partagé, peut donner de plaisir au monde, tu m'es devenue si chère que je n'ai plus osé désirer d'être heureux à tes dépens, et qu'un seul refus de ta part eût fait taire un délire insensé. Je m'en serais livré plus innocemment aux douceurs de l'état où tu m'avais mis ; l'épreuve de ta force m'eût rendu plus circonspect à t'exposer à des combats que j'avais trop peu su te rendre pénibles. J'avais tant de titres pour mériter que tes faveurs et ta pitié même ne me fussent point ôtées ; hélas ! que faut-il que je me dise pour me consoler de les avoir perdues, si ce n'est que j'aimais trop pour les savoir conserver? J'ai tout fait pour remplir les dures conditions que tu m'avais imposées ; je leur ai conformé toutes mes actions, et, si je n'ai pu contenir de même mes discours, mes regards, mes ardents désirs, de quoi peux-tu m'accuser, si ce n'est de m'être engagé, pour te plaire, à plus que la force humaine ne peut tenir ? Sophie ! j'aimai trente ans la vertu, ah ! crois-tu que j'aie déjà le cœur endurci au crime ? Non, mes remords égalent mes transports ; c'est tout dire ; mais pourquoi ce cœur se livrait-il aux légères faveurs que tu daignais m'accorder, tandis que son murmure effrayant me 
détournait si fortement d'un attentat plus téméraire ? Tu le sais, toi qui vis mes égarements, si, même alors, ta personne me fut sacrée ! jamais mes ardents désirs, jamais mes tendres supplications n'osèrent un instant solliciter le bonheur suprême que je ne me sentisse arrêté par les cris intérieurs d'une âme épouvantée. Cette voix terrible qui ne trompe point me faisait frémir à la seule idée de souiller de parjure et d'infidélité celle que j'aime, celle que je voudrais voir aussi parfaite que l'image que j'en porte au fond de mon cœur, celle qui doit m'être inviolable à tant de titres. J'aurais donné l'univers pour un moment de félicité ; mais t'avilir, Sophie ! ah ! non, il n'est pas possible, et, quand j'en serais le maître, je t'aime trop pour te posséder jamais.

Rends donc à celui qui n'est pas moins jaloux que toi de ta propre gloire, des bontés qui ne sauraient la blesser. Je ne prétends m'excuser ni envers toi, ni envers moi-même; je me reproche tout ce que tu me fais désirer. S'il n'eût fallu triompher que de moi, peut-être l'honneur de vaincre m'en eût-il donné le pouvoir ; mais devoir au dégoût de ce qu'on aime des privations qu'on eût dû s'imposer, ah ! c'est ce qu'un cœur sensible ne peut supporter sans désespoir. Tout le prix de la victoire est perdu dès qu'elle n'est pas volontaire. Si ton cœur ne m'ôtait rien, qu'il serait digne du mien de tout refuser ! Si jamais je puis me guérir, ce sera quand je n'aurai que ma passion seule à combattre. Je suis coupable, je le sens trop, mais je m'en console en songeant que tu ne l'es pas. Une complaisance insipide à ton cœur, qu'est-elle pour toi, qu'un acte de pitié dangereux à la première épreuve, indifférent pour qui l'a pu supporter une fois ? O Sophie ! après des moments si doux, l'idée d'une éternelle privation est trop affreuse à celui qui gémit de ne pouvoir s'identifier avec toi. Quoi ! tes yeux attendris ne se baisseraient plus avec cette douce pudeur qui m'enivre de volupté ? Quoi ! mes lèvres brûlantes ne déposeraient plus sur ton cœur mon âme avec mes baisers ? Quoi ! je n'éprouverais plus ce frémissement céleste, ce feu rapide et dévorant qui, plus prompt que l'éclair... moment ! moment inexprimable ! quel cœur, quel homme, quel dieu peut t'avoir ressenti et renoncer à toi ?

Souvenirs amers et délicieux ! laisserez-vous jamais mes sens et mon cœur en paix ? et toutefois les plaisirs que vous me rappelez ne sont point ceux qu'il regrette le plus. Ah ! non, Sophie, il en fut pour moi de plus doux encore et dont ceux-là tirent leur plus grand prix, parce qu'ils en étaient le gage. Il fut, il fut un temps où mon amitié t'était chère et où tu savais me le témoigner. $\mathrm{Ne}$ m'eusses-tu rien dit, ne m'eusses-tu fait aucune caresse, un sentiment plus touchant et plus sûr m'avertissait que j'étais bien avec toi. Mon cœur te cherchait et le tien ne me repoussait pas. L'expression du plus tendre amour qui fut jamais n'avait rien de rebutant pour toi. On eût dit à ton empressement à me voir que je te manquais quand tu ne m'avais pas vu; tes yeux ne fuyaient pas les miens, et leurs regards n'étaient pas ceux de la froideur; tu cherchais mon bras à la promenade, tu n'étais pas si soigneuse à me dérober l'aspect de tes charmes, et quand ma bouche osait presser la tienne, quelquefois au moins je la sentais résister. Tu ne m'aimais pas, Sophie, mais tu te laissais aimer, et j'étais heureux. Tout est fini ; je ne suis plus rien, et, me sentant étranger, à charge, importun près de toi, je ne suis pas moins misérable de mon bonheur passé que de mes peines présentes. Ah ! si je ne t'avais jamais vue attendrie, je me consolerais de ton indifférence et me contenterais de t'adorer en secret ; mais me voir déchirer le cœur par la main qui me rendit heureux et être oublié de celle qui m'appelait son doux ami ! ô toi qui peux tout sur mon être, 
apprends-moi à supporter cet état affreux, ou le change, ou me fais mourir ! Je voyais les douleurs que m'apprêtait la fortune et je m'en consolais en y voyant tes plaisirs ; j'ai appris à braver les outrages du sort, mais les tiens ! qui me les fera supporter? La vallée que tu fuis pour me fuir, le prochain retour de ton amant, les intrigues de ton indigne sœur (3) l'hiver qui nous sépare, mes maux qui s'accroissent, ma jeunesse qui fuit de plus en plus, tandis que la tienne est dans sa fleur, tout se réunit pour m'ôter tout espoir ; mais rien n'est au-dessus de mon courage que tes mépris. Avec la consolation du cœur, je dédaignerais les plaisirs des sens, je m'en passerais au moins; si tu me plaignais, je ne serais plus à plaindre. Aide-moi, de grâce, à m'abuser moi-même ; mon cœur affligé ne demande pas mieux ; je cherche moi-même sans cesse à te supposer pour moi le tendre intérêt que tu n'as plus. Je force tout ce que tu me dis pour l'interpréter en ma faveur ; je m'applaudis de mes propres douleurs quand elles semblent t'avoir touchée ; dans l'impossibilité de tirer de toi de vrais signes d'attachement, un rien suffit pour m'en créer de chimériques. À notre dernière entrevue, où tu déployais de nouveaux charmes, pour m'enflammer de nouveaux feux, deux fois tu me regardas en dansant. Tous tes mouvements s'imprimaient au fond de mon âme ; mes avides regards traçaient tous tes pas ; pas un de tes gestes n'échappait à mon cœur, et, dans l'éclat de ton triomphe, ce faible cœur avait la simplicité de croire que tu daignais t'occuper de moi. Cruelle, rends-moi l'amitié qui m'est si chère ; tu me l'as offerte ; je l'ai reçue ; tu n'as plus droit de me l'ôter. Ah ! si jamais je te voyais un vrai signe de pitié ; que ma douleur ne te fût point importune; qu'un regard attendri se tournât sur moi ; que ton bras se jetât autour de mon cou ; qu'il me pressât contre ton sein; que ta douce voix me dît avec un soupir : Infortuné ! que je te plains ! oui, tu m'aurais consolé de tout ; mon âme reprendrait sa vigueur, et je redeviendrais digne encore d'avoir été bien voulu de toi... 


\section{Lettre 46}

\section{À M. [de Saint-Lambert]}

À l'Ermitage, le 29 octobre 1757

$\underline{\text { Retour à la table des matières }}$

Que de joie et de tristesse me viennent de vous, mon cher ami ! À peine l'amitié est-elle commencée entre nous, que vous m'en faites sentir en même temps tous les tourments et tous les plaisirs. Je ne vous parlerai point de l'impression que m'a faite la nouvelle de votre accident. Mme d Epinay en a été témoin. Je ne vous peindrai point non plus les agitations de notre amie ; votre cœur est fait pour les imaginer. Et moi, la voyant hors d'elle-même, j'avais à la fois le sentiment de votre état et le spectacle du sien; jugez de celui de votre ami. On voit bien à vos lettres que vous êtes de nous tous le moins sensible à vos maux. Mais, pour exciter le zèle et les soins que vous devez à votre guérison, songez, je vous en conjure, que vous avez en dépôt l'espoir de tout ce qui vous est cher. Au reste, quel que soit l'effet des eaux, dont j'attends tout, le bonheur ne réside point dans le sentiment d'une jambe et d'un bras. Tant que votre cœur sera sensible, soyez sûr, mon cher et digne ami, qu'il pourra faire des heureux et l'être.

Notre amie vint mardi faire ses adieux à la vallée ; j'y passai une demijournée triste et délicieuse. Nos cœurs vous plaçaient entre eux, et nos yeux n'étaient point secs en parlant de vous. Je lui dis que son attachement pour vous était désormais une vertu; elle en fut si touchée, qu'elle voulut que je vous l'écrivisse, et je lui obéis volontiers. Oui, mes enfants, soyez à jamais 
unis ; il n'est plus d'âme comme les vôtres, et vous méritez de vous aimer jusqu'au tombeau. Il m'est doux d'être en tiers dans une amitié si tendre. Je vous remercie du cœur que vous m'avez rendu, et dont le mien n'est pas indigne. L'estime que vous lui devez, et celle dont elle m'honore, vous feront sentir toute votre vie l'injustice de vos soupçons.

Vous savez mon raccommodement avec Grimm : j'ai cette obligation de plus à Mme d'Epinay, et l'honneur d'avoir fait toutes les avances. J'en fis autant avec Diderot, et j'eus cette obligation à notre amie. Qu'on ait tort ou qu'on ait raison, je trouve qu'il est toujours doux de revenir à son ami ; et le plaisir d'aimer me semble plus cher à un cœur sensible que les petites vanités de l'amour-propre.

Vous savez aussi le prochain départ de Mme d'Epinay pour Genève. Elle m'a proposé de l'accompagner, sans me montrer là-dessus beaucoup d'empressement. Moi, la voyant escortée de son mari, du gouverneur de son fils, de cinq ou six domestiques, aller chez son médecin et son ami, et par conséquent mon cortège lui étant fort inutile, sentant d'ailleurs qu'il me serait impossible de supporter, avec mon mal, et dans la saison où nous entrons, une chaise de poste jusqu'à Genève, et, joignant aux obstacles tirés de ma situation présente la gêne insurmontable que j'éprouve toujours à vivre chez autrui, je n'ai pas accepté le voyage, et elle s'est contentée de mes raisons. Là-dessus Diderot m'écrit un billet extravagant dans lequel, me disant surchargé du poids des obligations que j'ai à Mme d'Epinay, il me représente ce voyage comme indispensable, en quelque état que soit ma santé, jusqu'à vouloir que je suive plutôt à pied la chaise de poste. Mais ce qui m'a surtout percé le cœur, c'est de voir que votre amie est du même avis, et m'ose donner les conseils de la servitude. On dirait qu'il y a une ligue entre tous mes amis, pour abuser de mon état précaire et me livrer à la merci de Mme d'Epinay. Laissant ici les gens qu'il faut entretenir, partant sans argent, sans habits, sans linge, je serai forcé de tout recevoir d'elle, et peut-être de lui tout demander. L'amitié peut confondre les biens ainsi que les cœurs; mais dès qu'il sera question de devoirs et d'obligations, étant encore à ses gages, je ne serai plus chez elle comme son ami, mais comme son valet; et, quoi qu'il arrive, je ne veux pas l'être, ni m'aller étaler, dans mon pays, à la suite d'une fermière générale. Cependant j'ai écrit à Grimm une longue lettre, dans laquelle je lui dis mes raisons, et le laisse maître de décider si je dois partir ou non, résolu de suivre à l'instant son avis ; mais j'espère qu'il ne m'avilira pas. Jusqu'ici je n'ai point de réponse positive ; et j'apprends que Mme d'Epinay part demain. Je me sens, en écrivant cet article, dans une agitation qui me le ferait indiscrètement prolonger; il faut finir. Mon ami que n'êtes-vous ici ! Je verserais mes peines dans votre âme; elle entendrait la mienne, et ne donnerait point à ma juste fierté le vil nom d'ingratitude. Quoi qu'il en soit, on ne m'enchaînera jamais par certains bienfaits ; je m'en suis toujours défendu ; je méprise l'argent ; je ne sais point mettre à prix ma liberté ; et, si le sort me réduit à choisir entre les deux vices que j'abhorre le plus, mon parti est pris, et j'aime encore mieux être un ingrat qu'un lâche.

Je ne dois point finit cette lettre sans vous donner un avis qui nous importe à tous. La santé de notre amie se délabre sensiblement. Elle est maigrie ; son estomac va mal ; elle ne digère point, elle n'a plus d'appétit; et ce qu'il y a de pis est que le peu qu'elle mange ne sont que des choses malsaines. Elle était 
déjà changée avant votre accident : jugez de ce qu'elle est, et de ce qu'elle va devenir. Elle confie à des quidams la direction de sa santé : on lui a conseillé les eaux de Passy ; mais ce qui importe beaucoup plus à lui conseiller est le choix d'un médecin qui sache l'examiner et la conduire, et d'un régime qui n'augmente pas le désordre de son estomac. J'ai dit là-dessus tout ce que j'ai pu, mais inutilement. C'est à vous d'obtenir ce qu'elle refuse à mon amitié. C'est surtout par le soin que vous prendrez de vous que vous l'engagerez à en prendre d'elle. Adieu, mon ami. 


\section{Lettre 47}

\section{À Mme la comtesse d'Houdetot}

À l'Ermitage, le 1er novembre 1757

Retour à la table des matières

Je viens de recevoir de Grimm une lettre qui m'a fait frémir et que je me suis hâté de lui renvoyer de peur de la lire une seconde fois. Madame, tous ceux que j'aimais me haïssent, et vous connaissez mon cœur ; c'est vous en dire assez. Tout ce que j'avais appris de Mme d'Epinay n'est que trop vrai, et j'en sais davantage encore; je ne trouve de toutes parts que des sujets de désespoir. Il me reste une seule espérance; elle peut me consoler de tout et me rendre le courage. C'est à vous de la confirmer ou de la détruire. Ai-je encore une amie et un ami ? Un mot, un seul mot, et je puis vivre.

Je vais déloger de l'Ermitage. Mon dessein est de chercher un asile éloigné et inconnu ; mais il faut passer l'hiver, et les ordres que vous m'avez prescrits m'empêchent de l'aller passer à Paris, quand j'en serais tenté. Je vais donc m'établir à Montmorency comme je pourrai en attendant le retour du printemps. Ma respectable amie, je ne vous reverrai jamais; je le sens à la tristesse qui me serre le cœur; mais je m'occuperai de vous dans ma retraite ; je songerai que j'ai deux amis au monde, et j'oublierai que j'y suis seul.

Un mot de réponse, je vous conjure. 


\section{Lettre 48}

\section{À Mme [d'Houdetot]}

Ce 2 novembre

jour de deuil et d'affliction, 1757

\section{Retour à la table des matières}

Voici la 4e lettre que je vous écris sans réponse. Ah ! si vous continuez de vous taire, je vous aurai trop entendue. Songez à l'état où je suis, et consultez votre cœur. Je puis être abandonné de tout le monde et le supporter ; mais vous !... - Vous, me haïr ! -Vous me mépriser, vous qui connaissez mon cœur ! Grand Dieu ! Suis-je un scélérat ? Un scélérat ! moi ! Je l'apprends bien tard. C'est M. Grimm, c'est mon ancien ami, c'est celui qui me doit tous les amis qu'il m'ôte, qui a fait cette belle découverte et qui la publie. Hélas, il est l'honnête homme, et moi l'ingrat, il jouit des honneurs de la vertu pour avoir perdu son ami, et moi je suis dans l'opprobre, et pourquoi ? Pour n'avoir pu flatter une femme perfide, ni m'asservir à celle que j'étais forcé de haïr.

Mais il faut se taire et se laisser mépriser. Providence, Providence ! et l'âme ne serait pas immortelle ! Je suis un méchant, moi ? quoi ! Cette indignation de l'honneur outragé, ces élancements de douleur, ces sanglots qui me suffoquent seraient la syndérèse du crime ! Ah ! si je suis un méchant, que tout le genre humain est vil ! Qu'on me montre un homme meilleur que Moi ! qu'on me montre une âme plus aimante, plus sensible, plus éprise des charmes de l'amitié, plus touchée de l'honnête et du beau, qu'on me la montre, et je me tais. 
Vous qui m'avez connu, dites-moi : tu es un méchant, et je me punis. L'agitation m'oppresse, je ne puis respirer. Ah ! mon amie, ah ! Saint-Lambert, fallait-il céder aux séductions de la fausseté, et faire mourir de douleur celui qui ne vivait que pour vous aimer? Cruelle, je ne supporterai pas longtemps mon opprobre. J'espère que la nature ne tardera pas à vous délivrer de moi, et à me venger de vous, en vous laissant quelque regret de mon sort, et de votre injustice. Adieu, je ne vous parlerai plus de moi, mais si je ne puis vous oublier, je vous défie d'oublier à votre tour ce cœur ami de la vertu, ce cœur que vous méprisez, ni d'en trouver jamais un semblable.

Je veux écrire à Saint-Lambert, j'en ai besoin pour la paix de mon âme surchargée d'ennuis. Je vous prie de me faire dire si vous permettez que je vous adresse la lettre, ou de m'apprendre s'il est à Aix-la-Chapelle, et si c'est là qu'il faut lui écrire. Un mot que vous chargeriez votre laquais de m'écrire suffit pour cela. Il me serait bien doux d'apprendre en même temps comment il se porte. 


\section{Lettre 49}

\section{À Mme [d'Houdetot]}

Le 3 novembre 1757

Retour à la table des matières

Votre barbarie est inconcevable ; elle n'est pas de vous. Ce silence est un raffinement de cruauté qui n'a rien d'égal. On vous dira l'état où je suis depuis huit jours. Et vous aussi ! et vous aussi, Sophie, vous me croyez un méchant ! Ah Dieu ! si vous le croyez, à qui donc en appellerai-je ?... Mais pourtant comment se fait-il que la vertu me soit si chère ? que je sente en moi le cœur d'un homme de bien ? Non : quand je tourne les yeux sur le passé, et que je vois quarante ans d'honneur à côté d'une mauvaise lettre, je ne puis désespérer de moi.

Je n'affecterai point une fermeté dont je suis bien loin ; je me sens accablé de mes maux. Mon âme est épuisée de douleurs et d'ennuis. Je porte dans un cœur innocent toutes les horreurs du crime ; je ne fuis point des humiliations qui conviennent à mon infortune ; et si j'espérais vous fléchir j'irais, ne pouvant arriver jusqu'à vous, vous attendre à votre sortie, me prosterner audevant de vous, trop heureux d'être foulé aux pieds des chevaux, écrasé sous votre carrosse, et de vous arracher au moins un regret à ma mort. N'en parlons plus : la pitié n'efface point le mépris ; et, si vous me croyez digne du vôtre, il faut ne me regarder jamais. 
Ah ! méprisez-moi si vous le pouvez; il me sera plus cruel de vous savoir injuste que moi déshonoré, et j'implore de la vertu la force de supporter le plus douloureux des opprobres. Mais, pour m'avoir ôté votre estime, faut-il renoncer à l'humanité ? Méchant ou bon, quel bien attendez-vous de mettre un homme au désespoir? Voyez ce que je vous demande; et, si vous n'êtes pire que moi, osez me refuser. Je ne vous verrai plus; les regards de Sophie ne doivent tomber que sur un homme estimé d'elle, et l'œil du mépris n'a jamais souillé ma personne. Mais vous fûtes, après Saint-Lambert, le dernier attachement de mon cœur ; ni lui, ni vous, n'en sortirez jamais ; il faut que je m'occupe de vous sans cesse, et je ne puis me détacher de vous qu'en renonçant à la vie. Je ne vous demande aucun témoignage de souvenir; ne parlez plus de moi ; ne m'écrivez plus ; oubliez que vous m'avez honoré du nom de votre ami, et que j'en fus digne. Mais ayant à vous parler de vous, ayant à vous tenir le sacré langage de la vérité, que vous n'entendrez peut-être que de moi seul, que je sois sûr au moins que vous daignerez recevoir mes lettres, qu'elles ne seront point jetées au feu sans les lire, et que je ne perdrai pas ainsi les chers et derniers travaux auxquels je consacre le reste infortuné de ma vie. Si vous craignez d'y trouver le venin d'une âme noire, je consens qu'avant de les lire, vous les fassiez examiner pourvu que ce ne soit pas par cet honnête homme qui se complaît si fort à faire un scélérat de son ami. Que la première où l'on trouvera la moindre chose à blâmer fasse à jamais révoquer la permission que je vous demande. Ne soyez par surprise de cette étrange prière ; il y a si longtemps que j'apprends à aimer sans retour, que mon cœur y est tout accoutumé. 


\title{
Lettre 50
}

\section{À Mme [d'Houdetot]}

\author{
À l'Ermitage, \\ le 10 novembre 1757
}

\section{Retour à la table des matières}

Je ne vois rien de vous, mon aimable et chère amie, qui n'augmente mon estime et mon attachement pour vous, et c'est ce qui m'arrive encore dans ce que vous exigez de moi vis-à-vis de Mme d'Epinay. Cependant le bien même est quelquefois sujet à l'excès ; et vous ne voudriez pas, pour quelques vains ménagements, compromettre l'honneur de votre ami. Or pour bien juger du cas présent, trouvez bon que je vous rappelle ou que je vous expose exactement les faits.

Vous avez vu l'étroite amitié qui a régné entre Mme d'Epinay et moi durant plusieurs années ; vous avez vu tout ce que cette amitié lui a suggéré de zèle et de bontés pour moi ; tout ce qu'elle a fait pour me rapprocher d'elle et me rendre mon sort agréable autant qu'il était possible. Vous connaissez trop bien mon cœur pour que j'aie besoin de vous dire l'effet que toutes les avances du sien y produisirent, il suffit que vous vous rappeliez ces conversations que nous avons eues autrefois à Epinay vous et moi sur son compte. Insensiblement elle jeta sur son ami les liens de l'assujettissement; non contente des temps où le désir de la voir m'attirait auprès d'elle, il fallait s'y rendre toutes les fois qu'elle était seule, tous mes jours m'étaient prescrits, sans consulter ni mon amour pour ma retraite, ni le besoin où j'étais de travailler pour vivre, ni mes maux, ni ma répugnance à vivre dans la maison d'autrui, je n'osais presque plus sortir de la sienne ; mais le joug de l'amitié me fut toujours doux, 
et je le portais sans murmure. L'été dernier vous m'avez recherché ; pouvais-je moins faire que de répondre à vos avances ? Le moyen de vous connaître sans vous aimer; insensiblement je me suis attaché à vous, et mes voyages d'Aubonne ne m'ont point été pardonnés. Mme d'Epinay n'a pu souffrir qu'ayant accoutumé de disposer de moi tout entier, vous lui dérobassiez une partie de mes soins; ce n'est point un mouvement de vanité qui me donne cette idée, c'est le désir de trouver au moins quelque motif à son inconcevable conduite, et de ne pas l'attribuer à la seule méchanceté. Elle jura de nous désunir; elle s'en vanta ; et ses propres termes furent : Cela finira de manière ou d'autre. Incrédule à l'honneur, à l'amour, à la foi, à l'amitié sacrée, elle osa ternir par ses calomnies ce qu'il y a de plus respecté des hommes, et jeter d'indignes soupçons sur les deux personnes à qui elle devait le plus d'estime. Sa sœur ! son ami !... Elle s'efforça de jeter le trouble et la discorde dans mon petit ménage où la paix est le seul dédommagement de la pauvreté. Elle osa solliciter une personne qui m'est attachée à me quitter avec éclat, et se réfugier chez elle... Je sens la colère et l'indignation se réveiller dans mon cœur à tant de souvenirs horribles. Achevons rapidement. Je sus tout. Le témoin qui me l'avait rapporté ne voulut point être compromis, je donnai ma foi, il a fallu la tenir, et ç'a été mon plus cruel supplice d'être forcé de dissimuler et de cacher à une amie perfide le mépris qu'elle m'avait inspiré. Mais le mépris se cache-til ? elle a trop vu le mien. Dans la crainte qu'elle n'eût fait pis que je n'en savais encore, je lui témoignais mes soupçons avec la hauteur et le dédain que les siens avaient mérités. Les larmes, les étreintes de l'amitié, les protestations furent sa justification, je la crus justifiée au moins sur ce point et pensai qu'on m'avait grossi le reste, quoique dans ce temps même votre visible refroidissement ne dut que trop me rendre tous mes ombrages. Je pris le parti qui convenait à ma franchise, j'écrivis à votre ami ; j'ai l'âme trop haute et je pense trop bien de la sienne pour daigner relever de basses calomnies. je n'ai point été trompé dans mon attente, ni lui dans son estime, ni vous dans votre amitié, nos trois cœurs sont faits pour s'aimer et s'honorer, non pour se mépriser ni pour se craindre. Cependant les manèges de Mme d'Epinay ont continué jusqu'au moment de son départ. Vous ne m'avez pas écrit un billet qu'on n'ait accusé, nous n'avons pas fait une promenade dans son parc qu'on n'ait critiquée. Le bonheur a voulu qu'on s'est adressé pour cela au plus sûr témoin de votre conduite et de la mienne, et mon repos n'en a point été troublé. Instruit de tout, chaque jour j'étais près d'éclater; je me suis contenu avec peine jusqu'au moment de son départ. Voilà, Madame, indépendamment de tout autre motif, la personne qu'on m'obligeait à accompagner à Genève.

Mes amis ont pris sur moi un tel empire que je ne puis plus faire un pas sans leur rendre compte de mes raisons. Il faut désormais. que ma vie se passe en apologies. Vous avez vu l'indiscret billet de Diderot. Il fallait y répondre. Je choisis le meilleur ami de Mme d'Epinay, et, à ce que je pensais le plus discret des miens pour lui exposer celles de mes raisons que je pouvais dire. Vous pouvez croire qu'avec ma raison secrète et l'humeur que Diderot m'avait donnée, cette lettre n'était pas bien tendre ; cependant je défie que dans toute sa sécheresse on y trouve un seul mot offensant pour Mme d'Epinay. On y voit seulement que je n'ai pas pour elle une amitié bien vive et que je ne me crois pas obligé à une grande reconnaissance ; quant aux emportements puérils qui y règnent, ils regardent seulement la gêne de ma situation et ma répugnance à la servitude. Rien d'applicable à Mme d'Epinay. 
On me répond là-dessus un billet provisionnel équivoque et louche, qui ressemble fort au style d'un méchant homme qui médite sourdement un mauvais coup ; puis, après le départ vient une seconde lettre... Non, le plus scélérat des hommes n'en reçut jamais de semblable. Hé bien, Madame, c'est à moi qu'elle est adressée.

Pour savoir maintenant si je dois demeurer à l'Ermitage ou non, voici ce qu'il faut considérer : d'abord, j'y suis dans la maison d'une femme que je ne puis ni aimer ni estimer et qui m'a voulu perdre. Il me semble que tout est déjà dit. Mais poursuivons. L'auteur de la lettre en question me disait il y a quelque temps : Il me semble que si vous étiez mécontent de Mme d'Epinay, vous ne resteriez pas à l'Ermitage. Son avis à lui-même est donc parfaitement conforme au mien. Or jugez si depuis le départ de Mme d'Epinay j'ai lieu d'être plus content d'elle. Premièrement, elle m'avait promis de m'écrire de Paris, elle n'en a rien fait. Je lui ai de plus écrit un billet qui n'a rien d'offensant ; elle n'y a point répondu; je lui ai demandé des nouvelles de son fils, elle ne m'en a point donné. Elle est dans mon pays, et ne me donne pas la moindre nouvelle, ni de son voyage ni de son arrivée. J'ai encore un autre indice que l'infâme lettre qui m'a été écrite a été concertée avec elle et que la mienne lui a été montrée, en ce que je demandais si, continuant de payer le jardinier, je ferais bien de passer l'hiver à l'Ermitage, pour ne point afficher une rupture. Pour toute réponse, on est venu de la part de M. d'Epinay m'offrir le remboursement des gages du jardinier. Assurément, si après tout cela j'attends un congé en meilleure forme c'est sans doute qu'on me vienne mettre dehors à coups de bâton.

Une ancienne amitié, même éteinte, a des droits que je respecterai toujours. J'ai résolu de garder un éternel silence sur l'odieuse conduite de Mme d'Epinay avec moi. Mes griefs contre elle resteront concentrés entre moi et mes intimes amis dont je veux conserver l'estime. Je sais donc bien que tout le monde me blâmera mais qu'importe. Il n'est pas question de ce qu'on dira, mais de ce que je dois faire. Je ne sais comment vous pouvez me conseiller de rester, quand la voix intérieure qui ne me trompe jamais, me crie que chaque jour que je reste à l'Ermitage est une bassesse qu'il faut me reprocher. Vous voulez que j'écrive à Mme d'Epinay! Et que lui écrirai-je ? Dictez-moi donc ma lettre ; je vous en prie.

N'abusez point de votre pouvoir jusqu'à me forcer de choisir entre mon honneur et votre volonté. Voici pourtant ce que le désir de vous complaire me fait accorder en murmurant et contre le cri de ma conscience. J'ai fait écrire à Mme d'Epinay par Cahouët pour avoir ses ordres au sujet des meubles qu'il ne faut pas laisser ici exposés aux voleurs, et j'ai promis de rester jusqu'au temps nécessaire pour que la réponse arrive. $\mathrm{Si}$ avec cette réponse il vient pour moi une lettre honnête de Mme d'Epinay pour m'engager à passer ici l'hiver, je consens d'y rester. Je consens d'y rester encore, même sans lettre de sa part, pourvu que vous lui écriviez très positivement que vous l'avez exigé sous peine de disgrâce, que j'y reste à contre-cœur, et par seule déférence pour vous. Alors en faisant un voyage au printemps, je sortirai d'ici sans éclat. Choisissez entre ces deux conditions, ou laissez-moi partir, comme je devrais déjà avoir fait. 
$\mathrm{Au}$ reste, je dois vous avertir que loin qu'il me reste ni agitation ni colère, je me sens d'une faiblesse, d'un accablement qui m'ôte la force de penser, d'agir, et qui me fait trembler à la seule idée d'un délogement. Ainsi, croyez que je n'ai point actuellement à me défier de mes résolutions, et qu'au contraire si je me sens encore la force de les tenir, c'est parce que l'honneur est la dernière chose qui s'éteint chez un honnête homme.

Je n'ai point de nouvelles de Diderot. Prompt à quereller ses amis, il les laisse au milieu de leurs peines boire à loisir la coupe de l'affliction. Je ne puis plus supporter l'état où il me tient, et je lui enverrai samedi Mlle le Vasseur. Elle ira aussi savoir de vos nouvelles et prendre votre réponse. Adieu, ma chère amie et mon unique consolatrice. 


\section{Lettre 51}

\section{À Mme [d'Epinay]}

À l'Ermitage, le 23 novembre 1757

$\underline{\text { Retour à la table des matières }}$

Si l'on mourait de douleur, je ne serais pas en vie. Mais enfin j'ai pris mon parti. L'amitié est éteinte entre nous, Madame ; mais celle qui n'est plus garde encore des droits que je sais respecter. Je n'ai point oublié vos bontés pour moi, et vous pouvez compter de ma part sur toute la reconnaissance qu'on peut avoir pour quelqu'un qu'on ne doit plus aimer. Toute autre explication serait inutile : j'ai pour moi ma conscience et vous renvoie à la vôtre.

J'ai voulu quitter l'Ermitage, et je le devais. Mais on prétend qu'il faut que j'y reste jusqu'au printemps, et puisque mes amis le veulent, j'y resterai si vous y consentez. 
Jean-Jacques Rousseau, Lettres (1728-1778)

\section{Cinquième partie}

\section{Le commerce des grands}

$1758-1762$

Retour à la table des matières

Chassé de l'Ermitage, Rousseau s'établit à peu de distance, à Mont-louis, puis au petit château de Montmorency, dont le maréchal de Luxembourg lui ouvrit généreusement la porte. C'était passer du monde des « traitants » à celui de la haute noblesse. Mais le défenseur de la vérité et de la vertu savait bien que la postérité lui demanderait compte de toutes ses faiblesses. D'où l'incertitude et l'ambiguïté d'une position qui lui permit de connaître tour à tour d'intenses jouissances d'amour-propre et la peur de se manquer à luimême. Ce qui le justifie, toutefois, à ses propres jeux (lisez, la lettre du 28 janvier 1762 à M. de Malesherbes), c'est le sincère attachement de son cœur pour le duc et la duchesse.

Les années 1758-1762 sont celles aussi de la grande production littéraire et philosophique : la Lettre à d'Alembert sur les Spectacles, la Nouvelle Hélö̈se, l'Émile et le Contrat social paraissent successivement. Rousseau s'est reconquis lui-même et sa vertu s'est revigorée par le travail et par la profondeur de sa méditation. "Pour la première fois de ma vie j'eus du courage », dira-t-il dans la troisième Rêverie, et c'est au succès de son projet de réforme, assure-t-il, qu'il doit «d'avoir pu soutenir l'horrible destinée qui dès lors commençait à m'envelopper... », - allusion aux certitudes religieuses qu'il a 
exprimées dans la Profession de Foi du Vicaire savoyard; allusion aussi à des angoisses qu'entretient un état maladif ponctué de crises où il lui semble à chaque fois que «son sort est décidé ».

L'histoire vient répondre à ces craintes : le 9 Juin 1762, le Parlement de Paris condamne l'Émile. Rousseau est décrété de prise de corps. Il prend la fuite le même jour. 


\section{Lettre 52}

\section{À Mme [d'Houdetot]}

Ce 5 janvier 1758

$\underline{\text { Retour à la table des matières }}$

Je continuais vos copies, Madame, quand j'ai été arrêté par une réflexion qu'il faut que je vous communique.

Je commencerai par vous dire que le style équivoque et louche de vos dernières lettres ne m'a point échappé. J'ai tout fait pour vous donner occasion de vous expliquer, je vous ai demandé des éclaircissements ; je vous ai priée d'en demander à votre ami. Vous avez tout éludé. La franchise de vous autres gens du monde est de ne jamais dire ce que vous pensez qu'avec précautions, réserves, poliment à double entente, à demi-mots. Ma puérile franchise à moi, comme vous l'appelez vous-même, est d'interpréter tout cela dans mon langage rustique, et de répondre sans détour à tout ce qu'on me fait entendre adroitement. Puis donc qu'au lieu de vous honorer de mon amitié, vous en avez honte, je la retire, pour ne vous en pas laisser rougir plus longtemps. Méprisez-moi désormais si vous pouvez; je ne m'en offenserai plus. Je vous déclare que, dès cet instant, je ne vois plus en vous que Mme la Comtesse, ni en lui avec tout son génie, que M. le Marquis ; et c'est être plus descendus que vous ne pensez. 
Ce n'est pas que j'aie oublié ce que je vous dois, ni les bienfaits que j'ai reçus de vous. Ces bienfaits ne sont ni de l'or, ni de l'argent, dont je vous aurais su peu de gré, et dont je ne me souviendrais plus aujourd'hui. Mais quand mon cœur gonflé d'ennuis trouvait des consolations près de vous; quand vous me renvoyiez dans le sein de mon ami ; quand vous me parliez avec tant de plaisir du vôtre dans d'aimables promenades ; quand je m'en trouvais plus heureux d'être homme de bien pour mériter votre estime ; quand, indignement outragé et abandonné pour ne vouloir pas être le valet d'une femme méprisable, vous seule en dernier lieu souteniez mon courage abattu ; c'étaient là des bienfaits précieux qui me rendaient la vie douce et délicieuse. Ah ! vous n'étiez pas comtesse, alors; et vous me sembliez, malgré vos faiblesses, un ange du Ciel qui venait ranimer en moi la constance et la vertu. Que vous avez changé ! Mais ce cœur, que les âmes basses et vénales osent traiter d'ingrat, ne change point. S'il doit oublier qui le méprise, il sait toujours estimer et honorer le mérite ; il ne perd point le tendre souvenir des bienfaits reçus. Enfin, quoique je sois résolu de ne jamais chercher à vous voir, la seule reconnaissance est encore un sentiment si doux que si je vous revois jamais, ce ne sera point sans plaisir.

Voilà ce qu'il fallait d'abord que vous sussiez; venons maintenant à ce que j'avais à vous dire en commençant.

Je vois manifestement par vos lettres que la chose à laquelle vous donnez le plus grand prix dans le monde est l'argent. Vous n'admettez pour bienfaits dignes de reconnaissance que ceux qui se font par son moyen, ou du moins vous ne mettez nulle autre espèce en comparaison avec celle-là. Le riche est l'unique dispensateur des bienfaits à votre compte ; et nous sommes privés, nous autres pauvres, du plaisir d'exercer jamais le plus doux acte de l'humanité.

Moi, au contraire, je sépare toujours les possessions d'avec la personne, je ne vois pas que celui qui donne beaucoup d'argent donne rien du sien ; au lieu que celui qui donne son temps, sa liberté, ses sentiments, ses talents, ses soins, se donne vraiment lui-même, et tout ce qui constitue son être, son sort et sa vie. Il tire, pour ainsi dire de sa propre substance, tout le bien qu'il fait à autrui. Pour raisonner conséquemment, vous ne devez pas trouver le pélican un fort tendre père, attendu qu'il ne nourrit ses petits que de son sang, au lieu que les autres oiseaux nourrissent les leurs à bien plus grand prix de ce qu'ils ramassent. Pour moi, dans cet échange de bienfaits, quand l'un des deux aurait donné tout l'or de l'univers, et que l'autre ne donnerait qu'une heure de sa vie, je tiens que le premier ne saurait être quitte envers lui.

Appliquons, Madame, nos principes aux copies que je fais pour vous ; je vois qu'il n'y a qu'un moyen de nous accorder sur le prix que nous leur donnerons ; c'est que je n'en reçoive aucun paiement ; car alors je vous devrai une chose très douce qui est d'avoir employé mon temps à vous servir. Mais sitôt que vous me voudrez payer en comparant la chose reçue avec la chose donnée, et m'ayant donné de l'argent pour mon temps, vous prétendrez que je serai fort en reste avec vous ; et moi je prétendrai tout le contraire : car je puis gagner de mille autres manières autant d'argent que vous m'en aurez donné ; mais, quoi que vous fassiez, il vous est impossible de me jamais rendre aucune des heures que j'aurai employées pour vous. Ainsi, Madame, voyant 
que nous ne saurions nous accorder en rien sur l'estimation des choses, et ne voulant pas aussi passer pour ingrat envers vous, je suspends mon travail jusqu'à votre réponse. Ou trouvez bon que j'aie le plaisir de vous offrir mes copies, ou cherchez un autre copiste. 


\section{Lettre 53}

\section{À Mme [d'Houdetot]}

À Montmorency, le 10 janvier 1758

$\underline{\text { Retour à la table des matières }}$

Il n'est jamais permis d'être malhonnête ; ma lettre l'était; j'en suis justement puni. Je la désavouais même en l'écrivant ; vous ne l'ignorez pas ; mais contente d'y trouver le prétexte de rupture que vous cherchiez depuis longtemps, en violant la foi de l'amitié, vous avez pu mettre les procédés de votre côté, tandis que les sentiments étaient du mien. Tel est l'ordinaire partage des gens du monde et des solitaires. Les apparences me condamnent, j'en conviens : mais j'en appelle à votre cœur ; il connaît le mien ; qu'il me juge.

J'ai dû m'attendre à ce qui m'arrive ; il y a longtemps qu'on me l'a prédit. Il y a longtemps même que j'en pressens l'accomplissement, et voilà le seul de mes maux qui a rendu tous les autres insupportables. Si vous aviez si peu de temps à donner au commerce de notre amitié, pourquoi donc en tant perdre à la former? J'étais heureux et tranquille, quand vous vîntes troubler mon repos ; vous avez bien pu trouver tout le temps qu'il fallait pour me rendre misérable ; vous n'en avez plus trouvé pour me consoler. Si j'ai mal mérité de vous en quelque chose ; si la plus simple amitié connaît quelques devoirs que je n'aie pas remplis ; si votre repos ne me fut pas toujours plus cher que le mien ; si tous mes malheurs mêmes n'attestent pas la force et la pureté de mon attachement pour vous, daignez le dire, et je me tais. Comment les deux billets 
que j'ai trouvés joints au vôtre vous ont-ils permis de l'écrire avec tant de sécheresse ? Comment ne vous êtes-vous pas dit en les revoyant: S'il était moins sensible à mon bonheur et à ma gloire, il serait encore l'ami de Mme d'Epinay? Mais vous avez attendu, pour m'ôter votre amitié, qu'il ne me restât plus de preuve à vous donner de la mienne.

Vous vous trompez pourtant. Il m'en reste une plus forte et plus digne de moi que toutes les autres ; c'est de vous conserver toute ma vie cette même amitié que vous dédaignez et de la rendre indépendante de toutes les marques d'indifférence et de mépris que je puis recevoir de vous. Il est toujours doux d'être sensible, et mon cœur désormais fermé à tout nouvel attachement n'en nourrira qu'avec plus de charmes le dernier qu'il a formé. De tous les amis dont vous me parlez, il ne m'en reste qu'un et la raison en est bien simple, c'est que je n'en eus jamais d'autre ; car celui-là seul a résisté à mon adversité, et tout le reste s'est évanoui comme le faux or à la coupelle. Hé bien ! je l'aimerai et il m'aimera ; je vous aimerai, et vous ne m'aimerez point. Si le premier sentiment partagé me rend plus heureux, le dernier me rendra plus digne de l'être en nourrissant au fond de mon âme le sublime désintéressement dont elle est capable. Oui, Sophie, vous m'êtes plus chère que jamais, et mon cœur veut nourrir jusqu'à mon dernier soupir le vif et pur attachement qu'il a conçu pour vous. N'en soyez point alarmée, mon amitié ne vous sera plus importune, et comme elle n'exige ni n'attend plus rien de vous, elle ne causera plus entre nous de querelle, et ne vous coûtera aucun soin. Je ne renonce pas au plaisir de vous écrire; il est la seule consolation qui me reste ; mais comme vous êtes quitte avec les bienséances et ne serez point obligée à répondre, rien ne vous empêchera, si mes lettres vous ennuyent, de les jeter au feu sans les lire. Que si vous êtes importunée même de les recevoir, vous pouvez me le dire encore et je suis prêt à vous sacrifier cette dernière consolation ; car comme ce n'est plus de votre gré que je suis votre ami, je ne veux plus que cette amitié vous donne aucune sorte de gêne; peut-être en serez-vous plus tranquille en m'oubliant tout à fait, et moi j'en serai plus content en ne vous déplaisant en rien.

Il est bien étrange que vous me parliez encore de la lettre à Voltaire. Comment en vient-on là quand on fut amis. Bien loin que ma conduite, en cette occasion, dût vous déplaire, elle était un devoir envers vous. Cette lettre n'avait pas été communiquée à vous seule, elle l'avait été à Mme d'Epinay et à un certain homme. Sur le bruit qu'elle se répandait, je résolus de remonter à la source pour constater l'infidélité ; mais je dus vous en parler auparavant, à vous en particulier, de peur de vous compromettre, si malheureusement la communication venait de vous, ce qui eût été une faiblesse et non pas un crime; mais sur le premier mot que vous m'en dîtes, il ne me resta pas le moindre doute, et j'étais si persuadé que vous n'aviez aucune part à cette indiscrétion que j'allais travailler à en faire la honte aux coupables, en me justifiant envers M. de Voltaire, quand j'appris que la lettre en question n'était pas la mienne, mais celle d'un autre Genevois nommé M. Vernet. Réparez donc votre injustice envers moi ; je ne connais point d'amitié sans estime et sans confiance, et vous savez si j'en ai pour vous. Je vous crois capable de faiblesse et de légèreté, mais jamais d'infidélité ni de mensonge. Vous devez me connaître assez pour savoir que si je ne le pensais pas je ne le dirais pas. 
Au nom du Ciel, laissez-moi oublier les indignités que je vous ai écrites au sujet des copies. Si vous croyez que rien de semblable soit sorti de mon cœur, je déclare franchement que vous devez ne me regarder jamais. Dites-moi que vous le croyez, et je me condamne. Ah ! Sophie, Sophie, si je pouvais perdre votre amitié sans douleur, je vous dirais moins d'injures et vous outragerais davantage. 


\section{Lettre 54}

\section{À Mme la comtesse d'Houdetot}

Le 11 janvier [1758]

$\underline{\text { Retour à la table des matières }}$

Votre lettre m'a donné le plus pur, le plus vrai plaisir que j'aie goûté de ma vie. Ah! si vous m'eussiez toujours écrit ainsi, que de tourments vous m'eussiez épargnés ! J'ai mis hier une lettre à la poste par laquelle vous connaîtrez mes vrais sentiments ; je serais inconsolable si votre retour eût prévenu le mien. Croyez-moi, chère Sophie, mon cœur est fait pour vous aimer, il en est digne et vous serez toujours, après la vertu, ce qu'il aura de plus cher au monde; soyons amis pour mon bonheur et peut-être pour le vôtre ; si mon cœur ne me trompe pas, nous en deviendrons meilleurs tous les deux. Je me conforme entièrement à ce que vous exigez; je ne vous écrirai plus sans votre permission et seulement par la voie que vous m'indiquerez. Si vous gardez un long silence, je pourrai être en peine sur votre santé ou sur votre repos ; mais après la démarche que vous venez de faire, je jure de ne l'être de ma vie sur votre amitié et d'emporter au tombeau celle que je vous ai vouée. Adieu, ma digne et chère amie, la crise est faite, les indignités que j'ai souffertes ont fait la révolution dont j'avais besoin. Me voilà rendu à moimême et à mes maximes ; trois ans d'esclavage m'avaient avili l'âme, j'avais pris sans y songer la plupart des préjugés du monde. Grâce au Ciel, ils sont effacés, et je puis rendre au peu d'amis qui me restent un cœur digne de leur estime et qui ne se démentira plus. 


\section{Lettre 55}

\section{À M. [Diderot]}

Le 2 mars 1758

$\underline{\text { Retour à la table des matières }}$

Il faut, mon cher Diderot, que je vous écrive encore une fois en ma vie : vous ne m'en avez que trop dispensé ; mais le plus grand crime de cet homme que vous noircissez d'une si étrange manière est de ne pouvoir se détacher de vous.

Mon dessein n'est point d'entrer en explication, dans ce moment-ci, sur les horreurs que vous m'imputez. Je vois que cette explication serait à présent inutile ; car, quoique né bon avec une âme franche, vous avez pourtant un malheureux penchant à mésinterpréter les discours et les actions de vos amis. Prévenu contre moi comme vous l'êtes, vous tourneriez en mal tout ce que je pourrais dire pour me justifier, et mes plus ingénues explications ne feraient que fournir à votre esprit subtil de nouvelles interprétations à ma charge. Non, Diderot, je sens que ce n'est pas par là qu'il faut commencer. Je veux d'abord proposer à votre bon sens des préjugés plus simples, plus vrais, mieux fondés que les vôtres, et dans lesquels je ne pense pas, au moins, que vous puissiez trouver de nouveaux crimes.

Je suis un méchant homme, n'est-ce pas ? vous en avez les témoignages les plus sûrs ; cela vous est bien attesté. Quand vous avez commencé à l'apprendre, il y avait seize ans que j'étais pour vous un homme de bien, et quarante ans que je l'étais pour tout le monde : en pouvez-vous dire autant de ceux qui vous ont communiqué cette belle découverte ? Si l'on peut porter à faux si longtemps le masque d'un honnête homme, quelle preuve avez-vous que le masque ne couvre pas leur visage aussi bien que le mien ? Est-ce un moyen bien propre à donner du poids à leur autorité que de charger en secret 
un homme absent, hors d'état de se défendre ? Mais ce n'est pas de cela qu'il s'agit.

Je suis un méchant ; mais pourquoi le suis-je ? Prenez bien garde, mon cher Diderot, ceci mérite votre attention : on n'est pas malfaisant pour rien, s'il $\mathrm{y}$ avait quelque monstre ainsi fait, il n'attendrait pas quarante ans à satisfaire ses inclinations dépravées. Considérez donc ma vie, mes passions, mes goûts, mes penchants ; cherchez, si je suis méchant, quel intérêt m'a pu porter à l'être. Moi qui, pour mon malheur, portai toujours un cœur trop sensible, que gagnerais-je à rompre avec ceux qui m'étaient chers ? À quelle place ai-je aspiré ? à quelles pensions, à quels honneurs m'a-t-on vu prétendre ? quels concurrents ai-je à écarter? Que m'en peut-il revenir de mal faire ? Moi qui ne cherche que la solitude et la paix, moi dont le souverain bien consiste dans la paresse et l'oisiveté, moi dont l'indolence et les maux me laissent à peine le temps de pourvoir à ma subsistance, à quel propos, à quoi bon m'irais-je plonger dans les agitations du crime, et m'embarquer dans l'éternel manège des scélérats ? Quoi que vous en disiez, on ne fuit point les hommes quand on cherche à leur nuire ; le méchant peut méditer ses coups dans la solitude, mais c'est dans la solitude qu'il les porte. Un fourbe a de l'adresse et du sang-froid ; un perfide se possède et ne s'emporte point : reconnaissez-vous en moi quelque chose de tout cela ? je suis emporté dans la colère, et souvent étourdi de sang-froid. Ces défauts font-ils le méchant? Non, sans doute; mais le méchant en profite pour perdre celui qui les a.

Je voudrais que vous pussiez aussi réfléchir un peu sur vous-même. Vous vous fiez à votre bonté naturelle ; mais savez-vous à quel point l'exemple et l'erreur peuvent la corrompre ? N'avez-vous jamais craint d'être entouré d'adulateurs adroits qui n'évitent de louer grossièrement en face que pour s'emparer plus adroitement de vous sous l'appât d'une feinte sincérité ? Quel sort pour le meilleur des hommes d'être égaré par sa candeur même, et d'être innocemment, dans la main des méchants, l'instrument de leur perfidie ! Je sais que l'amour-propre se révolte à cette idée, mais elle mérite l'examen de la raison.

Voilà des considérations que je vous prie de bien peser : pensez-y longtemps avant que de me répondre. Si elles ne vous touchent pas, nous n'avons plus rien à nous dire ; mais si elles font quelque impression sur vous, alors nous entrerons en éclaircissements ; vous retrouverez un ami digne de vous, et qui peut-être ne vous aura pas été inutile. J'ai, pour vous exhorter à cet examen, un motif de grand poids, et ce motif le voici.

Vous pouvez avoir été séduit et trompé. Cependant votre ami gémit dans sa solitude, oublié de tout ce qui lui était cher. Il peut y tomber dans le désespoir, y mourir enfin, maudissant l'ingrat dont l'adversité lui fit tant verser de larmes, et qui l'accable indignement dans la sienne. Il se peut que les preuves de son innocence vous parviennent enfin, que vous soyez forcé d'honorer sa mémoire, et que l'image de votre ami mourant ne vous laisse pas des nuits tranquilles. Diderot, pensez-y. je ne vous en parlerai plus. 


\section{Lettre 56}

\section{À un jeune homme}

[Printemps 1758]

$\underline{\text { Retour à la table des matières }}$

Vous ignorez, Monsieur, que vous écrivez à un pauvre homme accablé de maux, et de plus, fort occupé, qui n'est guère en état de vous répondre, et qui le serait encore moins d'établir avec vous la société que vous lui proposez. Vous m'honorez en pensant que le pouvais vous y être utile, et vous êtes louable du motif qui vous l'a fait désirer ; mais sur le motif même, je ne vois rien de moins nécessaire que de venir vous établir à Montmorency. Vous n'avez pas besoin d'aller chercher si loin les principes de la morale. Rentrez dans votre cœur, et vous les y trouverez; et je ne pourrai rien vous dire à ce sujet que ne vous dise encore mieux votre conscience, quand vous voudrez la consulter. La Vertu, Monsieur, n'est pas une science qui s'apprend avec tant d'appareil ; pour être vertueux, il suffit de vouloir l'être ; et si vous avez bien cette volonté, tout est fait ; votre bonheur est décidé. S'il m'appartenait de vous donner des conseils, le premier que je voudrais vous donner, serait de ne point vous livrer à ce goût que vous dites avoir pour la vie contemplative, et qui n'est qu'une paresse de l'âme, condamnable à tout âge, et surtout au vôtre. L'Homme n'est point fait pour méditer, mais pour agir; la vie laborieuse que Dieu nous impose n'a rien que de doux au cour de l'Homme-de-bien, qui s'y livre en vue de remplir son devoir, et la vigueur de la jeunesse ne vous a pas été donnée pour la perdre à d'oisives contemplations. Travaillez donc, Monsieur, dans l'état où vous ont placé vos parents et la Providence. Voilà le 
premier précepte de la Vertu que vous voulez suivre ; et si le séjour de Paris, joint à l'emploi que vous remplissez, vous paraît d'un trop difficile alliage avec elle, faites mieux, Monsieur, retournez dans votre province, allez vivre dans le sein de votre famille, servez, soignez vos vertueux parents, c'est là que vous remplirez véritablement les soins que la Vertu vous impose ; une vie dure est plus facile à supporter en province que la Fortune à poursuivre à Paris, surtout quand on sait, comme vous ne l'ignorez pas, que les plus indignes manèges y font plus de fripons gueux que de parvenus. Vous ne devez point vous estimer malheureux de vivre comme fait $M$. votre père, et il n'y a point de sort que le travail, la vigilance, l'innocence et le contentement de soi ne rendent supportable, quand on s'y soumet en vue de remplir son devoir. Voilà, Monsieur, des conseils qui valent tous ceux que vous pourriez venir prendre à Montmorency. Peut-être ne seront-ils pas de votre goût, et je crains que vous ne preniez pas le parti de les suivre; mais je suis sûr que vous vous en repentirez un jour. je vous souhaite un sort qui ne vous force jamais à vous en souvenir. Je vous prie, Monsieur, d'agréer mes salutations très humbles. 


\section{Lettre 57}

\section{À M. d'Alembert}

À Montmorency, le 25 juin 1758

$\underline{\text { Retour à la table des matières }}$

J'ai dû, Monsieur, répondre à votre article sur Genève ; je l'ai fait, et je vous ai même adressé cet écrit. Je suis sensible aux témoignages de votre souvenir, et à l'honneur que j'ai reçu de vous en plus d'une occasion ; mais vous nous donnez un conseil pernicieux, et si mon père en avait fait autant, je n'aurais pu ni dû me taire. J'ai tâché d'accorder ce que je vous dois avec ce que je dois à ma patrie, quand il a fallu choisir ; j'aurais fait un crime de balancer. Si ma témérité vous offense, vous n'en serez que trop vengé par la faiblesse de l'ouvrage. Vous y chercherez en vain les restes d'un talent qui n'est plus, et qui ne se nourrissait peut-être que de mon mépris pour mes adversaires. Si je n'avais consulté que ma réputation j'aurais certainement supprimé cet écrit ; mais il n'est pas ici question de ce qui peut vous plaire ou m'honorer, en faisant mon devoir, je serai toujours assez content de moi et assez justifié près de vous. 


\section{Lettre 58}

\section{À M. [M.-M. Rey, libraire à Amsterdam]}

À Montmorency, le 8 juillet 1758

Retour à la table des matières

Je n'ai reçu qu'avant-hier, mon cher Rey, votre paquet adressé à $M$. Coindet, contenant les deux feuilles $\mathrm{M}$ et $\mathrm{N}$, la préface, et un mot de lettre du 28. À l'égard de la feuille L que vous dites m'avoir envoyée par M. Dupin, elle ne m'est point parvenue, et si vous y aviez joint quelque chose par écrit qu'il importe que je sache, vous ferez bien de me le répéter. J'ai bien peur que vous n'ayez confondu M. Dupin fermier général avec M. Dupin de Chenonceaux aussi fermier général. Si vous aviez suivi exactement l'adresse que je vous ai envoyée, cela ne serait pas arrivé. J'enverrai demain à Paris exprès pour m'informer de ce paquet. Ne vous pressez pas de me renvoyer la feuille L, jusqu'à ce que je vous marque par un autre courrier si en effet la première est perdue sans retour.

Voici de nouvelles corrections non moins indispensables que les précédentes, mais j'ai moins de regret à votre peine depuis que je vois que vos fautes viennent d'avoir voulu corriger les miennes et de vous être mis en tête qu'on parle mieux français à Amsterdam qu'à Paris. Au reste, afin que vous ne m'accusiez ni d'humeur ni d'entêtement, je veux bien vous rendre raison des leçons que je suis forcé de rétablir.. Préface. Page XVIII, pénultième ligne, accueillerez, il faut accueillirez comme j'avais mis premièrement parce que 
c'est l'usage des gens qui parlent bien, et puis parce que l'analogie le demande, attendu qu'on ne dit pas vous faillerez et vous cueillerez; enfin parce que la pénultième syllabe de ce mot doit être appuyée par un accent et qu'un $e$ muet n'en saurait comporter. Changez donc cet $e$ en $i$. Cette faute est si choquante à la place où elle est que, si malheureusement la préface était déjà tirée, il faudrait absolument un carton pour rétablir ce mot. Comme j'espère qu'elle ne l'est pas, je vous prie aussi, même page, ligne 6, de mettre simplement Lecteur, au singulier, et d'ôter l'O.

Je voudrais bien encore que vous pussiez faire en sorte que la citation latine de la page XVI n'eût pas besoin de tourner.

2. Page 186, ligne 5 en remontant, femmes, je n'avais point mis cette $s$, ôtez-la ; vous me direz qu'elle est fort indifférente et vous avez raison quant au sens ; mais outre que le singulier est plus élégant, ce pluriel ajoute dans la phrase une syllabe qui en gâte absolument l'harmonie, et l'harmonie me paraît d'une si grande importance en fait de style que je la mets immédiatement après la clarté, même avant la correction.

3. Page 181, ligne 4, j'avais mis il faudra, vous avez mis il faudrait. Ce changement, non plus, n'altère pas le sens et c'est tant pis, car on ne le prendra pas pour une faute d'impression. Or, voyez quelle chaîne de solécismes il étend sur les temps qui suivent. Rétablissez donc il faudra, comme vous pourrez, et ne vous en prenez qu'à vous-même de la peine que je vous donne malgré moi. Quand l'ouvrage sera fini, je vous enverrai la note des fautes dont je ne vous parle pas, et vous en serez étonné.

Vous avez tort de m'envoyer vos paquets par la poste à vos frais, puisque ces paquets n'étant pas des épreuves, j'aurais attendu patiemment, comme je vous l'ai marqué, que vous trouvassiez quelque occasion pour me les faire tenir. Heureusement nous approchons de la fin, et je ne pense pas qu'il vous reste encore beaucoup d'envois à me faire par la poste.

Quand vous serez prêt à faire vos envois je vous marquerai comment je souhaite de partager mes exemplaires ; en attendant, je vous prie de ne pas oublier M. d'Alembert avant que l'ouvrage paraisse, ni, s'il y a moyen, M. de Saint-Lambert à Nancy quand il paraîtra. Adieu, mon cher Rey, je vous embrasse de tout mon cœur. 


\section{Lettre 59}

\section{À M. R[omilly], étudiant à Genève}

À Montmorency, le 6 février 1759

$\underline{\text { Retour à la table des matières }}$

On ne saurait aimer les pères sans aimer des enfants qui leur sont si chers ; ainsi, Monsieur, je vous aimais sans vous connaître et vous croyez bien que ce que je reçois de vous n'est pas propre à relâcher cet attachement. J'ai lu votre ode, j'y ai trouvé de l'énergie, des images nobles, et quelquefois des vers heureux ; mais votre poésie paraît gênée, elle sent la lampe et n'a pas acquis la correction. Vos rimes, quelquefois riches, sont rarement élégantes, et le mot propre ne vous vient pas toujours. Mon cher R[omilly] quand je paie les compliments par des vérités, je rends mieux que ce qu'on me donne.

Je vous crois du talent, et je ne doute pas que vous ne vous fassiez honneur dans la carrière où vous entrez. J'aimerais pourtant mieux, pour votre bonheur, que vous eussiez suivi la profession de votre digne père ; surtout si vous aviez pu vous y distinguer comme lui. Un travail modéré, une vie égale et simple, la paix de l'âme et la santé du corps qui sont le fruit de tout cela valent mieux pour vivre heureux que le savoir et la gloire. Du moins en cultivant les talents des gens de lettres, n'en prenez pas les préjugés ; n'estimez votre état que ce qu'il vaut et vous en vaudrez davantage. 
Je vous dirai que je n'aime pas la fin de votre lettre; vous me paraissez juger trop sévèrement les riches. Vous ne songez pas qu'ayant contracté dès leur enfance mille besoins que nous n'avons point, les réduire à l'état des pauvres, ce serait les rendre plus misérables qu'eux. Il faut être juste envers tout le monde, même envers ceux qui ne le sont pas pour nous. Eh ! Monsieur, si nous avions les vertus contraires aux vices que nous leur reprochons, nous ne songerions pas même qu'ils sont au monde, et bientôt ils auraient plus besoin de nous que nous d'eux. Encore un mot et je finis : pour avoir le droit de mépriser les riches, il faut être économe et prudent soi-même, afin de n'avoir jamais besoin de richesses.

Adieu, mon cher R[omilly], je vous embrasse de tout mon cœur. 


\section{Lettre 60}

\section{À M. [le maréchal de Luxembourg]}

À Montmorency, le 30 avril 1759

$\underline{\text { Retour à la table des matières }}$

Monsieur,

Je n'ai oublié ni les grâces dont vous m'avez comblé, ni l'engagement auquel le respect et la reconnaissance ne m'ont pas permis de me refuser. Je n'ai perdu ni la volonté de tenir ma parole, ni le sentiment avec lequel il me convient d'accepter l'honneur que vous m'avez fait. Mais, Monsieur le Maréchal, cet engagement ne pouvait être que conditionnel ; et, dans l'extrême distance qu'il y a de vous à moi, ce serait de ma part une témérité inexcusable d'oser habiter votre maison sans savoir si j'y serais vu de vous et de Madame la Maréchale avec la même bienveillance qui vous a porté à me l'offrir.

Vos bontés m'ont mis dans une perplexité qu'augmente le désir de n'en pas être indigne. Je conçois comment on rejette avec un respect froid et repoussant les avances des grands qu'on n'estime pas : mais comment, sans m'oublier, en userais-je avec vous, Monsieur, que mon cœur honore, avec vous que je rechercherais si vous étiez mon égal ? N'ayant jamais voulu vivre qu'avec mes amis, je n'ai qu'un langage, celui de l'amitié, de la familiarité. Je n'ignore pas combien de mon état au vôtre il faut modifier ce langage ; je sais que mon respect pour votre personne ne me dispense pas de celui que je dois à votre rang ; mais je sais mieux encore que la pauvreté qui s'avilit devient bientôt méprisable ; je sais qu'elle a aussi sa dignité, que l'amour même de la vertu 
l'oblige de conserver. Je suis ainsi toujours dans le doute de manquer à vous ou à moi, d'être familier ou rampant; et ce danger même, qui me préoccupe, m'empêche de rien faire ou de rien dire à propos. Déjà, sans le vouloir, je puis avoir commis quelque faute, et cette crainte est bien raisonnable à un homme qui ne sait point comment on doit se conduire avec les grands, qui ne s'est point soucié de l'apprendre, et qui n'aura qu'une fois en sa vie regretté de ne le pas savoir.

Pardonnez donc, Monsieur le Maréchal, la timidité qui me fait hésiter à me prévaloir d'une grâce à laquelle je devais si peu m'attendre, et dont je voudrais ne pas abuser. Je n'ai point, quant à moi, changé de résolution ; mais je crains de vous avoir donné lieu de changer de sentiment sur mon compte. Si M. Chassot m'apprend, de votre part et de celle de Madame la Maréchale, que je suis toujours le bienvenu, vous verrez, par mon empressement à profiter de vos grâces, que ce n'est pas la crainte d'être ingrat qui m'a fait balancer.

Soit que j'habite votre maison et que je sois admis quelquefois auprès de vous, soit que je reste dans la distance qui me convient, les bontés dont vous m'avez honoré, et la manière dont j'ai tâché d'y répondre, ont mis désormais un intérêt commun entre nous. L'estime réciproque rapproche tous les états ; quelque élevé que vous soyez, quelque obscur que je puisse être, la gloire de chacun des deux ne doit plus être indifférente à l'autre. Je me dirai tous les jours de ma vie : souviens-toi que M. le Maréchal duc de Luxembourg t'honora de sa visite, et vint s'asseoir sur ta chaise de paille, au milieu de tes pots cassés, ce ne fut ni pour ton nom ni pour ta fortune, mais pour quelque réputation de probité que tu t'es acquise ; ne le fais jamais rougir de l'honneur qu'il t'a fait. Daignez, Monsieur le Maréchal, vous dire aussi quelquefois : il est dans le patrimoine de mes pères un solitaire qui s'intéresse à moi, qui s'attendrit au bruit de ma bénéficence, qui joint les bénédictions de son cœur à celles des malheureux que je soulage, et qui m'honore, non parce que je suis grand, mais parce que je suis bon.

Recevez, Monsieur le Maréchal, les humbles témoignages de ma reconnaissance et de mon profond respect. 


\section{Lettre 61}

\section{À M. [le maréchal de Luxembourg]}

Au petit Château, le 27 mai 1759

Retour à la table des matières

Monsieur,

Votre maison est charmante ; le séjour en est délicieux. Il le serait plus encore si la magnificence que j'y trouve et les attentions qui m'y suivent me laissaient un peu moins apercevoir que je ne suis pas chez moi. À cela près, il ne manque au plaisir avec lequel je l'habite que celui de vous en voir le témoin.

Vous savez, Monsieur le Maréchal, que les solitaires ont tous l'esprit romanesque. Je suis plein de cet esprit; je le sens et ne m'en afflige point. Pourquoi chercherais-je à guérir d'une si douce folie, puisqu'elle contribue à me rendre heureux ? Gens du monde et de la cour, n'allez pas vous croire plus sages que moi : nous ne différons que par nos chimères.

Voici donc la mienne en cette occasion. Je pense que, si nous sommes tous deux tels que j'aime à le croire, nous pouvons former un spectacle rare, et peut-être unique, dans un commerce d'estime et d'amitié (vous m'avez dicté ce mot) entre deux hommes d'états si divers, qu'ils ne semblaient pas faits pour avoir la moindre relation entre eux. Mais pour cela, Monsieur, il faut rester tel que vous êtes, et me laisser tel que je suis. Ne veuillez point être mon patron ; je vous promets, moi, de ne point être votre panégyriste; je vous promets de 
plus que nous aurons fait tous deux une très belle chose, et que notre société, si j'ose employer ce mot, sera, pour l'un et pour l'autre, un sujet d'éloge préférable à tous ceux que l'adulation prodigue. Au contraire, si vous voulez me protéger, me faire des dons, obtenir pour moi des grâces, me tirer de mon état, et que j'acquiesce à vos bienfaits, vous n'aurez recherché qu'un faiseur de phrases, et vous ne serez plus qu'un grand à mes yeux. J'espère que ce n'est pas à cette opinion réciproque qu'aboutiront les bontés dont vous m'honorez.

Mais, Monsieur, il faut vous avouer tout mon embarras. Je n'imagine point la possibilité de ne voir que vous et Madame la Maréchale, au milieu de la foule inséparable de votre rang, et dont vous êtes sans cesse environnés. C'est pourtant une condition dont j'aurais peine à me départir. Je ne veux ni complaire aux curieux, ni voir, pas même un moment, d'autres hommes que ceux qui me conviennent; et si j'avais cru faire pour vous une exception, je ne l'aurais jamais faite. Mon humeur ne souffre aucune gêne, mes incommodités qui ne la sauraient supporter, mes maximes sur lesquelles je ne veux point me contraindre, et qui sûrement offenseraient tout autre que vous, la paix surtout et le repos de ma vie, tout m'impose la douce loi de finir comme j'ai commencé. Monsieur le Maréchal, je souhaite de vous voir, de cultiver votre estime, d'apprendre de vous à la mériter; mais je ne puis vous sacrifier ma retraite. Faites que je puisse vous voir seul, et trouvez bon que je ne vous voie que de cette manière.

Je ne me pardonnerais jamais d'avoir ainsi capitulé avec vous avant d'accepter l'honneur de vos offres, et c'est encore un hommage que je crois devoir à votre générosité, de ne vous dire mes fantaisies qu'après m'être mis en votre pouvoir : car, en sentant quels devoirs j'allais contracter, j'en ai pris l'engagement sans crainte. Je n'ignore pas que mon séjour ici, qui n'est rien pour vous, est pour moi d'une extrême conséquence. Je sais que, quand je n'y aurais couché qu'une nuit, le public, la postérité peut-être, me demanderaient compte de cette seule nuit. Sans doute ils me le demanderont du reste de ma vie ; je ne suis pas en peine de la réponse. Monsieur, ce n'est pas à moi de la faire. En vous nommant, il faut que je sois justifié, ou jamais je ne saurais l'être.

Je ne crois pas avoir besoin d'excuse pour le ton que je prends avec vous. Il me semble que vous devez m'entendre. Monsieur le Maréchal, je pourrais, il est vrai, vous parler en termes plus respectueux, mais non pas plus honorables. 


\section{Lettre 62}

\section{À Mme [la maréchale de Luxembourg]}

À Montmorency, le 29 octobre 1759

$\underline{\text { Retour à la table des matières }}$

Où êtes-vous à présent, Madame la Maréchale ? À Paris, à l'Isle-Adam ? À Versailles ? Car je sais que vous avez fait ce mois-ci tous ces voyages. Vous me trouverez curieux ; mais puisque cette curiosité m'intéresse, elle est dans l'ordre. À Versailles, vous parlez de moi avec M. le Maréchal ; à l'Isle-Adam, vous en parlez avec le chevalier de Lorenzi, mais à Paris avec qui en parlezvous ? Je m'imagine que c'est à Paris qu'on va oublier les gens qu'on aime ; et comme je le hais, je l'accuse de tous les maux que je crains. De grâce, Madame la Maréchale, songez quelquefois qu'il existe à Montmorency un pauvre ermite à qui vous avez rendu votre souvenir nécessaire, et qui ne va point à Paris. Mais en vérité, je ne sais de quoi je m'inquiète ; après les bontés dont vous m'avez honoré, dois-je craindre d'être oublié dans vos courses, et dans quelque lieu que vous puissiez être, n'en sais-je pas un duquel vous ne sortez point?

Vos copies ne sont pas encore commencées, mais elles vont l'être. En toutes choses, il faut suivre l'ordre et la justice. Quelqu'un, vous le savez, est en date avant vous ; ce quelqu'un me presse, et il faut bien tenir ma parole, puisque vous ne voulez pas que je dise les raisons que j'aurais de la retirer. Je vais finir la 5e partie et avant de commencer la 6e, je ferai en sorte de vous envoyer la première. Mais, Madame la Maréchale, quoique vous soyez 
sûrement une fort bonne pratique, je me fais quelque peine de prendre votre argent. Régulièrement, ce serait à moi de payer le plaisir que j'aurai de travailler pour vous.

Grondez un peu M. le Maréchal, je vous supplie, de ce que dans l'embarras où il est, il prend la peine de m'écrire lui-même. J'ai désiré d'avoir souvent de ses nouvelles et des vôtres, mais non pas que ce fût lui qui m'en donnât ; ne sait-il pas que je n'ai plus besoin qu'il m'écrive ? S'il m'écrit encore une fois de tout le quartier, je croirai lui avoir déplu. Pour vous, Madame, il n'en est pas tout à fait de même. Je crois que j'ai encore besoin de quelques mots d'amitié, et puis quand je serai sûr également de tous deux, vous pourrez ne jamais m'écrire ni l'un ni l'autre que je n'en serai pas moins content, pourvu que Mme Gertrude ou M. Dubettier m'apprennent de temps en temps que vous vous portez bien. 


\section{Lettre 63}

\section{À Mme la marquise de Verdelin à Paris}

Mercredi 12 [mars 1760]

\section{$\underline{\text { Retour à la table des matières }}$}

Vous avez presque honte de votre santé, Madame; que dirai-je de la mienne, moi qui dois des excuses au public d'être encore en vie ? Depuis que j'ai le cœur dur, que je n'aime plus personne, et que j'appelle tout le monde mon ami, j'engraisse comme un cochon. je ne sache point de meilleure recette pour se porter bien que l'insensibilité ; si c'est la vôtre, je vous en félicite ; et on jouit fort paisiblement d'une santé gagnée à ce prix. On dit que nous ne tarderons pas à vous voir en ce pays-ci; j'attends ce moment avec un empressement que je tâche de rendre médiocre, afin qu'il ne nuise pas à mon embonpoint.

On m'écrit qu'on a renouvelé depuis peu le miracle de la broche, et l'on ajoute que la sainte étant cuite, mangera le poulet qu'on avait fait cuire avec elle. J'ai assez de leurs miracles, qu'on ne m'en parle plus. S'ils commencent par faire rire, ils finissent par faire gémir. Gloire de la philosophie ! le siècle des philosophes est le siècle des fous, des lâches et des fripons. On dit que tous ces gens-là combattent mes maximes. On se trompe ; ils travaillent sans cesse à les prouver. Bonjour, Madame. 


\section{Lettre 64}

\section{À M. Lenieps}

À Montmorency, le 15 mai 1760

$\underline{\text { Retour à la table des matières }}$

Quoique je sois si pressé, si accablé, mon bon ami, qu'on ne me laisse pas un seul moment de libre, il faut que j'en prenne un pour vous tranquilliser sur la difficulté qui vous inquiète dans l'introduction des sondes. Car je crois que, pour la comparaison de votre état au mien, vous avez de quoi vous moins alarmer, quand vous saurez, et $\mathrm{M}$. Cabanis a pu dans le temps vous le dire, qu'il y a dix ans et plus que ni sondes ni bougies, quelque minces qu'elles fussent, n'ont pu entrer dans le canal de l'urètre de votre ami ; qu'il y en a plus de quinze qu'il urine avec difficulté, sans qu'il puisse passer un seul grain de gravier par les urines, tellement que se filtrant à travers les embarras avec la plus grande peine, elles laissent dans la vessie tous les dépôts qui s'y accumulent incessamment ; que malgré cela, convaincu que tous les secours humains me sont aussi inutiles que douloureux, j'y ai renoncé depuis huit ans et ne m'en trouve pas plus mal. Au contraire, ôtez les attaques douloureuses auxquelles je ne fais rien que prendre patience, au surplus, je vais, viens, agis, mange et bois, et jouis même à présent d'un embonpoint dont j'ai presque honte. Mon bon ami, si vous n'aviez rien fait du tout, votre attaque se serait passée, vous seriez aussi bien guéri que vous l'êtes; et l'embarras que vous sentez dans l'urètre ne sera rien, pourvu qu'on ne l'augmente point en vous tracassant avec des bougies et des sondes. Il faut prendre le parti de supporter le mal quand il vient, et de se porter bien sitôt qu'on ne souffre plus. Tel est mon avis, et telle est ma pratique. 
Quand vous pourrez me venir voir, marquez-moi le jour d'avance, afin que je sois libre et tout à vous. Après tous les maux que vous venez de souffrir, il me sera bien doux de vous voir bien portant dans ma solitude. M. Roguin m'avait promis d'y passer quelques jours ce printemps ; je n'ai rien dit tant que sa compagnie et ses consolations vous étaient utiles ; mais maintenant je vois bien qu'il m'oublie. S'il veut me prouver le contraire, engagez-le à vous accompagner à Montmorency; et qu'il fasse au moins pour vous ce qu'il ne veut pas faire pour moi. Au reste, il ne faut pas venir pour s'en retourner le même jour, et ne soyez pas en peine du gîte ; on aura soin de pourvoir à tout. Adieu, mon bon ami; portez à votre digne fille les respects de l'homme du monde qui l'honore le plus. 


\section{Lettre 65}

\section{À M. [de Voltaire]}

À Montmorency, le 17 juin 1760

$\underline{\text { Retour à la table des matières }}$

Je ne pensais pas, Monsieur, me trouver jamais en correspondance avec vous. Mais apprenant que la lettre que je vous écrivis en 1756 a été imprimée à Berlin, je dois vous rendre compte de ma conduite à cet égard, et je remplirai ce devoir avec vérité et simplicité.

Cette lettre, vous ayant été réellement adressée, n'était point destinée à l'impression. Je la communiquai sous condition à trois personnes à qui les droits de l'amitié ne me permettaient pas de rien refuser de semblable, et à qui les mêmes droits permettaient encore moins d'abuser de leur dépôt en violant leur promesse. Ces trois personnes sont : Mme de Chenonceaux, belle-fille de Mme Dupin, Mme la comtesse d'Houdetot, et un Allemand nommé $\mathrm{M}$. Grimm. Mme de Chenonceaux souhaitait que cette lettre fût imprimée, et me demanda mon consentement pour cela. Je lui dis qu'il dépendait du vôtre. Il vous fut demandé, vous le refusâtes, et il n'en fut plus question.

Cependant, M. l'abbé Trublet, avec qui je n'ai nulle espèce de liaison, vient de m'écrire par une attention pleine d'honnêteté qu'ayant reçu les feuilles d'un journal de M. Formey, il y avait lu cette même lettre, avec un avis dans lequel l'éditeur dit sous la date du 23 octobre 1759 qu'il l'a trouvée il y a quelques semaines chez les libraires de Berlin, et que, comme c'est une de ces feuilles 
volantes qui disparaissent bientôt sans retour, il a cru lui devoir donner place dans son journal.

Voilà, Monsieur, tout ce que j'en sais. Il est très sûr que jusqu'ici l'on n'avait pas même ouï parler à Paris de cette lettre. Il est très sûr que l'exemplaire, soit manuscrit, soit imprimé, tombé dans les mains de M. Formey, n'a pu lui venir que de vous, ce qui n'est pas vraisemblable ; ou d'une des trois personnes que je viens de nommer. Enfin, il est très sûr que les deux dames sont incapables d'une pareille infidélité. Je n'en puis savoir davantage de ma retraite. Vous avez des correspondances au moyen desquelles il vous serait aisé, si la chose en valait la peine, de remonter à la source, et de vérifier le fait.

Dans la même lettre, M. l'abbé Trublet me marque qu'il tient la feuille en réserve et ne la prêtera point sans mon consentement qu'assurément je ne donnerai pas. Mais cet exemplaire peut n'être pas le seul à Paris. Je souhaite, Monsieur, que cette lettre n'y soit pas imprimée, et je ferai de mon mieux pour cela ; mais si je ne pouvais éviter qu'elle ne le fût, et qu'instruit à temps, je pusse avoir la préférence, alors, je n'hésiterais pas à la faire imprimer moimême. Cela me paraît juste et naturel.

Quant à votre réponse à la même lettre, elle n'a été communiquée à personne, et vous pouvez compter qu'elle ne sera point imprimée sans votre aveu qu'assurément je n'aurai point l'indiscrétion de vous demander, sachant bien que ce qu'un homme écrit à un autre, il ne l'écrit pas au public. Mais si vous en vouliez faire une pour être publiée et me l'adresser, je vous promets de la joindre fidèlement à ma lettre et de n'y pas répliquer un seul mot.

Je ne vous aime point, Monsieur ; vous m'avez fait les maux qui pouvaient m'être les plus sensibles, à moi votre disciple et votre enthousiaste. Vous avez perdu Genève pour le prix de l'asile que vous y avez reçu. Vous avez aliéné de moi mes concitoyens pour le prix des applaudissements que je vous ai prodigués parmi eux : c'est vous qui me rendez le séjour de mon pays insupportable ; c'est vous qui me ferez mourir en terre étrangère, privé de toutes les consolations des mourants, et jeté pour tout honneur dans une voirie, tandis que tous les honneurs qu'un homme peut attendre vous accompagneront dans mon pays. Je vous hais, enfin, puisque vous l'avez voulu; mais je vous hais en homme encore plus digne de vous aimer si vous l'aviez voulu. De tous les sentiments dont mon cour était pénétré pour vous, il n'y reste que l'admiration qu'on ne peut refuser à votre beau génie et l'amour de vos écrits. Si je ne puis honorer en vous que vos talents, ce n'est pas ma faute. Je ne manquerai jamais au respect qui leur est dû ni aux procédés que ce respect exige. 


\section{Lettre 66}

\section{À Mme [de Luxembourg]}

Ce dimanche 26 octobre (1760)

$\underline{\text { Retour à la table des matières }}$

Permettez, Madame la Maréchale, que je vous envoie le bulletin de ma journée d'hier. J'appris le matin que vous deviez passer à Saint-Brice entre midi et une heure ; je dînai à onze heures et demie, et de peur d'arriver trop tard, voulant gagner le temps du relais, j'allai couper le grand chemin au barrage de Pierre-fite, de là je remontai au petit pas jusqu'à la vue de SaintBrice ; là, les premières gouttes de pluie m'ayant surpris, je fus me réfugier chez le curé de Groslay, d'où voyant que la pluie ne faisait qu'augmenter je pris enfin le parti de me remettre en route, et j'arrivai chez moi mouillé jusqu'aux os, crotté jusqu'au dos, et qui pis est, ne vous ayant point vue. Je voudrais bien, Madame la Maréchale, que tous ces maux excitassent votre pitié, et me valussent un petit emplâtre de papier blanc. 


\section{Lettre 67}

\section{À Mme la marquise de Verdelin}

À Montmorency, le 5 novembre 1760

Retour à la table des matières

Vous me dites, Madame, que vous ne vous êtes pas bien expliquée pour me faire entendre que je m'explique mal ; vous me parlez de votre prétendue bêtise pour me faire sentir la mienne ; vous vous vantez de n'être qu'une bonne femme, comme si vous aviez peur d'être prise au mot; et vous me faites des excuses pour m'apprendre que je vous en dois. Oui, Madame, je le sais bien ; c'est moi qui suis une bête, un bon homme, et pis encore, s'il est possible. C'est moi qui choisis mal mes termes, au gré d'une belle dame française, qui fait tant d'attention aux paroles, et qui parle aussi bien que vous. Mais considérez que je les prends dans le sens commun de la langue, sans être au fait ou en souci des honnêtes acceptions qu'on leur donne dans les vertueuses sociétés de Paris. Si quelquefois mes expressions ont un tour équivoque, je tâche de vivre de manière que ma conduite en détermine le sens.

Je me suis rendu peu difficile, Madame, sur vos premiers présents, ou dons, ou cadeaux, ou comme il vous plaira de les appeler; car je ne sais pas trouver le mot propre. J'y recevais avec reconnaissance les témoignages de votre bon cœur et comme vous disiez vous-même, les soins de votre amitié. Quand ils ont commencé à devenir plus fréquents et plus incommodes, je vous l'ai dit. Alors, Mlle le Vasseur vous a servi de prétexte, et enfin M. Coindet, comme si ce qu'on m'envoie à manger chez moi pouvait paraître ailleurs que sur ma table. Je ne sais, Madame, si vous vous plaisez à me contraindre, ou si 
vous me soupçonnez de ne faire que jouer; mais je sais bien que ces jeux-là me lassent, et que je n'en veux plus souffrir. Au reste, je trouve assez injuste que, donnant tant d'importance à ce que je dis et si peu à ce que je fais, vous me traitiez en homme par mes paroles, et en enfant par mes actions.

Je n'ai point oublié et je n'oublierai jamais les attentions et les bontés dont vous m'avez honoré, et ce souvenir ne peut qu'augmenter le regret que j'ai de n'être pas d'un meilleur commerce et plus digne d'être admis dans votre société. J'avais besoin sans doute d'être averti que je ne suis près de vous qu'une simple connaissance. Si vous me l'eussiez dit plus tôt, Madame, je vous aurais épargné l'ennui de mes visites, car pour moi je n'ai point de temps à donner à mes connaissances; je n'en ai que pour mes amis. Recevez, Madame, les assurances de mon profond respect. 


\section{Lettre 68}

\section{À M. Coindet, chez MM. Thelusson et Necker, rue Michel-le-Comte à Paris,}

ce lundi matin [19 janvier 1761]

$\underline{\text { Retour à la table des matières }}$

Les 3 estampes en question ne sauraient regarder les pages recto. Cela est de toute impossibilité pour celle du fiacre, attendu qu'elle regarderait une autre lettre que celle à laquelle elle appartient si elle était après, et qu'elle serait absurde si elle était avant, comme anticipant une situation qui n'est même pas supposée à la fin de la lettre. Les deux autres ne seraient guère moins ridicules. Le meilleur parti sera d'attacher vos estampes deux à deux, tout comme si elles regardaient le même côté ; si la marge est un peu large, il sera aisé d'attacher au livre ces trois estampes par le côté droit, et si la marge est trop étroite on pourra toujours les. mettre sur des onglets comme des cartons. Ce sera l'affaire des relieurs.

Plus je regarde la dernière estampe plus je la trouve ignoble, et c'est le plus grand défaut qu'elle puisse avoir. Il faudrait dans les figures de Claire et de Wolmar une certaine noblesse de maintien qui les distinguât du peuple qui est dans la chambre, et au contraire, Wolmar semble un vieux apothicaire et Claire une grosse joufflue de servante, qui tient un torchon. Il faut absolument remédier à cela et si cela ne se peut j'aimerais mieux supprimer l'estampe. Voici là-dessus quelques idées : 
Le voile doit être beaucoup plus ample et plus long, on doit juger de sa finesse par la forme des plis, et de sa richesse par la broderie qui paraît autour. Il est dit que c'est un voile d'or brodé de perles, apporté des Indes ; vous m'avouerez que celui de l'estampe n'est qu'une véritable panosse. Il me semble qu'avec un peu d'adresse il ne serait pas impossible de cacher en tout ou en partie le visage de la morte par quelques replis flottants du même voile, et sûrement cette finesse de l'art n'échapperait pas aux spectateurs.

Claire n'a pas la taille assez fine ; son visage est trop plein, on n'est pas ainsi dans une profonde affliction, surtout après beaucoup de fatigues et d'insomnies. Elle devrait être dans un déshabillé très négligé à la vérité, mais pourtant qui sentît sa dame, et l'on ne voit rien de cela; il faut ajouter au moins quelque manière de garniture à sa robe ou à sa jupe, et lui donner des manchettes plus longues et plus plissées qu'à la femme qui est à côté.

Je ne puis m'empêcher d'ajouter que si les plis de la robe tombaient moins perpendiculairement et qu'ils descendissent un peu plus de biais du devant en arrière, cela seul ferait supposer une robe plus traînante et donnerait à l'habillement beaucoup plus de noblesse et de grâce. L'habit de M. de Wolmar est si large, quoique boutonné, qu'il paraît un habit pris à la friperie ; il faut déboutonner l'habit, en sorte que les basques soient plus en arrière ou bien le rendre plus juste-au-corps. La morte elle-même ressemble à une ravaudeuse. La richesse de l'ameublement tranche ridiculement avec la bassesse des personnages ; on ne les croira jamais faits pour habiter cette chambre-là. Cette estampe devrait avoir je ne sais quel air de merveilleux, de féerie. Elle a précisément l'opposé. Adieu, cher Coindet, j'espère que vous me donnerez des nouvelles de Mme la Maréchale. Je vous embrasse. 


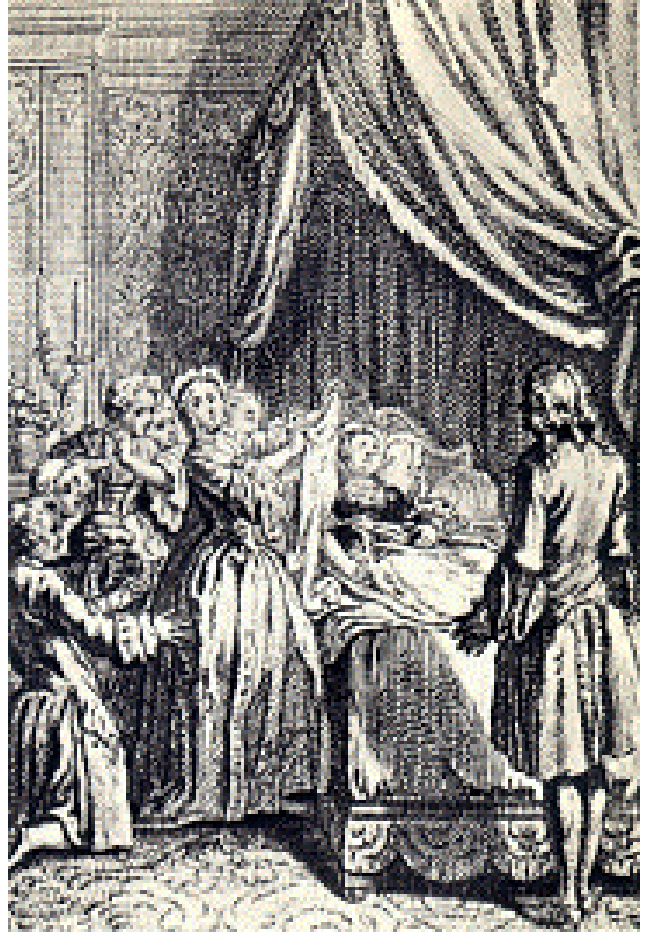

\section{Illustration 4}

La Mort de Julie (estampe pour la Nouvelle Héloüse)

$\underline{\text { Retour à la table des matières }}$ 


\section{Lettre 69}

\section{À Mme de Luxembourg}

À Montmorency, le 12 juin 1761

$\underline{\text { Retour à la table des matières }}$

Que de choses j'aurais à vous dire avant que de vous quitter! Mais le temps me presse ; il faut abréger ma confession, et verser dans votre cœur bienfaisant mon dernier secret. Vous saurez donc que depuis seize ans j'ai vécu dans la plus grande intimité avec cette pauvre fille qui demeure avec moi, excepté depuis ma retraite à Montmorency, que mon état m'a forcé de vivre avec elle comme avec ma sœur ; mais ma tendresse pour elle n'a point diminué et, sans vous, l'idée de la laisser sans ressource empoisonnerait mes derniers instants.

De ces liaisons sont provenus cinq enfants, qui tous ont été mis aux Enfants-Trouvés, et avec si peu de précaution pour les reconnaître un jour, que je n'ai même pas gardé la date de leur naissance. Depuis plusieurs années, le remords de cette négligence trouble mon repos, et je meurs sans pouvoir la réparer, au grand regret de la mère et au mien. Je fis mettre seulement dans les langes de l'aîné une marque dont j'ai gardé le double ; il doit être né, ce me semble, dans l'hiver de 1746 à 47, ou à peu près. Voilà tout ce que je me rappelle. S'il y avait le moyen de retrouver cet enfant, ce serait faire le bonheur de sa tendre mère ; mais j'en désespère, et je n'emporte point avec moi cette consolation. Les idées dont ma faute a rempli mon esprit ont contribué en grande partie à me faire méditer le Traité de l'Éducation; et vous y trouverez, dans le livre 1er, un passage qui peut vous indiquer cette 
disposition. Je n'ai point épousé la mère, et je n'y étais point obligé, puisque avant de me lier avec elle, je lui ai déclaré que je ne l'épouserais jamais, et même un mariage public nous eût été impossible à cause de la différence de religion ; mais du reste, je l'ai toujours aimée et honorée comme ma femme, à cause de son bon cœur, de sa sincère affection, de son désintéressement sans exemple, et de sa fidélité sans tache, sur laquelle elle ne m'a pas même occasionné le moindre soupçon.

Voilà, Madame la Maréchale, la trop juste raison de ma sollicitude sur le sort de cette pauvre fille après qu'elle m'aura perdu ; tellement que, si j'avais moins de confiance en votre amitié pour moi et en celle de M. le Maréchal, je partirais pénétré de douleur de l'abandon où je la laisse; mais je vous la confie, et je meurs en paix à cet égard. Il me reste à vous dire ce que je pense qui conviendrait le mieux à sa situation et à son caractère, et qui donnerait le moins de prise à ses défauts.

Ma première idée était de vous prier de lui donner asile dans votre maison, ou auprès de l'enfant qui en est l'espoir, jusqu'à ce qu'il sortît des mains des femmes; mais infailliblement, cela ne réussirait point; il y aurait trop d'intermédiaires entre vous et elle, et elle a, dans votre maison, des malveillants qu'elle ne s'est assurément point attirés par sa faute, et qui trouveraient infailliblement l'art de la disgracier tôt ou tard auprès de vous ou de Monsieur le Maréchal. Elle n'a pas assez de souplesse et de prudence pour se maintenir avec tant d'esprits différents, et se prêter aux petits manèges avec lesquels on gagne la confiance des maîtres, quelque éclairés qu'ils soient. Encore une fois, cela ne réussirait point ; ainsi je vous prie de n'y pas songer.

Je ne voudrais pas non plus qu'elle demeurât à Paris de quelque manière que ce fût ; bien sûr que, craintive et facile à subjuguer, elle y deviendrait la proie et la victime de sa nombreuse famille, gens d'une avidité et d'une méchanceté sans bornes, auxquels j'ai eu moi-même bien de la peine à l'arracher, et qui sont cause en grande partie de ma retraite en campagne. Si jamais elle demeure à Paris, elle est perdue, car, leur fût-elle cachée, comme elle est d'un bon naturel, elle ne pourra jamais s'abstenir de les voir, et en peu de temps, ils lui suceront le sang jusqu'à la dernière goutte, et puis la feront mourir de mauvais traitements.

Je n'ai pas de moins fortes raisons pour souhaiter qu'elle n'aille point demeurer avec sa mère, livrée à mes plus cruels ennemis, nourrie par eux à mauvaise intention, et qui ne cherchent que l'occasion de punir cette pauvre fille de n'avoir point voulu se prêter à leurs complots contre moi. Elle est la seule qui n'ait rien eu de sa mère, et la seule qui l'ait nourrie et soignée dans sa misère ; et si j'ai donné, durant douze ans, asile à cette femme, vous comprenez bien que c'est pour la fille que je l'ai fait. J'ai mille raisons, trop longues à détailler, pour désirer qu'elle ne retourne point avec elle. Ainsi, je vous prie d'interposer même, s'il le faut, votre autorité pour l'en empêcher.

Je ne vois que deux partis qui lui conviennent : l'un de continuer d'occuper mon logement, et de vivre en paix à Montmorency ; ce qu'elle peut faire à peu de frais avec votre assistance et protection, tant du produit de mes écrits que de celui de son travail, car elle coud très bien; et il ne lui manque que de l'occupation, que vous voudrez bien lui donner ou lui procurer, souhaitant 
seulement qu'elle ne soit point à la discrétion des femmes de chambre, car leur tyrannie et leur monopole me sont connus.

L'autre parti est d'être placée dans quelque communauté de province où l'on vit à bon marché, et où elle pourrait très bien gagner sa vie par son travail. J'aimerais moins ce parti que l'autre, parce qu'elle serait ainsi trop loin de vous, et pour d'autres raisons encore. Vous choisirez pour le mieux, Madame la Maréchale ; mais, quelque choix que vous fassiez, je vous supplie de faire en sorte qu'elle ait toujours sa liberté, et qu'elle soit la maîtresse de changer de demeure sitôt qu'elle ne se trouvera pas bien. Je vous supplie enfin de ne pas dédaigner de prendre soin de ses petites affaires, en sorte que, quoi qu'il arrive, elle ait du pain jusqu'à la fin de ses jours.

J'ai prié Monsieur le Maréchal de vous consulter sur le choix de la personne qu'il chargerait de veiller aux intérêts de la pauvre fille après mon décès. Vous n'ignorez pas l'injuste partialité que marque contre elle celui qui naturellement serait choisi pour cela. Quelque estime que j'ai conçue pour sa probité, je ne voudrais pas qu'elle restât à la merci d'un homme que je dois croire honnête, mais que je vois livré, par un aveuglement inconcevable, aux intérêts et aux passions d'un fripon.

Vous voyez, Madame la Maréchale, avec quelle simplicité, avec quelle confiance, j'épanche mon cœur devant vous. Tout le reste de l'univers n'est déjà plus rien à mes yeux. Ce cœur qui vous aima sincèrement, ne vit déjà plus que pour vous, pour M. le Maréchal, et pour la pauvre fille. Adieu, amis tendres et chéris ; aimez un peu ma mémoire ; pour moi, j'espère vous aimer encore dans l'autre vie ; mais quoi qu'il en soit de cet obscur et redoutable mystère, en quelque heure que la mort me surprenne, je suis sûr qu'elle me trouvera pensant à vous. 


\title{
Lettre 70
}

\section{Pour M. Du Parc [Dom Deschamps]}

\author{
À Montmorency, le 25 Juin 1761
}

$\underline{\text { Retour à la table des matières }}$

Vous me pardonnerez, Monsieur, le délai de ma réponse quand vous saurez que j'ai été très mal, et que je continue d'être en proie à des douleurs sans relâche qui ne me laissent guère la liberté d'écrire.

La vérité que j'aime n'est pas tant métaphysique que morale ; j'aime la vérité parce que je hais le mensonge ; je ne puis être inconséquent là-dessus que quand je serai de mauvaise foi. J'aimerais bien aussi la vérité métaphysique si je croyais qu'elle fût à notre portée ; mais je n'ai jamais vu qu'elle fût dans les livres, et désespérant de l'y trouver, je dédaigne leur instruction, persuadé que la vérité qui nous est utile est plus près de nous et qu'il ne faut pas pour l'acquérir un si grand appareil de science. Votre ouvrage, Monsieur, peut donner cette démonstration promise et manquée par tous les philosophes, mais je ne puis changer de maxime sur des raisons que je ne connais pas. Cependant votre confiance m'en impose ; vous promettez tant et si hautement, je trouve d'ailleurs tant de justesse et de raison dans votre manière d'écrire que je serais surpris qu'il n'y en eût pas dans votre philosophie, et je devrais peu l'être avec ma courte vue que vous vissiez où je n'avais pas cru qu'on pût voir. Or, ce doute me donne de l'inquiétude, parce que la vérité que je connais, ou ce que je prends pour elle, est très aimable, qu'il en résulte pour moi un état très doux, et que je ne conçois pas comment j'en pourrais changer sans y perdre. Si mes sentiments étaient démontrés, je m'inquiéterais peu des vôtres ; 
mais à parler sincèrement, je suis bien plus persuadé que convaincu ; je crois, mais je ne sais pas; je ne sais pas même si la science qui me manque me sera bonne ou mauvaise, et si peut-être après l'avoir acquise, il ne faudra pas dire : alto quaesivit coelo lucem ingemuitque reperta.

Voilà, Monsieur, la solution ou du moins l'éclaircissement des inconséquences que vous me reprochez. Cependant, il me paraît dur qu'il faille que je me justifie pour vous avoir dit mon sentiment quand vous me l'avez demandé. Je n'ai pris la liberté de vous juger que pour vous complaire ; je puis mêtre trompé, sans doute ; mais l'erreur en ceci n'est pas un tort.

Vous me demandez pourtant encore un conseil sur un sujet très grave, et je vais peut-être encore vous répondre tout de travers. Mais heureusement, ce conseil est de ceux qu'un auteur ne demande guère que quand il a déjà pris son parti.

Je remarquerai d'abord que la supposition que votre ouvrage renferme la découverte de la vérité ne vous est pas particulière, elle est commune à tous les philosophes. Sur ce motif, ils publient leurs livres, et la vérité reste à découvrir.

J'ajouterai qu'il ne suffit pas de considérer le bien qu'un livre contient en lui-même, mais qu'on doit aussi peser le mal auquel il peut donner lieu, il faut songer qu'il trouvera moins de lecteurs bien disposés que de mauvais cœurs et de têtes mal faites. Il faut avant de le publier comparer le bien et le mal qu'il peut faire, et les usages avec les abus ; c'est par celui de ces deux effets qui doit l'emporter sur l'autre qu'il est bon ou mauvais à publier.

Si je vous connaissais, Monsieur, si je savais quel est votre sort, votre état, votre âge, j'aurais peut-être aussi quelque chose à vous dire par rapport à vous. On peut courir des hasards tandis qu'on est jeune, mais il n'est pas sensé d'exposer le repos de sa vie après avoir atteint la maturité. J'ai souvent ouï dire à feu M. de Fontenelle que jamais livre n'avait donné tant de plaisir que de chagrins à son auteur ; c'était l'heureux Fontenelle qui disait cela. Jusqu'à quarante ans, je fus sage, à quarante ans, je pris la plume et je la pose avant cinquante, maudissant tous les jours de ma vie celui où mon sot orgueil me la fit prendre et où je vis mon bonheur, mon repos, ma santé s'en aller en fumée sans espoir de les recouvrer jamais. Voilà l'homme à qui vous demandez conseil sur la publication d'un livre. Je vous salue, Monsieur, de tout mon cœur. 


\section{Lettre 71}

\section{À Jacqueline Danel}

À Montmorency, le 22 juillet 1761

$\underline{\text { Retour à la table des matières }}$

Votre lettre, ma chère Jacqueline, est venue réjouir mon cœur dans un moment où je n'étais guère en état d'y répondre. Je saisis un temps de relâche pour vous remercier de votre souvenir, et de votre amitié, qui me sera toujours chère. Pour moi, je n'ai point cessé de penser à vous et de vous aimer. Souvent, je me suis dit dans mes souffrances que si ma bonne Jacqueline n'eût pas tant pris de peine à me conserver étant petit, je n'aurais pas souffert tant de maux étant grand. Soyez persuadée que je ne cesserai jamais de prendre le plus tendre intérêt à votre santé et à votre bonheur, et que ce sera toujours un vrai plaisir pour moi de recevoir de vos nouvelles. Adieu, ma chère et bonne Jacqueline. Je ne vous parle pas de ma santé, pour ne point vous affliger ; que le bon Dieu conserve la vôtre, et vous comble de tous les biens que vous désirez. Votre pauvre Jean-Jacques qui vous embrasse de tout son cœur. 


\section{Lettre 72}

\section{À M. Du Parc \\ [Dom Deschamps]}

À Montmorency, le 12 septembre 1761

Retour à la table des matières

Ce que vous m'apprenez, Monsieur, dans votre dernière lettre me fait trembler sur la publication de votre ouvrage. Si j'avais dix raisons de vous en détourner, j'en ai maintenant dix mille. Je comprends combien vous devez en être tenté, mais vous qui avez une tête si judicieuse ne sauriez disconvenir avec vous-même qu'une telle démarche ne le fut très peu. Je suis presque assuré que vous feriez le malheur de votre vie. Je ne puis trop vous conjurer d'y bien réfléchir. S'il ne s'agissait que de vous procurer les facilités que vous n'avez pas, c'est un petit service que je pourrais rendre à vous et peut-être au public, mais que vous ne devez jamais attendre de moi que vous ne m'ayez prouvé que vous ne risquez rien du tout.

Vos épîtres m'ont fait plaisir, mais c'est trop d'une. Vous ne sauriez dédier à la fois votre livre au public et à votre meilleur ami ; ce serait se moquer de l'un des deux ou plutôt de tous les deux. Le mot des dieux dans celle en vers est bien effarouchant; je ne hais pas cette franchise qui va jusqu'à l'audace. Je l'ai quelquefois impunément parce que je ne tiens à rien et que je mets hardiment tout le monde au pis ; mais vous ne pouvez pas dire la même chose. Cette idée de la protection des hommes me semble un peu romanesque. Un homme que protégerait le genre humain serait fort mal protégé, parce que le 
genre humain n'est rien ; il n'y a que les puissances qui soient quelque chose. Or, vous n'ignorez pas sans doute que sur rien au monde les puissances ne sont ni ne peuvent être de l'avis du public.

J'avais déjà remarqué sur quelques endroits de votre préface et je remarque encore dans votre épître aux hommes, que vos périodes sont quelquefois un peu enchevêtrées. Prenez garde à cela, surtout dans un livre de métaphysique. Je ne connais point de style plus clair que le vôtre ; mais il le deviendra plus encore si vous pouvez couper un peu plus vos périodes et retrancher quelques pronoms.

Je vous aimais sur vos lettres, je vous aime encore plus sur votre portrait, je ne me défie pas même beaucoup de la partialité de l'auteur, précisément à cause qu'il dit de lui sans détour le bien qu'il en pense. Je me souviens que vous m'avez loué d'être modeste; à la bonne heure, mais je vous avoue que j'aimerai toujours beaucoup les gens qui auront le courage de ne l'être pas. Je suis persuadé que vous ressemblez à votre portrait, et j'en suis fort aise. Au reste, je suis persuadé qu'on est toujours très bien peint lorsqu'on s'est peint soi-même, quand même le portrait ne ressemblerait point.

Vous êtes bien bon de me tancer sur mes inexactitudes en fait de raisonnements. En êtes-vous à vous apercevoir que je vois très bien certains objets, mais que je n'en sais point comparer; que je suis assez fertile en propositions sans jamais voir de conséquences ; qu'ordre et méthode qui sont vos dieux sont mes furies ; que jamais rien ne s'offre à moi qu'isolé et qu'au lieu de lier mes idées dans mes écrits j'use d'une charlatanerie de transitions qui vous en impose tous les premiers à tous vous autres grands philosophes. C'est à cause de cela que je me suis mis à vous mépriser, voyant bien que je ne pouvais pas vous atteindre.

C'est, je pense, répondre assez à l'article qui regarde l'impression de nos lettres que de vous écrire celle-ci ; vous devez voir qu'un homme qui écrit de pareilles folies ne les écrit pas pour être imprimées, pas même pour être relues, encore moins copiées. Je veux être libre, incorrect, sans conséquence dans mes lettres comme dans ma conversation; je ne voudrais plus d'un commerce où il faudrait sans cesse être auteur. Cependant, si vous assez de temps et de soins à perdre pour vouloir garder et copier mes lettres, je ne vous gêne point là-dessus, pourvu qu'il ne soit jamais question d'impression. Quant aux vôtres, j'ai toujours été fidèle à les brûler et ne les ai point copiées, et vous devez croire que je n'en userai pas plus négligemment à l'avenir aussi longtemps que vous continuerez à l'exiger, puisque j'en sens mieux la conséquence. Bonjour, Monsieur, je vous embrasse. 


\title{
Lettre 73
}

\author{
À M. Moultou
}

À Montmorency, le 23 décembre 1761

Retour à la table des matières

C'en est fait, cher Moultou, nous ne nous reverrons plus que dans le séjour des justes. Mon sort est décidé par les suites de l'accident dont je vous ai parlé ci-devant ; et quand il en sera temps, je pourrai sans scrupule prendre chez milord Édouard les conseils de la vertu même. Ce qui m'humilie et m'afflige est une fin si peu digne, j'ose dire, de ma vie, et du moins de mes sentiments. Il y a six semaines que je ne fais que des iniquités, et n'imagine que des calomnies contre deux honnêtes libraires, dont l'un n'a de tort que quelques retards involontaires, et l'autre un zèle plein de générosité et de désintéressement, que j'ai payé, pour toute reconnaissance, d'une accusation de fourberie. Je ne sais quel aveuglement, quelle sombre humeur, inspirée dans la solitude par un mal affreux, m'a fait inventer, pour en noircir ma vie et l'honneur d'autrui, ce tissu d'horreurs, dont le soupçon, changé dans mon esprit prévenu presque en certitude, n'a pas mieux été déguisé à d'autres qu'à vous. je sens pourtant que la source de cette folie ne fut jamais dans mon cœur. Le délire de la douleur m'a fait perdre la raison avant la vie : en faisant des actions de méchant, je n'étais qu'un insensé.

Toutefois, dans l'état de dérangement où est ma tête, ne me fiant plus à rien de ce que je vois et de ce que je crois, j'ai pris le parti d'achever la copie du morceau dont je vous ai parlé ci-devant, et même de vous l'envoyer, très persuadé qu'il ne sera jamais nécessaire d'en faire usage, mais plus sûr encore 
que je ne risque rien de le confier à votre probité. C'est avec la plus grande répugnance que je vous extorque les frais immenses que ce paquet vous coûtera par la poste. Mais le temps presse, et, tout bien pesé, j'ai pensé que de tous les risques, celui que je pouvais regarder comme le moindre était celui d'un peu d'argent. Certainement, j'aurais fait mieux si je l'avais pu sans danger. Mais au reste, en supposant, comme je l'espère, qu'il ne sera jamais nécessaire d'ébruiter cette affaire, je vous en demande le secret, et je mets mes dernières fautes à couvert sous l'aile de votre charité. Le paquet sera mis demain, 24 décembre, à la poste, sans lettre, et même il y a quelque apparence que c'est ici la dernière que je vous écrirai. Adieu, cher Moultou : vous concevrez aisément que la profession de foi du Vicaire savoyard est la mienne. Je désire trop qu'il y ait un Dieu pour ne pas le croire, et je meurs avec la ferme confiance que je trouverai dans son sein le bonheur et la paix dont je n'ai pu jouir ici-bas. J'ai toujours aimé tendrement ma patrie et mes concitoyens; j'ose attendre de leur part quelque témoignage de bienveillance pour ma mémoire. Je laisse une gouvernante presque sans récompense, après dix-sept ans de services et de soins très pénibles auprès d'un homme presque toujours souffrant. Il me serait affreux de penser qu'après m'avoir consacré ses plus belles années, elle passerait ses vieux jours dans la misère et l'abandon. J'espère que cela n'arrivera pas : je lui laisse pour protecteurs et pour appuis tous ceux qui m'ont aimé de mon vivant. Toutefois, si cette assistance venait à lui manquer, je crois pouvoir espérer que mes compatriotes ne lui laisseraient pas mendier son pain. Engagez, je vous supplie, ceux d'entre eux en qui vous connaissez l'âme genevoise à ne jamais la perdre de vue, et à se réunir, s'il le fallait, pour lui aider à couler ses jours en paix, à l'abri de la pauvreté.

Voici une lettre pour mon très honoré disciple. Je crois que j'aurais été son maître en amitié ; en tout le reste je me serais glorifié de prendre leçon de lui. Je souhaite fort qu'il accepte la proposition de faire la préface du recueil de mes œuvres, et, en ce cas, vous voudrez bien faire avec M. le maréchal de Luxembourg des arrangements pour lui faire agréer un présent sur l'édition. Au reste si les choses ne tournaient pas comme je l'espère pour une édition en France, je n'ai point à me plaindre de la probité de Rey, et je crois qu'il n'a pas non plus à se plaindre de mes écrits. On pourrait s'adresser à lui.

Adieu derechef. Aimez vos devoirs, cher Moultou ; ne cherchez point les vertus éclatantes. Élevez avec grand soin vos enfants; édifiez vos nouveaux compatriotes sans ostentation et sans dureté, et pensez quelquefois que la mort perd beaucoup de ses horreurs quand on en approche avec un cœur content de sa vie.

Gardez-moi tous deux le secret sur ces lettres, du moins jusqu'après l'événement, dont j'ignore encore le temps, quoique sûrement peu éloigné. Je commence par les amis et les affaires, pour voir ensuite en repos avec JeanJacques si par hasard il n'a rien oublié. 


\section{Lettre 74}

\section{À M. Roustan, ministre du saint Évangile, à Genève}

À Montmorency, le 23 décembre 1761

Retour à la table des matières

Mon disciple bien aimé, quand je reçus votre dernière lettre j'espérais encore vous voir et vous embrasser un jour; mais le Ciel en ordonne autrement, il faut nous quitter avant que de nous connaître. Je crois que nous y perdons tous deux. Vous avez du talent, cher Roustan, quand je finissais ma courte carrière vous commenciez la vôtre, et j'augurais que vous iriez loin. La gêne de votre situation vous a forcé d'accepter un emploi qui vous éloigne de la culture des lettres. Je ne regarde point cet éloignement comme un malheur pour vous. Mon cher Roustan, pesez bien ce que je vais vous dire. J'ai fait quelque essai de la gloire, tous mes écrits ont réussi, pas un homme de lettres vivant, sans en excepter Voltaire, n'a eu des moments plus brillants que les miens ; et cependant je vous proteste que depuis le moment que j'ai commencé de faire imprimer, ma vie n'a été que peine, angoisse et douleur de toute espèce ; je n'ai vécu tranquille, heureux et n'ai eu de vrais amis que durant mon obscurité. Depuis lors il a fallu vivre de fumée, et tout ce qui pouvait plaire à mon cœur a fui sans retour. Mon enfant, fais-toi petit, disait à son fils cet ancien politique, et moi, je dis à mon disciple Roustan : mon enfant, reste obscur, profite du triste exemple de ton maître. Gardez cette lettre, Roustan, je vous en conjure. Si vous en dédaignez les conseils, vous pourrez réussir sans 
doute ; car encore une fois vous avez du talent quoique encore mal réglé par la fougue de la jeunesse ; mais si jamais vous avez un nom, relisez ma lettre, et je vous promets que vous ne l'achèverez pas sans pleurer. Votre famille, votre fortune étroite, un émule, tout vous tentera ; résistez, et sachez que quoi qu'il arrive l'indigence est moins dure, moins cruelle à supporter que la réputation littéraire.

Toutefois voulez-vous faire un essai, l'occasion est belle, le titre dont vous m'honorez vous la fournit, et tout le monde approuvera qu'un tel disciple fasse une préface à la tête du recueil des écrits de son maître ; faites donc cette préface, faites-la même avec soin, concertez-vous là-dessus avec Moultou ; mais gardez-vous d'aller faire le fade louangeur: vous feriez plus de tort à votre réputation que de bien à la mienne. Louez-moi d'une seule chose, mais louez-m'en de votre mieux, parce qu'elle est louable et belle, c'est d'avoir eu quelque talent et de ne m'être point pressé de le montrer, d'avoir passé sans écrire tout le feu de la jeunesse, d'avoir pris la plume à quarante ans et de l'avoir quittée avant cinquante ; car vous savez que telle était ma résolution, et le Traité de l'Éducation devait être mon dernier ouvrage, quand j'aurais encore vécu cinquante ans. Ce n'est pas qu'il n'y ait chez Rey un traité du Contrat social duquel je n'ai encore parlé à personne et qui ne paraîtra peut-être qu'après l'éducation, mais il lui est antérieur d'un grand nombre d'années. Faites donc cette préface, et puis des sermons, et jamais rien de plus. Au surplus, soyez bon père, bon mari, bon régent, bon ministre, bon citoyen, homme simple en toute chose, et rien de plus, et je vous promets une vie heureuse. Adieu Roustan, tel est le conseil de votre maître et ami prêt à quitter la vie, en ce moment où ceux mêmes qui n'ont pas aimé la vérité la disent. Adieu. 


\section{Lettre 75}

\section{À M. [de Malesherbes]}

À Montmorency, le 23 décembre 1761

Retour à la table des matières

Il fut un temps, Monsieur, où vous m'honorâtes de votre estime et où je ne m'en sentais pas indigne ; ce temps est passé, je le reconnais enfin, et quoique votre patience et vos bontés envers moi soient inépuisables, je ne puis plus les attribuer à la même cause sans le plus ridicule aveuglement. Depuis plus de six semaines, ma conduite et mes lettres ne sont qu'un tissu d'iniquités, de folies, d'impertinences. Je vous ai compromis, Monsieur, j'ai compromis Mme la Maréchale de la manière du monde la plus punissable. Vous avez tout enduré, tout fait pour calmer mon délire, et cet excès d'indulgence qui pouvait le prolonger est en effet ce qui l'a détruit. J'ouvre en frémissant les yeux sur moi et je me vois tout aussi méprisable que je le suis devenu. Devenu ?

Non. L'homme qui porta cinquante ans le cœur que je sens renaître en moi n'est point celui qui put s'oublier au point que je viens de faire. On ne demande point pardon à mon âge parce qu'on n'en mérite plus. Mais, Monsieur, je ne prends aucun intérêt à celui qui vient d'usurper et de déshonorer mon nom. Je l'abandonne à votre juste indignation ; mais il est mort pour ne plus renaître. Daignez rendre votre estime à celui qui vous écrit maintenant; il ne saurait s'en passer et ne méritera jamais de la perdre. Il en a pour garant non sa raison, mais son état qui le met désormais à l'abri des grandes passions. 


\section{Lettre 76}

\section{À M. [de Malesherbes]}

À Montmorency, le 4 janvier 1762

$\underline{\text { Retour à la table des matières }}$

J'aurais moins tardé, Monsieur, à vous remercier de la dernière lettre dont vous m'avez honoré, si j'avais mesuré ma diligence à répondre sur le plaisir qu'elle m'a fait. Mais, outre qu'il m'en coûte beaucoup d'écrire, j'ai pensé qu'il fallait donner quelques jours aux importunités de ces temps-ci pour ne vous pas accabler des miennes. Quoique je ne me console point de ce qui vient de se passer, je suis très content que vous en soyez instruit, puisque cela ne m'a point ôté votre estime ; elle en sera plus à moi quand vous ne me croirez pas meilleur que je ne suis.

Les motifs auxquels vous attribuez les partis qu'on m'a vu prendre, depuis que je porte une espèce de nom dans le monde, me font peut-être plus d'honneur que je n'en mérite ; mais ils sont certainement plus près de la vérité que ceux que me prêtent ces hommes de lettres, qui, donnant tout à la réputation, jugent de mes sentiments par les leurs.

J'ai un cœur trop sensible à d'autres attachements pour l'être si fort à l'opinion publique ; j'aime trop mon plaisir et mon indépendance, pour être esclave de la vanité au point qu'ils le supposent : celui pour qui la fortune et l'espoir de parvenir ne balança jamais un rendez-vous, un souper agréable ne doit pas naturellement sacrifier son bonheur au désir de faire parler de lui. Il n'est point du tout croyable qu'un homme qui se sent quelques talents, et qui 
tarde jusqu'à quarante ans à se faire connaître, soit assez sot pour aller s'ennuyer le reste de ses jours dans un désert, uniquement pour acquérir la réputation d'un misanthrope. Mais, Monsieur, quoique je haïsse souverainement l'injustice et la méchanceté, cette passion n'est pas assez dominante pour me déterminer seule à fuir la société des hommes, si j'avais en les quittant quelque grand sacrifice à faire; non, mon motif est moins noble et plus près de moi. Je suis né avec un amour naturel pour la solitude, qui n'a fait qu'augmenter à mesure que j'ai mieux connu les hommes. Je trouve mieux mon compte avec les êtres chimériques que je rassemble autour de moi, qu'avec ceux que je vois dans le monde ; et la société, dont mon imagination fait les frais dans ma retraite, achève de me dégoûter de toutes celles que j'ai quittées. Vous me supposez malheureux et consumé de mélancolie. Oh! Monsieur, combien vous vous trompez ! C'est à Paris que je l'étais ; c'est à Paris qu'une bile noire rongeait mon cœur ; et l'amertume de cette bile ne se fait que trop sentir dans tous les écrits que j'ai publiés tant que j'y suis resté. Mais, Monsieur, comparez ces écrits avec ceux que j'ai faits dans ma solitude : ou je suis trompé, ou vous sentirez dans ces derniers une certaine sérénité d'âme qui ne se joue point et sur laquelle on peut porter un jugement certain de l'état intérieur de l'auteur. L'extrême agitation que je viens d'éprouver vous a pu faire porter un jugement contraire ; mais il est facile à voir que cette agitation n'a point son principe dans ma situation actuelle, mais dans une imagination déréglée, prête à s'effaroucher sur tout et à porter tout à l'extrême. Des succès continus m'ont rendu sensible à la gloire, et il n'y a point d'homme, ayant quelque hauteur d'âme et quelque vertu, qui pût penser, sans le plus mortel désespoir, qu'après sa mort on substituerait sous son nom à un ouvrage utile, un ouvrage pernicieux, capable de déshonorer sa mémoire et de faire beaucoup de mal. Il se peut qu'un tel bouleversement ait accéléré le progrès de mes maux, mais dans la supposition qu'un tel accès de folie m'eût pris à Paris, il n'est point sûr que ma propre volonté n'eût pas épargné le reste de l'ouvrage à la Nature.

Longtemps, je me suis abusé moi-même sur la cause de cet invincible dégoût que j'ai toujours éprouvé dans le commerce des hommes ; je l'attribuais au chagrin de n'avoir pas l'esprit assez présent pour montrer dans la conversation le peu que j'en ai, et, par contre-coup, à celui de ne pas occuper dans le monde la place que j'y croyais mériter. Mais, quand, après avoir barbouillé du papier, j'étais bien sûr, même en disant des sottises, de n'être pas pris pour un sot, quand je me suis vu recherché de tout le monde, et honoré de beaucoup plus de considération que ma ridicule vanité n'en eût osé prétendre, et que malgré cela j'ai senti ce même dégoût plus augmenté que diminué, j'ai conclu qu'il venait d'une autre cause et que ces espèces de jouissances n'étaient point celles qu'il me fallait.

Quelle est donc enfin cette cause ? Elle n'est autre que cet indomptable esprit de liberté que rien n'a pu vaincre, et devant lequel les honneurs, la fortune et la réputation même ne me sont rien. Il est certain que cet esprit de liberté me vient moins d'orgueil que de paresse. Mais cette paresse est incroyable ; tout l'effarouche; les moindres devoirs de la vie civile lui sont insupportables : un mot à dire, une lettre à écrire, une visite à faire, dès qu'il le faut, sont pour moi des supplices. Voilà pourquoi, quoique le commerce ordinaire des hommes me soit odieux, l'intime amitié m'est si chère, parce qu'il n'y a plus de devoir pour elle : on suit son cœur et tout est fait. Voilà 
encore pourquoi j'ai toujours tant redouté les bienfaits, car tout bienfait exige reconnaissance ; et je me sens le cœur ingrat, par cela seul que la reconnaissance est un devoir. En un mot, l'espèce de bonheur qu'il me faut, n'est pas tant de faire ce que je veux, que de ne pas faire ce que je ne veux pas. La vie active n'a rien qui me tente; je consentirais cent fois plutôt à ne jamais rien faire, qu'à faire quelque chose malgré moi, et j'ai cent fois pensé que je n'aurais pas vécu trop malheureux à la Bastille, n'y étant tenu à rien du tout qu'à rester là.

J'ai cependant fait dans ma jeunesse quelques efforts pour parvenir ; mais ces efforts n'ont jamais eu pour but que la retraite et le repos dans ma vieillesse ; et comme ils n'ont été que par secousses, comme ceux d'un paresseux, ils n'ont jamais eu le moindre succès. Quand les maux sont venus, ils m'ont servi d'un beau prétexte pour me livrer à ma passion dominante. Trouvant que c'était une folie de me tourmenter pour un âge auquel je ne parviendrais pas, j'ai tout planté là et je me suis dépêché de jouir. Voilà, Monsieur, je vous le jure, la véritable cause de cette retraite, à laquelle nos gens de lettres ont été chercher des motifs d'ostentation, qui supposent une constance, ou plutôt une obstination à tenir à ce qui me coûte, directement contraire à mon caractère naturel.

Vous me direz, Monsieur, que cette indolence supposée s'accorde mal avec les écrits que j'ai composés depuis dix ans, et avec ce désir de gloire qui a dû m'exciter à les publier. Voilà une objection à résoudre, qui m'oblige à prolonger ma lettre, et qui, par conséquent, me force à la finir. J'y reviendra, Monsieur, si mon ton familier ne vous déplaît pas. C'est dans l'épanchement de mon cœur que je vous écris, et je n'en saurais prendre un autre. Je me peindrai sans fard et sans modestie ; je me montrerai à vous tel que je me vois et tel que je suis ; car, passant ma vie avec moi, je dois me connaître, et je vois, par la manière dont ceux qui pensent me connaître interprètent mes actions et ma conduite, qu'ils n'y connaissent rien ; personne au monde ne me connaît que moi seul : vous en jugerez quand j'aurai tout dit.

Ne me renvoyez point mes lettres, Monsieur, je vous supplie. Brûlez-les, parce qu'elles ne valent pas la peine d'être gardées ; mais non pas par égard pour moi ; ne songez pas non plus, de grâce, à retirer celles qui sont entre les mains de Duchesne. S'il fallait effacer dans le monde les traces de toutes mes folies, il y aurait trop de lettres à retirer, et je ne remuerais pas le bout du doigt pour cela. À charge et à décharge, je ne crains point d'être vu tel que je suis : je connais mes grands défauts, et je sens vivement tous mes vices ; avec tout cela, je mourrai plein d'espoir dans le Dieu suprême, et très persuadé que, de tous les hommes que j'ai connus en ma vie, aucun ne fut meilleur que moi. 


\section{Lettre 77}

\section{À M. de Malesherbes}

À Montmorency, le 12 janvier 1762

$\underline{\text { Retour à la table des matières }}$

Je continue, Monsieur, à vous rendre compte de moi, puisque j'ai commencé, car ce qui peut m'être le plus défavorable est d'être connu à demi, et puisque mes fautes ne m'ont point ôté votre estime, je ne présume pas que ma franchise me la doive ôter.

Une âme paresseuse qui s'effraie de tout soin, un tempérament ardent, bilieux, facile à s'affecter et sensible à l'excès à tout ce qui l'affecte, semblent ne pouvoir s'allier dans le même caractère, et ces deux contraires composent pourtant le fond du mien. Quoique je ne puisse résoudre cette opposition par des principes, elle existe pourtant : je la sens, rien n'est plus certain, et j'en puis du moins donner par les faits une espèce d'historique qui peut servir à la concevoir. J'ai eu plus d'activité dans l'enfance, mais jamais comme un autre enfant : cet ennui de tout m'a de bonne heure jeté dans la lecture. À six ans, Plutarque me tomba sous la main ; à huit, je le savais par cœur, j'avais lu tous les romans ; ils m'avaient fait verser des seaux de larmes, avant l'âge où le cœur prend intérêt aux romans. De là se forma dans le mien ce goût héroïque et romanesque qui n'a fait qu'augmenter jusqu'à présent, et qui acheva de me dégoûter de tout, hors de ce qui ressemblait à mes folies. Dans ma jeunesse, je croyais trouver dans le monde les mêmes gens que j'avais connus dans mes 
livres, je me livrais sans réserve à quiconque savait m'en imposer par un certain jargon dont j'ai toujours été la dupe. J'étais actif, parce que j'étais fou ; à mesure que j'étais détrompé, je changeais de goûts, d'attachements, de projets, et dans tous ces changements, je perdais toujours ma peine et mon temps, parce que je cherchais toujours ce qui n'était point. En devenant plus expérimenté, j'ai perdu peu à peu l'espoir de le trouver, et par conséquent, le zèle de le chercher. Aigri par les injustices que j'avais éprouvées, par celles dont j'avais été le témoin, souvent affligé du désordre où l'exemple et la force des choses m'avaient entraîné moi-même, j'ai pris en mépris mon siècle et mes contemporains; et sentant que le ne trouverais point au milieu d'eux une situation qui pût contenter mon cœur, je l'ai peu à peu détaché de la société des hommes, et je m'en suis fait une autre dans mon imagination, laquelle m'a d'autant plus charmé que je la pouvais cultiver sans peine, sans risque, et la trouver toujours sûre et telle qu'il me la fallait.

Après avoir passé quarante ans de ma vie ainsi mécontent de moi-même et des autres, je cherchais inutilement à rompre les liens qui me tenaient attaché à cette société que j'estimais si peu, et qui m'enchaînaient aux occupations le moins de mon goût, par des besoins que j'estimais ceux de la nature et qui n'étaient que ceux de l'opinion. Tout à coup, un heureux hasard vint m'éclairer sur ce que j'avais à faire pour moi-même, et à penser de mes semblables, sur lesquels mon cœur était sans cesse en contradiction avec mon esprit, et que je me sentais encore porté à aimer, avec tant de raisons de les haïr. Je voudrais, Monsieur, vous pouvoir peindre ce moment, qui a fait dans ma vie une si singulière époque et qui me sera toujours présent, quand je vivrais éternellement.

J'allais voir Diderot, alors prisonnier à Vincennes ; j'avais dans ma poche un Mercure de France, que je me mis à feuilleter le long du chemin. Je tombe sur la question de l'Académie de Dijon qui a donné lieu à mon premier écrit. Si jamais quelque chose a ressemblé à une inspiration subite, c'est le mouvement qui se fit en moi à cette lecture : tout à coup, je me sens l'esprit ébloui de mille lumières, des foules d'idées vives s'y présentèrent à la fois avec une force et une confusion qui me jeta dans un trouble inexprimable ; je sens ma tête prise par un étourdissement semblable à l'ivresse. Une violente palpitation m'oppresse, soulève ma poitrine ; ne pouvant plus respirer en marchant, je me laisse tomber sous un des arbres de l'avenue, et j'y passe une demi-heure dans une telle agitation qu'en me relevant, j'aperçus tout le devant de ma veste mouillé de mes larmes, sans avoir senti que j'en répandais. Oh ! Monsieur, si j'avais jamais pu écrire le quart de ce que j'ai vu et senti sous cet arbre, avec quelle clarté j'aurais fait voir toutes les contradictions du système social, avec quelle force j'aurais exposé tous les abus de nos institutions, avec quelle simplicité j'aurais démontré que l'homme est bon naturellement, et que c'est par ces institutions seules que les hommes deviennent méchants. Tout ce que j'ai pu retenir de ces foules de grandes vérités, qui, dans un quart d'heure, m'illuminèrent sous cet arbre, a été bien faiblement épars dans les trois principaux de mes écrits, savoir ce premier discours, celui sur l'inégalité, et le traité de l'éducation, lesquels trois ouvrages sont inséparables et forment ensemble un même tout. Tout le reste a été perdu, et il n'y eut d'écrit sur le lieu même que la prosopopée de Fabricius. Voilà comment, lorsque j'y pensais le moins, je devins auteur presque malgré moi. Il est aisé de concevoir comment l'attrait d'un premier succès et les critiques des barbouilleurs me jetèrent tout 
de bon dans la carrière. Avais-je quelque vrai talent pour écrire ? je ne sais. Une vive persuasion m'a toujours tenu lieu d'éloquence, et j'ai toujours écrit lâchement et mal quand je n'ai pas été fortement persuadé. Ainsi c'est peutêtre un retour caché d'amour-propre qui m'a fait choisir et mériter ma devise, et m'a si passionnément attaché à la vérité, ou à tout ce que j'ai pris pour elle. $\mathrm{Si}$ je n'avais écrit que pour écrire, je suis convaincu qu'on ne m'aurait jamais lu.

Après avoir découvert ou cru découvrir dans les fausses opinions des hommes la source de leurs misères et de leur méchanceté, je sentis qu'il n'y avait que ces mêmes opinions qui m'eussent rendu malheureux moi-même, et que mes maux et mes vices me venaient bien plus de ma situation que de moimême. Dans le même temps, une maladie, dont j'avais dès l'enfance senti les premières atteintes, s'étant déclarée absolument incurable, malgré toutes les promesses des faux guérisseurs, dont je n'ai pas été longtemps la dupe, je jugeai que, si je voulais être conséquent et secouer une fois de dessus mes épaules le pesant joug de l'opinion, je n'avais pas un moment à perdre. Je pris brusquement mon parti avec assez de courage, et je l'ai assez bien soutenu jusqu'ici, avec une fermeté dont moi seul peux sentir le prix, parce qu'il n'y a que moi seul qui sache quels obstacles j'ai eus, et j'ai encore tous les jours à combattre pour me maintenir sans cesse contre le courant. Je sens pourtant bien que depuis dix ans, j'ai un peu dérivé, mais si j'estimais seulement en avoir encore quatre à vivre, on me verrait donner une deuxième secousse et remonter tout au moins à mon premier niveau, pour n'en plus guère redescendre; car toutes les grandes épreuves sont faites, et il est désormais démontré pour moi, par l'expérience, que l'état où je me suis mis est le seul où l'homme puisse vivre bon et heureux, puisqu'il est le plus indépendant de tous, et le seul où on ne se trouve jamais pour son propre avantage dans la nécessité de nuire à autrui.

J'avoue que le nom que m'ont fait mes écrits a beaucoup facilité l'exécution du parti que j'ai pris. Il faut être cru bon auteur pour se faire impunément mauvais copiste et ne pas manquer de travail pour cela. Sans ce premier titre, on m'eût pu trop prendre au mot sur l'autre, et peut-être cela m'aurait-il mortifié, car je brave aisément le ridicule, mais je ne supporterais pas si bien le mépris. Mais si quelque réputation me donne à cet égard un peu d'avantage, il est bien compensé par tous les inconvénients attachés à cette même réputation, quand on n'en veut point être esclave, et qu'on veut vivre isolé et indépendant. Ce sont ces inconvénients en partie qui m'ont chassé de Paris, et qui, me poursuivant encore dans mon asile, me chasseraient très certainement plus loin, pour peu que ma santé vînt à se raffermir. Un autre de mes fléaux dans cette grande ville était ces foules de prétendus amis qui s'étaient emparés de moi, et qui, jugeant de mon cœur par les leurs, voulaient absolument me rendre heureux à leur mode, et non pas à la mienne. Au désespoir de ma retraite, ils m'y ont poursuivi pour m'en tirer : je n'ai pu m'y maintenir sans tout rompre ; je ne suis vraiment libre que depuis ce temps-là.

Libre ! non, je ne le suis point encore ; mes derniers écrits ne sont point encore imprimés, et, vu le déplorable état de ma pauvre machine, je n'espère plus survivre à l'impression du recueil de tous : mais si, contre mon attente, je puis aller jusque là et prendre une fois congé du public, croyez, Monsieur, 
qu'alors je serai libre, ou que jamais homme ne l'aura été. O utinam ! O jour trois fois heureux ! Non, il ne me sera pas donné de le voir.

Je n'ai pas tout dit, Monsieur, et vous aurez peut-être encore au moins une lettre à essuyer. Heureusement rien ne vous oblige de les lire, et peut-être y seriez-vous bien embarrassé. Mais pardonnez, de grâce ; pour recopier ces longs fatras, il faudrait les refaire, et en vérité, je n'en ai pas le courage. J'ai sûrement bien du plaisir à vous écrire, mais je n'en ai pas moins à me reposer, et mon état ne me permet pas d'écrire longtemps de suite. 


\section{Lettre 78}

\section{À M. de Malesherbes}

À Montmorency, le 26 janvier 1762

$\underline{\text { Retour à la table des matières }}$

Après vous avoir exposé, Monsieur, les vrais motifs de ma conduite, je voudrais vous parler de mon état moral dans ma retraite. Mais je sens qu'il est bien tard : mon âme aliénée d'elle-même est toute à mon corps ; le délabrement de ma pauvre machine l'y tient de jour en jour plus attachée, et jusqu'à ce qu'elle s'en sépare enfin tout à coup. C'est de mon bonheur que je voudrais vous parler, et l'on parle mal du bonheur quand on souffre.

Mes maux sont l'ouvrage de la nature, mais mon bonheur est le mien. Quoi qu'on en puisse dire, j'ai été sage, puisque j'ai été heureux autant que ma nature m'a permis de l'être : je n'ai point été chercher ma félicité au loin, je l'ai cherchée auprès de moi et l'y ai trouvée. Spartien dit que Similis, courtisan de Trajan, ayant sans aucun mécontentement personnel quitté la Cour et tous ses emplois pour aller vivre paisiblement à la campagne, fit mettre ces mots sur sa tombe : J'ai demeuré soixante et seize ans sur la terre et j'en ai vécu sept. Voilà ce que je puis dire à quelque égard, quoique mon sacrifice ait été moindre : je n'ai commencé de vivre que le 9 avril 1756.

Je ne saurais vous dire, Monsieur, combien j'ai été touché de voir que vous m'estimiez le plus malheureux des hommes. Le public sans doute en jugera comme vous, et c'est encore ce qui m'afflige. O, que le sort dont j'ai joui n'estil connu de tout l'univers ! Chacun voudrait s'en faire un semblable ; la paix 
régnerait sur la terre, les hommes ne songeraient plus à se nuire, et il n'y aurait plus de méchants quand nul n'aurait intérêt à l'être. Mais de quoi jouissais-je enfin quand j'étais seul ? De moi, de l'univers entier, de tout ce qui est, de tout ce qui peut être, de tout ce qu'a de beau le monde sensible, et d'imaginable le monde intellectuel : je rassemblais autour de moi tout ce qui pouvait flatter mon cœur ; mes désirs étaient la mesure de mes plaisirs. Non, jamais les plus voluptueux n'ont connu de pareilles délices, et j'ai cent fois plus joui de mes chimères qu'ils ne font des réalités.

Quand mes douleurs me font tristement mesurer la longueur des nuits, et que l'agitation de la fièvre m'empêche de goûter un seul instant de sommeil, souvent je me distrais de mon état présent, en songeant aux divers événements de ma vie, et les repentirs, les doux souvenirs, les regrets, l'attendrissement, se partagent le soin de me faire oublier quelques moments mes souffrances. Quels temps croiriez-vous, Monsieur, que je me rappelle le plus souvent et le plus volontiers dans mes rêves ? Ce ne sont point les plaisirs de ma jeunesse : ils furent trop rares, trop mêlés d'amertumes, et sont déjà trop loin de moi. Ce sont ceux de ma retraite, ce sont mes promenades solitaires, ce sont ces jours rapides, mais délicieux, que j'ai passés tout entiers avec moi seul, avec ma bonne et simple gouvernante, avec mon chien bien-aimé, ma vieille chatte, avec les oiseaux de la campagne et les biches de la forêt, avec la nature entière et son inconcevable auteur. En me levant avant le soleil pour aller voir, contempler son lever dans mon jardin, quand je voyais commencer une belle journée, mon premier souhait était que ni lettres ni visites n'en vinssent troubler le charme. Après avoir donné la matinée à divers soins, que je remplissais tous avec plaisir parce que je pouvais les remettre à un autre temps, je me hâtais de dîner pour échapper aux importuns et me ménager un plus long après-midi. Avant une heure, même les jours les plus ardents, je partais par le grand soleil avec le fidèle Achate, pressant le pas dans la crainte que quelqu'un ne vînt s'emparer de moi avant que j'eusse pu m'esquiver ; mais quand une fois j'avais pu doubler un certain coin, avec quel battement de cœur, avec quel pétillement de joie, je commençais à respirer, en me sentant sauvé, en me disant : Me voilà maître de moi pour le reste de ce jour ! J'allais alors d'un pas plus tranquille chercher quelque lieu sauvage dans la forêt, quelque lieu désert où rien ne montrant la main des hommes n'annonçât la servitude et la domination, quelque asile où je pusse croire avoir pénétré le premier, et où nul tiers importun ne vînt s'interposer entre la nature et moi. C'était là qu'elle semblait déployer à mes yeux une magnificence toujours nouvelle. L'or des genêts et la pourpre des bruyères frappaient mes yeux d'un luxe qui touchait mon cœur; la majesté des arbres qui me couvraient de leur ombre, la délicatesse des arbustes qui m'environnaient, l'étonnante variété des herbes et des fleurs que je foulais sous mes pieds tenaient mon esprit dans une alternative continuelle d'observation et d'admiration : le concours de tant d'objets intéressants qui se disputaient mon attention, m'attirant sans cesse de l'un à l'autre, favorisait mon humeur rêveuse et paresseuse, et me faisait souvent redire en moi-même : Non, Salomon dans toute sa gloire ne fut jamais vêtu comme l'un d'eux.

Mon imagination ne laissait pas longtemps déserte la terre ainsi parée. Je la peuplais bientôt d'êtres selon mon cœur, et, chassant bien loin l'opinion, les préjugés, toutes les passions factices, je transportais dans les asiles de la nature des hommes dignes de les habiter. Je m'en formais une société 
charmante, dont je ne me sentais pas indigne ; je me faisais un siècle d'or à ma fantaisie, et remplissant ces beaux jours de toutes les scènes de ma vie qui m'avaient laissé de doux souvenirs, et de toutes celles que mon cœur pouvait désirer encore, je m'attendrissais jusqu'aux larmes sur les vrais plaisirs de l'humanité, plaisirs si délicieux, si purs, et qui sont désormais si loin des hommes. Oh ! si dans ces moments quelque idée de Paris, de mon siècle et de ma petite gloriole d'auteur venait troubler mes rêveries, avec quel dédain je la chassais à l'instant pour me livrer, sans distraction, aux sentiments exquis dont mon âme était pleine ! Cependant au milieu de tout cela, je l'avoue, le néant de mes chimères venait quelquefois la contrister tout à coup. Quand tous mes rêves se seraient tournés en réalités, ils ne m'auraient pas suffi : j'aurais imaginé, rêvé, désiré encore. Je trouvais en moi un vide inexplicable, que rien n'aurait pu remplir, un certain élancement de cœur vers une autre sorte de jouissance, dont je n'avais pas d'idée et dont pourtant je sentais le besoin. Hé bien ! Monsieur, cela même était jouissance, puisque j'en étais pénétré d'un sentiment très vif et d'une tristesse attirante que je n'aurais pas voulu ne pas avoir.

Bientôt de la surface de la terre, j'élevais mes idées à tous les êtres de la nature, au système universel des choses, à l'Être incompréhensible qui embrasse tout. Alors, l'esprit perdu dans cette immensité, je ne pensais pas, je ne raisonnais pas, je ne philosophais pas : je me sentais, avec une sorte de volupté, accablé du poids de cet univers, je me livrais avec ravissement à la confusion de ces grandes idées, j'aimais à me perdre en imagination dans l'espace ; mon cœur resserré dans les bornes des êtres s'y trouvait trop à l'étroit, j'étouffais dans l'univers, j'aurais voulu m'élancer dans l'infini. Je crois que, si j'eusse dévoilé tous les mystères de la nature, je me serais senti dans une situation moins délicieuse que cette étourdissante extase, à laquelle mon esprit se livrait sans retenue, et qui, dans l'agitation de mes transports, me faisait écrier quelquefois : O grand Être ! ô grand Être ! sans pouvoir dire ni penser rien de plus.

Ainsi s'écoulaient dans un délire continuel les journées les plus charmantes que jamais créature humaine ait passées ; et quand le coucher du soleil me faisait songer à la retraite, étonné de la rapidité du temps, je croyais n'avoir pas assez mis à profit ma journée, je pensais en pouvoir jouir davantage encore, et, pour réparer le temps perdu, je me disais : Je reviendrai demain.

Je revenais à petits pas, la tête un peu fatiguée, mais le cœur content; je me reposais agréablement au retour, en me livrant à l'impression des objets, mais sans penser, sans imaginer, sans rien faire autre chose que sentir le calme et le bonheur de ma situation. Je trouvais mon couvert mis sur ma terrasse. je soupais de grand appétit dans mon petit domestique ; nulle image de servitude et de dépendance ne troublait la bienveillance qui nous unissait tous. Mon chien lui-même était mon ami, non mon esclave : nous avions toujours la même volonté, mais jamais il ne m'a obéi. Ma gaieté durant toute la soirée témoignait que j'avais vécu seul tout le jour ; j'étais bien différent quand j'avais vu de la compagnie, j'étais rarement content des autres et jamais de moi. Le soir, j'étais grondeur et taciturne : cette remarque est de ma gouvernante, et, depuis qu'elle me l'a dite, je l'ai toujours trouvée juste en m'observant. Enfin, après avoir fait encore quelques tours dans mon jardin, ou 
chanté quelque air sur mon épinette, je trouvais dans mon lit un repos de corps et d'âme cent fois plus doux que le sommeil même.

Ce sont là les jours qui ont fait le vrai bonheur de ma vie, bonheur sans amertume, sans ennuis, sans regrets et, auquel j'aurais borné volontiers tout celui de mon existence. Oui, Monsieur, que de pareils jours remplissent pour moi l'éternité, je n'en demande point d'autres et n'imagine pas que je sois beaucoup moins heureux dans ces ravissantes contemplations que les intelligences célestes. Mais un corps qui souffre ôte à l'esprit sa liberté ; désormais, je ne suis plus seul, j'ai un hôte qui m'importune, il faut m'en délivrer pour être à moi, et l'essai que j'ai fait de ces douces jouissances ne sert plus qu'à me faire attendre avec moins d'effroi le moment de les goûter sans distraction.

Mais me voici déjà à la fin de ma seconde feuille. Il m'en faudrait pourtant encore une. Encore une lettre, donc, et puis plus. Pardon, Monsieur ; quoique j'aime trop à parler de moi, je n'aime pas à en 


\section{Lettre 79}

\section{À M. [de Malesherbes]}

À Montmorency, le 28 janvier 1762

\section{Retour à la table des matières}

Je vous ai montré, Monsieur, dans le secret de mon cœur, les vrais motifs de ma retraite et de toute ma conduite, motifs bien moins nobles sans doute que vous ne les avez supposés, mais tels pourtant qu'ils me rendent content de moi-même, et m'inspirent la fierté d'âme d'un homme qui se sent bien ordonné, et qui, ayant eu le courage de faire ce qu'il fallait pour l'être, croit pouvoir s'en imputer le mérite. Il dépendait de moi non de me faire un autre tempérament, ni un autre caractère, mais de tirer parti du mien, pour me rendre bon à moi-même, et nullement méchant aux autres. C'est beaucoup que cela, Monsieur, et peu d'hommes en peuvent dire autant. Aussi je ne vous déguiserai point que, malgré le sentiment de mes vices, j'ai pour moi une haute estime.

Vos gens de lettres ont beau crier qu'un homme seul est inutile à tout le monde et ne remplit pas ses devoirs dans la société. J'estime, moi, les paysans de Montmorency des membres plus utiles à la société que tous ces tas de désœuvrés payés de la graisse du peuple pour aller la semaine bavarder dans une académie ; et je suis plus content de pouvoir, dans l'occasion, faire quelque plaisir à mes pauvres voisins que d'aider à parvenir à ces foules de petits intrigants dont Paris est plein, qui tous aspirent à l'honneur d'être des fripons en place, et que, pour le bien public, ainsi que pour le leur, on devrait 
tous renvoyer labourer la terre dans leurs provinces. C'est quelque chose que de donner l'exemple aux hommes de la vie qu'ils devraient tous mener. C'est quelque chose, quand on n'a plus ni force ni santé pour travailler de ses bras, d'oser, de sa retraite, faire entendre la voix de la vérité. C'est quelque chose d'avertir les hommes de la folie des opinions qui les rendent misérables. C'est quelque chose d'avoir pu contribuer à empêcher ou différer au moins, dans ma patrie, l'établissement pernicieux que, pour faire sa cour à Voltaire, à nos dépens, d'Alembert voulait qu'on fît parmi nous. Si j'eusse vécu dans Genève, je n'aurais pu ni publier l'épître dédicatoire du Discours sur l'Inégalité ni parler même contre l'établissement de la comédie, du ton que je l'ai fait. Je serais beaucoup plus inutile à mes compatriotes, vivant au milieu d'eux, que je ne puis l'être, dans l'occasion, de ma retraite. Qu'importe en quel lieu j'habite, si j'agis où je dois agir ? D'ailleurs les habitants de Montmorency sont-ils moins hommes que les Parisiens, et quand je puis en dissuader quelqu'un d'envoyer son enfant se corrompre à la ville, fais-je moins de bien que si je pouvais de la ville le renvoyer au foyer paternel ? Mon indigence seule ne m'empêcherait-elle pas d'être inutile de la manière que tous ces beaux parleurs l'entendent, et puisque je ne mange du pain qu'autant que j'en gagne, ne suis-je pas forcé de travailler pour ma subsistance, et de payer à la société tout le besoin que je puis avoir d'elle? Il est vrai que je me suis refusé aux occupations qui ne m'étaient pas propres ; ne me sentant point le talent qui pouvait me faire mériter le bien que vous m'avez voulu faire, l'accepter eût été le voler à quelque homme de lettres aussi indigent que moi et plus capable de ce travail-là ; en me l'offrant, vous supposiez que j'étais en état de faire un extrait, que je pouvais m'occuper de matières qui m'étaient indifférentes ; et cela n'étant pas, je vous aurais trompé ; je me serais rendu indigne de vos bontés en me conduisant autrement que je n'ai fait ; on n'est jamais excusable de faire mal ce qu'on fait volontairement ; je serais maintenant mécontent de moi, et vous aussi, et je ne goûterais pas le plaisir que je prends à vous écrire. Enfin, tant que mes forces me l'ont permis, en travaillant pour moi, j'ai fait, selon ma portée, tout ce que j'ai pu pour la société ; si j'ai peu fait pour elle, j'en ai encore moins exigé, et je me crois si bien quitte avec elle dans l'état où je suis que, si je pouvais désormais me reposer tout à fait et vivre pour moi seul, je le ferais sans scrupule. J'écarterai du moins de moi, de toutes mes forces, l'importunité du bruit public. Quand je vivrais encore cent ans, je n'écrirais pas une ligne pour la presse, et ne croirais vraiment recommencer à vivre que quand je serais tout à fait oublié.

J'avoue pourtant qu'il a tenu à peu que je ne me sois trouvé rengagé dans le monde et que je n'aie abandonné ma solitude, non par dégoût pour elle, mais par un goût non moins vif que j'ai failli lui préférer. Il faudrait, Monsieur, que vous connussiez l'état de délaissement et d'abandon de tous mes amis où je me trouvais, et la profonde douleur dont mon âme en était affectée, lorsque M. et Mme de Luxembourg désirèrent de me connaître, pour juger de l'impression que firent sur mon cœur affligé leurs avances et leurs caresses. J'étais mourant : sans eux, je serais infailliblement mort de tristesse ; ils m'ont rendu la vie ; il est bien juste que je l'emploie à les aimer.

J'ai un cœur très aimant, mais qui peut se suffire à lui-même. J'aime trop les hommes pour avoir besoin de choix parmi eux ; je les aime tous, et c'est parce que je les aime que je hais l'injustice ; c'est parce que je les aime que je les fuis ; je souffre moins de leurs maux quand je ne les vois pas. Cet intérêt 
pour l'espèce suffit pour nourrir mon cœur : je n'ai pas besoin d'amis particuliers, mais, quand j'en ai, j'ai grand besoin de ne les pas perdre, car, quand ils se détachent, ils me déchirent. En cela d'autant plus coupables que je ne leur demande que de l'amitié, et que, pourvu qu'ils m'aiment et que je le sache, je n'ai pas même besoin de les voir. Mais ils ont toujours voulu mettre, à la place du sentiment, des soins et des services, que le public voyait et dont je n'avais que faire. Quand je les aimais, ils ont voulu paraître m'aimer. Pour moi, qui dédaigne en tout les apparences, je ne m'en suis pas contenté, et, ne trouvant que cela, je me le suis tenu pour dit. Ils n'ont pas précisément cessé de m'aimer ; j'ai seulement découvert qu'ils ne m'aimaient pas.

Pour la première fois de ma vie, je me trouvai donc tout à coup le cœur seul, et cela, seul aussi dans ma retraite et presque aussi malade que je le suis aujourd'hui. C'est dans ces circonstances que commença ce nouvel attachement, qui m'a si bien dédommagé de tous les autres, et dont rien ne me dédommagera, car il durera, j'espère, autant que ma vie, et quoi qu'il arrive, il sera le dernier. Je ne puis vous dissimuler, Monsieur, que j'ai une violente aversion pour les états qui dominent les autres ; j'ai même tort de dire que je ne puis vous le dissimuler, car je n'ai nulle peine à vous l'avouer, à vous, né d'un sang illustre, fils du chancelier de France et premier président d'une cour souveraine; oui, Monsieur, à vous qui m'avez fait mille biens sans me connaître, et à qui, malgré mon ingratitude naturelle, il ne m'en coûte rien d'être obligé. Je hais les grands, je hais leur état, leur dureté, leurs préjugés, leur petitesse, et tous leurs vices; et je les haïrais bien davantage si je les méprisais moins. C'est avec ce sentiment que j'ai été comme entraîné au château de Montmorency ; j'en ai vu les maîtres, ils m'ont aimé, et moi, Monsieur, je les ai aimés et les aimerai tant que je vivrai, de toutes les forces de mon âme ; je donnerais pour eux, je ne dis pas ma vie, le don serait faible dans l'état où je suis, je ne dis pas ma réputation parmi mes contemporains, dont je ne me soucie guère, mais la seule gloire qui jamais ait touché mon cœur, l'honneur que j'attends de la postérité et qu'elle me rendra, parce qu'il m'est dû et que la postérité est toujours juste. Mon cœur, qui ne sait point s'attacher à demi, s'est donné à eux sans réserve et je ne m'en repens pas : je m'en repentirais même inutilement car il ne serait plus temps de m'en dédire ; dans la chaleur de l'enthousiasme qu'ils m'ont inspiré, j'ai cent fois été sur le point de leur demander un asile dans leur maison, pour y passer le reste de mes jours auprès d'eux, et ils me l'auraient accordé avec joie, si même, à la manière dont ils s'y sont pris, je ne dois pas me regarder comme ayant été prévenu par leurs offres. Ce projet est certainement un de ceux que j'ai médités le plus longtemps et avec le plus de complaisance. Cependant il a fallu sentir à la fin, malgré moi, qu'il n'était pas bon. Je ne pensais qu'à l'attachement des personnes, sans songer aux intermédiaires, qui nous auraient tenus éloignés, et il y en avait de tant de sortes, surtout dans l'incommodité attachée à mes maux, qu'un tel projet n'est excusable que par le sentiment qui l'avait inspiré. D'ailleurs la manière de vivre qu'il aurait fallu prendre choque trop directement tous mes goûts, toutes mes habitudes; je n'y aurais pas pu résister seulement trois mois. Enfin nous aurions eu beau nous rapprocher d'habitation, la distance restant toujours la même entre les états, cette intimité délicieuse qui fait le plus grand charme d'une étroite société eût toujours manqué à la nôtre. Je n'aurais été ni l'ami ni le domestique de M. le maréchal de Luxembourg; j'aurais été son hôte ; en me sentant hors de chez moi, j'aurais soupiré souvent après mon ancien asile, et il vaut cent fois mieux être 
éloigné des personnes qu'on aime et désirer d'être auprès d'elles que de s'exposer à faire un souhait opposé. Quelques degrés plus rapprochés eussent peut-être fait révolution dans ma vie. J'ai cent fois supposé dans mes rêves $M$. de Luxembourg point duc, point maréchal de France, mais bon gentilhomme de campagne, habitant quelque vieux château, et J.-J. Rousseau point auteur, point faiseur de livres, mais ayant un esprit médiocre et un peu d'argent, se présentant au seigneur châtelain et à la dame, leur agréant, trouvant auprès d'eux le bonheur de sa vie et contribuant au leur. Si, pour rendre le rêve plus agréable, vous me permettiez de pousser d'un coup d'épaule le château de Malesherbes à demi-lieue de là, il me semble, Monsieur, qu'en rêvant de cette manière, je n'aurais de longtemps envie de me réveiller.

Mais c'en est fait; il ne me reste plus qu'à terminer le long rêve, car les autres sont désormais tous hors de saison, et c'est beaucoup si je puis me promettre encore quelques-unes des heures délicieuses que j'ai passées au château de Montmorency. Quoi qu'il en soit, me voilà tel que je me sens affecté : jugez-moi sur tout ce fatras, si j'en vaux la peine, car je n'y saurais mettre plus d'ordre et je n'ai pas le courage de recommencer. Si ce tableau trop véridique m'ôte votre bienveillance, j'aurai cessé d'usurper ce qui ne m'appartenait pas. Mais si je la conserve, elle m'en deviendra plus chère comme en étant plus à moi ! 


\section{Lettre 80}

\section{À Mme la marquise de Créqui}

À Montmorency, le 7 juin 1762

$\underline{\text { Retour à la table des matières }}$

Je vous remercie, Madame, de l'avis que vous voulez bien me donner; on me le donne de toutes parts, mais il n'est pas de mon usage. Jean-Jacques Rousseau ne sait point se cacher. D'ailleurs, je vous avoue qu'il m'est impossible de concevoir à quel titre un citoyen de Genève imprimant un livre en Hollande, avec privilège des États-Généraux, en peut devoir compte au Parlement de Paris. Au reste, j'ai rendu gloire à Dieu et parlé pour le bien des hommes. Pour une si digne cause, je ne refuserai jamais de souffrir. Je vous réitère mes remerciements, Madame, et n'oublierai point ce soin de votre amitié. 
Jean-Jacques Rousseau, Lettres (1728-1778)

\section{Sixième partie}

\section{L'exil : Môtiers, l'Île de Saint-Pierre}

$1762-1765$

Retour à la table des matières

L'existence à Môtiers est variée. Outre les promenades dans un pays de montagnes que l'exilé se plaît à décrire par le menu dans une lettre au Maréchal, ily a les visites au Château de Colombier où réside le gouverneur écossais de Neuchâtel, les herborisations dans les vallons et les pâturages, les importuns à accueillir ou à éconduire, l'écho des événements politiques de Genève auxquels Jean-Jacques se trouve mêlé puisque les « représentants » finissent par prendre sa défense contre le Petit-Conseil, qui a fait brûler l'Émile et le Contrat social (son intervention personnelle et décisive dans les affaires genevoises sera la publication des Lettres de la Montagne, 1764). Il y a aussi le repos, les conversations amicales, les plaisirs de la table, Thérèse accommodant à merveille les cailles, les bécasses, les gigots de mouton, sans parier des truites de l'Areuse (voyez le témoignage d'Escherny). On fait aussi de la musique, et on chante au bord de la rivière, les soirs d'été. Mais tout tourne mal : la religion de Rousseau est suspecte, aux yeux de la vénérable classe des pasteurs ; le vêtement d'Arménien, à longue robe, que porte le philosophe, effarouche les villageois ; Thérèse enfin, elle-même horriblement bavarde, se chamaille avec les commères. Et C'est la «lapidation » de Môtiers... Dans l'île de Saint-Pierre, à l'automne de 1765, Rousseau croira 
pouvoir faire ses adieux au monde : «Quand le soir approchait je descendais des cimes de l'île et j'allais volontiers m'asseoir au bord du lac, sur la grève, dans quelque asile caché... » (5e Rêverie). C'est là, et peut-être aussi dans le creuset de sa mémoire, que s'alimenteront ses extases les plus dépouillées. Mais encore une fois on le chasse : le Sénat de Berne en a décidé ainsi.

Abandonnant l'île (à l'automne de 1765 ), Rousseau confie à son ami Du Peyrou les brouillons des six premiers livres des Confessions. L'idée de raconter sa vie l'occupait depuis longtemps, il rassemblait lettres et documents, il composait des pages d'abord dispersées ; mais l'élan lui fut donné, au terme de l'année 1764, quand un pamphlet venu de Genève le fustigea, pour sa colère et pour sa honte - le Sentiment des Citoyens, où on (Rousseau n'en soupçonna jamais l'auteur, Voltaire lui-même) prétendait dénoncer au monde le scandale de sa vie. 


\section{Lettre 81}

\section{À M. [le maréchal de Luxembourg]}

À Yverdon, le 15 juin 1762

$\underline{\text { Retour à la table des matières }}$

Enfin, j'ai mis le pied dans cette terre de justice et de liberté qu'il ne fallait jamais quitter. Je ne puis écrire aujourd'hui... Il était temps d'arriver.

Mon adresse, sous le couvert de M. Daniel Roguin à Yverdon, en Suisse. Les lettres ne parviennent ici qu'affranchies jusqu'à la frontière. De grâce, Monsieur le Maréchal, un mot de Mlle le Vasseur. J'attends sa résolution pour prendre la mienne. 


\section{Lettre 82}

\section{À Mlle le Vasseur}

Yverdon, le 17 juin 1762

$\underline{\text { Retour à la table des matières }}$

Ma chère enfant, vous apprendrez avec grand plaisir que je suis en sûreté. Puissé-je apprendre bientôt que vous vous portez bien et que vous m'aimez toujours! je me suis occupé de vous en partant et durant tout mon voyage ; je m'occupe à présent du soin de nous réunir. Voyez ce que vous voulez faire, et ne suivez en cela que votre inclination ; car, quelque répugnance que j'aie à me séparer de vous, après avoir si longtemps vécu ensemble, je le puis cependant sans inconvénient, quoique avec regret; et même votre séjour en ce pays trouve des difficultés qui ne m'arrêteront pourtant pas s'il vous convient d'y venir. Consultez-vous donc, ma chère enfant, et voyez si vous pourrez supporter ma retraite. Si vous venez, je tâcherai de vous la rendre douce, et je pourvoirai même, autant qu'il sera possible, à ce que vous puissiez remplir les devoirs de votre religion aussi souvent qu'il vous plaira. Mais si vous aimez mieux rester, faites-le sans scrupule, et je concourrai toujours de tout mon pouvoir à vous rendre la vie commode et agréable.

Je ne sais rien de ce qui se passe ; mais les iniquités du Parlement ne peuvent plus me surprendre, et il n'y a point d'horreurs auxquelles je ne sois déjà préparé. Mon enfant, ne me méprisez pas à cause de ma misère. Les hommes peuvent me rendre malheureux, mais ils ne sauraient me rendre 
méchant ni injuste; et vous savez mieux que personne que je n'ai rien fait contre les lois.

J'ignore comment on aura disposé des effets qui sont restés dans ma maison ; j'ai toute confiance en la complaisance qu'a eue M. Dumoulin de vouloir bien en être le gardien. Je crois que cela pourra lever bien des difficultés que d'autres auraient pu faire. Je ne présume pas que le Parlement, tout injuste qu'il est, ait la bassesse de confisquer mes guenilles. Cependant, si cela arrivait, venez avec rien, mon enfant, et je serai consolé de tout quand je vous aurai près de moi. $\mathrm{Si}$, comme je le crois, on ferme les yeux et qu'on vous laisse disposer de tout, consultez MM. Mathas, Dumoulin, de La Roche, sur la manière de vous défaire de tout cela ou de la plus grande partie, surtout des livres et des gros meubles, dont le transport coûterait plus qu'ils ne valent; et vous ferez emballer le reste avec soin, afin qu'il me soit envoyé par une voie qui est connue de M. le Maréchal ; mais, avant tout, vous tâcherez de me faire parvenir une malle pleine de linge et de hardes, dont j'ai un très grand besoin, donnant avec la malle un mémoire exact de tout ce qu'elle contient. Si vous venez, vous garderez ce qu'il y a de meilleur et qui occupe le moins de volume, pour l'apporter avec vous, ainsi que l'argent que le reste aura produit, dont vous vous servirez pour votre voyage. Si cela, joint à l'appoint du compte de M. de La Roche, excède ce qui est nécessaire, vous le convertirez en lettre de change par le banquier qui dirigera votre voyage ; car, contre mon attente, j'ai trouvé qu'il faisait ici très cher vivre, que tout coûtait beaucoup, et que s'il faut nous remonter absolument en meubles et hardes, ce ne sera pas une petite affaire. Vous savez qu'il y a l'épinette et quelques livres à restituer, et $\mathrm{M}$. Mathas, et le boucher, et mon barbier à payer : je vous enverrai un mémoire sur tout cela. Vous avez dû trouver dans le couvercle de la boîte aux bonbons, trois ou quatre écus qui doivent suffire pour le paiement du boucher.

Je ne suis pas encore déterminé sur l'asile que je choisirai dans ce pays. J'attends votre réponse pour me fixer; car si vous ne veniez pas, je m'arrangerais différemment. je vous prie de témoigner à MM. Mathas et Dumoulin, à Mme de Verdelin, à MM. Alamanni et Mandard à M. et Mme de La Roche, et généralement à toutes les personnes qui vous paraîtront s'intéresser à mon sort, combien il m'en a coûté pour quitter si brusquement tous mes amis et un pays où j'étais bien voulu. Vous savez le vrai motif de mon départ ; si personne n'eût été compromis dans cette malheureuse affaire, je ne serais sûrement jamais parti, n'ayant rien à me reprocher. Ne manquez pas aussi de voir de ma part $\mathrm{M}$. le curé et de lui marquer avec quelle édification j'ai toujours admiré son zèle et toute sa conduite, et combien j'ai regretté de m'éloigner d'un pasteur si respectable dont l'exemple me rendait meilleur. M. Alamanni avait promis de me faire faire un bandage semblable à un modèle qu'il m'a montré, excepté que ce qui était à droite devait être à gauche ; je pense que ce bandage peut très bien se faire sans mesure exacte, en n'ouvrant pas les boutonnières, en sorte que je les pourrais faire ouvrir ici à ma mesure. S'il voulait bien prendre la peine de m'en faire deux semblables, je lui en serais sensiblement obligé ; vous auriez soin de lui en rembourser le prix, et de me les envoyer dans la première malle que vous me ferez parvenir. N'oubliez pas aussi les étuis à bougies, et soyez attentive à envelopper le tout avec le plus grand soin. 
Adieu, ma chère enfant. Je me console un peu des embarras où je vous laisse, par les bontés et la protection de M. le Maréchal et de Mme la Maréchale qui ne vous abandonneront pas au besoin. $\mathrm{M}$. et Mme Dubettier m'ont paru bien disposés pour vous; je souhaiterais que vous fissiez les avances d'un raccommodement auquel ils se prêteront sûrement : que ne puisje les raccommoder de même avec M. et Mme de La Roche ! Si j'étais resté, j'aurais tenté cette bonne œuvre, et j'ai dans l'esprit que j'aurais réussi. Adieu derechef. Je vous recommande toutes choses, mais surtout de vous conserver et de prendre soin de vous. 


\section{Lettre 83}

\section{À [Milord Maréchal] Vitam impendere vero.}

[Vers le 11 juillet 1762]

$\underline{\text { Retour à la table des matières }}$

Milord,

Un pauvre auteur proscrit de France, de sa patrie, du canton de Berne, pour avoir dit ce qu'il pensait être utile et bon, vient chercher un asile dans les États du Roi. Milord, ne me l'accordez pas si je suis coupable, car je ne demande point grâce et ne crois point en avoir besoin ; mais si je ne suis qu'opprimé, il est digne de vous et de Sa Majesté de ne pas me refuser le feu et l'eau qu'on veut m'ôter par toute la terre. J'ai cru devoir déclarer ma retraite, et mon nom est trop connu par mes malheurs. Ordonnez de mon sort, je suis soumis à vos ordres ; mais si vous m'ordonnez de partir dans l'état où je suis, obéir m'est impossible, et de plus je ne saurais où fuir.

Daignez, Milord, agréer les assurances de mon profond respect. 


\title{
Lettre 84
}

\section{Au Roi de Prusse}

\author{
À Môtiers-Travers \\ [vers le 11] juillet 1762
}

\section{$\underline{\text { Retour à la table des matières }}$}

J'ai dit beaucoup de mal de vous ; j'en dirai peut-être encore : cependant, chassé de France, de Genève, du canton de Berne, je viens chercher un asile dans vos États. Ma faute est peut-être de n'avoir pas commencé par là ; cet éloge est de ceux dont vous êtes digne. Sire, je n'ai mérité de vous aucune grâce, et je n'en demande pas ; mais, j'ai cru devoir déclarer à Votre Majesté que j'étais en son pouvoir, et que j'y voulais être : elle peut disposer de moi comme il lui plaira. 


\section{Lettre 85}

\section{[Au roi de Prusse, Frédéric II]}

À Môtiers-Travers, le 1er novembre 1762

$\underline{\text { Retour à la table des matières }}$

Sire,

Vous êtes mon protecteur et mon bienfaiteur, et je porte un cœur fait pour la reconnaissance; je veux m'acquitter avec vous, si je puis.

Vous voulez me donner du pain : n'y a-t-il aucun de vos sujets qui en manque ?

Ôtez de devant mes yeux cette épée qui m'éblouit et me blesse. Elle n'a que trop bien fait son service, et le sceptre est abandonné. La carrière des rois de votre étoffe est grande; vous êtes encore loin du terme. Cependant, le temps presse, et il ne vous reste pas un moment à perdre pour y arriver. Sondez bien votre cœur, ô Frédéric ! Pourrez-vous vous résoudre à mourir sans avoir été le plus grand des hommes ?

Puissé-je voir Frédéric le juste et le redouté couvrir enfin ses États d'un peuple heureux dont il soit le père, et Jean-Jacques Rousseau, l'ennemi des rois, ira mourir de joie aux pieds de son trône.

Que Votre Majesté, Sire, daigne agréer mon zèle et mon très profond respect. 


\section{Lettre 86}

\section{À Mlle Duchesne, sœur de l'Hôtel-Dieu de Montmorency}

Môtiers, le 16 janvier 1763

Retour à la table des matières

Non, Mademoiselle, on n'oublie ici ni votre amitié, ni vos services ; et si Mlle le Vasseur ne vous a pas remboursé plus tôt les deux louis que vous avez eu la bonté de lui prêter, c'est que sa mère, qui les a reçus, lui avait promis et lui a encore fait écrire qu'elle vous les rendrait. Elle n'en a rien fait, cela n'est pas étonnant: ils sont passés avec le reste. Assurément si cette femme a mangé tout l'argent qu'elle a tiré de sa fille et de moi, depuis vingt ans, il faut qu'elle ait une terrible avaloire. Si vous pouvez, Mademoiselle, attendre sans vous gêner jusqu'à Pâques, cet argent vous sera remboursé à Montmorency ; sinon, prenez la peine, quand vous irez à Paris, de passer à l'Hôtel de Luxembourg, et en montrant cette lettre à $M$. de La Roche, que d'ailleurs j'aurai soin de prévenir ; il vous remettra ces deux louis pour lesquels Mlle le Vasseur vous fait ses tendres remerciements ainsi que pour toutes les bontés dont vous l'avez honorée.

À l'égard de la dame Maingot, il est très sûr qu'il ne lui est rien dû. J'en ai pour preuves, premièrement la probité de Mlle le Vasseur, bien incapable assurément de nier une dette ; la somme qu'elle demande, qui passe ce que j'ai pu acheter de volaille durant tout mon séjour à Montmorency ; mon usage constant de tout payer comptant à mesure que j'achetais ; le fait particulier de 
quatre poulettes qu'acheta Mlle le Vasseur, pour avoir des œufs durant le carême, et qu'elle paya comptant au garçon de ladite Maingot, en présence de la mère Nanon, passé laquelle emplette il n'est pas entré une pièce de volaille dans ma maison; enfin l'exactitude même de la dame Maingot à se faire payer, puisque ma retraite fit trop de bruit pour être ignorée d'elle, et qu'il n'est pas apparent que, venant tous les mercredis au marché, elle ne se fût pas avisée de venir chez moi demander son dû. C'est pour payer les bagatelles que je pouvais devoir que Mlle le Vasseur est restée après moi. Pourquoi ne s'estelle pas adressée à elle ? Donner à la dame Maingot ce qu'elle demande serait récompenser la friponnerie : ce n'est assurément pas mon avis.

Je regrette beaucoup le bon $\mathrm{M}$. Mathas et je crois qu'il sera regretté dans tout le pays. Il faut espérer que M. Dumoulin le remplacera à tous égards et n'héritera pas moins de sa bonté que de son bien. Je savais que Mme de Verdelin avait fait inoculer ses demoiselles, mais je suis en peine d'elle-même, n'ayant pas de ses nouvelles depuis longtemps, quoique je lui aie écrit le dernier. Comme il faut nécessairement affranchir les lettres, les domestiques ne sont pas toujours exacts là-dessus, et il s'en perd beaucoup de cette manière. Si elle vient ce printemps à Soisy, je vous prie de lui parler de moi ; c'est une bonne et aimable dame, dont l'amitié m'était bien chère et dont je regretterai toute ma vie le voisinage. Je suis très sensible, Mademoiselle, au souvenir de toute votre famille ; je vous prie de lui en marquer ma reconnaissance et d'y faire à tout le monde mes salutations, de même qu'à tous les honnêtes gens de Montmorency qui vous paraîtront avoir conservé quelque amitié pour moi. Mes respects en particulier à M. le curé, si vous en trouvez l'occasion. Recevez ceux de Mlle le Vasseur et les assurances de son éternel attachement. Croyez aussi, je vous supplie, que je conserverai toute ma vie les sentiments de respect, d'estime et d'amitié que je vous ai voués. 


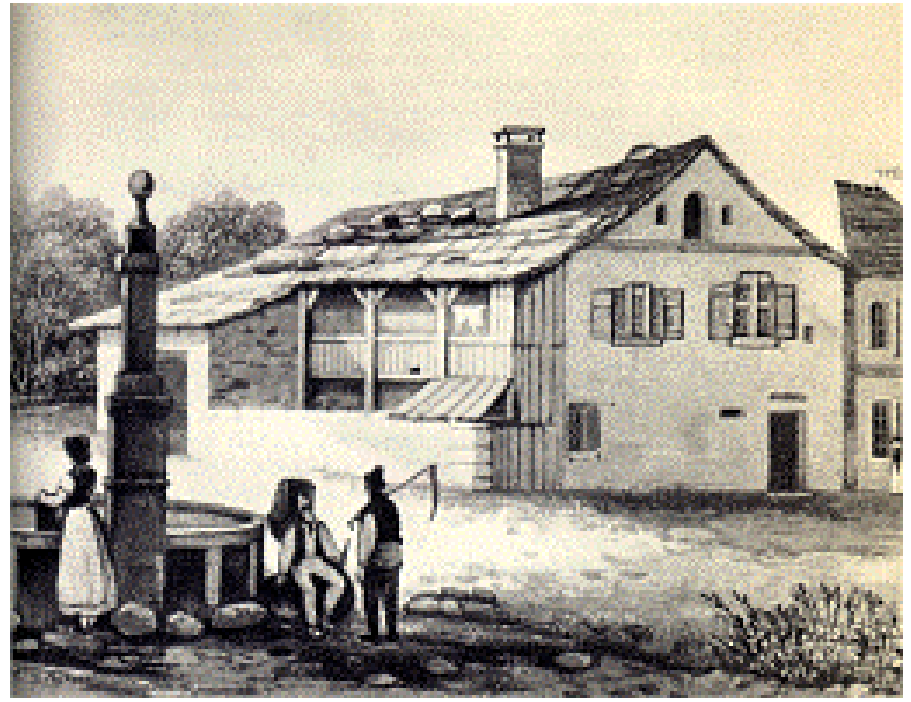

\section{Illustration 5}

L'habitation de J.-J. Rousseau à Môtiers-Travers

$\underline{\text { Retour à la table des matières }}$ 


\section{Lettre 87}

\section{À M. le maréchal de Luxembourg}

Môtiers, le 20 janvier 1763

$\underline{\text { Retour à la table des matières }}$

Vous voulez, M. le Maréchal, que je vous décrive le pays que j'habite. Mais comment faire ? Je ne sais voir qu'autant que je suis ému ; les objets indifférents sont nuls à mes yeux ; je n'ai de l'attention qu'à proportion de l'intérêt qui l'excite : et quel intérêt puis-je prendre à ce que je retrouve si loin de vous ? Des arbres, des rochers, des maisons, des hommes même, sont autant d'objets isolés dont chacun en particulier donne peu d'émotion à celui qui le regarde; mais l'impression commune de tout cela, qui le réunit en un seul tableau, dépend de l'état où nous sommes en le contemplant. Ce tableau, quoique toujours le même, se peint d'autant de manières qu'il y a de dispositions différentes dans les cœurs des spectateurs; et ces différences, qui font celles de nos jugements, n'ont pas lieu seulement d'un spectateur à l'autre, mais dans le même en différents temps. C'est ce que j'éprouve bien sensiblement en revoyant ce pays que j'ai tant aimé. J'y croyais retrouver ce qui m'avait charmé dans ma jeunesse : tout est changé ; c'est un autre paysage, un autre air, un autre ciel, d'autres hommes ; et, ne voyant plus mes montagnons avec des yeux de vingt ans, je les trouve beaucoup vieillis. On regrette le bon temps d'autrefois ; je le crois bien : nous attribuons aux choses tout le changement qui s'est fait en nous, et lorsque le plaisir nous quitte nous croyons qu'il n'est plus nulle part. D'autres voient les choses comme nous les avons vues, et les verront comme nous les voyons aujourd'hui. Mais ce sont des descriptions 
que vous me demandez, non des réflexions, et les miennes m'entraînent comme un vieux enfant qui regrette encore ses anciens jeux. Les diverses impressions que ce pays a faites sur moi à différents âges me font conclure que nos relations se rapportent toujours plus à nous qu'aux choses, et que, comme nous décrivons bien plus ce que nous sentons que ce qui est, il faudrait savoir comment était affecté l'auteur d'un voyage en l'écrivant, pour juger de combien ses peintures sont au deçà ou au delà du vrai. Sur ce principe ne vous étonnez pas de voir devenir aride et froid, sous ma plume, un pays jadis si verdoyant, si vivant, si riant, à mon gré : vous sentirez trop aisément dans ma lettre en quel temps de ma vie et en quelle saison de l'année elle a été écrite.

Je sais, M. le Maréchal, que, pour vous parler d'un village, il ne faut pas commencer par vous décrire toute la Suisse, comme si le petit coin que j'habite avait besoin d'être circonscrit d'un si grand espace. Il y a pourtant des choses générales qui ne se devinent point, et qu'il faut savoir pour juger des objets particuliers. Pour connaître Môtiers, il faut avoir quelque idée du comté de Neuchâtel, et pour connaître le comté de Neuchâtel, il faut en avoir de la Suisse entière.

Elle offre à peu près partout les mêmes aspects, des lacs, des prés, des bois, des montagnes; et les Suisses ont aussi tous à peu près les mêmes mœurs, mêlées de l'imitation des autres peuples et de leur antique simplicité. Ils ont des manières de vivre qui ne changent point, parce qu'elles tiennent pour ainsi dire au sol, au climat, aux besoins divers, et qu'en cela les habitants sont toujours forcés de se conformer à ce que la nature des lieux leur prescrit. Telle est, par exemple, la distribution de leurs habitations, beaucoup moins réunies en villes et en bourgs qu'en France, mais éparses et dispersées çà et là sur le terrain avec beaucoup plus d'égalité. Ainsi, quoique la Suisse soit en général plus peuplée à proportion que la France, elle a de moins grandes villes et de moins gros villages : en revanche, on y trouve partout des maisons ; le village couvre toute la paroisse, et la ville s'étend sur tout le pays. La Suisse entière est comme une grande ville divisée en treize quartiers, dont les uns sont sur les vallées, d'autres sur les coteaux, d'autres sur les montagnes. Genève, Saint-Gall, Neuchâtel sont comme les faubourgs : il y a des quartiers plus ou moins peuplés, mais tous le sont assez pour marquer qu'on est toujours dans la ville : seulement les maisons, au lieu d'être alignées, sont dispersées sans symétrie et sans ordre, comme on dit qu'étaient celles de l'ancienne Rome. On ne croit plus parcourir des déserts quand on trouve des clochers parmi les sapins, des troupeaux sur des rochers, des manufactures dans des précipices, des ateliers sur des torrents. Ce mélange bizarre a je ne sais quoi d'animé, de vivant, qui respire la liberté, le bien-être, et qui fera toujours du pays où il se trouve un spectacle unique en son genre, mais fait seulement pour des yeux qui sachent voir.

Cette égale distribution vient du grand nombre de petits états qui divise les capitales, de la rudesse du pays, qui rend les transports difficiles, et de la nature des productions, qui, consistant pour la plupart en pâturages, exige que la consommation s'en fasse sur les lieux mêmes, et tient les hommes aussi dispersés que les bestiaux. Voilà le plus grand avantage de la Suisse, avantage que ses habitants regardent peut-être comme un malheur, mais qu'elle tient d'elle seule, que rien ne peut lui ôter, qui, malgré eux, contient ou retarde le progrès du luxe et des mauvaises mœurs, et qui réparera toujours à la longue 
l'étonnante déperdition d'hommes qu'elle fait dans les pays étrangers. Voilà le bien. Voici le mal amené par ce bien même. Quand les Suisses, qui jadis vivant renfermés dans leurs montagnes se suffisaient à eux-mêmes, ont commencé à communiquer avec d'autres nations, ils ont pris goût à leur manière de vivre, et ont voulu l'imiter; ils se sont aperçus que l'argent était une bonne chose, et ils ont voulu en avoir ; sans productions et sans industrie pour l'attirer, ils se sont mis en commerce eux-mêmes, ils se sont vendus en détail aux puissances; ils ont acquis par là précisément assez d'argent pour sentir qu'ils étaient pauvres ; les moyens de le faire circuler étant presque impossibles dans un pays qui ne produit rien et qui n'est pas maritime, cet argent leur a porté de nouveaux besoins sans augmenter leurs ressources. Ainsi leurs premières aliénations de troupes les ont forcés d'en faire de plus grandes et de continuer toujours. La vie étant devenue plus dévorante, le même pays n'a plus pu nourrir la même quantité d'habitants. C'est la raison de la dépopulation qu'on commence à sentir dans toute la Suisse. Elle nourrissait ses nombreux habitants quand ils ne sortaient pas de chez eux ; à présent qu'il en sort la moitié, à peine peut-elle nourrir l'autre.

Le pis est que de cette moitié qui sort il en rentre assez pour corrompre tout ce qui reste par l'imitation des usages des autres pays, et surtout de la France, qui a plus de troupes suisses qu'aucune autre nation. Je dis corrompre, sans entrer dans la question si les mœurs françaises sont bonnes ou mauvaises en France, parce que cette question est hors de doute quant à la Suisse, et qu'il n'est pas possible que les mêmes usages conviennent à des peuples qui, n'ayant pas les mêmes ressources et n'habitant ni le même climat ni le même sol, seront toujours forcés de vivre différemment.

Le concours de ces deux causes, l'une bonne et l'autre mauvaise, se fait sentir en toutes choses ; il rend raison de tout ce qu'on remarque de particulier dans les mœurs des Suisses, et surtout de ce contraste bizarre de recherche et de simplicité qu'on sent dans toutes leurs manières. Ils tournent à contre sens tous les usages qu'ils prennent, non par faute d'esprit, mais par la force des choses. En transportant dans leurs bois les usages des grandes villes, ils les appliquent de la façon la plus comique ; ils ne savent ce que c'est qu'habits de campagne ; ils sont parés dans leurs rochers comme ils l'étaient à Paris ; ils portent sous leurs sapins tous les pompons du Palais-Royal, et j'en ai vu revenir de faire leurs foins en petite veste à falbala de mousseline. Leur délicatesse a toujours quelque chose de grossier, leur luxe a toujours quelque chose de rude. Ils ont des entremets, mais ils mangent du pain noir ; ils servent des vins étrangers, et boivent de la piquette ; des ragoûts fins accompagnent leur lard rance et leurs choux; ils vous offriront à déjeuner du café, du fromage ; à goûter, du thé avec du jambon; les femmes ont de la dentelle et de fort gros linge, des robes de goût avec des bas de couleur: leurs valets, alternativement laquais et bouviers, ont l'habit de livrée en servant à table, et mêlent l'odeur du fumier à celle des mets.

Comme on ne jouit du luxe qu'en le montrant, il a rendu leur société plus familière sans leur ôter pourtant le goût de leurs demeures isolées. Personne ici n'est surpris de me voir passer l'hiver en campagne ; mille gens du monde en font tout autant. On demeure donc toujours séparé, mais on se rapproche par de longues et fréquentes visites. Pour étaler sa parure et ses meubles il faut attirer ses voisins et les aller voir ; et comme ces voisins sont souvent 
éloignés, ce sont des voyages continuels. Aussi jamais n'ai-je vu de peuple si allant que les Suisses; les Français n'en approchent pas. Vous ne rencontrez de toute part que voitures ; il n'y a pas une maison qui n'ait la sienne, et les chevaux, dont la Suisse abonde, ne sont rien moins qu'inutiles dans le pays. Mais, comme ces courses ont souvent pour objet des visites de femmes, quand on monte à cheval, ce qui commence à devenir rare, on y monte en jolis bas blancs bien tirés, et l'on fait à peu près, pour courir la poste, la même toilette que pour aller au bal. Aussi rien n'est si brillant que les chemins de la Suisse ; on y rencontre à tout moment de petits messieurs et de belles dames ; on n'y voit que bleu, vert, couleur de rose : on se croirait au jardin du Luxembourg.

Un effet de ce commerce est d'avoir presque ôté aux hommes le goût du vin ; et un effet contraire de cette vie ambulante est d'avoir cependant rendu les cabarets fréquents et bons dans toute la Suisse. Je ne sais pas pourquoi l'on vante tant ceux de France ; ils n'approchent sûrement pas de ceux-ci. Il est vrai qu'il y fait très cher vivre ; mais cela est vrai aussi de la vie domestique, et cela ne saurait être autrement dans un pays qui produit peu de denrées et où l'argent ne laisse pas de circuler.

Les trois seules marchandises qui leur en aient fourni jusqu'ici sont les fromages, les chevaux, et les hommes ; mais depuis l'introduction du luxe ce commerce ne leur suffit plus, et ils y ont ajouté celui des manufactures dont ils sont redevables aux réfugiés français : ressource qui cependant a plus d'apparence que de réalité ; car, comme la cherté des denrées augmente avec les espèces, et que la culture de la terre se néglige quand on gagne davantage à d'autres travaux, avec plus d'argent ils n'en sont pas plus riches, ce qui se voit par la comparaison avec les Suisses catholiques, qui, n'ayant pas la même ressource, sont plus pauvres d'argent et ne vivent pas moins bien.

Il est fort singulier qu'un pays si rude, et dont les habitants sont si enclins à sortir, leur inspire pourtant un amour si tendre, que le regret de l'avoir quitté les y ramène presque tous à la fin, et que ce regret donne à ceux qui n'y peuvent revenir une maladie quelquefois mortelle, qu'ils appellent, je crois, le hemvé. Il y a dans la Suisse un air célèbre appelé le ranz des vaches, que les bergers sonnent sur leurs cornets, et dont ils font retentir tous les coteaux du pays. Cet air, qui est peu de chose en lui-même, mais qui rappelle aux Suisses mille idées relatives au pays natal, leur fait verser des torrents de larmes quand ils l'entendent en terre étrangère. Il en a même fait mourir de douleur un si grand nombre, qu'il a été défendu, par ordonnance du Roi, de jouer le ranz des vaches dans les troupes suisses. Mais, M. le Maréchal, vous savez peut-être tout cela mieux que moi, et les réflexions que ce fait présente ne vous auront pas échappé. Je ne puis m'empêcher de remarquer seulement que la France est assurément le meilleur pays du monde, où toutes les commodités et tous les agréments de la vie concourent au bien-être des habitants. Cependant il n'y a jamais eu, que je sache, de hemvé ni de ranz des vaches qui fît pleurer et mourir de regret un Français en pays étranger; et cette maladie diminue beaucoup chez les Suisses depuis qu'on vit plus agréablement dans leur pays.

Les Suisses en général sont justes, officieux, charitables, amis solides, braves soldats, et bons citoyens, mais intrigants, défiants, jaloux, curieux, avares, et leur avarice contient plus leur luxe que ne fait leur simplicité. Ils sont ordinairement graves et flegmatiques, mais ils sont furieux dans la colère, 
et leur joie est une ivresse. Je n'ai rien vu de si gai que leurs jeux. Il est étonnant que le peuple français danse tristement, languissamment, de mauvaise grâce, et que les danses suisses soient sautillantes et vives. Les hommes y montrent leur vigueur naturelle, et les filles y ont une légèreté charmante ; on dirait que la terre leur brûle les pieds.

Les Suisses sont adroits et rusés dans les affaires. Les Français qui les jugent grossiers sont bien moins déliés qu'eux ; ils jugent de leur esprit par leur accent. La Cour de France a toujours voulu leur envoyer des gens fins, et s'est toujours trompée. À ce genre d'escrime ils battent communément les Français : mais envoyez-leur des gens droits et fermes, vous ferez d'eux ce que vous voudrez, car naturellement ils vous aiment. Le marquis de Bonnac, qui avait tant d'esprit, mais qui passait pour adroit, n'a rien fait en Suisse ; et jadis le maréchal de Bassompierre y faisait tout ce qu'il voulait, parce qu'il était franc, ou qu'il passait chez eux pour l'être. Les Suisses négocieront toujours avec avantage, à moins qu'ils ne soient vendus par leurs magistrats, attendu qu'ils peuvent mieux se passer d'argent que les puissances ne peuvent se passer d'hommes ; car, pour votre blé, quand ils voudront ils n'en auront pas besoin. Il faut avouer que, s'ils font bien leurs traités, ils les exécutent encore mieux : fidélité qu'on ne se pique pas de leur rendre. Je ne vous dirai rien, $M$. le Maréchal, de leur gouvernement et de leur politique, parce que cela me mènerait trop loin, et que je ne veux vous parler que de ce que j'ai vu. Quant au comté de Neuchâtel où j'habite, vous savez qu'il appartient au roi de Prusse. Cette petite principauté, après avoir été démembrée du royaume de Bourgogne et passé successivement dans les maisons de Châlons, d'Hochberg, et de Longueville, tomba enfin en 1707 dans celle de Brandebourg par la décision des Etats du pays, juges naturels des droits des prétendants. Je n'entrerai point dans l'examen des raisons sur lesquelles le roi de Prusse fut préféré au prince de Conti, ni des influences que purent avoir d'autres puissances dans cette affaire ; je me contenterai de remarquer que, dans la concurrence entre ces deux princes, c'était un honneur qui ne pouvait manquer aux Neuchâtelois d'appartenir un jour à un grand capitaine. Au reste, ils ont conservé sous leurs souverains à peu près la même liberté qu'ont les autres Suisses ; mais peut-être en sont-ils plus redevables à leur position qu'à leur habileté ; car je les retrouve bien remuants pour des gens sages.

Tout ce que je viens de remarquer des Suisses, en général, caractérise encore plus fortement ce peuple-ci ; et le contraste du naturel et de l'imitation s'y fait encore mieux sentir, avec cette différence pourtant que le naturel a moins d'étoffe, et qu'à quelque petit coin près la dorure couvre tout le fond. Le pays, si l'on excepte la ville et les bords du lac, est aussi rude que le reste de la Suisse ; la vie y est aussi rustique ; et les habitants, accoutumés à vivre sous des princes, s'y sont encore plus affectionnés aux grandes manières; de sorte qu'on trouve ici du jargon, des airs, dans tous les états ; de beaux parleurs labourant les champs, et des courtisans en souquenille. Aussi appelle-t-on les Neuchâtelois les Gascons de la Suisse. Ils ont de l'esprit, et ils se piquent de vivacité ; ils lisent, et la lecture leur profite ; les paysans mêmes sont instruits ; ils ont presque tous un petit recueil de livres choisis qu'ils appellent leur bibliothèque ; ils sont même assez au courant pour les nouveautés ; ils font valoir tout cela dans la conversation d'une manière qui n'est point gauche, et ils ont presque le ton du jour comme s'ils vivaient à Paris. Il y a quelque temps qu'en me promenant je m'arrêtai devant une maison où des filles faisaient de la 
dentelle ; la mère berçait un petit enfant, et je la regardais faire, quand je vis sortir de la cabane un gros paysan qui, m'abordant d'un air aisé, me dit: Vous voyez qu'on ne suit pas trop bien vos préceptes; mais nos femmes tiennent autant aux vieux préjugés qu'elles aiment les nouvelles modes. Je tombais des nues. J'ai entendu parmi ces gens-là cent propos du même ton.

Beaucoup d'esprit et encore plus de prétention, mais sans aucun goût, voilà ce qui m'a d'abord frappé chez les Neuchâtelois. Ils parlent très bien, très aisément ; mais ils écrivent platement et mal, surtout quand ils veulent écrire légèrement, et ils le veulent toujours. Comme ils ne savent pas même en quoi consiste la grâce et le sel du style léger, lorsqu'ils ont enfilé des phrases lourdement sémillantes ils se croient autant de Voltaires et de Crébillons. Ils ont une manière de journal dans lequel ils s'efforcent d'être gentils et badins. Ils y fourrent même de petits vers de leur façon. Mme la Maréchale trouverait, sinon de l'amusement, au moins de l'occupation dans ce Mercure, car c'est d'un bout à l'autre un logogriphe qui demande un meilleur Edipe que moi.

C'est à peu près le même habillement que dans le canton de Berne, mais un peu plus contourné. Les hommes se mettent assez à la française ; et c'est ce que les femmes voudraient bien faire aussi ; mais comme elles ne voyagent guère, ne prenant pas comme eux les modes de la première main, elles les outrent, les défigurent; et, chargées de pretintailles et de falbalas, elles semblent parées de guenilles.

Quant à leur caractère, il est difficile d'en juger, tant il est offusqué de manières : ils se croient polis parce qu'ils sont façonniers, et gais parce qu'ils sont turbulents. Je crois qu'il n'y a que les Chinois au monde qui puissent l'emporter sur eux à faire des compliments. Arrivez-vous fatigué, pressé, n'importe, il faut d'abord prêter le flanc à la longue bordée ; tant que la machine est montée elle joue, et elle se remonte toujours à chaque arrivant. La politesse française est de mettre les gens à leur aise, et même de s'y mettre aussi : la politesse neuchâteloise est de gêner et soi-même et les autres. Ils ne consultent jamais ce qui vous convient, mais ce qui peut étaler leur prétendu savoir-vivre. Leurs offres exagérées ne tentent point ; elles ont toujours je ne sais quel air de formule, je ne sais quoi de sec et d'apprêté qui vous invite au refus. Ils sont pourtant obligeants, officieux, hospitaliers très réellement, surtout pour les gens de qualité ; on est toujours sûr d'être accueilli d'eux en se donnant pour marquis ou comte; et comme une ressource aussi facile ne manque pas aux aventuriers, ils en ont souvent dans leur ville, qui pour l'ordinaire y sont très fêtés : un simple honnête homme avec des malheurs et des vertus ne le serait pas de même; on peut y porter un grand nom sans mérite, mais non pas un grand mérite sans nom. Du reste, ceux qu'ils servent une fois, ils les servent bien. Ils sont fidèles à leurs promesses, et n'abandonnent pas aisément leurs protégés. Il se peut même qu'ils soient aimants et sensibles ; mais rien n'est plus éloigné du ton du sentiment que celui qu'ils prennent ; tout ce qu'ils font par humanité semble être fait par ostentation, et leur vanité cache leur bon cœur.

Cette vanité est leur vice dominant; elle perce partout, et d'autant plus aisément qu'elle est maladroite. Ils se croient tous gentilshommes, quoique leurs souverains ne fussent que des gentilhommes eux-mêmes. Ils aiment la chasse, moins par goût que parce que c'est un amusement noble. Enfin jamais 
on ne vit des bourgeois si pleins de leur naissance : ils ne la vantent pourtant pas, mais on voit qu'ils s'en occupent; ils n'en sont pas fiers, ils n'en sont qu'entêtés.

Au défaut de dignités et de titres de noblesse ils ont des titres militaires ou municipaux en telle abondance, qu'il y a plus de gens titrés que de gens qui ne le sont pas. C'est M. le colonel, M. le major, M. le capitaine, M. le lieutenant, M. le conseiller, M. le châtelain, M. le maire, M. le justicier, M. le professeur, M. le docteur, M. l'ancien : si j'avais pu reprendre ici mon ancien métier, je ne doute pas que je n'y fusse M. le copiste. Les femmes portent aussi les titres de leurs maris : Mme la conseillère, Mme la ministre ; j'ai pour voisins Mme la major; et comme on n'y nomme les gens que par leurs titres, on est embarrassé comment dire aux gens qui n'ont que leur nom ; c'est comme s'ils n'en avaient point.

Le sexe n'y est pas beau; on dit qu'il a dégénéré. Les filles ont beaucoup de liberté et en font usage. Elles se rassemblent souvent en société, où l'on joue, où l'on goûte, où l'on babille, et où l'on attire tant qu'on peut les jeunes gens ; mais par malheur ils sont rares, et il faut se les arracher. Les femmes vivent assez sagement; il y a dans le pays d'assez bons ménages, et il y en aurait bien davantage si c'était un air de bien vivre avec son mari. Du reste, vivant beaucoup en campagne, lisant moins et avec moins de fruit que les hommes, elles n'ont pas l'esprit fort orné ; et, dans le désœuvrement de leur vie, elles n'ont d'autre ressource que de faire de la dentelle, d'épier curieusement les affaires des autres, de médire, et de jouer. Il y en a pourtant de fort aimables ; mais en général on ne trouve pas dans leur entretien ce ton que la décence et l'honnêteté même rendent séducteur, ce ton que les Françaises savent si bien prendre quand elles veulent, qui montre du sentiment, de l'âme, et qui promet des héroïnes de roman. La conversation des Neuchâteloises est aride ou badine ; elle tarit sitôt qu'on ne plaisante pas. Les deux sexes ne manquent pas de bon naturel ; et je crois que ce n'est pas un peuple sans mœurs, mais c'est un peuple sans principes, et le mot de vertu y est aussi étranger ou aussi ridicule qu'en Italie. La religion dont ils se piquent sert plutôt à les rendre hargneux que bons. Guidés par leur clergé, ils épilogueront sur le dogme ; mais pour la morale, ils ne savent ce que c'est ; car quoiqu'ils parlent beaucoup de charité, celle qu'ils ont n'est assurément pas l'amour du prochain, c'est seulement l'affectation de donner l'aumône. Un chrétien pour eux est un homme qui va au prêche tous les dimanches ; quoi qu'il fasse dans l'intervalle, il n'importe pas. Leurs ministres, qui se sont acquis un grand crédit sur le peuple tandis que leurs princes étaient catholiques, voudraient conserver ce crédit en se mêlant de tout, en chicanant sur tout, en étendant à tout la juridiction de l'Église : ils ne voient pas que leur temps est passé. Cependant ils viennent encore d'exciter dans l'État une fermentation qui achèvera de les perdre. L'importante affaire dont il s'agissait était de savoir si les peines des damnés étaient éternelles. Vous auriez peine à croire avec quelle chaleur cette dispute a été agitée ; celle du jansénisme en France n'en a pas approché. Tous les corps assemblés, les peuples prêts à prendre les armes, ministres destitués, magistrats interdits ; tout marquait les approches d'une guerre civile ; et cette affaire n'est pas tellement finie qu'elle ne puisse laisser de longs souvenirs. Quand ils se seraient tous arrangés pour aller en enfer, ils n'auraient pas plus de souci de ce qui s'y passe. 
Voilà les principales remarques que j'ai faites jusqu'ici sur les gens du pays où je suis. Elles vous paraîtraient peut-être un peu dures pour un homme qui parle de ses hôtes, si je vous laissais ignorer que je ne leur suis redevable d'aucune hospitalité. Ce n'est point à MM. de Neuchâtel que je suis venu demander un asile qu'ils ne m'auraient sûrement pas accordé, c'est à Milord Maréchal, et je ne suis ici que chez le roi de Prusse. Au contraire, à mon arrivée sur les terres de la principauté, le magistrat de la ville de Neuchâtel s'est, pour tout accueil, dépêché de défendre mon livre sans le connaître ; la classe des ministres l'a déféré de même au Conseil d'Éat : on n'a jamais vu de gens plus pressés d'imiter les sottises de leurs voisins. Sans la protection déclarée de Milord Maréchal, on ne m'eût sûrement point laissé en paix dans ce village. Tant de bandits se réfugient dans le pays, que ceux qui le gouvernent ne savent pas distinguer des malfaiteurs poursuivis les innocents opprimés, ou se mettent peu en peine d'en faire la différence. La maison que j'habite appartient à une nièce de mon vieux ami M. Roguin. Ainsi, loin d'avoir nulle obligation à MM. de Neuchâtel, je n'ai qu'à m'en plaindre. D'ailleurs je n'ai pas mis le pied dans leur ville, ils me sont étrangers à tous égards ; je ne leur dois que justice en parlant d'eux, et je la leur rends.

Je la rends de meilleur cœur encore à ceux d'entre eux qui m'ont comblé de caresses, d'offres, de politesses de toute espèce. Flatté de leur estime et touché de leurs bontés, je me ferai toujours un devoir et un plaisir de leur marquer mon attachement et ma reconnaissance ; mais l'accueil qu'ils m'ont fait n'a rien de commun avec le Gouvernement neuchâtelois, qui m'en eût fait un bien différent s'il en eût été le maître. Je dois dire encore que, si la mauvaise volonté du corps des ministres n'est douteuse, j'ai beaucoup à me louer en particulier de celui dont j'habite la paroisse. Il me vint voir à mon arrivée, il me fit mille offres de services qui n'étaient point vaines, comme il me l'a prouvé dans une occasion essentielle où il s'est exposé à la mauvaise humeur de plus d'un de ses confrères pour s'être montré vrai pasteur envers moi. Je m'attendais d'autant moins de sa part à cette justice, qu'il avait joué dans les précédentes brouilleries un rôle qui n'annonçait pas un ministre tolérant. C'est au surplus un homme assez gai dans la société, qui ne manque pas d'esprit, qui fait quelquefois d'assez bons sermons, et souvent de fort bons contes.

Je m'aperçois que cette lettre est un livre, et je n'en suis encore qu'à la moitié de ma relation. Je vais, M. le Maréchal, vous laisser reprendre haleine, et remettre le second tome à une autre fois. 


\section{Lettre 88}

\section{À M. le maréchal de Luxembourg}

Môtiers le 28 janvier 1763

$\underline{\text { Retour à la table des matières }}$

Il faut, Monsieur le Maréchal, avoir du courage pour décrire en cette saison le lieu que j'habite. Des cascades, des glaces, des rochers nus, des sapins noirs couverts de neige, sont les objets dont je suis entouré ; et à l'image de l'hiver, le pays ajoutant l'aspect de l'aridité, ne promet, à le voir, qu'une description fort triste. Aussi a-t-il l'air assez nu en toute saison ; mais il est presque effrayant dans celle-ci. Il faut donc vous le représenter comme je l'ai trouvé en y arrivant, et non comme je le vois aujourd'hui, sans quoi l'intérêt que vous prenez à moi m'empêcherait de vous en rien dire.

Figurez-vous donc un vallon d'une bonne demi-lieue de large et d'environ deux lieues de long, au milieu duquel passe une petite rivière appelée l'Areuse, dans la direction du nord-ouest au sud-est. Ce vallon, formé par deux chaînes de montagnes qui sont des branches du Mont-Jura et qui se resserrent par les deux bouts, reste pourtant assez ouvert pour laisser voir au loin ses prolongements, lesquels, divisés en rameaux par les bras des montagnes, offrent plusieurs belles perspectives. Ce vallon, appelé le Val-de-Travers, du nom d'un village qui est à son extrémité orientale, est garni de quatre ou cinq autres villages à peu de distance les uns des autres : celui de Môtiers, qui forme le milieu, est dominé par un vieux château désert, dont le voisinage et la situation solitaire et sauvage m'attirent souvent dans mes promenades du 
matin, d'autant plus que je puis sortir de ce côté par une porte de derrière sans passer par la rue ni devant aucune maison. On dit que les bois et les rochers qui environnent ce château sont fort remplis de vipères ; cependant, ayant beaucoup parcouru tous les environs et, m'étant assis à toutes sortes de places, je n'en ai point vu jusqu'ici.

Outre ces villages, on voit vers le bas des montagnes plusieurs maisons éparses, qu'on appelle des prises, dans lesquelles on tient des bestiaux et dont plusieurs sont habitées par les propriétaires, la plupart paysans. Il y en a une entre autres à mi-côte nord, par conséquent exposée au midi, sur une terrasse naturelle, dans la plus admirable position que j'aie jamais vue, et dont le difficile accès m'eût rendu l'habitation très commode. J'en fus si tenté que dès la première fois, je m'étais presque arrangé avec le propriétaire pour y loger ; mais on m'a depuis tant dit de mal de cet homme, qu'aimant encore mieux la paix et la sûreté qu'une demeure agréable, j'ai pris le parti de rester où je suis. La maison que j'occupe est dans une moins belle position, mais elle est grande, assez commode ; elle a une galerie extérieure où je me promène dans les mauvais temps; et, ce qui vaut mieux que tout le reste, c'est un asile offert par l'amitié.

L'Areuse a sa source au-dessus d'un village appelé Saint-Sulpice, à l'extrémité occidentale du vallon; elle en sort au village de Travers, à l'autre extrémité, où elle commence à se creuser un lit, qui devient bientôt précipice, et la conduit enfin dans le lac de Neuchâtel. Cette Areuse est une très jolie rivière, claire et brillante comme de l'argent, où les truites ont bien de la peine à se cacher dans des touffes d'herbes. On la voit sortir tout d'un coup de terre à sa source, non point en petite fontaine ou ruisseau, mais toute grande et déjà rivière, comme la fontaine de Vaucluse, en bouillonnant à travers les rochers. Comme cette source est fort enfoncée dans les rochers escarpés d'une montagne, on y est toujours à l'ombre ; et la fraîcheur continuelle, le bruit, les chutes, le cours de l'eau, m'attirant l'été à travers ces roches brûlantes, me font souvent mettre en nage pour aller chercher le frais près de ce murmure, ou plutôt près de ce fracas, plus flatteur à mon oreille que celui de la rue SaintMartin.

L'élévation des montagnes qui forment le vallon n'est pas excessive, mais le vallon même est montagne, étant fort élevé au-dessus du lac ; et le lac, ainsi que le sol de toute la Suisse, est encore extrêmement élevé sur les pays des plaines, élevés à leur tour au-dessus du niveau de la mer. On peut juger sensiblement de la pente totale par le long et rapide cours des rivières, qui, des montagnes de la Suisse, vont se rendre les unes dans la Méditerranée et les autres dans l'Océan. Ainsi, quoique l'Areuse traversant le vallon soit sujette à de fréquents débordements, qui font des bords de son lit une espèce de marais, on n'y sent point le marécage, l'air n'y est point humide et malsain, la vivacité qu'il tire de son élévation l'empêchant de rester longtemps chargé de vapeurs grossières ; les brouillards, assez fréquents les matins, cèdent pour l'ordinaire à l'action du soleil à mesure qu'il s'élève.

Comme entre les montagnes et les vallées, la vue est toujours réciproque, celle dont je jouis ici dans un fond n'est pas moins vaste que celle que j'avais sur les hauteurs de Montmorency, mais elle est d'un autre genre ; elle ne flatte pas, elle frappe ; elle est plus sauvage que riante; l'art n'y étale pas ses 
beautés, mais la Majesté de la nature en impose ; et quoique le parc de Versailles soit plus grand que ce vallon, il ne paraîtrait qu'un colifichet en sortant d'ici. Au premier coup d'œil, le spectacle, tout grand qu'il est, semble un peu nu; on voit très peu d'arbres dans la vallée ; ils y viennent mal, et ne donnent presque aucun fruit ; l'escarpement des montagnes, étant très rapide, montre en divers endroits le gris des rochers ; le noir des sapins coupe ce gris d'une nuance qui n'est pas riante, et ces sapins si grands, si beaux quand on est dessous, ne paraissent au loin que des arbrisseaux, ne promettent ni l'asile ni l'ombre qu'ils donnent ; le fond du vallon, presque au niveau de la rivière, semble n'offrir à ses deux bords qu'un large marais où l'on ne saurait marcher ; la réverbération des rochers n'annonce pas, dans un lieu sans arbres, une promenade bien fraîche quand le soleil luit; sitôt qu'il se couche, il laisse à peine un crépuscule, et la hauteur des monts interceptant toute la lumière, fait passer presque à l'instant du jour à la nuit.

Mais, si la première impression de tout cela n'est pas agréable, elle change insensiblement par un examen plus détaillé ; et, dans un pays où l'on croyait avoir tout vu du premier coup d'œil, on se trouve avec surprise environné d'objets chaque jour plus intéressants. Si la promenade de la vallée est un peu uniforme, elle est en revanche extrêmement commode; tout y est du niveau le plus parfait, les chemins y sont unis comme des allées de jardin, les bords de la rivière offrent par places de larges pelouses d'un plus beau vert que les gazons du Palais-Royal, et l'on s'y promène avec délices le long de cette belle eau, qui dans le vallon prend un cours paisible en quittant ses cailloux et ses rochers qu'elle retrouve au sortir du Val-de-Travers. On a proposé de planter ses bords de saules et de peupliers, pour donner, durant la chaleur du jour, de l'ombre au bétail désolé par les mouches. Si jamais ce projet s'exécute, les bords de l'Areuse deviendront aussi charmants que ceux du Lignon, et il ne leur manquera plus que des Astrées, des Silvandres, et un d'Urfé.

Comme la direction du vallon coupe obliquement le cours du soleil, la hauteur des monts jette toujours de l'ombre par quelque côté sur la plaine; de sorte qu'en dirigeant ses promenades, et choisissant ses heures, on peut aisément faire à l'abri du soleil tout le tour du vallon. D'ailleurs, ces mêmes montagnes, interceptant ses rayons, font qu'il se lève tard et se couche de bonne heure, en sorte qu'on n'en est pas longtemps brûlé. Nous avons presque ici la clé de l'énigme du ciel de trois aulnes, et il est certain que les maisons qui sont près de la source de l'Areuse n'ont pas trois heures de soleil même en été.

Lorsqu'on quitte le bas du vallon pour se promener à mi-côte, comme nous fîmes une fois, Monsieur le Maréchal, le long des Champeaux, du côté d'Andilly, on n'a pas une promenade aussi commode, mais cet agrément est bien compensé par la variété des sites et des points de vue, par les découvertes que l'on fait sans cesse autour de soi, par les jolis réduits qu'on trouve dans les gorges des montagnes, où le cours des torrents qui descendent dans la vallée, les hêtres qui les ombragent, les coteaux qui les entourent, offrent des asiles verdoyants et frais quand on suffoque à découvert. Ces réduits, ces petits vallons, ne s'aperçoivent pas tant qu'on regarde au loin les montagnes, et cela joint à l'agrément du lieu celui de la surprise, lorsqu'on vient tout d'un coup à les découvrir. Combien de fois je me suis figuré, vous suivant à la promenade et tournant autour d'un rocher aride, vous voir surpris et charmé de retrouver 
des bosquets pour les dryades, où vous n'auriez cru trouver que des antres et des ours!

Tout le pays est plein de curiosités naturelles qu'on ne découvre que peu à peu, et qui, par ces découvertes successives, lui donnent chaque jour l'attrait de la nouveauté. La botanique offre ici ses trésors à qui saurait les connaitre ; et souvent, en voyant autour de moi cette profusion de plantes rares, je les foule à regret sous le pied d'un ignorant. Il est pourtant nécessaire d'en connaître une pour se garantir de ses terribles effets ; c'est le napel. Vous voyez une très belle plante haute de trois pieds, garnie de jolies fleurs bleues, qui vous donnent envie de la cueillir ; mais, à peine l'a-t-on gardée quelques minutes, qu'on se sent saisi de maux de tête, de vertiges, d'évanouissements, et l'on périrait si l'on ne jetait promptement ce funeste bouquet. Cette plante a souvent causé des accidents à des enfants et à d'autres gens qui ignoraient sa pernicieuse vertu. Pour les bestiaux, ils n'en approchent jamais, et ne broutent pas même l'herbe qui l'entoure. Les faucheurs l'extirpent autant qu'ils peuvent ; quoi qu'on fasse, l'espèce en reste, et je ne laisse pas d'en voir beaucoup en me promenant sur les montagnes; mais on l'a détruite à peu près dans le vallon.

À une petite lieue de Môtiers, dans la seigneurie de Travers, est une mine d'asphalte, qu'on dit qui s'étend sous tout le pays ; les habitants lui attribuent modestement la gaieté dont ils se vantent, et qu'ils prétendent se transmettre même à leurs bestiaux. Voilà sans doute une belle vertu de ce minéral ; mais, pour en pouvoir sentir l'efficace, il ne faut pas avoir quitté le château de Montmorency. Quoi qu'il en soit des merveilles qu'ils disent de leur asphalte, j'ai donné au seigneur de Travers un moyen sûr d'en tirer la médecine universelle ; c'est de faire une bonne pension à Lorry ou à Bordeu.

Au-dessus de ce même village de Travers, il se fit, il y a deux ans, une avalanche considérable, et de la façon du monde la plus singulière. Un homme qui habite au pied de la montagne avait son champ devant sa fenêtre, entre la montagne et sa maison. Un matin, qui suivit une nuit d'orage, il fut bien surpris, en ouvrant sa fenêtre, de trouver un bois à la place de son champ ; le terrain, s'éboulant tout d'une pièce, avait recouvert son champ des arbres d'un bois qui était au-dessus ; et cela, dit-on, fait entre les deux propriétaires le sujet d'un procès qui pourrait trouver place dans le recueil de Pitaval. L'espace que l'avalanche a mis à nu est fort grand et paraît de loin ; mais il faut en approcher pour juger de la force de l'éboulement, de l'étendue du creux, et de la grandeur des rochers qui ont été transportés. Ce fait récent et certain rend croyable ce que dit Pline d'une vigne qui avait été ainsi transportée d'un côté du chemin à l'autre. Mais rapprochons-nous de mon habitation.

J'ai vis-à-vis de mes fenêtres une superbe cascade, qui, du haut de la montagne, tombe par l'escarpement d'un rocher dans le vallon, avec un bruit qui se fait entendre au loin surtout quand les eaux sont grandes. Cette cascade est très en vue ; mais ce qui ne l'est pas de même est une grotte à côté de son bassin, de laquelle l'entrée est difficile, mais qu'on trouve au-dedans assez espacée, éclairée par une fenêtre naturelle, cintrée en tiers-point, et décorée d'un ordre d'architecture qui n'est ni toscan ni dorique, mais l'ordre de la nature, qui sait mettre des proportions et de l'harmonie dans ses ouvrages les moins réguliers. Instruit de la situation de cette grotte, je m'y rendis seul l'été 
dernier pour la contempler à mon aise. L'extrême sécheresse me donna la facilité d'y entrer par une ouverture enfoncée et très surbaissée, en me traînant sur le ventre, car la fenêtre est trop haute pour qu'on puisse y passer sans échelle. Quand je fus au-dedans, je m'assis sur une pierre, et je me mis à contempler avec ravissement cette superbe salle dont les ornements sont des quartiers de roche diversement situés, et formant la décoration la plus riche que j'aie jamais vue, si du moins on peut appeler ainsi celle qui montre la plus grande puissance, celle qui attache et intéresse, celle qui fait penser, qui élève l'âme, celle qui force l'homme à oublier sa petitesse pour ne penser qu'aux œuvres de la nature. Des divers rochers qui meublent cette caverne, les uns détachés et tombés de la voûte, les autres encore pendants et diversement situés, marquent tous dans cette mine naturelle l'effet de quelque explosion terrible dont la cause paraît difficile à imaginer, car même un tremblement de terre ou un volcan n'expliquerait pas cela d'une manière satisfaisante. Dans le fond de la grotte, qui va en s'élevant de même que sa voûte, on monte sur une espèce d'estrade, et de là, par une pente assez raide, sur un rocher qui mène de biais à un enfoncement très obscur par où l'on pénètre sous la montagne. Je n'ai point été jusque-là, ayant trouvé devant moi un trou large et profond qu'on ne saurait franchir qu'avec une planche. D'ailleurs, vers le haut de cet enfoncement, et presque à l'entrée de la galerie souterraine, est un quartier de rocher très imposant ; car, suspendu presque en l'air, il porte à faux par un de ses angles, et penche tellement en avant qu'il semble se détacher et partir pour écraser le spectateur. Je ne doute pas cependant qu'il ne soit dans cette situation depuis bien des siècles, et qu'il n'y reste encore plus longtemps ; mais ces sortes d'équilibres, auxquels les yeux ne sont pas faits, ne laissent pas de causer quelque inquiétude; et quoiqu'il fallût peut-être des forces immenses pour ébranler ce rocher qui paraît si prêt à tomber, je craindrais d'y toucher du bout du doigt, et ne voudrais pas plus rester dans la direction de sa chute que sous l'épée de Damoclès.

La galerie souterraine, à laquelle cette grotte sert de vestibule, ne continue pas d'aller en montant ; mais elle prend sa pente un peu vers le bas, et suit la même inclinaison dans tout l'espace qu'on a jusqu'ici parcouru. Les curieux s'y sont engagés à diverses fois avec des domestiques, des flambeaux, et tous les secours nécessaires, mais il faut du courage pour pénétrer loin [en] cet effroyable lieu, et de la vigueur pour ne pas s'y trouver mal. On est allé jusqu'à près de demi-lieue, en ouvrant le passage où il est trop étroit, et sondant avec précaution les gouffres et fondrières qui sont à droite et à gauche : mais on prétend, dans le pays, qu'on peut aller par le même souterrain à plus de deux lieues jusqu'à l'autre côté de la montagne, où l'on dit qu'il aboutit du côté du lac, non loin de l'embouchure de l'Areuse.

Au-dessous du bassin de la même cascade est une autre grotte plus petite, dont l'abord est embarrassé de plusieurs grands cailloux et quartiers de roche qui paraissent avoir été entraînés là par les eaux. Cette grotte-ci, n'étant pas si praticable que l'autre, n'a pas de même tenté les curieux. Le jour que j'en examinai l'ouverture, il faisait une chaleur insupportable ; cependant, il en sortait un vent si vif et si froid, que je n'osai rester longtemps à l'entrée, et toutes les fois que j'y suis retourné, j'ai toujours senti le même vent ; ce qui me fait juger qu'elle a une communication plus immédiate et moins embarrassée que l'autre. 
À l'ouest de la vallée, une montagne la sépare en deux branches ; l'une fort étroite, où sont le village de Saint-Sulpice, la source de l'Areuse, et le chemin de Pontarlier. Sur ce chemin, l'on voit encore une grosse chaîne, scellée dans le rocher, et mise là jadis par les Suisses pour fermer de ce côté-là le passage aux Bourguignons.

L'autre branche, plus large, et à gauche de la première, mène par le village de Butte à un pays perdu appelé La Côte-aux-Fées, qu'on aperçoit de loin parce qu'il va en montant. Ce pays, n'étant sur aucun chemin, passe pour très sauvage, et en quelque sorte pour le bout du monde. Aussi prétend-on que c'était autrefois le séjour des fées, et le nom lui en est resté ; on y voit encore leur salle d'assemblée dans une troisième caverne qui porte aussi leur nom, et qui n'est pas moins curieuse que les précédentes. Je n'ai pas vu cette grotte aux Fées, parce qu'elle est assez loin d'ici ; mais on dit qu'elle était superbement ornée, et l'on y voyait encore, il n'y a pas longtemps, un trône et des sièges très bien taillés dans le roc. Tout cela a été gâté et ne paraît presque plus aujourd'hui. D'ailleurs, l'entrée de la grotte est presque entièrement bouchée par les décombres, par les broussailles ; et la crainte des serpents et des bêtes venimeuses rebute les curieux d'y vouloir pénétrer. Mais si elle eût été praticable encore et dans sa première beauté, et que Mme la Maréchale eût passé dans ce pays, je suis sûr qu'elle eût voulu voir cette grotte singulière, n'eût-ce été qu'en faveur de Fleur-d'Épine et des Facardins.

Plus j'examine en détail l'état et la position de ce vallon, plus je me persuade qu'il a jadis été sous l'eau ; que ce qu'on appelle aujourd'hui le Valde-Travers fut autrefois un lac formé par l'Areuse, la cascade et d'autres ruisseaux, et contenu par les montagnes qui l'environnent, de sorte que je ne doute point que je n'habite l'ancienne demeure des poissons; en effet, le sol du vallon est si parfaitement uni qu'il n'y a qu'un dépôt formé par les eaux qui puisse l'avoir ainsi nivelé. Le prolongement du vallon, loin de descendre, monte le long du cours de l'Areuse ; de sorte qu'il a fallu des temps infinis à cette rivière pour se caver, dans les abîmes qu'elle forme, un cours en sens contraire à l'inclinaison du terrain. Avant ces temps, contenue de ce côté, de même que de tous les autres, et forcée de refluer sur elle-même, elle dut enfin remplir le vallon jusqu'à la hauteur de la première grotte que j'ai décrite, par laquelle elle trouva ou s'ouvrit un écoulement dans la galerie souterraine qui lui servait d'aqueduc.

Le petit lac demeura donc constamment à cette hauteur jusqu'à ce que, par quelques ravages, fréquents au pied des montagnes dans les grandes eaux, des pierres ou graviers embarrassèrent tellement le canal que les eaux n'eurent plus un cours suffisant pour leur écoulement. Alors s'étant extrêmement élevées, et agissant avec une grande force contre les obstacles qui les retenaient, elles s'ouvrirent enfin quelque issue par le côté le plus faible et le plus bas. Les premiers filets échappés ne cessent de creuser et de s'agrandir, et le niveau du lac baissant à proportion, à force de temps le vallon dut enfin se trouver à sec. Cette conjecture, qui m'est venue en examinant la grotte où l'on voit des traces sensibles du cours de l'eau, s'est confirmée premièrement par le rapport de ceux qui ont été dans la galerie souterraine, et qui m'ont dit avoir trouvé des eaux croupissantes dans les creux des fondrières dont j'ai parlé ; elle s'est confirmée encore dans les pèlerinages que j'ai faits à quatre lieues d'ici pour aller voir Milord Maréchal à sa campagne au bord du lac, et où je 
suivais, en montant la montagne, la rivière qui descendait à côté de moi par des profondeurs effrayantes, que, selon toute apparence, elle n'a pas trouvées toutes faites, et qu'elle n'a pas creusées en un jour. Enfin, j'ai pensé que l'asphalte, qui n'est qu'un bitume durci, était encore un indice d'un pays longtemps imbibé par les eaux. Si j'osais croire que ces folies pussent vous amuser, je tracerais sur le papier une espèce de plan qui pût vous éclaircir tout cela ; mais il faut attendre qu'une saison plus favorable et un peu de relâche à mes maux me laissent en état de parcourir le pays.

On peut vivre ici puisqu'il y a des habitants. On y trouve même les principales commodités de la vie, quoique un peu moins facilement qu'en France. Les denrées y sont chères, parce que le pays en produit peu et qu'il est fort peuplé, surtout depuis qu'on y a établi des manufactures de toile peinte, et que les travaux d'horlogerie et de dentelle s'y multiplient. Pour y avoir du pain mangeable, il faut le faire chez soi, et c'est le parti que j'ai pris avec l'aide de Mlle le Vasseur ; la viande y est mauvaise, non que le pays n'en produise de bonne; mais tout le bœuf va à Genève ou à Neuchâtel, et l'on ne tue ici que de la vache. La rivière fournit d'excellente truite, mais si délicate qu'il faut la manger sortant de l'eau. Le vin vient de Neuchâtel, et il est très bon, surtout le rouge : pour moi, je m'en tiens au blanc, bien moins violent, à meilleur marché, et selon moi beaucoup plus sain. Point de volaille, peu de gibier, point de fruit, pas même des pommes ; seulement des fraises bien parfumées, en abondance, et qui durent longtemps. Le laitage est excellent, moins pourtant que le fromage de Viry, préparé par Mlle Rose ; les eaux y sont claires et légères : ce n'est pas pour moi une chose indifférente que de bonne eau, et je me sentirai longtemps du mal que m'a fait celle de Montmorency. J'ai sous ma fenêtre une très belle fontaine dont le bruit fait une de mes délices. Ces fontaines, qui sont élevées et taillées en colonnes ou en obélisques, et coulent par des tuyaux de fer dans de grands bassins, sont un des ornements de la Suisse. Il n'y a si chétif village qui n'en ait au moins deux ou trois ; les maisons écartées ont presque chacune la sienne, et l'on en trouve même sur les chemins pour la commodité des passants, hommes et bestiaux. Je ne saurais exprimer combien l'aspect de toutes ces belles eaux coulantes est agréable au milieu des rochers et des bois durant les chaleurs ; l'on est déjà rafraîchi par la vue, et l'on est tenté d'en boire sans avoir soif.

Voilà, Monsieur le Maréchal, de quoi vous former quelque idée du séjour que j'habite, et auquel vous voulez bien prendre intérêt. Je dois l'aimer comme le seul lieu de la terre où la vérité ne soit pas un crime, ni l'amour du genre humain une impiété. J'y trouve la sûreté sous la protection de Milord Maréchal, et l'agrément dans son commerce. Les habitants du lieu m'y montrent de la bienveillance et ne me traitent point en proscrit. Comment pourraisje n'être pas touché des bontés qu'on m'y témoigne, moi qui dois tenir à bienfait de la part des hommes tout le mal qu'ils ne me font pas ? Accoutumé à porter depuis si longtemps les pesantes chaînes de la nécessité, je passerais ici sans regret le reste de ma vie, si j'y pouvais voir quelquefois ceux qui me la font encore aimer. 


\title{
Lettre 89
}

\section{À M. [Jacob Favre, premier syndic de la République de Genève]}

\author{
À Môtiers-Travers, le 12 mai 1763
}

Retour à la table des matières

Monsieur,

Revenu du long étonnement où m'a jeté, de la part du Magnifique Conseil, le procédé que j'en devais le moins attendre, je prends enfin le parti que l'honneur et la raison me prescrivent, quelque cher qu'il coûte à mon cœur. Je vous déclare donc, Monsieur, et je vous prie de déclarer de ma part au Magnifique Conseil, que j'abdique à perpétuité mon droit de bourgeoisie et de cité dans la Ville et République de Genève. Ayant rempli de mon mieux les devoirs attachés à ce titre sans jouir d'aucun de ses avantages, je ne crois point être en reste envers l'État, en le quittant.

J'ai tâché d'honorer le nom genevois : j'ai tendrement aimé mes compatriotes ; je n'ai rien oublié pour me faire aimer d'eux : on ne saurait plus mal réussir. Je veux leur complaire jusque dans leur haine : le dernier sacrifice qui me reste à leur faire est celui d'un nom qui me fut si cher.

Mais, Monsieur, ma patrie, en me devenant étrangère, ne peut me devenir indifférente ; je lui reste attaché par un tendre souvenir, et je n'oublie d'elle que ses outrages. Puisse-t-elle prospérer toujours et voir augmenter sa gloire : puisse-t-elle abonder en citoyens meilleurs et surtout plus heureux que moi !

Recevez, Monsieur, je vous supplie, les assurances de mon profond respect. 


\section{Lettre 90}

\section{À M. [Grumet, curé d'Ambérieu]}

Môtiers-Travers, le 21 août 1763

$\underline{\text { Retour à la table des matières }}$

Vos bontés, Monsieur, pour ma gouvernante et pour moi sont sans cesse présentes à mon cœur et au sien. À force d'y penser, nous voilà tentés d'en user encore, et peut-être d'en abuser. Il faut vous communiquer notre idée, afin que vous voyiez si elle ne vous sera point importune, et si vous voudrez bien porter l'humanité jusqu'à y acquiescer.

L'état de dépérissement où je suis ne peut durer; et, à moins d'un changement bien imprévu, je dois naturellement, avant la fin de l'hiver, trouver un repos que les hommes ne pourront plus troubler. Mon unique regret sera de laisser cette bonne et honnête fille sans appui et sans amis, et de ne pouvoir pas même lui assurer la possession des guenilles que je puis laisser. Elle s'en tirera comme elle pourra : il ne faut pas lutter inutilement contre la nécessité. Mais, comme elle est bonne catholique, elle ne veut pas rester dans un pays d'une autre religion que la sienne, quand son attachement pour moi ne l'y retiendra plus. Elle ne voudrait pas non plus retourner à Paris ; il y fait trop cher vivre, et la vie bruyante de ce pays-là n'est pas de son goût. Elle voudrait trouver, dans quelque province reculée, où l'on vécût à bon compte, un petit asile, soit dans une communauté de filles, soit en prenant son petit ménage dans un village ou ailleurs, pourvu qu'elle y soit tranquille. 
J'ai pensé, Monsieur, au pays que vous habitez, lequel a, ce me semble, les avantages qu'elle cherche, et n'est pas bien éloigné d'ici.

Voudriez-vous bien avoir la charité de lui accorder votre protection et vos conseils, devenir son patron et lui tenir lieu de père ? Il me semble que je ne serais plus en peine d'elle en la laissant sous votre garde ; et il me semble aussi qu'un pareil soin n'est pas moins digne de votre bon cœur que de votre ministère. C'est, je vous assure, une bonne et honnête fille, qui me sert depuis vingt ans avec l'attachement d'une fille à son père, plutôt que d'un domestique à son maître. Elle a des défauts, sans doute ; c'est le sort de l'humanité ; mais elle a des vertus rares, un cœur excellent, une honnêteté de mœurs, une fidélité et un désintéressement à toute épreuve. Voilà de quoi je réponds après vingt ans d'expérience. D'ailleurs, elle n'est plus jeune et ne veut d'établissement d'aucune espèce. Je souhaite qu'elle passe ses jours dans une honnête indépendance, et qu'elle ne serve personne après moi. Elle n'a pas pour cela de grandes ressources, mais elle saura se contenter de peu. Tout son revenu se borne à une pension viagère de trois cents francs, que lui a faite mon libraire. Le peu d'argent que je pourrai lui laisser servira pour son voyage et pour son petit emménagement. Voilà tout, Monsieur : voyez si cela pourra suffire à cette pauvre fille pour subsister dans le pays où vous êtes, et si, par la connaissance que vous avez du local, vous voudrez bien lui en faciliter les moyens. Si vous consentez, je ferai ce qu'il faut; et je n'aurai plus de souci pour elle, si je puis me flatter qu'elle vivra sous vos yeux. Un mot de réponse, Monsieur, je vous en supplie, afin que je prenne mes arrangements. je vous demande pardon du désordre de ma lettre ; mais je souffre beaucoup ; et, dans cet état, ma main ni ma tête ne sont pas aussi libres que je voudrais bien.

Je me flatte, Monsieur, que cette lettre vous atteste mes sentiments pour vous ; ainsi je n'y ajouterai rien davantage que les assurances de mon respect.

Je suis obligé de vous prévenir, Monsieur, que par la Suisse, il faut affranchir jusqu'à Pontarlier. Quoique votre précédente lettre me soit parvenue, il serait fort douteux si j'aurais ce bonheur une seconde fois. Je sens toute mon indiscrétion ; mais, ou je me trompe fort, ou vous ne regretterez pas de payer le plaisir de faire du bien. 


\section{Lettre 91}

\section{À Mme Boy de la Tour}

À Môtiers, le 19 novembre 1763

$\underline{\text { Retour à la table des matières }}$

Hier, Madame, j'ai fait remettre aux Rosselets un bonnet de bouracan sur la mesure duquel je vous prie de vouloir bien faire faire les deux autres. De ces trois bonnets, j'en voudrais deux pour l'été, savoir celui de bouracan sans fourrure, garni d'un petit galon et d'une houppe d'or comme l'année dernière, un autre bordé dans la même largeur de petit gris ou martre ou autre jolie fourrure légère ; quant au troisième, je le voudrais de quelque drap léger comme silésie ou carcassonne doublé de quelque étoffe un peu chaude, et fourré aussi, mais non pas en dedans. Le tout ou gris ou couleur modeste, et surtout point d'écarlate. Je vous prie aussi de vouloir bien faire ajouter aux autres articles deux pièces de padou, l'une bleue et l'autre grise, quelques lacets de soie jaune pour des bottines de maroquin, et enfin un manchon de femme un peu joli que je voudrais donner à Mlle le Vasseur pour ses étrennes. N'oubliez pas aussi, je vous supplie, d'ajouter à toutes ces commissions le mémoire afin que je compte avec moi, ne pouvant compter avec vous, à qui je dois tant de choses sans pouvoir m'acquitter en rien.

Je vous dirai là-dessus qu'après toutes les dépenses que vous avez faites pour moi le loyer de dix écus par mois n'est pas même proposable. Ce serait de ma part une ingratitude monstrueuse de croire ainsi m'acquitter avec vous, et j'aimerais encore mieux vous être tout franchement redevable du tout et 
recevoir de vous l'hospitalité pleine et entière que de paraître payer mon loyer tandis qu'en effet je le payerais si mal. J'use vos meubles, j'ôte à d'autres l'usage de votre maison, je vous ai constitué en dépense à la montagne. Si tout cela n'entrait pas en ligne de compte, il vaudrait mieux encore ne point compter du tout, et que les obligations que je vous ai fussent authentiques au gré de ma reconnaissance. Si donc il est vrai que je ne sois pas de trop dans votre maison, faites-moi de grâce un parti plus acceptable.

Mon état me permet moins que jamais de me décider sur rien. S'il n'est pas meilleur au printemps je ne puis songer à de longs voyages. En ce cas, mon arrangement est, sauf votre bon plaisir, d'aller faire un essai du séjour de la montagne, et si je vois qu'il me soit possible de m'y établir tout de bon, je le ferai. Il y aurait de l'imprudence à faire tout d'un coup cette transplantation sans s'assurer de pouvoir lever les difficultés qui s'y trouvent. Si cela ne se peut, je continuerai d'occuper votre maison tant qu'elle ne vous sera pas nécessaire; désirant pourtant de savoir si trouvant dans le pays ou au voisinage quelque autre séjour plus convenable que celui de Môtiers dont l'air ne me convient pas, vous désapprouveriez que je cherchasse à m'y établir ; car quoi qu'il pût se présenter, soyez bien persuadée, ma très bonne amie, que de mes jours je ne veux entendre parler de faire chose au monde qui vous déplaise en quoi que ce puisse être.

Je vous prie de dire à MM. vos fils que le désir de faire connaissance entre nous est bien de ma part réciproque ; puis-je être indifférent pour rien de ce qui vous appartient? Je souhaite de tout mon cœur que leurs affaires leur permettent de venir soit ensemble, soit séparément prendre possession de leur demeure. Quoique vous ne vouliez pas que je sois votre concierge, c'est une fonction que je remplirai avec joie, soit envers vous, soit envers toute votre famille si jamais j'ai le bonheur d'être dans le cas. Mille salutations, je vous supplie, à tous ces chers enfants si dignes de votre attachement et par là si sûrs de tout le mien. J'ai appris que M. Girardier a été malade, je vous prie de lui dire que je me réjouis de son rétablissement. Recevez les respects de Mlle le Vasseur et ceux d'un ami qui vous est attaché comme il le doit ; c'est tout dire.

Je ne sais pourquoi vos lettres ne me viennent jamais en droiture ; c'est peut-être parce que le mot de Pontarlier n'est pas tout au bas. Il faut que l'adresse se termine de cette manière :

\section{À Môtiers-Travers par Pontarlier.}

Point de manchon, s'il vous plaît, j'en trouve un ici par occasion, mais je vous prie d'ajouter à la place un bonnet de nuit de laine fine pour moi, et des plus grands, parce que j'ai la tête grosse.

On aurait besoin d'une demi-livre de laine conforme à peu près à l'échantillon. Si cela se trouve aisément, à la bonne heure, sinon l'on s'en passera. 


\section{Lettre 92}

\section{À M. [Séguier de Saint-Brisson]}

22 juillet 1764

Retour à la table des matières

Je crains, Monsieur, que vous n'alliez un peu vite en besogne dans vos projets ; il faudrait, quand rien ne vous presse, proportionner la maturité des délibérations à l'importance des résolutions. Pourquoi quitter si brusquement l'état que vous aviez embrassé, tandis que vous pouviez à loisir vous arranger pour en prendre un autre, si tant est qu'on puisse appeler un état le genre de vie que vous vous êtes choisi, et dont vous serez peut-être aussitôt rebuté que du premier ? Que risquiez-vous à mettre un peu moins d'impétuosité dans vos démarches, et à tirer parti de ce retard, pour vous confirmer dans vos principes, et pour assurer vos résolutions par une plus mûre étude de vousmême ? Vous voilà seul sur la terre dans l'âge où l'homme doit tenir à tout; je vous plains, et c'est pour cela que je ne puis vous approuver, puisque vous avez voulu vous isoler vous-même au moment où cela vous convenait le moins. Si vous croyez avoir suivi mes principes, vous vous trompez : vous avez suivi l'impétuosité de votre âge ; une démarche d'un tel éclat valait assurément la peine d'être bien pesée avant d'en venir à l'exécution. C'est une chose faite, je le sais : je veux seulement vous faire entendre que la manière de la soutenir ou d'en revenir demande un peu plus d'examen que vous n'en avez mis à la faire. 
Voici pis. L'effet naturel de cette conduite a été de vous brouiller avec Mme votre mère. Je vois, sans que vous me le montriez, le fil de tout cela; et, quand il n'y aurait que ce que vous me dites, à quoi bon aller effaroucher la conscience tranquille d'une mère, en lui montrant sans nécessité des sentiments différents des siens ? Il fallait, Monsieur, garder ces sentiments au dedans de vous pour la règle de votre conduite, et leur premier effet devait être de vous faire endurer avec patience les tracasseries de vos prêtres, et de ne pas changer ces tracasseries en persécutions, en voulant secouer hautement le joug de la religion où vous étiez né. Je pense si peu comme vous sur cet article, que quoique le clergé protestant me fasse une guerre ouverte, et que je sois fort éloigné de penser comme lui sur tous les points, je n'en demeure pas moins sincèrement uni à la communion de notre Église, bien résolu d'y vivre et d'y mourir s'il dépend de moi : car il est très consolant pour un croyant affligé de rester en communauté de culte avec ses frères, et de servir Dieu conjointement avec eux. Je vous dirai plus, et je vous déclare que si j'étais né catholique, je demeurerais catholique, sachant bien que votre Église met un frein très salutaire aux écarts de la raison humaine, qui ne trouve ni fond ni rive quand elle veut sonder l'abîme des choses, et je suis si convaincu de l'utilité de ce frein que je m'en suis moi-même imposé un semblable, en me prescrivant, pour le reste de ma vie, des règles de foi dont je ne me permets plus de sortir. Aussi je vous jure que je ne suis tranquille que depuis ce tempslà, bien convaincu que, sans cette précaution, je ne l'aurais été de ma vie. Je vous parle, Monsieur, avec effusion de cœur, et comme un père parlerait à son enfant. Votre brouillerie avec Mme votre mère me navre. J'avais dans mes malheurs la consolation de croire que mes écrits ne pouvaient faire que du bien : voulez-vous m'ôter encore cette consolation ? Je sais que s'ils font du mal, ce n'est que faute d'être entendus ; mais j'aurai toujours le regret de n'avoir pu me faire entendre. Cher Saint-Brisson, un fils brouillé avec sa mère a toujours tort : de tous les sentiments naturels, le seul demeuré parmi nous est l'affection maternelle. Le droit des mères est le plus sacré que je connaisse ; en aucun cas, on ne peut le violer sans crime. Raccommodez-vous donc avec la vôtre. Allez vous jeter à ses pieds ; à quelque prix que ce soit, apaisez-la ; soyez sûr que son cœur vous sera rouvert, si le vôtre vous ramène à elle. Ne pouvez-vous sans fausseté lui faire le sacrifice de quelques opinions inutiles, ou du moins les dissimuler? Vous ne serez jamais appelé à persécuter personne ; que vous importe le reste ? Il n'y a pas deux morales. Celle du christianisme et celle de la philosophie sont la même ; l'une et l'autre vous imposent ici le même devoir : vous pouvez le remplir, vous le devez; la raison, l'honneur, votre intérêt, tout le veut, et moi je l'exige pour répondre aux sentiments dont vous m'honorez. Si vous le faites, comptez sur mon amitié, sur toute mon estime, sur mes soins, si jamais ils vous sont bons à quelque chose. Si vous ne le faites pas, vous n'avez qu'une mauvaise tête; ou qui pis est, votre cœur vous conduit mal, et je ne veux conserver de liaisons qu'avec des gens dont la tête et le cœur soient sains. 


\title{
Lettre 93
}

\section{À M. Jean-André De Luc, banquier, rue de la Cité}

\author{
À Môtiers-Travers, \\ à Genève le 20 octobre 1764
}

\section{$\underline{\text { Retour à la table des matières }}$}

Je m'en vais, mon cher Monsieur, profiter peut-être fort indiscrètement de vos obligeantes offres ; car je sais que vous êtes fort occupé ; mais je vous prie de tenir toutes mes importunités pour non avenues si les objets dont elles traitent prennent le moins du monde sur vos occupations.

Je n'ai point reçu avec votre lettre la boîte de couleurs qui devait l'accompagner. Si elle n'est pas encore partie vous pourrez me l'envoyer par notre messager qui est actuellement en route pour Genève ou peut-être déjà arrivé. L'usage que j'en veux faire est d'enluminer des plantes et fleurs dans leurs couleurs naturelles et d'autres estampes et paysages pour une optique. Je connais ces boîtes de Nuremberg; les couleurs en sont mauvaises et falsifiées ; je voudrais avoir une petite provision des couleurs les plus nécessaires comme carmin, outremer, gomme-gutte, vert de Venise, vert de gris, encre de la Chine, etc., et je voudrais surtout que ces couleurs en petite quantité fussent bien choisies et aussi pures qu'il est possible. joignez-y aussi, je vous prie, un peu de gomme arabique ; car on ne trouve ici rien du tout. 
Le microscope est comme vous l'avez deviné pour la botanique, ainsi je désire qu'il ait un champ suffisant pour embrasser le pistil et les étamines d'une petite fleur. Du reste, je m'en rapporte absolument à vous.

C'est effectivement une optique telle que vous la décrivez dont nous avions parlé. Je n'aime point celles qui restant toutes ouvertes laissent de toutes parts entrer la lumière et présentent avec l'image les objets environnants. Vous me parlâtes d'une manière d'enclore tellement l'image dans la boîte par une espèce de cadre noir qu'on ne vît absolument que l'estampe. Voilà, Monsieur, ce que je désirerais, et si vous trouviez à Genève de bons verres, que vous connussiez quelque bon ouvrier que vous voulussiez bien diriger pour faire la boîte, je vous serais obligé de vouloir bien y donner quelques soins. Ces sortes de machines sont fort plates à moins qu'elles ne fassent tout à fait illusion, mais quand elles la font, elles sont très amusantes, et je sens que dans mon état, enfermé plus de six mois tous les ans, j'ai très grand besoin d'amusements qui fassent diversion aux excursions de ma tête et l'empêchent de me consumer dans ma prison.

Cherchant la plus grande illusion, il s'ensuit qu'il faut aussi les meilleures estampes : celles d'Angleterre me paraissent les plus propres à la chose ; il est vrai qu'elles sont extrêmement chères; si vous en pouviez rassembler une douzaine ou quinzaine de bien bonnes, cela me suffirait en attendant que j'en fisse chercher à Paris. Vous savez qu'il faut des lointains, des perspectives, des allées, avenues, galeries, marines, en un mot, tout ce qui chasse et prolonge l'espace ; l'architecture avec des cours et avant-cours, colonnades, etc., fait très bien aussi.

Ce n'est pas tout; me voici comme l'avare qui veut l'excellent à bon marché. Quoique les fantaisies soient dans mon état des choses presque nécessaires, je suis pourtant bien déterminé à renoncer à celle-là si elle passe un certain prix. Si vous jugez donc, Monsieur, que toute cette petite fourniture se puisse faire pour quatre ou cinq louis au plus, je puis les y mettre. Mais si elle passe, n'y pensons pas.

J'ai lu avec le plus grand plaisir la continuation des feuilles que vous m'avez fait parvenir. On ne peut rien de plus exact, de plus sensé, de mieux raisonné sans aucun verbiage. Quelquefois seulement, on n'y sent pas assez la liaison des choses, on ne les voit pas assez sortir les unes des autres. L'art d'écrire et d'intéresser est de faire que tout se tienne. Toute solution de continuité refroidit le lecteur. Il ne suffit pas que l'auteur ait un plan, il faut que le lecteur ne le perde jamais de vue. Assurément si cet ouvrage ne porte pas la lumière dans votre patrie, il faut qu'on y veuille fermer les yeux.

Recevez, Monsieur, mes excuses, mes remerciements, et mes salutations.

J'ai reçu les estampes, ce que je vous prie de dire à celui qui a pris la peine de les envoyer en attendant que je puisse lui écrire. 


\section{Lettre 94}

\section{À M. Du Peyrou, à Neuchâtel}

À Môtiers, le 4 novembre 1764

Retour à la table des matières

Bien des remerciements, Monsieur, du Dictionnaire philosophique. Il est agréable à lire ; il y règne une bonne morale ; il serait à souhaiter qu'elle fût dans le cœur de l'auteur et de tous les hommes. Mais ce même auteur est presque toujours de mauvaise foi dans les extraits de l'Écriture ; il raisonne souvent fort mal, et l'air de ridicule et de mépris qu'il jette sur des sentiments respectés des hommes, rejaillissant sur les hommes mêmes, m'apparaît un outrage fait à la société et punissable devant les tribunaux humains. Voilà mon sentiment et peut-être mon erreur, que je me crois permis de dire, mais que je n'entends faire adopter à qui que ce soit.

Je suis fort touché de ce que vous me marquez de la part de M. et Mme de Buffon. Je suis bien aise de vous avoir dit ce que je pensais de cet homme illustre avant que son souvenir réchauffât mes sentiments pour lui, afin d'avoir tout l'honneur de la justice que j'aime à lui rendre, sans que mon amour-propre s'en soit mêlé.

Ses écrits m'instruiront et me plairont toute ma vie. Je lui crois des égaux parmi ses contemporains en qualité de penseur et de philosophe, mais en qualité d'écrivain je ne lui en connais point. C'est la plus belle plume de son 
siècle; je ne doute point que ce ne soit là le jugement de la postérité. Un de mes regrets est de n'avoir pas été à portée de le voir davantage et de profiter de ses obligeantes invitations. Je sens combien ma tête et mes écrits auraient gagné dans son commerce. Je quittai Paris au moment de son mariage ; ainsi je n'ai point eu le bonheur de connaître Mme de Buffon, mais je sais qu'il a trouvé dans sa personne et dans son mérite l'aimable et digne récompense du sien. Que Dieu les bénisse l'un et l'autre de vouloir bien s'intéresser à ce pauvre proscrit. Leurs bontés sont une des consolations de ma vie : qu'ils sachent, je vous en supplie, que je les honore et les aime de tout mon cœur.

Je suis bien éloigné, Monsieur, de renoncer aux pèlerinages projetés. Si la ferveur de la botanique vous dure encore et que vous ne rebutiez pas un élève à barbe grise, je compte plus que jamais aller herboriser cet été sur vos pas. Mes pauvres Corses ont bien maintenant d'autres affaires que d'aller établir l'Utopie au milieu d'eux. Vous savez la marche des troupes françaises ; il faut voir ce qu'il en résultera. J'ai pourtant encore de la peine à croire que la France veuille devenir l'exécration de l'univers en livrant ce malheureux peuple à ses bouchers. Au reste si ce bel exploit la flatte si fort, il faudra qu'elle prenne le parti de détruire entièrement la nation corse, car c'est le seul moyen de soumettre l'île aux Génois. En attendant ce qu'il en arrivera, il faut gémir tout bas et aller herboriser.

Vous me rendez fier en me marquant que Mlle Bondely n'ose me venir voir à cause des bienséances de son sexe, et qu'elle a peur de moi comme d'un circoncis. Il y a plus de quinze ans que les jolies femmes me faisaient en France l'affront de me traiter comme un bonhomme sans conséquence, jusqu'à venir dîner avec moi tête-à-tête dans la plus insultante familiarité, jusqu'à m'embrasser dédaigneusement devant tout le monde, comme le grand-père de leur nourrice. Grâce au Ciel me voilà bien rétabli dans ma dignité, puisque les demoiselles me font l'honneur de ne m'oser venir voir.

Pendant mon séjour à Cressier, il m'est venu ici une lettre de $\mathrm{M}$. d'Escherny. À mon retour, je n'ai pas cru être à temps d'y répondre, sur le peu de séjour qu'il me marquait devoir faire à Paris. je vois, Monsieur, par votre lettre que j'aurais été à temps, mais que je n'y suis plus, et comme je n'ai ni lettre ni temps à perdre, j'attends le plaisir de le voir en ce pays. Vale. 


\section{Lettre 95}

\section{À M. Duclos}

Môtiers, le 13 janvier 1765

Retour à la table des matières

J'attendais, mon cher ami, pour vous remercier de votre présent que j'eusse eu le plaisir de lire cette nouvelle édition, et de la comparer avec la précédente; mais la situation violente où me jette la fureur de mes ennemis ne me laisse pas un moment de relâche ; et il faut renvoyer les plaisirs à des moments plus heureux, s'il m'est encore permis d'en attendre. Votre portrait n'avait pas besoin de la circonstance pour me causer de l'émotion ; mais il est vrai qu'elle en a été plus vive par la comparaison de mes misères présentes avec les temps où j'avais le bonheur de vous voir tous les jours. Je voudrais bien que vous me fissiez l'amitié de m'en donner une seconde épreuve pour mon portefeuille. Les vrais amis sont trop rares pour qu'en effet la planche ne restât pas longtemps neuve, si vous n'en donniez qu'une épreuve à chacun des vôtres ; mais j'ose dire ici, au nom de tous, qu'ils sont bien dignes que vous l'usiez pour eux.

Quoique je sache que vous n'êtes point fait pour en perdre, je suis peu surpris que vous ayez à vous plaindre de ceux avec lesquels j'ai été forcé de rompre. Je sens que quiconque est un faux ami pour moi n'en peut être un vrai pour personne. 
Ils travaillent beaucoup à me faciliter l'entreprise d'écrire ma vie, que vous m'exhortez de reprendre. Il vient de paraître à Genève un libelle effroyable, pour lequel la dame d'Epinay a fourni des mémoires à sa manière, lesquels me mettent déjà fort à mon aise vis-à-vis d'elle et de ce qui l'entoure. Dieu me préserve toutefois de l'imiter même en me défendant ! Mais, sans révéler les secrets qu'elle m'a confiés, il m'en reste assez de ceux que je ne tiens pas d'elle pour la faire connaître autant qu'il est nécessaire en ce qui se rapporte à moi. Elle ne me croit pas si bien instruit; mais, puisqu'elle m'y force, elle apprendra quelque jour combien j'ai été discret. je vous avoue, cependant, que j'ai peine encore à vaincre ma répugnance, et je prendrai du moins des mesures pour que rien ne paraisse de mon vivant. Mais j'ai beaucoup à dire, et je dirai tout; je n'omettrai pas une de mes fautes, pas même une de mes mauvaises pensées. Je me peindrai tel que je suis : le mal offusquera presque toujours le bien, et, malgré cela, j'ai peine à croire qu'aucun de mes lecteurs ose se dire, je suis meilleur que ne fut cet homme-là.

Cher ami, j'ai le cœur oppressé, j'ai les yeux gonflés de larmes ; jamais être humain n'éprouva tant de maux à la fois. je me tais, je souffre, et j'étouffe. Que ne suis-je auprès de vous ! du moins je respirerais. Je vous embrasse. 


\section{Lettre 96}

\section{À M. Du Peyrou, à Neuchâtel}

Ce vendredi 12 avril [1765]

\section{Retour à la table des matières}

Plus j'étais touché de vos peines, plus j'étais fâché contre vous ; et en cela j'avais tort; le commencement de votre lettre me le prouve. Je ne suis pas toujours raisonnable, mais j'aime toujours qu'on me parle raison. Je voudrais connaître vos peines pour les soulager, pour les partager, du moins. Les vrais épanchements du cœur veulent non seulement l'amitié mais la familiarité, et la familiarité ne vient que par l'habitude de vivre ensemble. Puisse un jour cette habitude si douce donner entre nous à l'amitié tous ses charmes ; je les sentirai trop bien pour ne pas vous les faire sentir aussi. La sentence de Ciceron que vous demandez est Amicus Plato, amicus Aristoteles, sed magis amica veritas. Mais vous pouvez la resserrer en n'employant que les deux premiers mots et les trois derniers, et souvenez-vous qu'elle emporte l'obligation de me dire mes vérités. Au lieu de vous dire précisément si vous devez employer le terme de Conclave inquisitorial, j'aime mieux vous exposer le principe sur lequel je me détermine en pareils doutes. Qu'une expression soit ou ne soit pas ce qu'on appelle française ou du bel usage, ce n'est pas de cela qu'il s'agit : on ne parle et l'on n'écrit que pour se faire entendre ; pourvu qu'on soit intelligible on va à son but, quand on est clair on y va encore mieux. Parlez donc clairement pour quiconque entend le français ; voilà la règle, et soyez sûr que fissiez-vous au surplus cinq cents barbarismes, vous n'en aurez pas moins bien écrit. Je vais 
plus loin, et je soutiens qu'il faut quelquefois faire des fautes de grammaire pour être plus lumineux ; c'est en cela, et non dans toutes les pédanteries du purisme que consiste le véritable art d'écrire. Ceci posé, j'examine sur cette règle le Conclave inquisitorial, et je me demande si ces deux mots réunis présentent à l'esprit une idée bien une et bien nette, et il me paraît que non. Le mot conclave en latin ne signifie qu'une chambre retirée, mais en français il signifie l'assemblée des cardinaux pour l'élection du pape. Cette idée n'a nul rapport à la vôtre et elle exclut même celle de l'inquisition. Voyez si peut-être en changeant le premier mot et mettant par exemple celui de Synode inquisitorial, vous n'iriez pas mieux à votre but. Il semble même que le mot de synode pris pour une assemblée de ministres, contrastant avec celui d'inquisitorial, ferait mieux sentir l'inconséquence de ces messieurs. L'union seule de ces deux mots ferait à mon sens un argument sans réplique, et voilà en quoi consiste la finesse de l'emploi des mots. Pardon, Monsieur, de mes longueries ; mais comme vous pouvez avoir quelquefois dans l'honnêteté de votre âme l'occasion de parler au public pour le bien de la vérité, j'ai cru que vous seriez peut-être bien aise de connaître la règle générale qui me paraît toujours bonne à suivre dans le choix des mots.

Comme je suis très persuadé que votre ouvrage n'aura nul besoin de ma révision, je vous prie de m'en dispenser à cause de la matière. Il convient que je puisse dire que je n'y ai aucune part et que je ne l'ai pas vu. Il est même inutile de m'envoyer aucune des pièces que vous vous proposez d'y mettre, puisqu'il me suffira de les trouver toutes dans l'imprimé.

$\mathrm{Au}$ train dont la neige tombe nous en aurons ce soir plus d'un pied : cela et mon état encore empiré m'ôtera le plaisir de vous aller voir aussi tôt que je l'espérais. Sitôt que je le pourrai comptez que vous verrez celui qui vous aime.

Je n'ai qu'une chose à vous recommander. Ne cherchez point d'épigrammes. Avant de jeter vos idées sur le papier retournez-les dans votre tête jusqu'à ce qu'elles y soient nettes et lumineuses. Alors écrivez-les clairement, simplement, brièvement mais sans gêne. Rien de plus, et tout ira bien. Ne direz-vous rien du Roi, de Mylord Maréchal, du Conseil d'État? 


\section{Lettre 97}

\section{À M. [de Voltaire]}

[31 mai 1765]

$\underline{\text { Retour à la table des matières }}$

Si M. de Voltaire a dit qu'au lieu d'avoir été secrétaire de l'ambassadeur de France à Venise, j'ai été son valet, $M$. de Voltaire en a menti comme un impudent.

Si dans les années 1743 et 1744, je n'ai pas été premier secrétaire de l'ambassade de France, si je n'ai pas fait les fonctions de secrétaire d'ambassade, si je n'en ai pas eu les honneurs au Sénat de Venise, j'en aurai menti moi-même. 


\section{Lettre 98}

\section{À M. Guy, chez Mme la veuve Duchesne, rue Saint-Jacques, à Paris}

À Môtiers-Travers, le 7 septembre 1765

$\underline{\text { Retour à la table des matières }}$

L'émeute est telle ici, Monsieur, parmi la canaille que la nuit dernière mes portes ont été forcées, mes vitres cassées et une pierre comme la tête est venue frapper presque jusqu'à mon lit.

On a tenu ce matin une justice extraordinaire, mais les assassins ne sont pas découverts. Le ministre s'est fait ouvertement chef d'une bande de coupejarrets. J'ai reçu ce matin une députation d'une communauté voisine dont je suis membre pour m'offrir asile, logement, défense et toute assistance possible. Avant d'accepter, je pars demain pour un petit voyage, et comme il est à présumer que j'aurai cette nuit à soutenir un siège, je suis bien armé, bien escorté, bien résolu, et ne soyez point en peine de moi, je vous réponds que les brigands trouveront à qui parler. On croit que le ministre devient absolument enragé. Vous sentez que jusqu'à ce que je sois fixé, je ne puis revoir ni même recevoir d'épreuve. Tout ceci est parvenu à un degré de violence qui ne peut durer. Je vous écrirai sitôt que l'orage sera passé. En attendant, ne soyez point en peine de moi ; tout va bien, à la santé près. Je vous embrasse. 


\title{
Lettre 99
}

\section{À M. Guy, libraire à Paris}

\author{
À l'île Saint-Pierre, au lac de Bienne, \\ le 1er octobre 1765
}

\section{Retour à la table des matières}

Je reçois, Monsieur, votre lettre du 10 septembre ; vous ne voyez pas que la crise que je viens d'essuyer puisse influer sur le voyage projeté ; elle y influe pourtant si bien que je suis désormais hors d'état d'y songer. Forcé, quand j'y pensais le moins, à quitter un village dont le ministre s'est fait capitaine de coupe-jarrets, et me voyant refuser le feu et l'eau chez toutes les puissances, il m'a fallu chercher un asile, et songer à un déménagement qui, pour être petit, ne laisse pas d'être embarrassant pour un homme dans mon état. Les soins nécessaires pour me ménager une retraite et des gens qui m'y souffrent ne me laissent point songer à un voyage qui ne me sauverait aucun des embarras que j'éprouve, et ne me laisserait pas le temps et les moyens d'y pourvoir. La petite île où je suis m'a paru propre à y fixer ma retraite. Elle est très agréable ; on y trouve ni gens d'église, ni brigands ameutés par eux. Toute la population consiste en une seule maison occupée par des gens très honnêtes, très gais, d'un très bon commerce, et chez qui l'on trouve tout ce qui est nécessaire à la vie. La grande difficulté est que l'île et la maison appartiennent à MM. de Berne, qui sont à la fois les propriétaires et les souverains, et vous savez que Leurs Excellences m'ont interdit, il y a trois ans, la demeure dans leurs États. Or vous savez aussi que les gouvernements révoquent très souvent le bien qu'ils font, mais jamais le mal ; c'est une des premières maximes d'état par toute la terre. Reste donc à voir si, après m'avoir 
chassé de leur pays, ils voudront bien me tolérer dans leur maison. Si j'obtiens d'eux cette grâce, je suis tout déterminé à fixer mon séjour dans cette île, et à y finir mes misères et mes jours.

Dans cette position, je serai hors d'état d'entretenir avec vous une correspondance aussi régulière qu'auparavant, puisqu'il n'y a point de postes au voisinage, que la communication avec la terre ferme, en tout temps incommode et coûteuse, est sujette à être interceptée ou par les vents ou par les glaces. Cependant, vous pourrez continuer à m'écrire par Pontarlier ; $M$. Junet continuera à me faire parvenir vos lettres; il ne serait pas même impossible que je visse ici mes épreuves, si les retards et l'irrégularité des envois ne rendaient cette révision trop incommode pour vous. Vous pourriez essayer, et l'expérience nous apprendrait ce qui peut se faire.

Je n'ai pas encore reçu la petite caisse, mais je sais qu'elle est à Pontarlier. Je me félicite beaucoup d'avoir pris le goût de la botanique ; elle me sera d'un grand secours dans cette île, si j'y fixe mon séjour. Donnez-moi de vos nouvelles et de celles de M. Lenieps et de M. Coindet. Mlle le Vasseur qui m'est venue joindre, vous fait ses salutations et vous réitère ses remerciements. En passant à Neuchâtel, elle a fait usage de la lettre de change, qui lui est venue bien à propos. L'argent ne nous manque pas, mais où achète-t-on le repos ? Voilà la seule chose dont j'ai besoin, et que je ne puis trouver. Bonjour, Monsieur. 


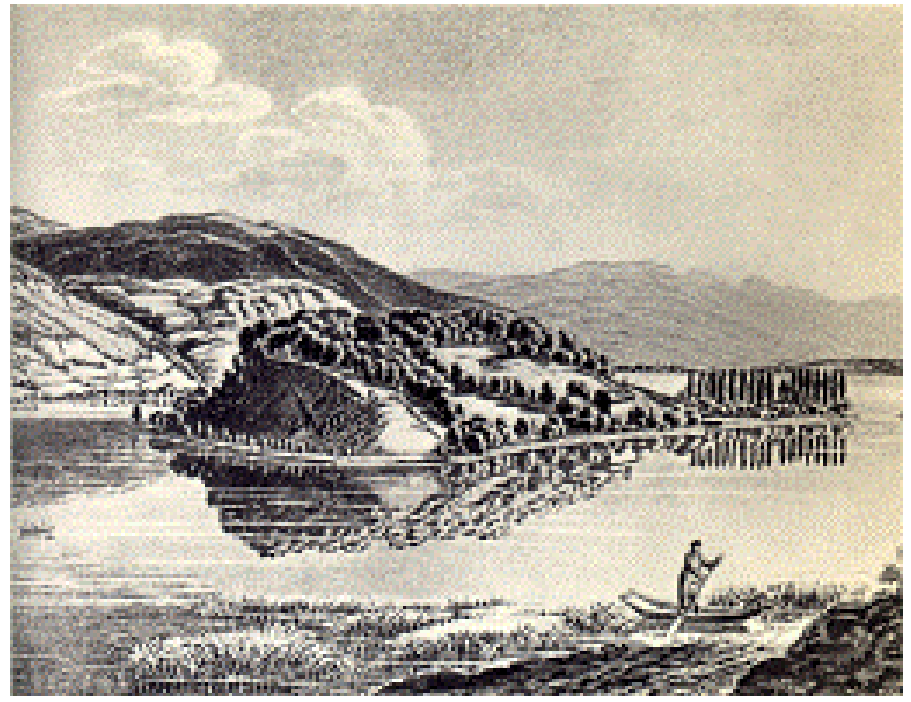

\section{Illustration 6}

Vue de l'île de Saint-Pierre

$\underline{\text { Retour à la table des matières }}$ 


\section{Lettre 100}

\section{À Monsieur Du Peyrou, à Neuchâtel}

À l'île, ce 17 octobre [1765]

$\underline{\text { Retour à la table des matières }}$

On me chasse d'ici, mon cher hôte ; le climat de Berlin est trop rude pour moi. Je me détermine à passer en Angleterre où j'aurais dû d'abord aller. J'aurais grand besoin de tenir conseil avec vous, mais je ne puis aller à Neuchâtel ; voyez si vous pourriez par charité vous dérober à vos affaires pour faire un tour jusqu'ici. Je vous embrasse. 


\title{
Lettre 101
}

\section{À M. [de Graffenried, bailli de Nidau]}

\author{
À l'île Saint-Pierre, le 20 octobre 1765
}

$\underline{\text { Retour à la table des matières }}$

Monsieur,

Le triste état où je me trouve et la confiance que j'ai dans vos bontés me déterminent à vous supplier de vouloir bien faire agréer à LL.EE. une proposition qui tend à me délivrer une fois pour toutes des agitations que j'éprouve, et qui va mieux, ce me semble, au but de ceux qui me poursuivent que ne fera mon éloignement. J'ai consulté ma situation, mon âge, mon humeur, mes forces : rien de tout cela ne me permet d'entreprendre en ce moment et sans préparation de longs et pénibles voyages, d'aller errant dans des pays froids, et de me fatiguer à chercher un asile dans une saison où mes infirmités ne me permettent pas même de sortir de la chambre. Après ce qui s'est passé, je ne puis me résoudre à rentrer dans le territoire de Neuchâtel où la protection du prince et du gouvernement ne saurait me garantir des fureurs d'une populace excitée, et qui ne connaît aucun frein, et vous comprenez, Monsieur, qu'aucun des États voisins ne voudra ou n'osera donner retraite à un malheureux si durement chassé de celui-ci. Dans cette extrémité, je ne vois pour moi qu'une seule ressource, et quelque effrayante qu'elle paraisse, je la prendrai non seulement sans répugnance, mais avec empressement si LL. EE. y veulent bien consentir. C'est qu'il leur plaise que je passe en prison le reste de mes jours dans quelqu'un de leurs châteaux ou tel autre lieu dans leurs 
États qu'il leur semblera bon de choisir. J'y vivrai à mes dépens et je donnerai sûreté de n'être jamais à leur charge. Je me soumets à n'avoir ni papier ni plume ni aucune communication au dehors si ce n'est pour l'absolue nécessité et par le canal de ceux qui seront chargés de moi. Seulement qu'on me laisse avec l'usage de quelques livres la liberté de me promener quelquefois dans un jardin, et je suis content.

Ne croyez point, Monsieur, qu'un expédient si violent en apparence soit le fruit du désespoir. J'ai l'esprit très calme en ce moment; je me suis donné le temps d'y bien penser et c'est d'après un sérieux examen de mon état que je m'y détermine. Considérez, je vous supplie, que si ce parti est extraordinaire, ma situation l'est encore plus. Mes malheurs sont sans exemple. La vie orageuse que je mène sans relâche depuis plusieurs années serait terrible pour un homme en santé ; jugez ce qu'elle doit être pour un pauvre infirme épuisé de maux et d'ennuis et qui n'aspire qu'à mourir en paix. Toutes les passions sont éteintes dans mon cœur, il n'y reste que l'ardent désir du repos et de la retraite. Je les trouverais dans l'habitation que je demande ; à couvert des importuns et exempt de nouvelles catastrophes, j'attendrais tranquillement la dernière, et n'étant plus instruit de ce qui se passe dans le monde, je ne serais plus attristé de rien. J'aime la liberté sans doute ; mais la mienne n'est point au pouvoir des hommes, et ce ne seront ni des murs ni des clés qui me l'ôteront. Cette captivité, Monsieur, me paraît si peu terrible, je sens si bien que j'y jouirais de tout le bonheur que je peux espérer dans cette vie que c'est par là même que, quoiqu'elle doive délivrer mes ennemis de toute inquiétude de ma part, je n'ose espérer l'obtenir. Mais je ne veux rien avoir à me reprocher vis-àvis de moi, non plus que vis-à-vis d'autrui, je veux pouvoir me rendre le témoignage que j'ai tenté tous les moyens praticables et honnêtes qui pouvaient m'assurer le repos et prévenir les nouveaux orages qu'on me force d'aller chercher.

Je connais, Monsieur, les sentiments d'humanité dont votre âme généreuse est remplie ; je sens tout ce qu'une grâce de cette espèce peut vous coûter à demander. Mais quand vous aurez compris que vu ma situation cette grâce en serait en effet une très grande pour moi, ces mêmes sentiments qui font votre répugnance me sont garants que vous saurez la surmonter. J'attends pour prendre définitivement mon parti qu'il vous plaise de m'honorer de quelque réponse.

Daignez, Monsieur, je vous supplie, agréer mes excuses et mon respect. 


\section{Lettre 102}

\section{À M. [Du Peyrou]}

[Fin octobre 1765]

$\underline{\text { Retour à la table des matières }}$

Il est impossible que nul autre que moi déchiffre ces brouillons qui contiennent l'histoire de ma jeunesse jusqu'à mon départ pour Paris en 1741. Gardez-les toutefois ; si jamais nous nous revoyons, je pourrai les mettre au net ; sinon, vous en pourrez toujours tirer par-ci par-là quelques anecdotes qui vous expliqueront bien des choses du caractère de votre ami qui n'est connu de personne. 
Jean-Jacques Rousseau, Lettres (1728-1778)

\title{
Septième partie
}

\section{L'exil : L'Angleterre}

\author{
$1765-1767$
}

$\underline{\text { Retour à la table des matières }}$

Le délire de persécution et d'interprétation va désormais priver Rousseau d'une partie de ses forces et «troubler sa tête » (la formule revient fréquemment dans ses lettres). Sans doute ce délire trouve-t-il en lui, dans sa nature hypersensible, ses racines secrètes. Il reste que Rousseau a été réellement persécuté, et que ses anciens amis devenus ses adversaires, Grimm, Diderot, Mme d'Epinay, inquiets à la pensée qu'ils allaient paraître dans les récits des Confessions, se sont concertés pour mettre leur auteur hors d'état de nuire. Mais ce qu'il faut remarquer, c'est que les persécutions qu'il a essuyées de la part des puissances temporelles et spirituelles l'ont laissé sans rancune et presque sans amertume. Au contraire, le «complot» à l'origine duquel son imagination n'a jamais cessé de placer ceux-là mêmes qu'il avait le plus aimés, l'a jeté dans le plus complet désarroi. Hume lui a-t-il voulu du mal en l'entraînant en Angleterre ? Certes non. Mais Hume est un être susceptible, et tout autant un observateur indiscret; il lui plaît de traiter son protégé en enfant, et le jour où l'enfant s'effraye, se fâche et accuse, il s'irrite à son tour ; aux clameurs de Jean-Jacques, répond alors «l'Exposé succinct » de la querelle. Jusqu'au printemps 1767 , l'exilé se maintient à Wootton, passant par des alternatives de terreur et d'abandon. Le 1er mai, il s'échappe, désireux de « sortir de l'Angleterre ou de la vie » (lettre au général Conway). 


\section{Lettre 103}

\section{À M. David Hume}

Strasbourg, le 4 décembre 1765

Retour à la table des matières

Vos bontés, Monsieur, me pénètrent autant qu'elles m'honorent. La plus digne réponse que je puisse faire à vos offres est de les accepter, et je les accepte. je partirai dans cinq ou six jours pour aller me jeter entre vos bras ; c'est le conseil de Mylord Maréchal, mon protecteur, mon ami, mon père ; c'est celui de Mme de Boufflers dont la bienveillance éclairée me guide autant qu'elle me console ; enfin j'ose dire, c'est celui de mon cœur, qui se plaît à devoir beaucoup au plus illustre de mes contemporains, dont la bonté surpasse la gloire. Je soupire après une retraite solitaire et libre où je puisse finir mes jours en paix. Si vos soins bienfaisants me la procurent, je jouirai tout ensemble et du seul bien que mon cœur désire, et du plaisir de le tenir de vous. Je vous salue, Monsieur, de tout mon cœur. 


\section{Lettre 104}

\section{À Mme [de Verdelin]}

À Wootton, le 9 avril 1766

$\underline{\text { Retour à la table des matières }}$

C'est à regret, Madame, que je vais affliger votre bon cœur, mais il faut absolument que vous connaissiez ce David Hume, à qui vous m'avez livré, comptant me procurer un sort tranquille. Depuis notre arrivée en Angleterre, où je ne connais personne que lui, quelqu'un qui est très au fait, et fait toutes mes affaires, travaille en secret, mais sans relâche, à m'y déshonorer, et réussit avec un succès qui m'étonne. Tout ce qui vient de m'arriver en Suisse a été déguisé ; mon dernier voyage de Paris et l'accueil que j'y ai reçu ont été falsifiés. On a fait entendre que j'étais généralement méprisé et décrié en France pour ma mauvaise conduite, et que c'est pour cela principalement que je n'osais m'y montrer. On a mis dans les papiers publics que, sans la protection de $\mathrm{M}$. Hume, je n'aurais osé dernièrement traverser la France pour m'embarquer à Calais ; mais qu'il m'avait obtenu le passeport dont je m'étais servi. On a traduit et imprimé comme authentique la fausse lettre du roi de Prusse, fabriquée par d'Alembert, et répandue à Paris par leur ami commun Walpole. On a pris à tâche de me présenter à Londres avec Mlle le Vasseur dans tous les jours qui pouvaient jeter sur moi du ridicule. On a fait supprimer, chez un libraire, une édition et traduction qui s'allait faire des lettres de M. Du Peyrou. Dans moins de six semaines, tous les papiers publics, qui d'abord ne parlaient de moi qu'avec honneur, ont changé de langage, et n'en ont plus parlé qu'avec mépris. 
La cour et le public ont de même rapidement changé sur mon compte; et les gens surtout avec qui M. Hume a le plus de liaisons sont ceux qui se distinguent par le mépris le plus marqué, affectant, pour l'amour de lui, de vouloir me faire la charité plutôt qu'honnêteté, sans le moindre témoignage d'affection ni d'estime, et comme persuadés qu'il n'y a que des services d'argent qui soient à l'usage d'un homme comme moi. Durant le voyage, il m'avait parlé du jongleur Tronchin comme d'un homme qui avait fait près de lui des avances traîtresses, et dont il était fondé à se défier : il se trouve cependant qu'il loge à Londres avec le fils dudit jongleur, vit avec lui dans la plus grande intimité, et vient de le placer auprès de $\mathrm{M}$. Michel, ministre à Berlin, où ce jeune homme va, sans doute, chargé d'instructions qui me regardent. J'ai eu le malheur de loger deux jours chez M. Hume, dans cette même maison, venant de la campagne à Londres. Je ne puis vous exprimer à quel point la haine et le dédain se sont manifestés contre moi dans les hôtesses et les servantes, et de quel accueil infâme on y a régalé Mlle le Vasseur. Enfin je suis presque assuré de reconnaître, au ton haineux et méprisant, tous les gens avec qui M. Hume vient d'avoir des conférences; et je l'ai vu cent fois, même en ma présence, tenir indirectement les propos qui pouvaient le plus indisposer contre moi ceux à qui il parlait. Deviner quel est son but, c'est ce qui m'est difficile, d'autant plus qu'étant à sa discrétion et dans un pays dont j'ignore la langue, toutes mes lettres ont passé jusqu'ici par ses mains ; qu'il a toujours été très avide de les voir et de les avoir ; que de celles que j'ai écrites, peu sont parvenues; que presque toutes celles que j'ai reçues avaient été ouvertes; et celles d'où j'aurais pu tirer quelque éclaircissement, probablement supprimées. Je ne dois pas oublier deux petites remarques: l'une, que le premier soir depuis notre départ de Paris, étant couchés tous trois dans la même chambre, j'entendis au milieu de la nuit David Hume s'écrier plusieurs fois à pleine voix, Je tiens J.J. Rousseau; ce que je ne pus alors interpréter que favorablement ; cependant il y avait dans le ton, je ne sais quoi d'effrayant et de sinistre que je n'oublierai jamais. La seconde remarque vient d'une espèce d'épanchement que j'eus avec lui après une autre occasion de lettre que je vais vous dire. J'avais écrit le soir sur sa table à Mme de Chenonceaux. Il était très inquiet de savoir ce que j'écrivais, et ne pouvait presque s'abstenir d'y lire. je ferme ma lettre sans la lui montrer : il la demande avidement, disant qu'il l'enverra le lendemain par la poste ; il faut bien la donner; elle reste sur sa table. Lord Nuneham arrive ; David sort un moment, je ne sais pourquoi. Je reprends ma lettre en disant que j'aurai le temps de l'envoyer le lendemain : mylord Nuneham s'offre de l'envoyer par le paquet de l'ambassadeur de France ; j'accepte. David rentre ; tandis que lord Nuneham fait son enveloppe, il tire son cachet; David offre le sien avec tant d'empressement qu'il faut s'en servir par préférence. On sonne, lord Nuneham donne la lettre au domestique pour l'envoyer sur-le-champ chez l'ambassadeur. Je me dis en moi-même : Je suis sûr que David va suivre le domestique. Il n'y manqua pas, et je parierais tout au monde que ma lettre n'a pas été rendue, ou qu'elle avait été décachetée.

À souper, il fixait alternativement sur Mlle le Vasseur et sur moi des regards qui m'effrayèrent et qu'un honnête homme n'est guère assez malheureux pour avoir reçus de la nature. Quand elle fut montée pour s'aller coucher dans le chenil qu'on lui avait destiné, nous restâmes quelque temps sans rien dire : il me fixa de nouveau du même air ; je voulus essayer de le fixer à mon tour, il me fut impossible de soutenir son affreux regard. Je sentis mon âme se troubler, j'étais dans une émotion horrible. Enfin le remords de 
mal juger d'un si grand homme sur des apparences prévalut; je me précipitai dans ses bras tout en larmes, en m'écriant : Non, David Hume n'est pas un traître, cela n'est pas possible ; et s'il n'était pas le meilleur des hommes, il faudrait qu'il en fût le plus noir. À cela mon homme, au lieu de s'attendrir avec moi, ou de se mettre en colère, au lieu de me demander des explications, reste tranquille, répond à mes transports par quelques caresses froides, en me frappant de petits coups sur le dos, et s'écriant plusieurs fois : Mon cher monsieur ! Quoi donc, mon cher monsieur ? J'avoue que cette manière de recevoir mon épanchement me frappa plus que tout le reste. Je partis le lendemain pour cette province, où j'ai rassemblé de nouveaux faits, réfléchi, combiné, et conclu, en attendant que je meure.

J'ai toutes mes facultés dans un bouleversement qui ne me permet pas de vous parler d'autre chose. Madame, ne vous rebutez pas par mes misères, et daignez m'aimer encore, quoique le plus malheureux des hommes.

J'ai vu le docteur Gatti en grande liaison avec notre homme et deux seules entrevues m'ont appris certainement que, quoi que vous en puissiez dire, le docteur Gatti ne m'aime pas. Je dois vous avertir aussi que la boîte que vous m'avez envoyée par lui avait été ouverte, et qu'on y avait mis un autre cachet que le vôtre. Il y a presque de quoi rire à penser combien mes curieux ont été punis. 


\section{Lettre 105}

\section{À Mme de Luze-Warney, Neuchâtel, en Suisse}

À Wootton, le 10 mai 1766

\section{Retour à la table des matières}

Suis-je assez heureux, Madame, pour que vous pensiez quelquefois à mes torts, et pour que vous me sachiez mauvais gré d'un si long silence ? J'en serais trop puni si vous n'y étiez pas sensible. Dans le tumulte d'une vie orageuse, combien j'ai regretté les douces heures que je passais près de vous ? Combien de fois les premiers moments du repos après lequel je soupirais ont été consacrés d'avance au plaisir de vous écrire? J'ai maintenant celui de remplir cet engagement, et les agréments du lieu que j'habite m'invitent à m'y occuper de vous, Madame, et de M. de Luze qui m'en a fait trouver beaucoup à y venir.

Quoique je n'aie point directement de ses nouvelles, j'ai su qu'il était arrivé à Paris en bonne santé, et j'espère qu'au moment où j'écris cette lettre il est heureusement de retour auprès de vous. Quelque intérêt que je prenne à ses avantages, je ne puis m'empêcher de lui envier celui-là, et je vous jure, Madame, que cette paisible retraite perd pour moi beaucoup de son prix, quand je songe qu'elle est à trois cents lieues de vous. je voudrais vous la décrire avec tous ses charmes, afin de vous tenter je n'ose dire de m'y venir voir, mais de la venir voir ; et moi j'en profiterais. 
Figurez-vous, Madame, une maison seule, non fort grande, mais fort propre, bâtie à mi-côte sur le penchant d'un vallon dont la pente est assez interrompue pour laisser des promenades de plain-pied sur la plus belle pelouse de l'univers. Au devant de la maison, règne une grande terrasse d'où l'œil suit dans une demi-circonférence de quelques lieues un paysage formé de prairies, d'arbres, de fermes éparses, de maisons plus ornées, et bordée en forme de bassin par des coteaux élevés qui bornent agréablement la vue quand elle ne pourrait aller au delà. Au fond du vallon qui sert à la fois de garenne et de pâturage, on entend murmurer un ruisseau qui d'une montagne voisine vient couler parallèlement à la maison, et dont les petits détours, les cascades, sont dans une telle direction que des fenêtres et de la terrasse l'œil peut assez longtemps suivre son cours. Le vallon est garni, par places, de rochers et d'arbres où l'on trouve des réduits délicieux et qui ne laissent pas de s'éloigner assez de temps en temps du ruisseau, pour offrir sur ses bords des promenades commodes à l'abri des vents et même de la pluie, en sorte que par les plus vilains temps du monde je vais tranquillement herboriser sous les roches avec les moutons et les lapins ; mais hélas, Madame, je n'y trouve point de scordium. Au bout de la terrasse, à gauche, sont des bâtiments rustiques et le potager ; à droite sont les bosquets et un jet d'eau. Derrière la maison est un pré entouré d'une lisière de bois, laquelle, tournant au delà du vallon, couronne le parc, si l'on peut donner ce nom à une enceinte à laquelle on a laissé toutes les beautés de la nature. Ce pré mène, à travers un petit village qui dépend de la maison, à une montagne, qui en est à une demi-lieue et dans laquelle sont diverses mines de plomb que l'on exploite. Ajoutez qu'aux environs on a le choix des promenades, soit dans des prairies charmantes, soit dans des bois, soit dans des jardins à l'anglaise, moins peignés mais de meilleur goût que ceux des Français.

La maison, quoique petite, est très logeable et bien distribuée. Il y a dans le milieu de la façade un avant-corps à l'anglaise par lequel la chambre du maître de la maison et la mienne qui est au-dessus ont une vue de trois côtés. Son appartement est composé de plusieurs pièces sur le devant et d'un grand salon sur le derrière ; le mien est distribué de même excepté que je n'occupe que deux chambres entre lesquelles et le salon est une espèce de vestibule ou d'antichambre fort singulière, éclairée par une large lanterne de vitrage au milieu du toit.

Avec cela, Madame, je dois vous dire qu'on fait ici bonne chère, à la mode du pays, c'est-à-dire simple et saine, précisément comme il me la faut. Le pays est humide et froid, ainsi les légumes ont peu de goût, le gibier aucun ; mais la viande y est excellente, le laitage abondant et bon. Le maître de cette maison la trouve trop sauvage et s'y tient peu. Il en a de plus riantes qu'il lui préfère, et auxquelles je la préfère, moi, par la même raison. J'y suis non seulement le maître, mais mon maître, ce qui est bien plus. Point de grand village aux environs ; la ville la plus voisine en est à deux lieues : par conséquent peu de voisins désœuvrés. Sans le ministre qui m'a pris dans une affection singulière, je serais ici dix mois de l'année absolument seul.

Que pensez-vous de mon habitation, Madame ? la trouvez-vous assez bien choisie et ne croyez-vous pas que pour en préférer une autre il faille être ou bien sage ou bien fou ? Hé bien ! Madame, il s'en prépare une peu loin du Biez, plus près du Tertre que je regretterai sans cesse et où, malgré l'envie, 
mon cœur habitera toujours. Je ne la regretterais pas moins quand celle-ci m'offrirait tous les autres biens possibles, excepté celui de vivre avec ses amis. Mais au reste, après vous avoir peint le beau côté, je ne veux pas vous dissimuler qu'il y en a d'autres, et que comme dans toutes les choses de la vie les avantages y sont mêlés d'inconvénients. Ceux du climat sont grands, il est tardif et froid, le pays est beau mais triste, la nature y est engourdie et paresseuse. À peine avons-nous déjà des violettes, les arbres n'ont encore aucunes feuilles, jamais on n'y entend de rossignols. Tous les signes du printemps disparaissent devant moi. Mais ne gâtons pas le tableau vrai que je viens de faire : il est pris dans le point de vue où je veux vous montrer ma demeure afin que vos idées s'y promènent avec plaisir. Ce n'est qu'auprès de vous, Madame, que je pourrais trouver une société préférable à la solitude. Pour la former dans cette province, il y faudrait transporter votre famille entière, une partie de Neuchâtel et presque tout Yverdon. Encore, après cela, comme l'homme est insatiable, me faudrait-il vos bois, vos monts, vos vignes, enfin tout, jusqu'au lac et ses poissons. 


\section{Lettre 106}

\section{À M. [le marquis de Mirabeau] (fragments)}

[Vers le 25 mars 1767]

\section{$\underline{\text { Retour à la table des matières }}$}

Votre lettre, Monsieur, du 20 février m'est parvenue assez promptement, et je puis vous assurer que les choses très agréables que j'y ai lues ne sont pourtant pas ce qui m'en a fait le plus de plaisir. Mais ne vous attendez pas toutefois de ma part à une correspondance en règle ; c'est un engagement que je ne veux pas prendre, parce que je me sens hors d'état de le tenir, même avec vous. Tout soin qu'il faut remplir me coûte et me pèse, par l'unique raison qu'il le faut, mais j'ai particulièrement une telle aversion pour écrire des lettres, que je ne me livre au plaisir d'en recevoir des gens que j'aime, qu'après m'être assuré qu'ils n'exigent pas de réponse. Pour un si grand ennemi de l'injustice, je ne vous paraîtrai peut-être pas trop conséquent. Je crois pourtant l'être, car, selon moi, c'est une injustice aux autres de m'imposer, même à mon profit, une loi que je ne puis supporter; et ce n'en est pas une à moi de me refuser à cette loi en renonçant, quoiqu'à regret, à ses avantages. Il est certain que vos lettres me plaisent et me font du bien; mais écrire me fait un mal extrême ; écrire est un devoir qui me tue ; je ne puis me soumettre à ce devoir que par la plus forte nécessité. Dans tous mes projets de béatitude temporelle, n'avoir ni montre ni écritoire a toujours été mon article favori. Si vous voulez porter jusqu'au bout la générosité que vous m'avez montrée, faites-moi du bien 
gratuitement, n'exigez point dans mes réponses plus d'exactitude que je n'y en puis mettre. Lorsqu'elle n'y sera pas, accusez-moi de négligence, non d'indifférence; vous auriez tort très assurément. Enfin, puisqu'il faut toujours que je sois en reste avec vous, ne marchandez pas sur le plus ou le moins, et passez, de grâce, la même inégalité dans le nombre et la mesure de nos lettres qu'il faut bien passer, malgré vous et moi, dans la valeur de leur contenu.

\section{(Autre rédaction :)}

Rien ne me fatigue tant que d'écrire, si ce n'est que de penser; et il me faudrait fatiguer un mois pour répondre à une de vos pages. N'exigez pas de moi à proportion de ce que vaut ce que vous m'écrivez, mais à proportion de ce qu'il vous coûte, et d'une page j'aurai payé dix de vos lettres ; au lieu que, par l'autre calcul, ce serait tout le contraire, et tout mon temps n'y suffirait pas. Vous voulez m'offrir, dites-vous, une autre philosophie. De la philosophie, à moi ? Eh ! Monsieur le Marquis, vous me faites un honneur que je ne mérite guère. Les systèmes de toute espèce sont trop au-dessus de moi : je n'en mets aucun dans ma vie et dans ma conduite. Réfléchir, comparer, chicaner, persister, combattre, n'est plus mon affaire ; je me laisse aller à l'impression du moment sans résistance et même sans scrupule ; car je suis parfaitement sûr que mon cœur n'aime que ce qui est bien. Tout le mal que j'ai fait en ma vie, je l'ai fait par réflexion; et le peu de bien que j'ai pu faire, je l'ai fait par impulsion. Cela fait que je me livre à mes penchants avec confiance; ils sont si simples, si faciles à suivre : pour les contenter, il en coûte si peu aux autres et à moi-même, qu'en vérité c'est vouloir escrimer à toute force que de se roidir contre eux. Vous supposez que je fuis la société par aversion pour elle : vous vous trompez dans les deux points. Je ne la hais ni ne la fuis. J'en hais la gêne que j'y trouve, et je hais cette gêne mortellement. Sans elle la société me serait agréable ; mais la gêne l'empoisonne, et je renonce à un bien dont je peux me passer, pour éviter un mal qui m'est insupportable. Les autres me disent qu'ils n'y trouvent pas cette gêne : tant mieux pour eux ; mais je l'y trouve, moi. Voulez-vous disputer sur un fait de sentiment ? Il faut que je parle, quand je n'ai rien à dire; que je reste en place, quand je voudrais marcher ; assis, quand je voudrais être debout ; enfermé dans une chambre, quand je soupire après le grand air ; que j'aille ici, quand je voudrais aller ailleurs ; que je mange à l'heure des autres; que je marche de leur pas ; que je réponde à leurs compliments ou à leurs sarcasmes; que je réponde à des billets verts et rouges, dont je n'entends pas un seul mot; que je raisonne avec les raisonneurs ; que je suive le phébus des beaux esprits ; que je dise des fadeurs aux femmes; enfin que je fasse toute la journée tout ce que je sais le moins et qui me déplaît le plus, et que je ne fasse rien, je ne dis pas seulement de ce que je voudrais faire, mais de ce que la nature et les plus pressants besoins me demandent, à commencer par celui de pisser, plus fréquent et plus tourmentant pour moi qu'aucun autre. Je frémis encore à m'imaginer dans un cercle de femmes, forcé d'attendre qu'un beau diseur ait fini sa phrase, n'osant sortir sans qu'on me demande si je m'en vais, trouvant dans un escalier bien éclairé d'autres belles dames qui me retardent, une cour pleine de carrosses toujours en mouvement, prêts à m'écraser, des femmes de chambre qui me regardent, MM. les laquais qui bordent les murs et se moquent de moi ; ne trouvant pas une muraille, une voûte, un malheureux petit coin qui me convienne ; ne pouvant en un mot pisser qu'en grand spectacle et sur quelque noble jambe à bas blancs. 
Monsieur, quand il n'y aurait que ce seul article, il suffirait pour me faire prendre en horreur l'habitation d'une ville. Moi qui même déteste les plaines et cherche toujours les lieux fourrés et sombres pour pouvoir, deux cents fois le jour, m'arrêter à mon aise, à l'instant du besoin, sans être vu même des paysans. Je me lève à l'heure qu'on se couche à Paris ; je me couche avant qu'on n'y soupe ; ma journée est presque finie avant qu'on l'y commence. Mon premier soin est d'aller errant en bonnet de nuit dans la campagne ; je vais et viens, rentre et ressors à tous les quarts d'heure. Je ne peux vivre que sub die ; je ne respire qu'au milieu des prés et des bois ; j'étouffe dans une chambre, dans une salle, dans une maison, dans une rue, dans la place Vendôme; le pavé, le gris des murs et des toits, me donne le cauchemar. Et vous voulez que j'aille passer ma vie, ou plutôt l'achever au milieu de tout cela, et il faudra que j'en passe les trois meilleurs quarts encloîtré dans cette triste ou plutôt dans cette horrible prison, ne sachant que faire, que devenir, n'ayant que la ressource effroyable des livres, ou de la funeste écritoire; ou bien il faudra qu'à soixante ans je renonce à mes vieilles habitudes, pour m'en faire de toutes nouvelles, comme si je me portais assez bien pour soutenir un pareil changement car, avec les habitudes que j'ai prises et les goûts invincibles dont je me sens subjugué à mon âge, si la dure nécessité me rappelle jamais au séjour des villes, ce ne sera que pour m'y faire enterrer.

Je consens fort que vous n'approuviez pas ma manière de vivre, pourvu que vous n'entrepreniez pas de m'en faire changer. Il n'y a point de raisonnement qui me puisse engager d'en prendre une autre, tant que je sentirai que la mienne me convient. Je vous promets de chercher la société dès qu'elle me sera nécessaire : jusque là permettez que je reste comme je suis ; moi, je vous permets de tout mon cœur, en échange, de trouver que j'ai très grand tort.

Je ne vous ai parlé jusqu'ici que du physique : commençons toujours par examiner ce point et nous passerons aux autres...

Je n'ai besoin ni de votre bourse, ni de vos amis, ni de votre crédit, ni de votre savoir, ni presque de votre temps, et dans deux jours, dans vingt-quatre heures, vous pouvez être débarrassé de moi. J'ai besoin de votre âme vertueuse, de votre bon sens, de quelques soins faciles et simples et du plus profond secret, voilà tout; et avec cela vous pouvez assurer la paix des derniers jours d'un infortuné qui met en vous seul toute son espérance.

Je ne suis point homme à vous importuner de mes lamentations ; je n'ai à vous parler ni de mes malheurs, ni de mes ennemis, ni de leurs complots, ni de personne au monde que de moi seul; tout ce que j'ai à vous dire est l'affaire d'une minute...

Mais je n'en suis plus aux essais, je les ai faits. J'en suis maintenant au résultat et je m'y tiens... 


\section{Lettre 107}

\section{À M. [Davenport]}

À Wootton, le 30 avril 1767

$\underline{\text { Retour à la table des matières }}$

Un maître de maison, Monsieur, est obligé de savoir ce qui se passe dans la sienne, surtout à l'égard des étrangers qu'il y reçoit. Si vous ignorez ce qui se passe dans la vôtre à mon égard depuis Noël, vous avez tort : mais le tort le moins excusable est d'avoir oublié votre promesse et d'être allé tranquillement vous établir à Davenport, sans vous embarrasser si l'homme qui vous attendait ici sur votre parole y était à son aise ou non. En voilà plus qu'il ne faut pour me faire prendre mon parti. Demain, Monsieur, je quitte votre maison. J'y laisse mon petit équipage et celui de Mlle le Vasseur, et je laisse le produit de mes estampes et livres pour sûreté des frais faits pour ma dépense depuis Noël. Je n'ignore ni les embûches qui m'attendent, ni l'impuissance où je suis de m'en garantir : mais, Monsieur, j'ai vécu ; il ne me reste qu'à finir avec courage une carrière passée avec honneur. Il est aisé de m'opprimer, mais difficile de m'avilir. Voilà ce qui me rassure contre les dangers que je vais courir. Recevez derechef mes vifs et sincères remerciements de la noble hospitalité que vous m'avez accordée. Si elle avait fini comme elle a commencé, j'emporterais de vous un souvenir bien tendre, qui ne s'effacerait jamais dans mon cœur. Adieu, Monsieur; je regretterai souvent la demeure que je quitte, mais je regretterai beaucoup davantage d'avoir eu un hôte aussi aimable, et de n'en avoir pu faire mon ami. 
Je laisse chez vous trois malles pleines, auxquelles les clés sont attachées ; je laisse sur la commode de la petite chambre les livres qui vont à la masse de l'acquisition faite par M. Dutens : la plupart, bouquins qui ne valent pas le transport, mais dont quelques-uns sont assez bons pour racheter l'inutilité du reste.

Sur la tablette du milieu de l'armoire aux livres qui est dans la chambre de Mlle le Vasseur sont mes livres de botanique qui auraient besoin d'une petite caisse, prise sur leur mesure. Sur la tablette au-dessous, dans la même armoire, est un recueil de musique choisie, où, si Mlle Davenport cultive cet art, elle trouvera des choses excellentes, et que je la supplie de conserver en mémoire de moi. J'ai remis dans la caisse des livres de M. Davenport ceux qu'il avait eu la bonté de me prêter. 


\title{
Lettre 108
}

\section{To Richd Davenport Esqr. at Wootton, Ashburnbag, Derbyshire}

\author{
Turn at Stilton \\ A Spalding en Lincolnshire, \\ le 11 mai 1767 (lundi)
}

\section{Retour à la table des matières}

Vous devez être offensé, Monsieur ; mais vous avez assez d'entrailles pour cesser de l'être quand vous songerez à mon sort. Je préférais la liberté au séjour de votre maison; ce sentiment est bien excusable. Mais je préfère infiniment le séjour de votre maison à toute autre captivité et je préférais toute autre captivité à celle où je suis, qui est horrible, et qui, quoi qu'il arrive, ne saurait durer. Si vous voulez bien, Monsieur, me recevoir derechef chez vous, je suis prêt à m'y rendre au cas qu'on m'en laisse la liberté ; et quand j'y serais, après l'expérience que j'ai faite, difficilement serais-je tenté d'en ressortir pour chercher de nouveaux malheurs. Si ma proposition vous agrée, tâchez, Monsieur, de me le faire savoir par quelque voie sûre, et de faciliter mon retour d'ici chez vous. Si vous ne faites que m'écrire par la poste, votre lettre me parviendra d'autant moins que je suis logé chez le maître de poste ; j'attends votre réponse avec impatience ; moins pour moi, je vous l'avoue, dont le cœur est mort désormais à tout plaisir, mais pour l'infortunée compagne de ma destinée dont le sort me fait frémir d'horreur si venant à me perdre elle reste ici seule et abandonnée. Au lieu qu'en me perdant chez vous, il lui reste au moins un appui : car je vous connais trop pour craindre que vous l'abandonniez en pareil cas. Je ne vous en dirai pas davantage, Monsieur ; mais je lâche cette lettre, doutant si elle vous parviendra. 


\section{Lettre 109}

\section{À M. le général Conway}

Douvres [vers le 18 ou 19 mai 1767]

Retour à la table des matières

Monsieur,

J'ose vous supplier de vouloir bien prendre sur vos affaires le temps de lire cette lettre, seul et avec attention. C'est à votre jugement éclairé, c'est à votre âme saine que j'ai à parler. Je suis sûr de trouver en vous tout ce qu'il faut pour peser avec sagesse et avec équité ce que j'ai à vous dire. J'en serai moins sûr si vous consultez tout autre que vous.

J'ignore avec quel projet j'ai été amené en Angleterre : il y en a eu un, cela est certain ; j'en juge par son effet, aussi grand, aussi plein qu'il aurait pu l'être, quand ce projet eût été une affaire d'État. Mais comment le sort, la réputation d'un pauvre infortuné, pourraient-ils jamais faire une affaire d'État ? C'est ce qui est trop peu concevable pour que je puisse m'arrêter à pareille supposition. Cependant, que les hommes les plus élevés, les plus distingués, les plus estimables, qu'une nation tout entière, se prêtent aux passions d'un particulier qui veut en avilir un autre, c'est ce qui se conçoit encore moins. Je vois l'effet ; la cause m'est cachée, et je me suis tourmenté vainement pour la pénétrer; mais, quelle que soit cette cause, les suites en seront les mêmes ; et c'est de ces suites qu'il s'agit ici. Je laisse le passé dans son obscurité ; c'est maintenant l'avenir que j'examine. 
J'ai été traité dans mon honneur aussi cruellement qu'il soit possible de l'être. Ma diffamation est telle en Angleterre que rien ne l'y peut relever de mon vivant. Je prévois cependant ce qui doit arriver après ma mort, par la seule force de la vérité, et sans qu'aucun écrit posthume de ma part s'en mêle ; mais cela viendra lentement, et seulement quand les révolutions du gouvernement auront mis tous les faits passés en évidence. Alors ma mémoire sera réhabilitée ; mais de mon vivant je ne gagnerai rien à cela.

Vous concevez, Monsieur, que cette ignominie intolérable au cœur d'un homme d'honneur rend au mien le séjour de l'Angleterre insupportable. Mais on ne veut pas que j'en sorte ; je le sens, j'en ai mille preuves, et cet arrangement est très naturel ; on ne doit pas me laisser aller publier au-dehors les outrages que j'ai reçus dans l'île, ni la captivité dans laquelle j'ai vécu ; on ne veut pas non plus que mes mémoires passent dans le continent et ailleurs instruire une autre génération des maux que m'a fait souffrir celle-ci. Quand je dis on, j'entends les premiers auteurs de mes disgrâces ; à Dieu ne plaise que l'idée que j'ai, Monsieur, de votre respectable caractère me permette jamais de penser que vous ayez trempé dans le fond du projet! Vous ne me connaissiez point ; on vous a fait croire de moi beaucoup de choses ; l'illusion de l'amitié vous a prévenu pour mes ennemis, ils ont abusé de votre bienveillance, et, par une suite de mon malheur ordinaire, les nobles sentiments de votre cœur, qui vous auraient parlé pour moi si j'eusse été mieux connu de vous, m'ont nui par l'opinion qu'on vous en a donnée. Maintenant le mal est sans remède ; il est presque impossible que vous soyez désabusé ; c'est ce que je ne suis pas à portée de tenter : et, dans l'erreur où vous êtes, la prudence veut que vous vous prêtiez aux mesures de mes ennemis.

J'oserai pourtant vous faire une proposition qui, je crois, doit parler également à votre cœur et à votre sagesse : la terrible extrémité où je suis réduit en fait, je l'avoue, ma seule ressource ; mais cette ressource en est peutêtre également une pour mes ennemis contre les suites désagréables que peut avoir pour eux mon dernier désespoir.

Je veux sortir, Monsieur, de l'Angleterre ou de la vie ; et je sens bien que je n'ai pas le choix. Les manœuvres sinistres que je vois m'annoncent le sort qui m'attend, si je feins seulement de vouloir m'embarquer. J'y suis déterminé pourtant, parce que toutes les horreurs de la mort n'ont rien de comparable à celles qui m'environnent. Objet de la risée et de l'exécration publique, je ne me vois environné que des signes affreux qui m'annoncent ma destinée. C'est trop souffrir, Monsieur, et toute interdiction de correspondance m'annonce assez que, sitôt que l'argent qui me reste sera dépensé, je n'ai plus qu'à mourir. Dans ma situation, ce sera un soulagement pour moi, et c'est le seul désormais qui me reste ; mais j'ai bien de la peine à penser que mon malheur ne laisse après lui nulle trace désagréable. Quelque habilement que la chose ait été concertée, quelque adroite qu'en soit l'exécution, il restera des indices peu favorables à l'hospitalité nationale. Je suis malheureusement trop connu pour que ma fin tragique ou ma disparition demeurent sans commentaires; et quand tant de complices garderaient le secret, tous mes malheurs précédents mettront trop de gens sur la trace de celui-ci pour que les ennemis de mes ennemis (car tout le monde en a) n'en fassent pas quelque jour un usage qui pourra leur déplaire. On ne sait jusqu'où ces choses-là peuvent aller, et l'on n'est plus maître de les 
arrêter quand une fois elles marchent. Convenez, Monsieur, qu'il y aurait quelque avantage à pouvoir se dispenser d'en venir à cette extrémité.

Or on le peut, et prudemment on le doit. Daignez m'écouter. Jusqu'à présent j'ai toujours pensé à laisser après moi des mémoires qui missent au fait la postérité des vrais événements de ma vie : je les ai commencés, déposés en d'autres mains, et désormais abandonnés. Ce dernier coup m'a fait sentir l'impossibilité d'exécuter ce dessein, et m'en a totalement ôté l'envie.

Je suis sans espoir, sans projet, sans désir même de rétablir ma réputation détruite, parce que je sais qu'après moi cela viendra de soi-même, et qu'il me faudrait des efforts immenses pour y parvenir de mon vivant. Le découragement m'a gagné ; la douce amitié, l'amour du repos, sont les seules passions qui me restent, et je n'aspire qu'à finir paisiblement mes jours dans le sein d'un ami. Je ne vois plus d'autre bonheur pour moi sur la terre ; et, quand j'aurais désormais à choisir, je sacrifierais tout à cet unique désir qui m'est resté.

Voilà, Monsieur, l'homme qui vous propose de le laisser aller en paix, et qui vous engage sa foi, sa parole, tous les sentiments d'honneur dont il fait profession, et toutes ces espérances sacrées qui font ici-bas la consolation des malheureux, que non seulement il abandonne pour toujours le projet d'écrire sa vie et ses mémoires mais qu'il ne lui échappera jamais, ni de bouche, ni par écrit, un seul mot de plainte sur les malheurs qui lui sont arrivés en Angleterre ; qu'il ne parlera jamais de M. Hume, ou qu'il n'en parlera qu'avec honneur ; et que, lorsqu'il sera pressé de s'expliquer sur les plaintes indiscrètes qui, dans le fort de ses peines, lui sont quelquefois échappées, il les rejettera sans mystère sur son humeur aigrie et portée à la défiance et aux ombrages par des malheurs continuels. Je pourrai parler de la sorte avec vérité, n'ayant que trop d'injustes soupçons à me reprocher par ce malheureux penchant, ouvrage de mes désastres, et qui maintenant y met le comble. Je m'engage solennellement à ne jamais écrire quoi que ce puisse être, et sous quelque prétexte que ce soit, pour être imprimé ou publié, ni sous mon nom, ni en anonyme, ni de mon vivant, ni après ma Mort.

Vous trouverez, Monsieur, ces promesses bien fortes ; elles ne le sont pas trop pour la détresse où je suis. Vous me demanderez des garants pour leur exécution ; cela est très juste : les voici ; je vous prie de les peser.

Premièrement, tous mes papiers relatifs à l'Angleterre y sont encore dans un dépôt. Je les ferai tous remettre entre vos mains, et j'y en ajouterai quelques autres assez importants qui sont restés dans les miennes. Je partirai à vide et sans autres papiers qu'un petit portefeuille absolument nécessaire à mes affaires, et que j'offre à visiter.

Secondement, vous aurez cette lettre signée pour garant de ma parole ; et, de plus, une autre déclaration que je remettrai en partant à qui vous me prescrirez, et telle que, si j'étais capable de jamais l'enfreindre de mon vivant, ou après ma mort, cette seule pièce anéantirait tout ce que je pourrais dire, en montrant dans son auteur un infâme qui, se jouant de ses promesses les plus solennelles, ne mérite d'être écouté sur rien. Ainsi mon travail détruisant son propre objet en rendrait la peine aussi ridicule que vaine. 
En troisième lieu, je suis prêt à recevoir toujours avec le même respect et la même reconnaissance la pension dont il plaît au Roi de m'honorer. Or je vous demande, Monsieur, si, lorsque honoré d'une pension du prince, j'étais assez vil, assez infâme pour mal parler de son gouvernement, de sa nation et de ses sujets, il serait possible en aucun temps qu'on m'écoutât sans indignation, sans mépris, et sans horreur. Monsieur, je me lie par les liens les plus forts et les plus indissolubles. Vous ne pouvez pas supposer que je veuille rétablir mon honneur par des moyens qui me rendraient le plus vil des mortels.

Il y a, Monsieur, un quatrième garant, plus sûr, plus sacré que tous les autres, et qui vous répond de moi, c'est mon caractère connu pendant cinquante et six ans. Esclave de ma foi, fidèle à ma parole, si j'étais capable de gloire encore, je m'en ferais une illustre et fière de tenir plus que je n'aurais promis ; mais, plus concentré dans moi-même, il me suffit d'avoir en cela la conscience de mon devoir. Eh! Monsieur, pouvez-vous penser que, de l'humeur dont je suis, je puisse aimer la vie en portant la bassesse et le remords dans ma solitude? Quand la droiture cessera de m'être chère, c'est alors que je serai vraiment mort au bonheur.

Non, Monsieur, je renonce pour jamais à tous souvenirs pénibles. Mes malheurs n'ont rien d'assez amusant pour les rappeler avec plaisir ; je suis assez heureux si je suis libre, et que je puisse rendre mon dernier soupir dans le sein d'un ami. Je ne vous promets en ceci que ce que je me promets à moimême, si je puis goûter encore quelques jours de paix avant ma mort.

Je n'ai parlé jusqu'ici, Monsieur, qu'à votre raison : je n'ai qu'un mot maintenant à dire à votre cœur. Vous voyez un malheureux réduit au désespoir, n'attendant plus que la manière de sa dernière heure. Vous pouvez rappeler cet infortuné à la vie, vous pouvez vous en rendre le sauveur, et du plus misérable des hommes en faire encore le plus heureux. Je ne vous en dirai pas davantage, si ce n'est ce dernier mot qui vaut la peine d'être répété : je vois mon heure extrême qui se prépare ; je suis résolu, s'il le faut, de l'aller chercher, et de périr ou d'être libre ; il n'y a plus de milieu. 
Jean-Jacques Rousseau, Lettres (1728-1778)

\section{Huitième partie}

La vie cachée

Trye, Bourgoin, Monquin

$1767-1770$

\section{Retour à la table des matières}

Pour comprendre cette fin de vie, il faut penser, comme l'a écrit Jean Guéhenno, que «Jean-Jacques a été traqué et en surveillance comme a pu l'être un juif des années $1940 »$ (car le décret de prise de corps n'a pas été rapporté). Sa sensibilité et tout son être étaient d'une contexture trop délicate pour résister à une pareille pression. Rousseau est condamné maintenant à suspecter tout le monde, même ceux qui l'admirent, qui le caressent - ceux-là surtout. Il est payé pour savoir ce que valent les compliments ; en réalité c'est lui qui doit payer toujours, qui se dépense et s'use horriblement à tous les obstacles. Puisque le cri public fait de lui un méchant, il se voudra «le meilleur des hommes »; parce que le sentiment de sa faute le sollicite en secret, il se posera en innocent, et il proclamera la culpabilité générale d'un siècle corrompu. Tout ce qui lui arrive - mais rien de ce qui lui arrive ne trouve sa fin ailleurs que dans le monde de l'imagination tragique - entre dans un système inexorable de compensations, que commandent d'obscurs rouages. Mais non! Il y a des jours d'oubli, des moments de grâce, que la musique fait naître, ou la cueillette ou l'étude des plantes (la botanique lui devient comme 
un exercice spirituel !). Un quart de vent et le ciel s'éclaire ; l'esprit d'enfance n'a jamais abandonné Jean-Jacques.

Ses protecteurs sont maintenant Mirabeau le physiocrate, homme terrible et «ami des hommes », et surtout un prince du sang, Conti, qui ne l'a jamais perdu de vue après son retour en France. À Bourgoin, à l'Auberge de la Fontaine-d'Or, Rousseau a connu des journées qui sont parmi les plus sombres; mais il reprend cœur à une lieue de là, dans la ferme isolée de Monquin (commune de Maubec), face au paysage des Alpes ; en novembre 1769, sous une impulsion mystérieuse, il décide de dire adieu à la botanique qui l'empêchait «de remplir d'indispensables devoirs»: il se met à la rédaction des livres VII à XII des Confessions (qu'il avait renoncé à achever), puis il gagnera Paris pour affronter ses adversaires. 


\section{Lettre 110}

\section{À M. le marquis de Mirabeau}

Ce vendredi 19 juin 1767

Retour à la table des matières

Je lirai votre livre, puisque vous le voulez; ensuite, j'aurai à vous remercier de l'avoir lu : mais il ne résultera rien de plus de cette lecture que la confirmation des sentiments que vous m'avez inspirés et de mon admiration pour votre grand et profond génie, ce que je me permets de vous dire en passant et seulement une fois. Je ne vous réponds pas même de vous suivre toujours, parce qu'il m'a toujours été pénible de penser, fatigant de suivre les pensées des autres, et qu'à présent, je ne le puis plus du tout. Je ne vous remercie point, mais je sors de votre maison fier d'y avoir été admis, et plus désireux que jamais de conserver les bontés et l'amitié du maître. Du reste, quelque mal que vous pensiez de la sensibilité prise pour toute nourriture, c'est l'unique qui m'est restée; je ne vis plus que par le cœur. Je veux vous aimer autant que je vous respecte : c'est beaucoup ; mais voilà tout; n'attendez jamais de moi rien de plus. J'emporterai si je puis votre livre de plantes ; s'il m'embarrasse trop, je le laisserai, dans l'espoir de revenir quelque jour le lire plus à mon aise. Adieu, mon cher et respectable hôte ; je pars plein de vous, et content de moi, puisque j'emporte votre estime et votre amitié. 


\section{Lettre 111 \\ À M. Coindet, Hôtel le Blanc, rue de Cléry, à Paris}

À Gisors, le 27 juin au soir [1767]

$\underline{\text { Retour à la table des matières }}$

Je suis venu ici, cher Coindet, au-devant de mon chien avec M. Cochois à qui j'assurais bien en venant qu'infailliblement il serait arrivé malheur au pauvre animal, et qui se moquait de moi comme de raison. Le carrosse arrive, on interroge le cocher, qui daigne à peine nous écouter et qui, dit-il, n'a point de chien. On le presse, on l'importune. Il l'a, dit-il, oublié à Pontoise. Tel a été le sort final du malheureux Sultan, et tel est le mien en toute chose. Adieu. 


\section{Lettre 112}

\section{À M. Coindet, à l'Hôtel le Blanc, rue de Cléry, à Paris}

Ce 28 juin [1767]

$\underline{\text { Retour à la table des matières }}$

Je me hâte de vous dire qu'on vient de ramener mon chien. J'en suis redevable à la précaution que vous avez prise, et que j'ignorais, de faire graver sur son collier le nom du château. J'ai reçu aussi votre envoi ; je vous remercie de tout et vous embrasse de tout mon coeur.

\section{Renou.}

Je signe exprès mon nom, afin que vous ne mettiez plus le $t$ dont vous nous gratifiez à l'insu de nos ancêtres, et qui, s'il passait contre l'orthographe de nos titres, serait capable de plonger dans la roture l'ancienne et illustre maison des Renou. 


\section{Lettre 113}

\section{À Mme [la marquise de Verdelin]}

Au Château de Trye, le 22 juillet 1767

\section{$\underline{\text { Retour à la table des matières }}$}

Que je vous plains, Madame, connaissant si bien votre cœur de mère, de voir toujours par les rechutes d'une fille chérie tromper l'attente du succès de vos soins pour sa guérison. N'ayez plus cette attente si souvent et si cruellement trompée, vos soins ne se relâcheront pas, mais leur inutilité vous tourmentera moins. Il y a quoi qu'on en dise, des situations où l'espérance même est cruelle, et où c'est une sorte de repos de n'en avoir plus. Je sens cette sorte de repos, Madame, tâchez de l'avoir de même à cet égard, et qu'il soit à jamais le seul où ce triste remède puisse être à votre usage.

Tous les détails que votre excellent cœur vous dicte, Madame, sur l'établissement champêtre dont vous me donnez le projet et dont vous voulez si généreusement me faciliter l'exécution sont autant de jouissances anticipées sur ma reconnaissance ; mais en vérité je suis rebuté pour jamais de tout projet et ne veux plus vivre qu'au jour la journée. Les choses de la vie ne valent pas les soins qu'elles nous coûtent et pour moi je suis déterminé à les laisser aller désormais leur train naturel à mon égard; au tournant des malheurs qui m'entraînent je ne veux pas joindre celui d'y vouloir résister ; que les coups de la dure nécessité me frappent à leur aise, je ne daignerai pas sortir de ma place pour leur échapper. 
J'en éprouve ici des plus pénibles auxquels je m'étais le moins attendu : car honoré des bontés et de la protection du maître de cette maison, je n'imaginais guère que je serais livré aux dédains de ses valets et aux insultes tant de la canaille qui les suit que de celle qu'ils ameutent. Il m'est impossible d'imaginer quelle main donne le premier branle à tout cela ; mais il est certain qu'il y en a une. Je vois dans le détail quelques causes, mais qui ne me paraissent pas proportionnées aux effets. La première est mon équipage et celui de ma sœur, un peu moins que bourgeois. Dans un protégé du Prince traité avec tant de distinction, l'on s'attendait à voir un homme à grands airs ; du galon, des rubans noirs ou rouges, un plumet, du moins une épée. Imaginez, Madame, à quel point ma figure a dû frapper des gens pleins de tout cela. Ils ont cru que le Prince se moquait d'eux et qu'il leur envoyait quelque faquin d'espion pour examiner leur conduite, et vous concevez qu'ils ne sont pas curieux de cet examen. Quand on m'a vu aller seul herborisant dans les bois, je suis devenu un faiseur d'Orviétan dont le Prince s'était engoué parce qu'il lui promettait la pierre philosophale, et comme on s'attend à me voir au premier jour chassé ignominieusement on croit faire d'avance la cour à S. A. en prévenant obligeamment ce soin de sa part. Le commandant de l'équipage de chasse, homme à ce qu'on dit très haut et très vain, parait outré de me voir occuper un appartement qu'il aurait peut-être voulu pour lui-même, et surtout de savoir qu'il ne tient qu'à moi d'aller à la chasse et à la pêche, grâce dont vous croyez que je n'ai pas abusé. Deux jours après mon arrivée est venu ici un nouveau concierge qui dès l'abord s'est montré fort mal disposé pour moi. Soit que mon voisinage l'incommode, soit qu'il trouve mauvais que je n'aie point été mis dans sa dépendance, soit comme on le prétend qu'il me croit placé ici par Mme de Boufflers dont il ose parler sur un ton à mériter une punition exemplaire, cet homme est à la tête de ceux qui se flattent de me faire sortir d'ici à force de désagréments. Il m'a même fait enfermer plusieurs fois tantôt hors du château tantôt dedans, et il a fallu que l'officier du Prince, pour éviter à l'avenir le même inconvénient, fit faire une autre clé du château pour moi. Le jardinier qui a eu l'ordre de me fournir des légumes, l'a trouvé fort mauvaise, m'a fait insulter par ses garçons conjointement avec les palefreniers, valets de chiens et autres gens dont je ne connais pas un seul : ils ont soulevé contre moi tout le village et les villages voisins; le vicaire s'est mis de la partie ; je ne saurais faire un pas dans le château ni dehors sans y recevoir quelque marque de dédain et de malveillance. L'officier du Prince a fait mettre en prison un garçon jardinier pour lequel j'ai voulu intercéder ; l'officier n'a pas paru content de me voir ainsi compter sur mon crédit. Il m'a dit que si je voulais être protégé il fallait le laisser faire, et sentant l'importance dont il est pour moi de ne pas indisposer le seul homme sous la sauvegarde duquel je suis, au milieu de tant d'ennemis, je l'ai laissé et je le laisserai faire sans plus me mêler de rien. Grâce au Ciel M. le P. de C. va revenir, l'équipage et sa suite vont retourner à l'Île-Adam et je puis espérer de rester ici un peu plus tranquille. Mais tranquille ou non, je suis bien déterminé à demeurer quoi qu'il arrive et à ne point sortir d'ici à moins que je n'en sois tout à fait chassé. Il n'est pas possible que S. A. ignore absolument ce qui s'est passé et je suis sûr que pour peu qu'elle en sache elle sera indignée et y mettra ordre pour l'avenir. Mais le public qui, quand les malheurs me viennent chercher, dit toujours que c'est moi qui les cherche, ne manquera pas de dire, aussi sagement qu'à son ordinaire, que je ne puis rester en repos nulle part; ce qui ne serait que trop vrai s'il voulait dire qu'en quelque lieu que je me réfugie on ne me laisse en 
repos nulle part. Au reste, comme je disais d'abord, les causes que je viens d'exposer ne suffisent pas pour expliquer ce qui se passe ; car il paraît, par la contenance de ceux dont j'aurais à me plaindre, qu'ils ne craignent rien, et que quand même on ferait contre eux des plaintes, ils sont très sûrs de l'impunité. Ce qui me semble annoncer qu'ils se sentent appuyés en secret de quelqu'un qui a du crédit. Voilà, Madame, à quoi je ne comprends rien. Quoi qu'il en soit, $\mathrm{j}$ 'attends et mets tout au pis.

L'ancienne habitude d'une confiance qui vous peut devenir importune, mais qui m'est toujours douce, vous attire, Madame, ces longs verbiages ; je vous supplie de les pardonner à la cause qui les produit.

Vous m'exhortez d'écrire à M. Davenport, pour le tirer de l'inquiétude où il est sur mon sort et qui dites-vous le rend malade: on vous trompe, Madame, sur ces deux points. Le mal qui retient M. Davenport dans sa chambre est la goutte à laquelle je n'ai certainement aucune part, et il n'a pu avoir aucune inquiétude par l'incertitude de ce que j'étais devenu, puisque depuis mon départ d'auprès de lui jusqu'à mon arrivée ici je lui ai écrit deux ou trois fois toutes les semaines, et que j'ai reçu moi-même de ses lettres assez souvent pour être assuré que toutes les miennes lui étaient parvenues. Ainsi, Madame, je vous supplie et vous conseille de vous fier un peu moins sur ce qui me regarde à la bonne foi des correspondants que vous pouvez avoir dans ce pays-là. Mes hommages, je vous supplie, aux trois grâces et à leur mère. Mon adresse est à M. Manourry, lieutenant des chasses de S. A. S. Mgr le Prince de Conti pour remettre à M. Renou au Château de Trye par Gisors. 


\section{Lettre 114}

\section{Au prince de Conti}

À Trye, le 19 novembre 1767

$\underline{\text { Retour à la table des matières }}$

Pardonnez, Monseigneur, mes longues importunités. Il convient que vous sachiez ce qui se passe ici, ou du moins ce que j'en sais moi-même. Je ne ferai que narrer ; je contiendrai les élans d'indignation qui m'étouffent.

V. A. S. a pu connaître dans quelles dispositions j'attendais M. Du Peyrou. Le moment où je l'embrassai me donna la plus pure et la plus vive joie que j'aie jamais sentie, et d'autant plus vive que j'osais à peine y compter. J'avais toujours craint qu'on n'apportât quelque obstacle à sa venue. Je connais mes ennemis, je sais ce qu'ils savent faire. Ils savaient que M. Du Peyrou était dépositaire de tous mes papiers, de tous mes secrets, de tous mes projets : ils n'ignoraient pas que celui d'aller finir mes jours avec lui était le projet favori de mon cœur ; ils savaient que je ne pouvais rien faire sans lui. Son voyage en Hollande excitait leur attention ; ils supposaient, et bien faussement, je le jure, qu'il était chargé de ma part de quelque affaire avec Rey. Tout cela me faisait présumer qu'ils ne me laisseraient pas jouir tranquillement de cette entrevue. Je ne prévoyais pas qu'au lieu d'y porter obstacle, ils sauraient en tirer parti.

Il arriva, très affaibli d'une longue convalescence, mais passablement remis d'une attaque de goutte qu'il avait eue à Paris, laquelle n'avait pas été si bien décidée qu'à l'ordinaire, et n'avait pas aussi nettement fini. En quittant les 
extrémités, elle avait reparu à la hanche, à l'épaule ; presque en même temps, il avait eu la grippe, qui n'avait pas eu non plus son progrès, et qu'il avait un peu brusquée pour venir plus tôt ici. On lui avait fait prendre des bouillons préparés, du petit-lait, des purgatifs qui lui avaient affaibli l'estomac ; on lui avait fait faire dans les oreilles des injections d'esprit d'urine, mêlé peut-être d'autres drogues, qu'il continuait à mon insu et qui pouvaient à la longue offenser son cerveau. Il passa huit à dix jours avec moi, gai, mangeant bien, dormant bien, reprenant journellement ses forces, prenant beaucoup plus de café que je n'aurais voulu, et n'ayant d'autre incommodité que quelques légères coliques, qu'il attribuait à l'eau que nous buvions, et quelques légers ressentiments de goutte, auxquels il faisait peu d'attention.

Un matin j'appris qu'il avait passé une très mauvaise nuit sans dormir, et dans des agitations continuelles: quand il vint pour déjeuner, il avait un visage de déterré ; il ne put achever sa tasse. Il nous montra sa main droite un peu enflée, et nous dit que son pied l'était aussi ; je lui trouvai de la fièvre. Il me proposa d'aller prendre l'air, espérant que cela se dissiperait ; j'y consentis. À peine pouvait-il mettre un pied devant l'autre; il était d'un assoupissement si profond qu'il s'asseyait, ou plutôt s'y laissait tomber, sous chaque arbre qu'il rencontrait et s'y endormait à l'instant. Cet assoupissement m'effraya plus encore que l'abattement et la fièvre. Je le crus menacé d'une attaque d'apoplexie, et après l'avoir ramené, non sans peine, je lui fis prendre dans un grand verre d'eau une cuillerée d'eau des Carmes, dont je bus aussi pour l'encourager. La fièvre et l'assoupissement continuèrent sans autre accident. Je crus alors, ainsi que lui, que c'était une espèce de courbature, venue de trop fortes marches, et telle que j'en avais eu quelquefois. Il resta deux jours dans cet état; après quoi le sommeil, le quittant tout à coup, fit place à la plus opiniâtre insomnie, accompagnée de continuelles agitations, durant lesquelles il s'occupait des échecs, auxquels nous avions joué tout l'après-midi qui précéda la nuit qu'il tomba malade. Il se sentit mal à la gorge, à la tête, à l'estomac, de l'oppression. Sa main et son pied étaient désenflés, mais il sentait des douleurs dans les genoux. Je jugeai que sa goutte, effarouchée par les drogues qu'il avait prises, était errante et menaçait de remonter. Je le lui dis, il n'en crut rien ; il soutint que tout son mal venait de sa grippe négligée. Peu d'accord sur la nature du mal, nous l'étions au moins que le traitement qu'on lui avait fait à Paris, mal à propos, avait occasionné cette rechute, et nous nous étions bien promis de ne consulter aucun médecin. Son état, cependant, devenait pressant; il ne buvait depuis plusieurs jours que de l'eau panée ; la suffocation augmentait, je proposai la moutarde sous les pieds, il la rejeta. Je vis même que cette proposition l'indisposait, et son domestique augmentait sa répugnance, en exagérant les douleurs de cette application. À force de me dire que je prenais le change sur la cause de son mal, il semblait m'accuser d'un aveuglement volontaire. Je ne compris rien à cette accusation, sinon que la fièvre le faisait extravaguer. Au défaut de la moutarde, qu'il refusait, je lui fis mettre les pieds dans de l'eau tiède ; après cela je tâchai de le faire suer, j'y parvins une fois, et j'excitai souvent une moiteur salutaire. La fièvre diminua, la douleur aux genoux augmenta et il y vint un peu d'enflure ; mais l'estomac souffrait toujours. Le malade commença à s'inquiéter extrêmement et d'une façon extraordinaire. Il parlait sans cesse des mauvais levains qu'il disait être dans son estomac. Ses regards, son air, ses mots entrecoupés, avaient quelque chose de si étrange que, m'en alarmant enfin tout de bon, je résolus d'en pénétrer le mystère. Que devins-je, quand à force de l'examiner, de le presser, 
de le conjurer d'expliquer son silence obstiné, je parvins à comprendre qu'il se croyait empoisonné, et par qui ?... mon Dieu !

J'ai toujours cru qu'il y avait des sortes de délires qui ne pouvaient jamais entrer dans la tête d'un honnête homme, fût-il devenu fou, et ce n'est pas surtout dans des têtes aussi bien organisées, et vivifiées par un cœur aussi sain que j'ai toujours cru le sien, que de tels délires peuvent prendre de la consistance. Je cherchai d'abord hors de lui la source d'une opinion où, par sa nature et ma position, l'on ne sait lequel domine, de l'atrocité, de l'absurdité, ou de l'impossibilité même, puisque M. Du Peyrou, depuis le moment de son arrivée jusqu'à celui où il est tombé malade, n'a rien mangé ni rien bu chez moi, quoi que ce puisse être, dont nous n'ayons mangé et bu avec lui. J'examinai plus attentivement son domestique, dont le patelinage m'avait toujours déplu, et bientôt je ne doutai plus que ce ne fût lui qui tournait la tête à son maître. J'avais prévu depuis longtemps qu'on cherchait à séduire les domestiques de mon ami, pour tâcher d'intercepter par eux nos lettres et de parvenir à visiter mes papiers. Dès son arrivée, je l'avais prié d'y veiller lorsqu'il serait de retour chez lui. Depuis sa maladie, les frayeurs affectées de ce garçon, son air effaré, son langage extraordinaire, sa défiance apparente, l'intimité secrète qui s'établit tout à coup entre lui et son maître, peu liant d'ordinaire avec ses gens, tout m'apprit que mes premiers soupçons n'étaient que trop bien fondés. Mais comment s'y était-il pris pour fasciner à ce point la raison d'un homme sage? Que lui avait-il dit? Sur quels indices s'était-il fondé? C'est ce que je m'efforçai vainement de pénétrer. Sentant de quelle importance il était pour la guérison de mon ami de le tranquilliser, de lui ôter ses noires et folles idées, je n'épargnai rien pour l'engager à m'ouvrir son cœur, à m'expliquer la cause d'une défiance aussi extravagante, à me mettre à portée de l'en guérir, à me dire au moins nettement qu'il se défiait de moi. Je ne vis que ses dangers; j'oubliai toute la fierté de l'amour-propre si justement indigné. Je fis parler le sentiment, la vérité, la vertu dans leur ton le plus énergique. Je le conjurai, dans les plus tendres effusions de mon âme, d'épancher la sienne avec moi. Tout fut inutile. Sourd à la plus touchante voix du sentiment et de l'amitié, il ne me fit que des réponses obscures, équivoques, trompeuses, faussement négatives et que démentaient ses regards et son air. Du Peyrou est froid et concentré ; je le savais et ne l'en estimais pas moins ; je le croyais au fond très sensible. Je me trompais ; puisqu'il ne fut point ému de mes angoisses, il ne le sera jamais de rien. Hors d'état de percer par là le mystère, je tentai de sonder son valet. Je lui dis quelques mots assez clairs, qu'il feignit de ne pas comprendre ; j'y revins en examinant sa contenance, il ne sourcilla pas; je crus voir dans ses yeux cette imperturbable assurance des scélérats, qui ressemble à la simplicité de l'innocence, et gémissant de douleur, je me vis forcé de renoncer à percer ce ténébreux mystère. Je résolus alors de faire appeler un médecin et j'en prévins le malade, qui continua de s'y opposer, craignant extrêmement d'être subjugué et drogué ; mais comme il le fallait absolument, j'insistai, promettant de ne laisser faire que ce qu'il approuverait lui-même, et par un billet que je lui montrai, je demandai moins le médecin qui raisonnait le mieux que celui qui entendait le mieux raison. Le médecin ne put venir que le lendemain matin. Il ne le trouva pas si mal qu'il croyait l'être et que son laquais le disait partout. Je lui détaillai tout ce que je crus nécessaire pour le mettre au fait du tempérament et de l'état présent du malade, et je n'oubliai pas de lui dire qu'il croyait que des levains vénéneux étaient la cause de son mal. Il l'examina soigneusement, le questionna, palpa 
les parties souffrantes, décida que son mal n'était autre qu'une goutte remontée, et en conséquence ordonna l'application de la moutarde, pour laquelle j'avais vainement insisté. La moutarde commença à opérer, les pieds enflèrent, la fièvre baissa encore, mais la faiblesse augmenta, au point d'alarmer presque le médecin. Le malade, toujours préoccupé de ses noires idées et sentant le siège de son mal dans l'estomac, laissait avec un sourire moqueur appliquer et renouveler la moutarde, mais il ne cessait de dire qu'on prenait le change et me demanda des fomentations sur l'estomac. Je le dis au médecin, ajoutant qu'en effet si l'on pouvait renforcer l'estomac, pour en chasser l'humeur, tandis qu'on l'attirait aux pieds, l'effet m'en paraissait devoir être et plus sûr et plus prompt. Le médecin goûta cet avis, mais, au lieu d'un topique, que demandait le malade, il ordonna une potion cordiale et antispasmodique qu'on apporta quelque temps après.

J'étais alors seul avec le malade, ayant envoyé coucher son domestique, qui avait passé la nuit auprès de lui. La potion devait être distribuée en plusieurs prises ; je voulus moi-même les lui donner. La couleur en était grise, un peu noirâtre, et le blanc de la tasse faisant paraître la liqueur encore plus noire ; cette couleur le frappa extrêmement. Il me dit, en me fixant et prenant la tasse : « Je la prends avec bien de la confiance. » Je vis à son air combien il mentait. Ce regard me déchira : mon âme, à la fois navrée, indignée et élevée, était prête à s'enflammer. Je me contins ; mais, sentant l'horreur de mon sort et la noblesse de mon rôle, je me vis à la place du médecin Philippe, et je lui dis d'un ton qui seul l'eût désabusé, s'il avait su lire : «Oui, mon excellent ami, ayez la confiance d'Alexandre, et je vous promets que vous en aurez le succès. » Il but ; malheureusement il se trouva de la poudre précipitée au fond de la tasse ; l'aspect de cette poudre acheva de l'effaroucher. Je le pressai de tout boire ; il le fit, se laissa tomber sur son chevet et s'endormit à l'instant.

Daignez, Monseigneur, vous mettre un moment à ma place et juger de mon état. Assis à son chevet, plus mourant que lui, je n'ôtais pas les yeux de dessus son visage. Je comptais les battements de son pouls, les reprises de sa respiration, les secondes que durait son sommeil. Il dormit ou parut dormir longtemps, et c'était la première fois depuis son insomnie. Je ne savais si je devais me féliciter ou m'effrayer de ce long somme... Je saisis des moments de réveil pour lui faire prendre les autres prises à leur heure; il les prenait et s'assoupissait de nouveau. Il y avait dans la potion des gouttes anodines d'Hoffmann, mais j'étais sûr de la dose. Le malade prit successivement à peu près tout et continua de sommeiller. Le médecin vint le soir et le trouva beaucoup mieux ; j'en jugeais de même. Il s'obstina à se trouver beaucoup plus mal, et son domestique parlait comme lui. Enfin l'air de désespoir que je vis autour de moi, les mots cruels et entrecoupés du maître, les accablantes exclamations du valet me troublèrent et l'emportèrent sur la certitude, que me donnaient son visage et son pouls, de son meilleur état. L'effroi, le frémissement, la douleur de perdre en lui tout ce qui m'attachait encore à la vie, les terribles circonstances de cette perte, tout cela me tourna la tête et me mit tout à fait hors de moi. Je me précipitai sur mon ami, collant mon visage sur le sien, l'inondant de mes pleurs et poussant des cris à demi étouffés. Je ne sais ce que je lui dis dans mon transport; mais je sais très certainement que le plus ardent de mes vœux était de pouvoir expirer à l'instant même. Quel effet croiriez-vous, Monseigneur, que fit tout cela sur son esprit rampant et préoccupé? Le barbare m'osa reprocher que je choisissais l'instant de sa plus 
grande faiblesse pour lui donner une commotion qui l'achevât. Cette indignité fit enfin l'effet que tout le reste n'avait pu faire. En ce moment, je sentis toute mon estime, tout mon attachement, toute ma tendresse pour lui s'éteindre jusqu'à la dernière étincelle ; dès lors je ne l'ai plus regardé que comme une âme basse, et mon cœur ne se sent pour lui que les sentiments qu'il lui doit. Je n'avais jusqu'alors pensé qu'à lui, dès lors je ne pensai plus qu'à moi. J'ai fait depuis tout par devoir, par humanité, par vertu, rien par amitié, et sans me relâcher en rien ; j'ai vu cet homme injuste et dur, insensible à mes infatigables soins, à ceux de ma sœur, aux alarmes, aux angoisses, aux embarras de toute espèce dont deux personnes seules sont surchargées par le maître et par le valet, s'exempter de toute sensibilité, de toute attention, de toute reconnaissance par une opinion non moins extravagante qu'horrible, qui ne saurait même être sincère, et que l'ingratitude seule a pu nourrir en lui, pour se dispenser de sentir qu'il me doit la vie.

Plein de tout ce qui venait de se passer, et toujours plus effrayé du manège du valet, qui semblait n'attendre à chaque instant que le dernier soupir de son maître, j'en vins dans ma terreur jusqu'à craindre que ce malheureux ne commît lui-même le crime qu'il semblait vouloir m'imputer, et ce noir soupçon prit tout à coup une si grande force que je résolus de rester toujours auprès du malade, et de veiller sur tout ce qu'il lui ferait prendre. Je restai jusqu'à minuit dans sa chambre, persistant dans cette résolution et l'exécutant. Cependant je ne tardai pas à sentir mon injustice et à en rougir. Convaincu que cet homme est un fourbe, mais non pas un empoisonneur, je me reprocherai toujours d'avoir pu soupçonner un valet d'un forfait abominable, dont mon ami n'a pas craint d'accuser dans son cœur son ami. Tandis que ces cruelles idées me tourmentaient, ce valet, quoique persuadé, à ce qu'il disait, que le malade allait mourir, ne laissait pas d'écrire à Paris à son camarade de lui envoyer, par le carrosse qui devait venir dans six jours, du linge et des hardes pour leur maître, et bien inquiet de savoir ses papiers chez son baigneur, quoique bien enfermés dans des tiroirs dans sa chambre et gardés par l'autre laquais, il balançait à lui envoyer les clés de ces tiroirs à l'insu de leur maître, pour prendre ces papiers et les transporter chez un ami. Il me tint là-dessus les propos les plus singuliers, cherchant à me faire approuver cette expédition, ce que je me gardai de faire. Je crus voir que ces deux drôles auraient bien voulu visiter les papiers de leur maître, selon les instructions de ceux qui les employaient. Ne pouvant rien obtenir de moi, il prit son parti de lui-même, et j'ai su qu'il écrivait à son camarade de transporter les papiers, sans dire comment ; ce que celui-ci n'osa faire au moyen d'une fracture, l'autre n'ayant osé envoyer les clés. J'ai jugé de ce qu'il écrivait à mon égard par ce qui est arrivé dans la suite. C'est tout ce que j'en puis savoir.

La continuation de l'assoupissement vrai ou affecté du malade fut telle que je pris la précaution de m'emparer de la fiole où était le reste de la potion ; je la cachetai de son cachet ; j'en fis autant d'une petite fiole de liqueur anodine, qui était aussi là, et après avoir dit au valet de mettre le cachet dans sa poche, j'emportai chez moi les deux fioles. Quelques heures après, le valet vint me redemander la liqueur anodine, disant que son maître était agité et ne pouvait dormir. Je la refusai ; je lui dis qu'après un si long assoupissement je ne voyais pas que le sommeil fût pour lui une chose si pressée, et qu'il fallait attendre le médecin. 
Je passai la nuit à délibérer sur ce que j'avais à faire et sur ce que je me devais en pareille occasion. je commençai à chercher un papier cacheté qu'il m'avait envoyé en Angleterre pour sûreté de ses engagements en cas de mort. Sur le dos de ce papier, que je n'avais point ouvert, j'écrivis et signai une déclaration que je renonçais à toute part dans les biens de M. Du Peyrou, à quelque titre que ce fût, que je me déclarais le dernier des infâmes si j'en acceptais jamais rien. Je voulais lui envoyer ce papier sur-le-champ. Mlle Renou me représenta qu'il m'accuserait encore d'avoir voulu lui donner le dernier coup par cet envoi. J'attendis le matin qu'il était plus calme. La certitude seule qu'il n'était point en danger me permit ce court délai ; car je n'aurais pu supporter qu'il n'eût pas de son vivant la preuve de la fausseté des indignes vues qu'il avait la bassesse de me prêter. Ma sœur lui ayant porté le papier me rapporta qu'en le recevant il lui avait demandé affectueusement de mes nouvelles, et me pressa fortement de passer chez lui.

C'était ce que j'avais résolu de ne plus faire. Je m'étais aperçu que ma vue le faisait souffrir, et la scène de la veille m'avait rendu la sienne peu agréable. J'étais déterminé à ne plus rentrer chez lui. Elle me fit renoncer, non sans peine, à ce projet extravagant. J'y rentrai enfin ; je le trouvai presque sans fièvre, et beaucoup mieux que je ne m'y attendais. Cette potion si terrible, jointe à la moutarde réitérée, avait dégagé l'estomac; les pieds étaient considérablement enflés ; il s'obstinait si bien à n'en vouloir rien croire que, pour l'en convaincre, il fallut les lui montrer dans un miroir. Alors il se retrancha à dire que ce n'était pas la goutte, parce qu'il n'y sentait point de douleur, et deux jours après, comme je fis percer des vessies que la moutarde avait faites, il demanda de quelle couleur était l'eau, et si elle n'était pas bien puante. On lui dit qu'elle était roussâtre et qu'elle ne sentait rien. Il n'en revenait pas.

Cette fatale nuit, la plus terrible de ma vie et dans le détail de laquelle j'ai cru devoir entrer, fut celle du lundi 9 au mardi 10 de ce mois. Le mardi matin, retrouvant, comme j'ai dit, le malade tranquille par son état, mais toujours agité par ses sombres idées, je fis mes derniers efforts pour l'en guérir. Je ne pris plus le ton tendre et touchant du sentiment, cela m'eût été impossible, mais je pris celui du plus simple bon sens et de la plus solide raison, qu'il devait du moins entendre. Je lui dis que les crimes abominables et périlleux ne se commettaient pas sans de grandes vues, et qu'il n'y en pouvait avoir que de petites et d'ineptes à celui qu'il imaginait ; je lui prouvai, ce qu'il savait aussi bien que moi, qu'en le perdant je perdais tout; que tous mes projets se rapportaient à lui seul, comme à leur instrument et comme à leur terme ; qu'en lui seul, après V. A., était ma dernière ressource, mon seul espoir pour finir mes jours en sécurité et en liberté ; que d'ailleurs je ne pouvais espérer de jouir en paix des conditions de notre traité que de son vivant; que, quelques mesures qu'il eût prises, il n'était pas possible qu'après sa mort je n'eusse à essuyer, de la part de ses héritiers, des difficultés que, dans ma position, j'étais hors d'état de suivre et de vaincre ; tandis que, lui vivant, je jouissais tranquillement et sans le moindre embarras ; qu'enfin le sort de mes papiers, qui tous étaient entre ses mains, était en quelque sorte attaché au sien; qu'après lui je n'en pouvais plus disposer ni savoir même ce qu'ils deviendraient ; qu'il y avait tout à parier qu'ils finiraient par tomber dans les mains de mes ennemis, et que cette idée, fût-elle seule, me rendait sa conservation plus précieuse que la mienne propre. Un homme sensé pouvait-il supposer que, 
pour le prix du plus exécrable de tous les crimes, je me fusse uniquement proposé, contre tous mes plus grands intérêts, de m'emparer de quelques effets qu'il pouvait avoir avec lui? Pouvait-il me croire assez stupide, assez bête, pour ne pas voir l'impossibilité d'exécuter impunément un si sot projet, à l'insu de sa famille et de mes alentours, sous les yeux de son domestique, qui savait le compte de tout, qui tenait tout, sans que jamais j'eusse mis l'œil ni la main sur rien?

Quand même le scellé n'aurait pas été mis, était-ce environné de surveillants, de malveillants attentifs à chercher l'occasion de me nuire, exacts à m'espionner, surtout dans de pareils instants, que sans avoir un seul homme de confiance, je pouvais espérer de soustraire la moindre chose secrètement? Forcé d'insister sur l'absurdité d'une supposition pareille, faute de pouvoir découvrir sur quels fondements il avait pu la bâtir, je le pressai de me mettre à portée de me justifier plus positivement, ne pouvant imaginer d'aucun côté le moindre indice qui pût lui rendre son ami suspect. Je lui montrai, le plus fortement qu'il me fut possible, le sacré devoir de ne condamner personne sans l'entendre, surtout en pareil cas, surtout un honnête homme et surtout son ami. Rien ; je n'obtins rien, pas un seul mot, sinon la certitude qu'il ne voulait ni m'entendre ni s'expliquer ; qu'il voulait se complaire dans son affreux délire, sans jamais laisser paraître la moindre trace des erreurs qui l'y avaient conduit. Comme il m'avait reproché l'effusion de cœur de la veille, il me reprocha le renvoi du papier comme fait dans la même vue; il me faisait autant de nouveaux crimes de tous mes efforts pour le désabuser. Ce reproche ne me toucha plus. Je lui dis froidement que mon seul repentir était d'avoir reçu ce papier, ou de ne l'avoir pas forcé de le reprendre quand, à Fleury, je voulus déjà le lui restituer. "Vous m'avez fait, ajoutai-je, de ce prompt renvoi un devoir indispensable ; s'il a été fait si tôt ou si tard, ne vous en prenez qu'à vous. »

Ennuyé, sans doute, de mes raisons et ne sachant qu'y répondre, il prit le parti de dormir ou d'en faire le semblant. Tandis qu'il avait les yeux fermés, je vis ses traits s'altérer, son visage prendre une figure difforme et presque hideuse ; je jugeai de ce qui se passait dans cette âme faible, troublée par l'effroi de la mort. Alors j'élevai la mienne au ciel, je me résignai dans les mains de la Providence et je lui remis le soin de ma justification, bien résolu de ne plus m'avilir jusqu'à entrer en explication sur mon innocence avec un forcené.

Toujours persuadé qu'il allait mourir, il guérissait cependant à vue d'œil, et pour ainsi dire malgré lui. La fièvre le quitta tout à fait, le sommeil revint, et cet appétit, aussi mal réglé que la tête du malade, me donna encore plus de peine à gouverner. On dirait qu'il est en quelque sorte fâché de guérir et que la honte de ses torts lui donne du regret de s'en convaincre. Voyant que la mort ne venait pas comme il l'attendait, il crut avoir pris un poison lent, qui le ferait languir quelque temps encore, et parce qu'il ne guérissait pas tout d'un coup, il crut ne jamais guérir. Ses mains étaient engourdies par l'humeur de goutte, rechassée aux extrémités: il se crut impotent pour le reste de sa vie et me le dit plusieurs fois. Les mains se dégagèrent, mais il lui restait un mal de gorge ; il crut le garder toujours. Le mal de gorge cessé, il avait encore un peu de roideur dans les mâchoires : il la regarda comme un effet permanent du venin. La roideur dissipée, il suintait quelque humeur des vessies ouvertes à ses pieds 
par la moutarde : cette humeur, nourrie par le poison, devait selon lui couler toujours ; elle est tarie et les pieds sont tout à fait secs et désenflés. je ne sais plus ce qu'il fera désormais, se sentant totalement guéri, cherchant du poison partout et n'en trouvant nulle part. Je commence à craindre que sa tête tout à fait altérée ne se remette jamais bien. Quelque effet qu'ait produit sur mon cœur son révoltant délire, j'ai suspendu de me décider sur son compte jusqu'à son parfait rétablissement, et je le lui ai dit, n'étant pas juste de juger irrévocablement un homme et un ami sur ce qu'il dit et fait dans la fièvre. Mais s'il se borne à être confus de sa folie et à vouloir l'oublier sans la réparer, tout est dit pour jamais entre lui et moi. S'il fait ce qu'il doit, je puis être encore, s'il veut, son ami, mais non pas son redevable. Quoi qu'il fasse et dans quelque situation que je me trouve, si jamais je me voyais forcé de recourir à l'assistance de quelque homme, j'aimerais mieux la recevoir du bourreau que de lui. Enfin si l'objet de mes ennemis a été de nous détacher l'un de l'autre, j'avoue avec douleur qu'ils ont parfaitement réussi. Ah! Monseigneur, que les hommes savent peu ce qu'ils désirent! J'aurais payé de bon cœur des trois quarts des jours qui me restent à vivre le plaisir de voir ici M. Du Peyrou, et je les donnerais aujourd'hui de meilleur cœur encore pour qu'il n'y fût jamais venu.

Voilà, Monseigneur, ce que je sais et que je ne puis expliquer qu'en supposant ce domestique venu avec des intentions sinistres et de l'adresse pour saisir l'occasion de les exécuter. J'ignore ce qu'il a pu écrire à Paris. Dès le commencement de l'attaque de M. Du Peyrou, j'écrivis chez lui à Neuchâtel, et à Paris à une de ses amies, et je continuais à lui donner des nouvelles du malade, quand je vis arriver, il y a quelque temps, un exprès de la part de cette dame, avec une lettre pour M. Du Peyrou et aucune pour moi. L'exprès demanda M. Du Peyrou, sans aucune mention de M. Renou ; il me vit et ne me parla pas. Il s'attendait à trouver le malade mort ; il fut bien surpris de le trouver debout, causant avec moi au coin du feu. Le valet qui est ici, ayant reçu à Gisors réponse de son camarade qui est à Paris, et craignant peut-être d'être obligé de montrer cette réponse, s'est pressé de dire qu'il l'avait perdue en chemin. Huit ou dix jours après, cette réponse, ou une autre qu'il avait eu le temps d'y substituer, s'est retrouvée. Peut-être l'avait-il laissé tomber en lieu apparent pour la répandre sans affectation dans le pays ; j'ignore ce qu'elle contient. Quoique le convalescent me paraisse très bien à présent et que, malgré ses folies, j'espère achever de le rétablir en dépit de lui, tant qu'il se gouvernera aussi mal, j'ai toujours à craindre quelque rechute. Si malheureusement elle arrivait, je supplie très instamment V. A. S. de donner des ordres pour qu'en cas d'accident tout se passe en règle ; que le scellé soit mis sur les effets de M. Du Peyrou, sur les miens, et surtout que le valet ne s'en retourne pas tranquillement chez lui jusqu'à ce que l'affaire soit bien éclaircie. 


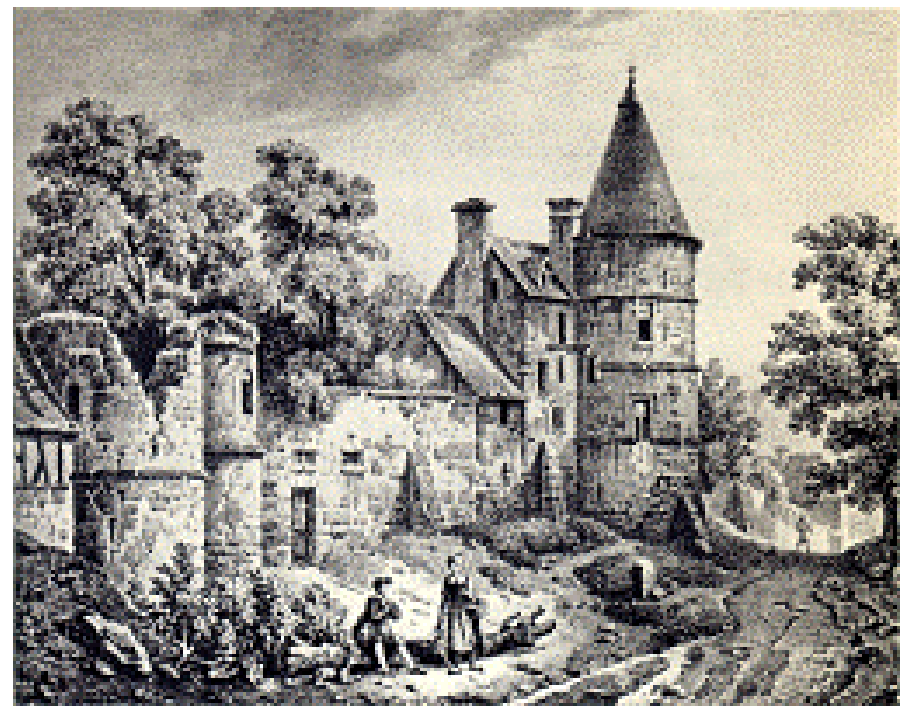

\section{Illustration 7}

\section{Le donjon de Trye-le-Château}

$\underline{\text { Retour à la table des matières }}$ 


\section{Lettre 115}

\section{À M. d'Ivernois, négociant à Genève}

À Trye, le 29 janvier 1768

Retour à la table des matières

J'ai reçu, mon digne ami, votre paquet du 22, et il me serait également parvenu sous l'adresse que je vous ai donnée quand vous n'auriez pas pris l'inutile précaution de la double enveloppe, sous laquelle il n'est pas même à propos que le nom de votre ami paraisse en aucune façon. C'est avec le plus sensible plaisir que j'ai enfin appris de vos nouvelles : mais j'ai été vivement ému de l'envoi de votre famille à Lausanne, cela m'apprend assez à quelle extrémité votre pauvre ville et tant de braves gens dont elle est pleine sont à la veille d'être réduits. Tout persuadé que je sois que rien ici-bas ne mérite d'être acheté au prix du sang humain, et qu'il n'y a plus de liberté sur la terre que dans le cœur de l'homme juste, je sens bien toutefois qu'il est naturel à des gens de courage, qui ont vécu libres, de préférer une mort honorable à la plus dure servitude. Cependant, même dans le cas le plus clair de la juste défense de vous-mêmes, la certitude où je suis qu'eussiez-vous pour un moment l'avantage vos malheurs n'en seraient ensuite que plus grands et plus sûrs, me prouve qu'en tout état de cause les voies de fait ne peuvent jamais vous tirer de la situation critique où vous êtes qu'en aggravant vos malheurs. Puis donc que perdus de toutes façons, supposé qu'on ose pousser la chose à l'extrême, 
vous êtes prêts à vous ensevelir sous les ruines de la patrie, faites plus : osez vivre pour sa gloire au moment qu'elle n'existera plus. Oui, Messieurs, il vous reste dans le cas que je suppose un dernier parti à prendre, et c'est, j'ose le dire, le seul qui soit digne de vous : c'est, au lieu de souiller vos mains dans le sang de vos compatriotes, de leur abandonner ces murs qui devaient être l'asile de la liberté et qui vont n'être plus qu'un repaire de tyrans. C'est d'en sortir tous, tous ensemble, en plein jour, vos femmes et vos enfants au milieu de vous, et puisqu'il faut porter des fers, d'aller porter du moins ceux de quelque grand prince, et non pas l'insupportable et odieux joug de vos égaux. Et ne vous imaginez pas qu'en pareil cas vous resteriez sans asile : vous ne savez pas quelle estime et quel respect votre courage, votre modération, votre sagesse ont inspirés pour vous dans toute l'Europe. Je n'imagine pas qu'il s'y trouve aucun souverain, je n'en excepte aucun, qui ne reçût avec honneur, j'ose dire avec respect, cette colonie émigrante d'hommes trop vertueux pour ne savoir pas être sujets aussi fidèles qu'ils furent zélés citoyens. Je comprends bien qu'en pareil cas plusieurs d'entre vous seraient ruinés, mais je pense que des gens qui savent sacrifier leur vie au devoir sauraient sacrifier leurs biens à l'honneur et s'applaudir de ce sacrifice, et qu'après tout, ceci n'est qu'un dernier expédient pour conserver sa vertu et son innocence quand tout le reste est perdu. Le cœur plein de cette idée, je ne me pardonnerais pas de n'avoir osé vous la communiquer. Du reste vous êtes éclairés et sages, je suis très sûr que vous prendrez toujours en tout le meilleur parti, et je ne puis croire qu'on laisse jamais aller les choses au point qu'il est bon d'avoir prévu d'avance pour être prêts à tout événement.

Si vos affaires vous laissent quelques moments à donner à d'autres choses qui ne sont rien moins que pressées, en voici une qui me tient au cœur, et sur laquelle je voudrais vous prier de prendre quelque éclaircissement dans quelqu'un des voyages que je suppose que vous ferez à Lausanne tandis que votre famille y sera. Vous savez que j'ai à Nyon une tante qui m'a élevé et que j'ai toujours tendrement aimée, quoique j'aie une fois, comme vous pouvez vous en souvenir, sacrifié le plaisir de la voir à l'empressement d'aller avec vous joindre nos amis. Elle est fort vieille, elle soigne un mari fort vieux ; j'ai peur qu'elle n'ait plus de peine que son âge ne comporte, et je voudrais lui aider à payer une servante pour la soulager. Malheureusement quoique je n'aie augmenté ni mon train ni ma cuisine, et que je n'aie aucun domestique à mes gages, et que je sois ici logé et chauffé gratuitement, ma position me rend la vie ici si dispendieuse que ma pension me suffit à peine pour les dépenses inévitables dont je suis chargé. Voyez, cher ami, si cent francs de France par an pourraient jeter quelque douceur dans la vie de ma pauvre vieille tante, et si vous pourriez les lui faire accepter. En ce cas, la première année courrait depuis le commencement de celle-ci, et vous pourriez la tirer sur moi d'avance, aussitôt que vous aurez arrangé cette petite affaire-là. Mais je vous conjure de voir que cet argent soit employé selon sa destination, et non pas au profit de parents ou voisins âpres, qui souvent obsèdent les vieilles gens. Pardon, cher ami, je choisis bien mal mon temps ; mais il se peut qu'il n'y en ait pas à perdre.

Je recevrai toujours avec plaisir de vos nouvelles et je présume qu'elles me parviendront sûrement ; cependant il convient par prudence que nous ne nous écrivions que quand il sera nécessaire, afin que notre correspondance, toute innocente qu'elle est, n'excite l'attention de personne. Lorsque vous serez dans 
le cas de votre voyage en Normandie, souvenez-vous de tout ce que je vous recommandais pour celui d'Angleterre ; c'est le même cas, et sans exception, pour plus de sûreté. Je vous embrasse de tout mon cœur. Mlle Renou est très touchée de votre souvenir et vous salue mille fois. 


\section{Lettre 116}

\section{À M. le prince de Conti}

Trye-le-Château, [18?] juin 1768

$\underline{\text { Retour à la table des matières }}$

Monseigneur,

Ceux qui composent votre maison (je n'en excepte personne) sont peu faits pour me connaître : soit qu'ils me prennent pour un espion, soit qu'ils me croient honnête homme, tous doivent également craindre mes regards. Aussi, Monseigneur, ils n'ont rien épargné, et ils n'épargneront rien, chacun par les manœuvres qui leur conviennent, pour me rendre haïssable et méprisable à tous les yeux, et pour me forcer de sortir enfin de votre château. Monseigneur, en cela je dois et je veux leur complaire. Les grâces dont m'a comblé Votre Altesse Sérénissime suffisent pour me consoler de tous les malheurs qui m'attendent en sortant de cet asile, où la gloire et l'opprobre ont partagé mon séjour. Ma vie et mon cœur sont à vous, mais mon honneur est à moi : permettez que j'obéisse à sa voix qui crie, et que je sorte dès demain de chez vous ; j'ose dire que vous le devez. Ne laissez pas un coquin de mon espèce parmi ces honnêtes gens. 


\section{Lettre 117}

\section{À M. Du Peyrou}

Lyon, le 20 juin 1768

Retour à la table des matières

Je ne me pardonnerais pas, mon cher hôte, de vous laisser ignorer mes marches, ou les apprendre par d'autres avant moi. Je suis à Lyon depuis deux jours, rendu des fatigues de la diligence, ayant grand besoin d'un peu de repos, et très empressé d'y recevoir de vos nouvelles, d'autant plus que le trouble qui règne dans le pays où vous vivez me tient en peine, et pour vous, et pour nombre d'honnêtes gens auxquels je prends intérêt. J'attends de vos nouvelles avec l'impatience de l'amitié. Donnez-m'en, je vous prie, le plus tôt que vous pourrez.

Le désir de faire diversion à tant d'attristants souvenirs qui, à force d'affecter mon cœur, altéraient ma tête, m'a fait prendre le parti de chercher, dans un peu de voyages et d'herborisations, les amusements et distractions dont j'avais besoin ; et le patron de la case ayant approuvé cette idée, je l'ai suivie : j'apporte avec moi mon herbier et quelques livres avec lesquels je me propose de faire quelques pèlerinages de botanique. Je souhaiterais, mon cher hôte, que la relation de mes trouvailles pût contribuer à vous amuser; j'en aurais encore plus de plaisir à les faire. Je vous dirai, par exemple, qu'étant allé hier voir Mme Boy de la Tour à sa campagne, j'ai trouvé dans sa vigne beaucoup d'aristoloche, que je n'avais jamais vue, et qu'au premier coup d'œil j'ai reconnue avec transport.

Adieu, mon cher hôte : je vous embrasse, et j'attends dans votre première lettre de bonnes nouvelles de vos yeux. 


\section{Lettre 118}

\section{À Mlle le Vasseur sous le nom de Mle Renou}

Grenoble, ce 25 juillet 1768 , à trois heures du matin,

\section{$\underline{\text { Retour à la table des matières }}$}

Dans une heure d'ici, chère amie, je partirai pour Chambéry, muni de bons passeports et de la protection des puissances, mais non pas du sauf-conduit des philosophes que vous savez. Si mon voyage se fait heureusement, je compte être ici de retour avant la fin de la semaine, et je vous écrirai sur-lechamp. Si vous ne recevez pas dans huit jours de mes nouvelles, n'en attendez plus, et disposez de vous, à l'aide des protections en qui vous savez que j'ai toute confiance, et qui ne vous abandonneront pas. Vous savez où sont les effets en quoi consistaient nos dernières ressources; tout est à vous. Je suis certain que les gens d'honneur qui en sont dépositaires ne tromperont point mes intentions ni mes espérances. Pesez bien toute chose avant de prendre un parti. Consultez Mme l'Abbesse ; elle est bienfaisante, éclairée ; elle nous aime ; elle vous conseillera bien ; mais je doute qu'elle vous conseille de rester auprès d'elle. Ce n'est pas dans une communauté qu'on trouve la liberté ni la paix : vous êtes accoutumée à l'une, vous avez besoin de l'autre. Pour être libre et tranquille, soyez chez vous, et ne vous laissez subjuguer par personne. Si j'avais un conseil à vous donner, ce serait de venir à Lyon. Voyez l'aimable Madelon ; demeurez, non chez elle, mais auprès d'elle. Cette excellente fille a rempli de tout point mon pronostic : elle n'avait pas quinze ans, que j'ai hautement annoncé quelle femme et quelle mère elle serait un jour. Elle l'est maintenant, et, grâce au ciel, si solidement et avec si peu d'éclat, que sa mère, 
son mari, ses frères, ses sœurs, tous ses proches ne se doutent pas eux-mêmes du profond respect qu'ils lui portent, et croient ne faire que l'aimer de tout leur cœur. Airnez-la comme ils font, chère amie ; elle en est digne, et vous le rendra bien. Tout ce qu'il restait de vertu sur la terre semble s'être réfugié dans vos deux cœurs. Souvenez-vous de votre ami l'une et l'autre, parlez-en quelquefois entre vous. Puisse ma mémoire vous être toujours chère, et mourir parmi les hommes avec la dernière des deux!

Depuis mon départ de Trye, j'ai des preuves de jour en jour plus certaines que l'œil vigilant de la malveillance ne me quitte pas d'un pas, et m'attend principalement sur la frontière; selon le parti qu'ils pourront prendre, ils me feront peut-être du bien sans le vouloir. Mon principal objet est bien, dans ce petit voyage, d'aller sur la tombe de cette tendre mère que vous avez connue pleurer le malheur que j'ai eu de lui survivre ; mais il y entre aussi, je l'avoue, du désir de donner si beau jeu à mes ennemis, qu'ils jouent enfin de leur reste ; car vivre sans cesse entouré de leurs satellites flagorneurs et fourbes est un état pour moi pire que la mort. Si toutefois mon attente et mes conjectures me trompent, et que je revienne comme je suis allé, vous savez, chère sœur, chère amie, qu'ennuyé, dégoûté de la vie, je n'y cherchais et n'y trouvais plus d'autre plaisir que de chercher à vous la rendre agréable et douce : dans ce qui peut m'en rester encore, je ne changerai ni d'occupation ni de goût. Adieu, chère sœur ; je vous embrasse en frère et en ami. 


\section{Lettre 119}

\section{À Madame de Lessert, née Boy de la Tour, à Lyon}

À Bourgoin, [fin août 1769]

$\underline{\text { Retour à la table des matières }}$

Je me hâte, chère cousine, de vous apprendre que ma sœur, par la grâce du Prince, est devenue ma femme par la grâce de Dieu. Je ne remplis jamais aucun devoir de meilleur cœur ni plus librement, puisque je ne lui en avais jamais donné la moindre espérance, et que deux minutes auparavant elle n'avait aucun soupçon de ce que je voulais faire. Nous avons eu l'un et l'autre la douceur de voir les deux hommes de mérite que j'avais choisis pour témoins de cet engagement fondre en larmes au moment qu'il a été contracté. Je ne devais pas moins à celle pour qui un attachement de vingt-cinq ans n'a fait qu'augmenter continuellement mon estime, et qui s'est déterminée à partager tous les malheurs qu'on m'apprête pour ne se pas séparer de moi. Puisqu'elle ne veut pas me quitter, je veux du moins qu'elle me suive avec honneur; chère amie, j'approuve d'autant moins la course que vous avez faite avec elle dans votre état et dont elle ne m'a parlé qu'avec les plus grandes alarmes pour votre santé, qu'elle-même en est malade, et qu'elle ne s'est pas trouvée bien un seul moment depuis son arrivée ici. Au reste, notre union, pour être devenue indissoluble, n'a pas changé de nature, et n'a pas cessé d'être aussi pure et aussi fraternelle qu'elle l'est depuis treize ans. 
Vos conseils, chère amie, sont pleins de raison, de justesse et d'amitié ; je les suivrais si j'en étais le maître ; mais ceux qui disposent de moi ne m'en laissent pas le moyen, et à force de vouloir me contraindre à rester en France, ils me mettent dans l'absolue nécessité d'en sortir. S'ils n'avaient voulu que s'assurer de moi et m'empêcher de dévoiler au public leurs manœuvres, j'étais tout résigné sur ce point à leur volonté et déterminé d'acheter à ce prix mon repos ; j'aurais fini mes jours dans le lieu qu'ils auraient voulu, sans plus faire aucune tentative pour leur échapper, mais me tenir captif n'est pas l'objet à quoi ils se bornent, et il ne leur suffit pas même de me diffamer s'ils ne me forcent à me déshonorer moi-même, en me réduisant à mourir de faim ou à recevoir d'eux ma subsistance. C'est dans cette vue qu'ils me font consumer mon temps et ma bourse à courir de lieu en lieu et d'auberge en auberge sans pouvoir trouver de gîte convenable ; c'est dans cette vue qu'ils me suscitent des difficultés, des frais et des embarras à tout et pour tout. Ils ont laissé venir ma compagne; ils ont senti que c'était un embarras de plus pour moi ; mais elle m'est venue sans mon argent, sans ses hardes, sans passeport, et si nue que hors ce qu'elle porte sur elle, elle n'a pas un seul manteau de lit, ni jupon pour changer. L'habitation des villes m'est interdite, le travail m'est interdit, mes finances ne sont pas inépuisables, c'est l'affaire de deux ou trois ans au plus pour manger le tout, sans avoir un liard à laisser à ma femme. C'est là qu'ils m'attendent, pour me forcer à mendier et à recevoir d'eux mon pain pour le prix de mon déshonneur. Je n'ai d'autre moyen d'éviter cette extrémité que de sortir du royaume où, libre au moins de tout engagement de ma part, je ne porterai que les chaînes de la nécessité sans être encore lié par mon consentement, et je serai pleinement maître de choisir pour subsister les moyens qui me paraîtront les meilleurs et les plus honnêtes.

Voilà les principaux motifs de ma résolution ; je ne puis pas d'ici vous tout dire : mais quoique je sois sûr de n'être exempt d'embûches nulle part, je ne suis pas moins sûr de ne pouvoir plus vivre avec honneur au milieu des fourbes qui m'ont circonvenu dans cette province, et m'étant engagé à ne pas m'établir dans la vôtre, je ne puis manquer à cette promesse sans manquer à mon devoir. Je ne puis, chère amie, vous en dire aujourd'hui davantage. J'ai du monde à dîner; on me presse de finir. Mais j'ajouterai seulement que je serais bien aise de savoir au juste à quoi je dois m'attendre pour le sort de mes malles, et de mon argent qui se promène de Paris à Lyon et de Lyon à Paris, sans que je sache comment ni pourquoi. M. votre frère m'offre d'y suppléer ; mais ce n'est pas de cela qu'il s'agit. Recevez, chère cousine, pour vous tout entière, vous m'entendez, tous les sentiments de deux cœurs qui n'en font qu'un, surtout pour vous aimer.

Avez-vous eu la bonté de faire retirer un jupon qui devait être dans le sac de nuit de la demoiselle Frère? Je voudrais bien donner une robe simple et honnête à ma femme. Voudriez-vous bien la choisir pour moi? Couleur modeste, cela s'entend. 


\section{Lettre 120}

\section{À M. Laliaud}

À Bourgoin, le 28 novembre 1768

$\underline{\text { Retour à la table des matières }}$

Je ne puis pas mieux vous détromper, Monsieur, sur la réserve dont vous me soupçonnez envers vous qu'en suivant en tout vos idées et vous en confiant l'exécution ; et c'est ce que je fais, je vous jure, avec une confiance dont mon cœur est content et dont le vôtre doit l'être. Voici une lettre pour M. le prince de Conti, où je parle comme vous le désirez et comme je pense. Je n'ai jamais ni désiré ni cru que ma lettre à $M$. l'ambassadeur d'Angleterre dût ni pût être un secret pour Son Altesse, ni pour les gens en place, mais seulement pour le public, et je vous préviens une fois pour toutes que, quelque secret que je puisse vous demander sur quoi que ce puisse être, il ne regardera jamais M. le prince de Conti, en qui j'ai autant et plus de confiance qu'en moi-même. Vous m'avez promis que ma lettre lui serait remise en main propre : je suppose que ce sera par vous ; j'y compte et je vous le demande.

Vous aurez pu voir que le projet de passer en Angleterre, qui me vint en recevant le passeport, a été presque aussitôt révoqué que formé : de nouvelles lumières sur ma situation m'ont appris que je me devais de rester en France, et j'y resterai. M. Davenport m'a fait une réponse très engageante et très honnête. L'ambassadeur ne m'a point répondu. Si j'avais su que le sieur Walpole était auprès de lui, vous jugez bien que je n'aurais pas écrit. Je m'imaginais bonnement que toute l'Angleterre avait conçu pour ce misérable et pour son 
camarade tout le mépris dont ils sont dignes. J'ai toujours agi d'après la supposition des sentiments de droiture et d'honneur innés dans les cœurs des hommes. Ma foi, pour le coup, je me tiens coi et je ne suppose plus rien; me voilà de jour en jour plus déplacé parmi eux et plus embarrassé de ma figure. Si c'est leur tort ou le mien, c'est ce que je les laisse décider à leur mode ; ils peuvent continuer à ballotter ma pauvre machine à leur gré, mais ils ne m'ôteront pas ma place : elle n'est pas au milieu d'eux.

J'ai été très bien pendant une dizaine de jours : j'étais gai, j'avais bon appétit, j'ai fait à mon herbier de bonnes augmentations. Depuis deux jours je suis moins bien : j'ai de la fièvre, un grand mal de tête, que les échecs où j'ai joué hier ont augmenté ; je les aime, et il faut que je les quitte. Mes plantes ne m'amusent plus; je ne fais que chanter des strophes du Tasse. Il est étonnant quel charme je trouve dans ce chant avec ma pauvre voix cassée et déjà tremblotante. Je me mis hier tout en larmes, sans presque m'en apercevoir, en chantant l'histoire d'Olinde et de Sophronie. Si j'avais une pauvre petite épinette pour soutenir un peu ma voix faiblissante, je chanterais du matin jusqu'au soir. Il est impossible à ma mauvaise tête de renoncer aux châteaux en Espagne. Le foin de la cour du château de Lavagnac, une épinette et mon Tasse, voilà celui qui m'occupe aujourd'hui malgré moi. Bonjour, Monsieur, ma femme vous salue de tout son cœur, j'en fais de même ; nous vous aimons tous deux bien sincèrement. 


\section{Lettre 121

\author{
À M. Tissot, \\ professeur en médecine, à Lausanne
}

À Bourgoin, [janvier 1769]

\section{$\underline{\text { Retour à la table des matières }}$}

Depuis que nous nous sommes vus, Monsieur, la gloire des grands talents et de la vertu a pris pour vous un nouveau lustre et je vois avec la plus vive joie par la justice que les hommes vous rendent qu'ils ne sont pas iniques en tout. Traité fort différemment j'ai été bien défiguré aux yeux du public, mais non pas aux vôtres, $j$ 'en suis très sûr. Ils sont faits pour percer le voile illusoire que le temps seul peut lever pour le vulgaire. Je suis le même, vous êtes le même, et j'ai trop éprouvé vos bontés pour ne pas vous écrire avec la même confiance que lorsque j'étais votre voisin. Je veux, Monsieur, vous décrire mon état présent. Comme il ne me paraît pas ordinaire, j'aime à croire que vous en pourrez peut-être tirer pour votre art quelqu'une de ces observations utiles que vous savez si bien mettre à profit, non pas pour vos semblables, car malheureusement vous n'en avez guère, mais pour le bien de l'humanité.

J'habite ici un pays marécageux, sujet aux fièvres, où peu de gens vieillissent, et qui généralement passe pour malsain. J'y ai passé cinq mois. Les trois premiers en automne dans la plus mauvaise saison de l'année, sans cependant m'en trouver incommodé ; au contraire, je paraissais engraissé, et mes habits rétrécis me faisaient juger que j'avais pris du ventre. Il y a deux mois environ que je me préparais à en sortir, et il y a environ deux mois que mon état change à vue d'œil. Je marquerais presque à un jour près l'époque de ce changement. Il a commencé par une abondance de vents par haut et bas 
d'une force et d'une puanteur extraordinaires. La putréfaction la plus abominable ne produit pas de pires exhalaisons. Dans le même temps, mon estomac s'est gonflé considérablement et même sensiblement. On voit l'enflure au dehors, on la sent, elle garnit tout le défaut des côtes, surtout du côté du foie où elle est plus considérable que de l'autre.

Cette enflure qui recouvre le creux de l'estomac et les fausses côtes est molle, mais non pas œéémateuse, elle s'étend sur toute la région voisine. Elle est, non pas douloureuse, mais si inquiétante que je ne puis endurer le contact des vêtements ni du linge en cette partie ; il s'y joint une inquiétude interne, de l'oppression et surtout la nuit. Je ne puis écrire sans m'arrêter et me redresser à chaque instant. Quand je veux me baisser, j'étouffe, et il m'est de toute impossibilité de mettre mes souliers. Les vents sont moins abondants, moins puants, mais plus contraints, la nécessité et la difficulté : de les exhaler me font faire pour cela beaucoup d'efforts souvent inutiles et ces efforts me fatiguent beaucoup. Quand je mange, la déglutition se fait avec quelque peine et comme si l'entrée de l'estomac était trop étroite, je sens les morceaux faire un peu d'effort pour passer. À propos de manger, je dois vous prévenir, Monsieur, que quoique j'aime la table, j'y suis toujours assez sobre, que je n'y ai fait aucun excès, et n'ai gagné aucune apparence d'indigestion depuis que je suis à Bourgoin. J'oubliais de vous dire qu'il se joint à mon mal de petites palpitations, que mon inquiétude d'estomac va quelquefois jusqu'à des élans douloureux, mais courts, que j'ai toutes les nuits de la fièvre, mal à la tête, des bourdonnements d'oreille qui non plus que la fièvre ne me sont pas nouveaux, mais deviennent plus forts et plus permanents. J'en dis autant de l'insomnie, ayant presque entièrement perdu le sommeil depuis plus de trente ans; mais à présent je perds aussi le repos, ne pouvant garder la nuit aucune attitude assez longtemps pour m'y tranquilliser. Ma pauvre femme m'a persécuté pour prendre des clystères. Par complaisance j'en ai pris trois jours de suite. Le premier ne me fit aucun mal et fit peu d'effet. Le second jour, je fus plus tourmenté. Le troisième, je souffris de grandes coliques. J'ai cessé d'en prendre. Cependant mon état fait des progrès qui m'annoncent ceux qu'il doit faire encore, et que mon espoir n'est pas d'arrêter quoique je ne doute point, Monsieur, que vous ne fissiez cette cure si les hommes la pouvaient faire ; mais ce n'est pas de cela qu'il s'agit, c'est de la cause de mon mal sur laquelle je m'abstiendrai de vous dire mon opinion parce qu'elle est de trop peu de poids, et qu'il faudrait pour marquer sur quoi je la fonde entrer dans des détails qui me mèneraient trop loin. Je dirai seulement que ma guérison fût-elle à espérer serait peu à désirer, et que le succès même en serait inutile, parce que la cause en renaîtrait toujours. Mettez, Monsieur, cette maladie dans vos registres si vous jugez qu'elle en vaille la peine, et puisse-t-elle vous fournir quelques réflexions instructives, soit pour la conservation de cette courte et misérable vie humaine, soit pour apprendre de plus en plus aux hommes à ne l'estimer que ce qu'elle vaut. Pour moi, je ne verrai pas sans consolation approcher la fin de la mienne si cette occasion peut m'attirer de votre part quelque témoignage de souvenir et d'amitié.

Renou. 


\section{Lettre 122}

\section{À Mme Rousseau}

Monquin, ce samedi 12 août 1769

Retour à la table des matières

Depuis vingt-six ans, ma chère amie, que notre union dure, je n'ai cherché mon bonheur que dans le vôtre, je ne me suis occupé qu'à tâcher de vous rendre heureuse ; et vous avez vu par ce que j'ai fait en dernier lieu, sans m'y être engagé jamais, que votre honneur et votre bonheur ne m'étaient pas moins chers l'un que l'autre. Je m'aperçois avec douleur que le succès ne répond pas à mes soins, et qu'ils ne vous sont pas aussi doux à recevoir qu'il me l'est de vous les rendre. Je sais que les sentiments de droiture et d'honneur avec lesquels vous êtes née ne s'altéreront jamais en vous ; mais quant à ceux de tendresse et d'attachement qui jadis étaient réciproques, je sens qu'ils n'existent plus que de mon côté. Ma chère amie, non seulement vous avez cessé de vous plaire avec moi, mais il faut que vous preniez beaucoup sur vous pour y rester quelques moments par complaisance. Vous êtes à votre aise avec tout le monde hors avec moi, tous ceux qui vous entourent sont dans vos secrets excepté moi, et votre seul véritable ami est le seul exclu de votre confidence. Je ne vous parle point de beaucoup d'autres choses. Il faut prendre nos amis avec leurs défauts, et je dois vous passer les vôtres comme vous me passez les miens. Si vous étiez heureuse avec moi, je serais content ; mais je vois clairement que vous ne l'êtes pas, et voilà ce qui me déchire. Si je pouvais faire mieux pour y contribuer, je le ferais et je me tairais ; mais cela n'est pas 
possible. Je n'ai rien omis de ce que j'ai cru pouvoir contribuer à votre félicité ; je ne saurais faire davantage, quelque ardent désir que j'en aie. En nous unissant, j'ai fait mes conditions ; vous y avez consenti, je les ai remplies. Il n'y avait qu'un tendre attachement de votre part qui pût m'engager à les passer et à n'écouter que notre amour au péril de ma vie et de ma santé. Convenez, ma chère amie, que vous éloigner de moi n'est pas le moyen de me rapprocher de vous : c'était pourtant mon intention, je vous le jure ; mais votre refroidissement m'a retenu, et des agaceries ne suffisent pas pour m'attirer lorsque le cœur me repousse. En ce moment même où je vous écris, navré de détresse et d'affliction, je n'ai pas de désir plus vif et plus vrai que celui de finir mes jours avec vous dans l'union la plus parfaite, et de n'avoir plus qu'un lit lorsque nous n'aurons plus qu'une âme.

Rien ne plaît, rien n'agrée de la part de quelqu'un qu'on n'aime pas. Voilà pourquoi, de quelque façon que je m'y prenne, tous mes soins, tous mes efforts auprès de vous sont insuffisants. Le cœur, ma chère amie, ne se commande pas, et ce mal est sans remède. Cependant, quelque passion que j'aie de vous voir heureuse à quelque prix que ce soit, je n'aurais jamais songé à m'éloigner de vous pour cela, si vous n'eussiez été la première à m'en faire la proposition. Je sais bien qu'il ne faut pas donner trop de poids à ce qui se dit dans la chaleur d'une querelle ; mais vous êtes revenue trop souvent à cette idée pour qu'elle n'ait pas fait sur vous quelque impression. Vous connaissez mon sort, il est tel qu'on n'oserait pas même le décrire, parce qu'on n'y saurait ajouter foi. Je n'avais, chère amie, qu'une seule consolation, mais bien douce, c'était d'épancher mon cœur dans le tien ; quand j'avais parlé de mes peines avec toi, elles étaient soulagées ; et quand tu m'avais plaint, je ne me trouvais plus à plaindre. Il est sûr que, ne trouvant plus que des cœurs fermés ou faux, toute ma ressource, toute ma confiance est en toi seule ; le mien ne peut vivre sans s'épancher, et ne peut s'épancher qu'avec toi. Il est sûr que, si tu me manques et que je sois réduit à vivre absolument seul, cela m'est impossible, et je suis un homme mort. Mais je mourrais cent fois plus cruellement encore, si nous continuions de vivre ensemble en mésintelligence, et que la confiance et l'amitié s'éteignissent entre nous. Ah! mon enfant! à Dieu ne plaise que je sois réservé à ce comble de misère! Il vaut mieux cent fois cesser de se voir, s'aimer encore, et se regretter quelquefois. Quelque sacrifice qu'il faille de ma part pour te rendre heureuse, sois-le à quelque prix que ce soit, et je suis content.

Je te conjure donc, ma chère femme, de bien rentrer en toi-même, de bien sonder ton cœur, et de bien examiner s'il ne serait pas mieux pour l'un et pour l'autre que tu suivisses ton projet de te mettre en pension dans une communauté pour t'épargner les désagréments de mon humeur, et à moi ceux de ta froideur; car, dans l'état présent des choses, il est impossible que nous trouvions notre bonheur l'un avec l'autre : je ne puis rien changer en moi, et j'ai peur que tu ne puisses rien changer en toi non plus. Je te laisse parfaitement libre de choisir ton asile et d'en changer sitôt que cela te conviendra. Tu n'y manqueras de rien, j'aurai soin de toi plus que de moi-même ; et sitôt que nos cœurs nous feront mieux sentir combien nous étions nés l'un pour l'autre, et le vrai besoin de nous réunir, nous le ferons pour vivre en paix et nous rendre heureux mutuellement jusqu'au tombeau. Je n'endurerais pas l'idée d'une séparation éternelle; je n'en veux qu'une qui nous serve à tous deux de leçon ; je ne l'exige point même, je ne l'impose point ; je crains seulement 
qu'elle ne soit devenue nécessaire. Je t'en laisse le juge et je m'en rapporte à ta décision. La seule chose que j'exige, si nous en venons là, c'est que le parti que tu jugeras à propos de prendre se prenne de concert entre nous; je te promets de me prêter là-dessus en tout à ta volonté, autant qu'elle sera raisonnable et juste, sans humeur de ma part et sans chicane. Mais quant au parti que tu voulais prendre dans ta colère de me quitter et de t'éclipser sans que je m'en mêlasse et sans que je susse même où tu voudrais aller, je n'y consentirai de ma vie, parce qu'il serait honteux et déshonorant pour l'un et pour l'autre, et contraire à tous nos engagements.

Je vous laisse le temps de bien peser toutes choses. Réfléchissez pendant mon absence au sujet de cette lettre. Pensez à ce que vous vous devez, à ce que vous me devez, à ce que nous sommes depuis longtemps l'un à l'autre, et à ce que nous devons être jusqu'à la fin de nos jours, dont la plus grande et la plus belle partie est passée, et dont il ne nous reste que ce qu'il faut pour couronner une vie infortunée, mais innocente, honnête, et vertueuse, par une fin qui l'honore et nous assure un bonheur durable. Nous avons des fautes à pleurer et à expier ; mais, grâce au ciel, nous n'avons à nous reprocher ni noirceurs ni crimes : n'effaçons pas par l'imprudence de nos derniers jours la douceur et la pureté de ceux que nous avons passés ensemble.

Je ne vais pas faire un voyage bien long ni bien périlleux; cependant la nature dispose de nous au moment que nous y pensons le moins. Vous connaissez trop mes vrais sentiments pour craindre qu'à quelque degré que mes malheurs puissent aller, je sois homme à disposer jamais de ma vie avant le temps que la nature ou les hommes auront marqué. Si quelque accident doit terminer ma carrière, soyez bien sûre, quoi qu'on puisse dire, que ma volonté n'y aura pas eu la moindre part. J'espère me retrouver en bonne santé dans vos bras, d'ici à quinze jours au plus tard ; mais s'il en était autrement, et que nous n'eussions pas le bonheur de nous revoir, souvenez-vous en pareil cas de l'homme dont vous êtes la veuve, et d'honorer sa mémoire en vous honorant. Tirez-vous d'ici le plus tôt que vous pourrez. Qu'aucun moine ne se mêle de vous ni de vos affaires en quelque façon que ce soit. Je ne vous dis point ceci par jalousie, et je suis bien convaincu qu'ils n'en veulent point à votre personne ; mais n'importe, profitez de cet avis, ou soyez sûre de n'attirer que déshonneur et calamité sur le reste de votre vie. Adressez-vous à M. de SaintGermain pour sortir d'ici ; tâchez d'endurer l'air méprisant de sa femme par la certitude que vous ne l'avez pas mérité. Cherchez à Paris, à Orléans, ou à Blois, une communauté qui vous convienne, et tâchez d'y vivre plutôt que seule dans une chambre. Ne comptez sur aucun ami ; vous n'en avez point ni moi non plus, soyez-en sûre ; mais comptez sur les honnêtes gens, et soyez sûre que la bonté de cœur et l'équité d'un honnête homme vaut cent fois mieux que l'amitié d'un coquin. C'est à ce titre d'honnête homme que vous pouvez donner votre confiance au seul homme de lettres que vous savez que je tiens pour tel. Ce n'est pas un ami chaud, mais c'est un homme droit qui ne vous trompera pas, et qui n'insultera pas ma mémoire, parce qu'il m'a bien connu et qu'il est juste ; mais il ne se compromettra pas, et je ne désire pas qu'il se compromette. Laissez tranquillement exécuter les complots faits contre votre mari ; ne vous tourmentez point à justifier sa mémoire outragée ; contentezvous de rendre honneur à la vérité dans l'occasion, et laissez la Providence et le temps faire leur œuvre ; cette œuvre se fera tôt ou tard. Ne vous rapprochez plus des grands ; n'acceptez aucune de leurs offres, encore moins de celles des 
gens de lettres. J'exclus nommément toutes les femmes qui se sont dites mes amies. J'excepte Mme Dupin et Mme de Chenonceaux; l'une et l'autre sont sûres à mon égard et incapables de trahison. Parlez-leur quelquefois de mes sentiments pour elles; ils vous sont connus. Vous aurez assez de quoi vivre indépendante avec les secours que M. Du Peyrou a dessein de vous donner, et qu'il vous doit, puisqu'il en a reçu l'argent. Si vous aimez mieux vivre seule chez vous que chez des religieuses, vous le pouvez; mais ne vous laissez pas subjuguer, ne vous livrez pas à vos voisines, et ne vous fiez pas aux gens avant de les connaître. Je finis ma lettre si à la hâte que je ne sais plus ce que je dis. Adieu, chère amie de mon cœur : à vous revoir. Et si nous ne nous revoyons pas, souvenez-vous toujours du seul ami véritable que vous ayez eu et que vous aurez jamais. Je ne me signerai pas Renou, puisque ce nom fut fatal à votre tendresse ; mais, pour ce moment, j'en veux reprendre un que votre cœur ne saurait oublier. 


\section{Lettre 123}

\section{À Mme Boy de la Tour née Roguin, à Lyon}

À Monquin, le 19 septembre 1769

\section{Retour à la table des matières}

Si je ne m'étais pas foulé la main par une chute, ma chère amie, je vous aurais répondu sur-le-champ pour vous tranquilliser sur la morsure de mon chien qui ne pouvait rien avoir de sinistre, vu que ce n'était qu'une jalousie de caresses et de préférences qui lui avait attiré cette morsure, ce qui ne ressemble point à celles qui ont du danger. Il est parfaitement guéri de même que, grâce au ciel, un de nos messieurs qui fut mordu lui-même à la jambe par un autre chien. Vous ne doutez pas, chère amie, du vif et vrai désir que j'ai de me rapprocher de vous. Mais les premiers froids dont je sens vivement l'atteinte me tiennent en crainte, et la saison des voyages est déjà passée pour moi. Je vous avoue, cependant, que le souvenir de l'hiver dernier me tient en peine sur celui-ci passé tout entier dans la solitude. L'été la promenade et l'herborisation m'amusent et me suffisent. Mais l'hiver la vie sédentaire et le défaut d'amusement prennent sur ma santé et même sur mon humeur. J'avais eu toujours un instrument de musique qui m'était très utile ; j'ai cruellement senti le défaut de cette ressource les deux hivers précédents. N'y aurait-il point moyen, chère amie, de me procurer celui-ci? J'ai pensé que peut-être $M$. Leonis voudrait bien à votre prière me procurer quelque épinette à louer pour six mois ; il me rendrait un service plus essentiel qu'il ne paraît s'il voulait bien se donner cette peine, et je lui en serais sensiblement obligé. Je ne 
voudrais pas une patraque, je voudrais une bonne épinette bien en état, et tout ce qu'il faudrait, cordes, plumes, marteau, écarlate, pour raccommoder ici ce qui se pourrait déranger. Je m'imagine que le transport serait un peu difficile pour qu'elle ne se dérangeât pas beaucoup, et je ne vois pas d'autre expédient que de la faire porter à dos d'homme. Si l'on pouvait trouver où vous êtes un homme attentif et posé qui la ménageât en route je vous serais très obligé de faire avec lui le marché et de me donner avis par lui de ce qu'il faut que je lui paye. Si vous ne trouvez pas aisément le porteur qu'il nous faut, j'en peux envoyer un d'ici.

L'épinette ne se trouvera peut-être pas aisément. En ce cas pourrais-je avoir du moins un violoncelle, qui fût bon, tout monté, des cordes de rechange et de la colophane? Comme cet instrument craint moins le transport, on pourrait l'envoyer par le carrosse, au moins s'il avait un étui, et l'adresser à Bourgoin chez M. la Tour, perruquier. Si le violoncelle à louer ne se trouve pas non plus, j'aimerais encore et même par préférence un bon cistre à cinq cordes monté dans le bas en cordes filées un peu grosses; et toujours à louer pour six mois. Enfin, chère amie, si rien de tout cela ne se trouve, je me rabats pour pis-aller à une flûte à bec dont je vous prie de me faire l'emplette, car ce n'est pas la peine de la louer. Voilà, je vous l'avoue, des commissions bien importunes pour des dames, mais j'espère que l'importance dont cette ressource peut m'être dans ma situation vous fera passer avec votre indulgence ordinaire par-dessus l'incongruité. La musique est pour moi un vrai remède, et le seul peut-être qui puisse être efficace dans mon état. Pourvu que j'aie un instrument quel qu'il soit, et un peu de papier réglé, je suis sûr de passer mon temps sans ennui et sans m'affecter beaucoup de quoi que ce puisse être. La botanique est amusante en été, mais en hiver elle ne fait que fatiguer et n'amuse guère. Il ne me faut rien qui me fatigue la mémoire et l'esprit.

J'espère qu'en me répondant, vous ne ferez pas comme moi qui ne vous parle ici que de ma triole (connaissez-vous ce mot Genevois?), que vous me parlerez au long de votre santé, de vous, de votre famille, surtout de Fourvière où je n'ai pas écrit depuis un temps infini. Parlez-moi de tout ce que vous savez qui intéresse les deux solitaires qui comptent ici les jours avec impatience jusqu'à ce qu'ils arrivent à celui de vous embrasser. Adieu, chère amie, voilà le commissionnaire qui attend ma lettre et qui me la fait finir.

Point de cistre à moins qu'il ne soit bon et à cinq cordes. On m'en a fait venir un de Lyon qui n'était qu'un vrai chaudron, totalement injouable. 


\section{Lettre 124}

\section{À Mme Boy de la Tour née Roguin, à Lyon}

À Monquin, le 6 octobre 1769

\section{Retour à la table des matières}

Je reconnais vos bontés ordinaires, mon excellente amie, dans celle que vous avez eue de vous occuper de mon indiscrète commission. Cependant comme elle ne laissait pas d'être de quelque importance pour mon état, je me suis fait moins de scrupule de charger de ce soin votre amitié et votre humanité. Le porteur de l'instrument pourra s'adresser à Bourgoin au Sr. la Tour, perruquier sur la place, qui lui indiquera le chemin pour venir ici. La Tour ou son frère viennent me raser tous les vendredis et mardis matin et si le voyage de l'homme pouvait s'ajuster sur ces mêmes jours, un des deux la Tour pourrait l'amener lui-même. Je vous prie de dire audit porteur que s'il ménage assez l'instrument en route pour qu'il arrive ici d'accord et en bon état, je lui donnerai trente sols pour boire par-dessus l'accord que vous aurez fait. Je regarde cette petite précaution comme fort essentielle.

Mme Renou, qui vous baise les mains de tout son cœur ainsi qu'à la chère cousine, veut que je vous importune encore de deux commissions, ce que je fais avec une confiance aussi inépuisable que votre complaisance et dans l'espoir que ce seront les dernières. L'une est d'une petite caisse de chandelles des six à la livre et d'une douzaine de livres. L'autre serait d'un bon bonnet de laine et d'une paire de bas drapés et de gants chauds pour votre pauvre ami qui 
commence à grelotter terriblement et que les premiers froids rendent bien malingre. Si vous y pouviez joindre une paire de mitaines de soie pour elle, j'aurais le plaisir de les lui donner pour sa fête qui est le quinze de ce mois. Lesdits envois peuvent se faire par le carrosse à l'adresse dudit Sr. la Tour, perruquier, pour M. Renou. Vous avez eu la bonté, chère amie, de me faire précédemment plusieurs petites emplettes pour lesquelles je dois avoir un compte ouvert chez vous. Après y avoir ajouté tous les susdits articles, veuillez s'il vous plaît en faisant mes salutations à $\mathbf{M}$. votre fils le prier de ma part de vous rembourser le tout sur l'argent qui est entre ses mains. Si vous jugez à propos d'ajouter à ce mémoire le loyer de l'épinette et le paiement du porteur, je n'aurai pas besoin de débourser ici cet argent, sinon je le lui remettrai. Soit fait à votre volonté, à condition que vous ne prendrez sur rien le bon marché dans votre poche, ce que je ne dois pas supposer parce que cela serait malhonnête.

Voici, chère amie, une lettre pour M. Dastier que je vous prie de vouloir bien faire affranchir à son exemple, et que je suis obligé de vous adresser pour cela parce que j'ai remarqué qu'on n'a aucun égard aux affranchissements que je fais faire à Bourgoin. Il a eu la bonté de me faire une petite fourniture de café pour laquelle suivant son compte je ne lui dois que douze francs. Or comment lui faire tenir ces douze francs à Carpentras? Voilà mon embarras. S'il y avait moyen de faire ce petit paiement par quelqu'un des correspondants de vos messieurs, je leur en serais extrêmement obligé et je marque à $\mathbf{M}$. Dastier que je vous en prie. L'embarras que son affranchissement de lettre me force à vous donner vous dit assez ce que je pense du vôtre : ainsi je ne vous en parlerai pas.

De grâce, chère amie, tolérez l'importunité de ces commissions avec autant d'indulgence que vous mettrez d'exactitude à les faire, c'est tout dire. Une des plus grandes rigueurs de ma destinée et de celles que je sens le plus est d'être toujours à charge à mes amis, et de leur être toujours inutile. Ceux qui disposent de moi avec autant de barbarie que d'iniquité ont bien choisi dans mon cœur les endroits les plus sensibles pour ne perdre aucun de leurs coups. Je leur suis obligé du moins d'en faire assez pour réveiller mon courage que des traitements moins indignes auraient peut-être laissé dormir. Bonjour ma chère et bonne amie. J'attends avec empressement le signe de vie de la chère cousine ; s'il faisait moins froid, que je fusse moins paresseux, moins malingre, elle ne me préviendrait sûrement pas. Recevez pour vous et pour elle les plus tendres amitiés des deux pauvres ermites. 


\section{Lettre 125}

\section{À Mme de Lessert, née Boy de la Tour, rue Piset, à Lyon.}

À Monquin, le 3 novembre 1769

$\underline{\text { Retour à la table des matières }}$

Vous ne doutez pas avec quel plaisir, chère cousine, $j$ 'apprends toutes les bonnes nouvelles que vous me donnez de tout ce qui vous touche. Aussi ne me presserais-je pas tant de vous le dire, si je n'avais à vous donner en même temps les éclaircissements que vous me demandez sur les importunes commissions dont vous ne vous lassez point, et qui sont aussitôt faites que dites. Puisque le papier est acheté, je le prendrai ; il ne sera pas de trop, et vaudra peut-être mieux pour l'usage que j'en veux faire que celui qu'on m'a envoyé. À l'égard de l'envoi, il faudra le suspendre encore quelque temps, jusqu'à ce que je voie si je puis vous envoyer une coquetière en droiture. Si d'ici à quinze jours il ne vous en vient point, vous pourrez, chère cousine, l'adresser par le carrosse ou autre voie à M. Perial, directeur des Postes, pour faire passer à M. Renou, à Bourgoin. Trois aunes et demie de cotonne ne suffisent pas pour deux grands tabliers ; il en faut cinq aunes et demie, que vous pourrez envoyer en même temps par la même.

Mme Renou est, grâce au Ciel, tout à fait rétablie. Tout bien considéré, je crois qu'une attaque de néphrétique, et qui n'a pas été la première en sa vie, a eu grande part à sa dernière maladie. Le mot d'aider la nature est assurément 
fort beau. C'est dommage qu'il soit ridicule. Car pour savoir et pouvoir aider la nature, il faudrait connaître à fond sa constitution, sa marche, ses forces, etc. Je me suis aidé quinze ans de tous ces aideurs de nature, et j'étais toujours mourant. En disant l'aider, ils la détruisaient. Depuis que je lui ai remis le soin d'elle-même, elle a repris courage ; j'ai repris des forces et je me trouve infiniment mieux. Nous avons fait souvent depuis quatorze ans de grandes maladies, tant ma femme que moi : nous n'avons rien fait que prendre patience, et nous sommes guéris très promptement... Une fois nous mourrons sans doute : croyez-vous, cousine, que les aideurs de nature empêchent de mourir? Tout ce qu'on gagne avec eux, même en guérissant, c'est de faire des maladies de six mois qui sans eux sont de six jours. Vous avez dans votre famille le sage Roguin, qui n'aide point la nature et qui s'en trouve, ce me semble, assez bien. Vous m'alléguez la germandrée : en cela vous avez raison. C'est une inconséquence, mais sans conséquence. Quand on veut savoir guérir, il faut commencer par savoir être malade. Faute de cet art, on a quelquefois besoin d'aide qui drogue l'esprit sans faire ni bien ni mal au corps. Voilà à quoi peut servir quelquefois la germandrée, ou autre bénigne herbe, qui fait bien parce qu'elle ne fait rien. Ma femme approche d'un temps critique, où les incommodités sont plus fréquentes qu'en d'autres temps. Je lui ai conseillé la continuation d'un exercice modéré, parce que j'ai remarqué que les paysannes qui en font ne sont presque point malades à ce passage, et que les femmes de ville qui n'en font point le sont quelquefois beaucoup. Si c'est là ce que vous appelez aider la nature, je suis d'accord avec vous ; mais à cela près, je croirai toujours, ne vous en déplaise, que l'homme ignorant et présomptueux qui se mêle d'agir contrarie très souvent la nature, et que l'homme sensé qui s'en rapporte à elle seule ne la contrarie jamais. Je suis peiné de ce que vous me marquez au sujet de l'état où est arrivée l'épinette. Ou vous m'avez interprété trop sévèrement, ou je me suis bien mal exprimé. Elle est arrivée, non pas en fort bon état, parce que cela n'était pas possible, mais en assez bon état, et aussi bon qu'il était possible après un pareil transport. Si vous avez grondé le pauvre homme qui l'a portée, je vous prie instamment de le faire revenir, de lui dire que je suis un sot, que je me suis plaint à tort, que réellement j'ai eu lieu d'être content de l'état où l'épinette est arrivée, et de lui donner pour mon compte encore vingt-quatre sols en réparation de l'injustice que je lui ai faite ; d'autant plus qu'au lieu de trente sols, il n'en a demandé que vingt-quatre pour boire, et que je ne lui ai donné que ce qu'il a dit lui avoir été promis. Ce n'est qu'en se permettant les petites injustices qu'on s'endurcit sur les grandes; je n'ai point encore acquis cet endurcissement et je ne veux pas commencer si tard.

Je compte, chère cousine, vous envoyer une coquetière qui partira d'ici mardi et à qui vous pourrez remettre le paquet. Si vous avez maintenant $\mathrm{M}$. de Lessert de retour, comme je l'espère, ne m'oubliez pas auprès de lui. Ma femme vous embrasse de tout cœur. Vous connaissez, chère cousine, les sentiments de votre ami. 

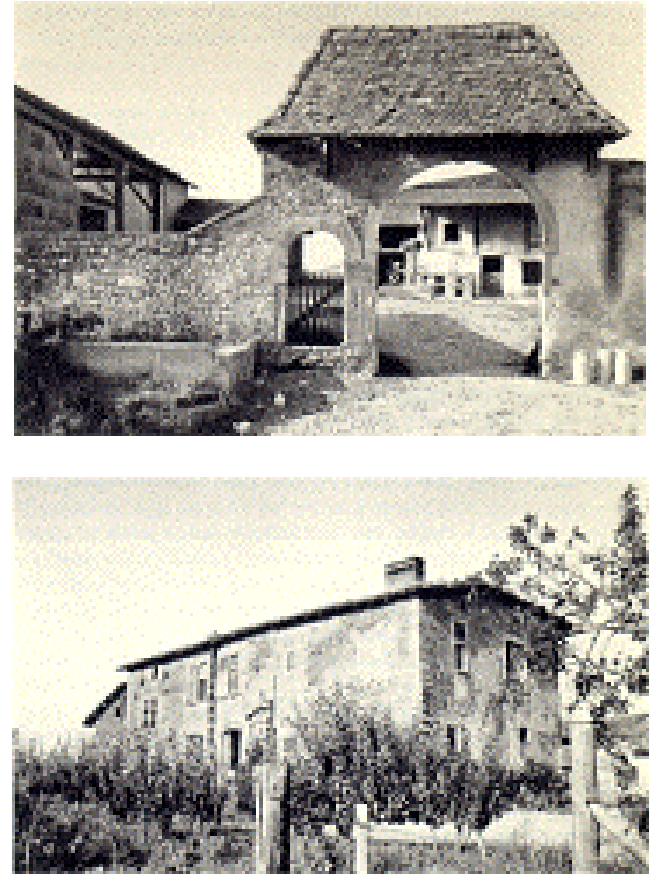

Illustration 8

La ferme de Monquin en son état actuel

$\underline{\text { Retour à la table des matières }}$ 


\section{Lettre 126}

\section{À M. Laliaud}

À Monquin, le 30 novembre 1769

Retour à la table des matières

J'apprends avec plaisir, Monsieur, que vous jouissez, en bonne santé et avec agrément, du beau climat que vous habitez, et que vous êtes content à la fois de votre séjour et de votre récolte. Vous avez deviné bien juste que, tandis que l'ardeur du soleil vous forçait encore quelquefois à chercher l'ombre, j'étais réduit à garder mes tisons, et nous avions eu déjà de fortes gelées et des neiges durables longtemps avant la réception de votre lettre. Cela, Monsieur, me chagrine en une chose, c'est de ne pouvoir plus, pour cette année, exécuter votre petite commission des rosiers à feuilles odorantes puisque ayant depuis longtemps perdu toutes leurs feuilles, ils seraient à présent impossibles à distinguer et difficiles même à trouver. Je suis donc forcé de remettre cette recherche à l'année prochaine, et je vous assure que vous me fournissez l'occasion d'une petite herborisation très agréable, en songeant que je la fais pour votre jardin.

Je vous dois et vous fais, Monsieur, bien des remerciements des lauriers que vous avez la bonne intention de m'envoyer pour mon herbier, quoique je ne me rappelle point du tout qu'il en ait été question entre nous. Ils ne laisseront pas de trouver leur place et de me rappeler votre obligeant souvenir, aussi longtemps que je resterai possesseur de mon herbier ; car il pourrait dans 
peu changer de maître, ainsi que mes livres de plantes, dont je cherche à me défaire, étant sur le point de quitter totalement la botanique.

J'ai fait votre commission auprès de Mme de Lessert, et je ne doute pas que, dans sa première lettre, elle ne me charge de ses remerciements et salutations pour vous. Elle a eu la bonté de me pourvoir d'une bonne épinette pour cet hiver ; cet instrument me fait plaisir encore et me donne quelque moment d'amusement, mais il ne me fournit plus de nouvelles idées de musique, et je me suis vainement efforcé d'en jeter quelqu'une sur le papier. Rien n'est venu, et je sens qu'il me faut renoncer désormais à la composition comme à tout le reste. Cela n'est pas surprenant.

Bonjour, Monsieur; le beau soleil qu'il fait ici dans ce moment me fait imaginer des promenades délicieuses en cette saison dans le pays où vous êtes, et si j'y étais aussi, j'aimerais bien à les faire avec vous. Bonjour derechef, portez-vous bien, amusez-vous, et donnez-moi quelquefois de vos nouvelles. 


\section{Lettre 127}

\section{À Mme Boy de la Tour née Roguin, à Lyon}

À Monquin, le 2 janvier 1770

$\underline{\text { Retour à la table des matières }}$

J'attendais, très chère amie, pour vous remercier et vous et ma chère cousine de vos cadeaux, le départ de la messagère qui doit vous reporter le panier, mais elle tarde si longtemps que je m'en ennuye, et je veux au moins vous dire que les confitures me font grand plaisir et que le vin me fait grand bien. C'est un secours aussi salutaire qu'agréable contre la rigueur de la saison et celle du logement que j'habite, véritable glacière où le plus grand feu ne fait que me rôtir d'un côté tandis que je gèle de l'autre. Je me réchauffe l'estomac et le cœur en buvant de cet excellent vin et pensant à celle qui l'envoie, mais pour les extrémités elles sont si glacées qu'il n'y a rien qui les puisse dégeler. J'ai tellement l'onglée aux doigts qu'il m'est impossible d'écrire. Lisez donc dans mon cœur, très chères amies, ce que mes doigts ne peuvent tracer, et croyez que les tendres amitiés et salutations que nous vous envoyons l'un et l'autre ne se ressentent pas des froides impressions de la saison ni du lieu.

Cette lettre part trois jours plus tard que la date. 


\section{Lettre 128}

\section{À Mme B. [de Berthier]}

À Monquin, le 17 janvier 1770

$\underline{\text { Retour à la table des matières }}$

Votre lettre, Madame, exigerait une longue réponse ; mais je crains que le trouble passager où je suis ne me permette pas de la faire comme il faudrait. Il m'est difficile de m'accoutumer assez aux outrages et à l'imposture, même la plus comique, pour ne pas sentir, à chaque fois qu'on les renouvelle, les bouillonnements d'un cœur fier qui s'indigne précéder le ris moqueur qui doit être ma seule réponse à tout cela. Je crois pourtant avoir gagné beaucoup : j'espère gagner davantage ; et je crois voir le moment assez proche où je me ferai un amusement de suivre dans leurs manœuvres souterraines ces troupes de noires taupes qui se fatiguent à me jeter de la terre sur les pieds. En attendant, nature pâtit encore un peu, je l'avoue : mais le mal est court, bientôt il sera nul. Je viens à vous.

J'eus toujours le cœur un peu romanesque, et j'ai peur d'être encore mal guéri de ce penchant en vous écrivant. Excusez donc, Madame, s'il se mêle un peu de visions à mes idées; et, s'il s'y mêle aussi un peu de raison, ne la dédaignez pas sous quelque forme et avec quelque cortège qu'elle se présente. Votre correspondance a commencé d'une manière à me la rendre à jamais intéressante, un acte de vertu dont je connais bien tout le prix, un besoin de nourriture à votre âme qui me fait présumer de la vigueur pour la digérer, et la 
santé qui en est la source. Ce vide interne dont vous vous plaignez ne se fait sentir qu'aux cœurs faits pour être remplis : les cœurs étroits ne sentent jamais le vide, parce qu'ils sont toujours pleins de rien ; il en est, au contraire, dont la capacité vorace est si grande, que les chétifs êtres qui nous entourent ne la peuvent remplir. Si la nature vous a fait le rare et funeste présent d'un cœur trop sensible au besoin d'être heureux, ne cherchez rien au dehors qui lui puisse suffire : ce n'est que de sa propre substance qu'il doit se nourrir. Madame, tout le bonheur que nous voulons tirer de ce qui nous est étranger est un bonheur faux ; les gens qui ne sont susceptibles d'aucun autre font bien de s'en contenter ; mais si vous êtes celle que je suppose, vous ne serez jamais heureuse que par vous-même ; n'attendez rien pour cela que de vous. Ce sens moral, si rare parmi les hommes, ce sentiment exquis du beau, du vrai, du juste, qui réfléchit toujours sur nous-mêmes, tient l'âme de quiconque en est doué dans un ravissement continuel qui est la plus délicieuse des jouissances : la rigueur du sort, la méchanceté des hommes, les maux imprévus, les calamités de toute espèce peuvent l'engourdir pour quelques moments, mais jamais l'éteindre ; et, presque étouffé sous le faix des noirceurs humaines, quelquefois une explosion subite peut lui rendre son premier éclat. On croit que ce n'est pas à une femme de votre âge qu'il faut dire ces choses-là ; et moi je crois, au contraire, que ce n'est qu'à votre âge qu'elles sont utiles, et que le cœur s'y peut ouvrir : plus tôt, il ne saurait les entendre; plus tard, son habitude est déjà prise, il ne saurait les goûter.

Comment s'y prendre? me direz-vous ; que faire pour cultiver et développer ce sens moral? Voilà, Madame, à quoi j'en voulais venir : le goût de la vertu ne se prend point par des préceptes, il est l'effet d'une vie simple et saine ; on parvient bientôt à aimer ce qu'on fait, quand on ne fait que ce qui est bien. Mais pour prendre cette habitude, qu'on ne commence à goûter qu'après l'avoir prise, il faut un motif; je vous en offre un que votre état me suggère : nourrissez votre enfant. J'entends les clameurs, les objections ; tout haut, les embarras, point de lait, un mari qu'on importune... tout bas, une femme qui se gêne, l'ennui de la vie domestique, les soins ignobles, l'abstinence des plaisirs... Des plaisirs? Je vous en promets, et qui rempliront vraiment votre âme. Ce n'est point par des plaisirs entassés qu'on est heureux, mais par un état permanent qui n'est point composé d'actes distincts : si le bonheur n'entre, pour ainsi dire, en dissolution dans notre âme, s'il ne fait que la toucher, l'effleurer par quelques points, il n'est qu'apparent, il n'est rien pour elle.

L'habitude la plus douce qui puisse exister est celle de la vie domestique qui nous tient plus près de nous qu'aucune autre ; rien ne s'identifie plus fortement, plus constamment avec nous que notre famille et nos enfants ; les sentiments que nous acquérons ou que nous renforçons dans ce commerce intime sont les plus vrais, les plus durables, les plus solides, qui puissent nous attacher aux êtres périssables, puisque la mort seule peut les éteindre ; au lieu que l'amour et l'amitié vivent rarement autant que nous. Ils sont aussi les plus purs, puisqu'ils tiennent de plus près à la nature, à l'ordre, et, par leur seule force, nous éloignent du vice et des goûts dépravés. J'ai beau chercher où l'on peut trouver le vrai bonheur, s'il en est sur la terre, ma raison ne me le montre que là... Les comtesses ne vont pas d'ordinaire l'y chercher, je le sais ; elles ne se font pas nourrices et gouvernantes ; mais il faut aussi qu'elles sachent se passer d'être heureuses ; il faut que, substituant leurs bruyants plaisirs au vrai bonheur, elles usent leur vie dans un travail de forçat pour échapper à l'ennui 
qui les étouffe aussitôt qu'elles respirent; et il faut que celles que la nature doua de ce divin sens moral qui charme quand on s'y livre, et qui pèse quand on l'élude, se résolvent à sentir incessamment gémir et soupirer leur cœur, tandis que leurs sens s'amusent.

Mais moi qui parle de famille, d'enfants... Madame, plaignez ceux qu'un sort de fer prive d'un pareil bonheur ; plaignez-les s'ils ne sont que malheureux ; plaignez-les beaucoup plus s'ils sont coupables. Pour moi, jamais on ne me verra, prévaricateur de la vérité, plier dans mes égarements mes maximes à ma conduite ; jamais on ne me verra falsifier les saintes lois de la nature et du devoir pour exténuer mes fautes. J'aime mieux les expier que les excuser : quand ma raison me dit que j'ai fait dans ma situation ce que j'ai dû faire, je l'en crois moins que mon cœur qui gémit et qui la dément. Condamnez-moi donc, Madame, mais écoutez-moi : vous trouverez un homme ami de la vérité jusque dans ses fautes, et qui ne craint point d'en rappeler lui-même le souvenir lorsqu'il en peut résulter quelque bien. Néanmoins je rends grâce au Ciel de n'avoir abreuvé que moi des amertumes de ma vie, et d'en avoir garanti mes enfants : j'aime mieux qu'ils vivent dans un état obscur sans me connaître, que de les voir, dans mes malheurs, bassement nourris par la traîtresse générosité de mes ennemis, ardents à les instruire à haïr, et peut-être à trahir leur père ; et j'aime mieux cent fois être ce père infortuné qui négligea son devoir par faiblesse, et qui pleure sa faute, que d'être l'ami perfide qui trahit la confiance de son ami, et, divulgue, pour le diffamer, le secret qu'il a versé dans son sein.

Jeune femme, voulez-vous travailler à vous rendre heureuse? Commencez d'abord par nourrir votre enfant; ne mettez pas votre fille dans un couvent, élevez-la vous-même ; votre mari est jeune, il est d'un bon naturel ; voilà ce qu'il vous faut. Vous ne me dites point comment il vit avec vous ; n'importe : fût-il livré à tous les goûts de son âge et de son temps, vous l'en arracherez par les vôtres sans lui rien dire ; vos enfants vous aideront à le retenir par des liens aussi forts et plus constants que ceux de l'amour ; vous passerez la vie la plus simple, il est vrai, mais aussi la plus douce et la plus heureuse dont j'aie l'idée. Mais encore une fois, si celle d'un ménage bourgeois vous dégoûte, et si l'opinion vous subjugue, guérissez-vous de la soif du bonheur qui vous tourmente, car vous ne l'étancherez jamais.

Voilà mes idées : si elles sont fausses ou ridicules, pardonnez l'erreur à l'intention ; je me trompe peut-être, mais il est sûr que je ne veux pas vous tromper. Bonjour, Madame ; l'intérêt que vous prenez à moi me touche, et je vous jure que je vous le rends bien. Toutes vos lettres sont ouvertes; la dernière l'a été, celle-ci le sera ; rien n'est plus certain. Je vous en dirais bien la raison, mais ma lettre ne vous parviendrait pas; comme ce n'est pas à vous qu'on en veut, et que ce ne sont pas vos secrets qu'on y cherche, je ne crois pas que ce que vous pourriez avoir à me dire fût exposé à beaucoup d'indiscrétion ; mais encore faut-il que vous soyez avertie. 


\section{Lettre 129}

\section{À Mme B. [de Berthier]}

Monquin, le 16 mars 1770

Retour à la table des matières

Rose, je vous crois, et je vous croirais avec plus de plaisir encore si vous eussiez moins insisté. La vérité ne s'exprime pas toujours avec simplicité, mais quand cela lui arrive, elle brille alors de tout son éclat. Je vais quitter cette habitation : je sais ce que je veux et dois faire; j'ignore encore ce que je ferai : je suis entre les mains des hommes ; ces hommes ont leurs raisons pour craindre la vérité, et ils n'ignorent pas que je me dois de la mettre en évidence, ou du moins de faire tous mes efforts pour cela. Seul et à leur merci, je ne puis rien, ils peuvent tout, hors de changer la nature des choses et de faire que la poitrine de J.-J. Rousseau vivant cesse de renfermer le cœur d'un homme de bien. Ignorant dans cette situation en quel lieu je trouverai, soit une pierre pour y poser ma tête, soit une terre pour y poser mon corps, je ne puis vous donner aucune adresse assurée. Mais si jamais je retrouve un moment tranquille, c'est un soin que je n'oublierai pas. Rose, ne m'oubliez pas non plus. Vous m'avez accordé de l'estime sur mes écrits ; vous m'en accorderiez encore plus sur ma vie si elle vous était connue ; et davantage encore sur mon cœur, s'il était ouvert à vos yeux : il n'en fut jamais un plus tendre, un meilleur, un plus juste ; la méchanceté ni la haine n'en approchèrent jamais. J'ai de grands vices sans doute, mais qui n'ont jamais fait de mal qu'à moi ; et tous mes malheurs ne me viennent que de mes vertus. Je n'ai pu, malgré tous 
mes efforts, percer le mystère affreux des trames dont je suis enlacé ; elles sont si ténébreuses, on me les cache avec tant de soin, que je n'en aperçois que la noirceur. Mais les maximes communes que vous m'alléguez sur la calomnie et l'imposture ne sauraient convenir à celle-là ; et les frivoles clameurs de la calomnie sont bien différentes dans leurs effets des complots tramés et concertés durant de longues années dans un profond silence, et dont les développements successifs, dirigés par la ruse, opérés par la puissance, se font lentement, sourdement, et avec méthode. Ma situation est unique ; mon cas est inouï depuis que le monde existe. Selon toutes les règles de la prévoyance humaine, je dois succomber ; et toutes les mesures sont tellement prises, qu'il n'y a qu'un miracle de la Providence qui puisse confondre les imposteurs. Pourtant une certaine confiance soutient encore mon courage. Jeune femme, écoutez-moi : quoi qu'il arrive, et quelque sort qu'on me prépare, quand on vous aura fait l'énumération de mes crimes, quand on vous en aura montré les frappants témoignages, les preuves sans réplique, la démonstration, l'évidence, souvenez-vous des trois mots par lesquels ont fini mes adieux : Je suis innocent.

Vous approchez d'un terme intéressant pour mon cœur : je désire d'en savoir l'heureux événement aussitôt qu'il sera possible. Pour cela, si vous n'avez pas avant ce temps-là de mes nouvelles, préparez d'avance un petit billet, que vous ferez mettre à la poste aussitôt que vous serez délivrée, sous une enveloppe à l'adresse suivante :

À Madame Boy de la Tour, née Roguin, à Lyon. 
Jean-Jacques Rousseau, Lettres (1728-1778)

\title{
Neuvième partie
}

\section{La vie cachée : Paris}

\author{
$1771-1778$
}

$\underline{\text { Retour à la table des matières }}$

Il y eut à Paris quatre séances de lecture des Confessions, du 7 novembre au début de mai de l'année suivante. On s'agita. Mme d'Epinay recourut au Préfet de police. Rousseau ne fut pas inquiété, mais il lui sembla qu'il avait manqué son but. Les Dialogues de Rousseau juge de Jean-Jacques, dont il commenta peu après la rédaction douloureuse, confrontant en un diptyque vertigineux le portrait du monstre qu'il croit être au regard des autres et le portrait (à demi rêvé) de son être véritable, attestent son angoisse de se sentir une fois de plus défiguré. C'est à la postérité qu'il s'adresse quand il imagine déposer le manuscrit des Dialogues sur le maître-autel de Notre-Dame, avec l'espoir qu'il parviendra aux mains du Roi. Espoir déçu ! Barré une fois de plus et sur le point de mourir étouffé - tel un personnage de Kafka - il interjette appel devant Dieu : c'est à « l'Être éternel » qu'il présente le livre des Confessions (livre posthume).

Pourtant, malgré des remous et des moments de panique, les deux dernières années de la vie de Rousseau, le temps de la composition des Rêveries $d u$ Promeneur solitaire, le voient s'apaiser peu à peu. L'aiguille du baromètre (l'image est de lui) demeure instable. Mais une attente, une rémission, un calme avant-coureur s'instaurent par degrés dans son âme. Rue Plâtrière, son 
existence avec Thérèse est celle de quelque petit bourgeois retraité qui travaille pour le plaisir (il copie toujours de la musique), qui se divertit par des chansons (« les consolations des misères de ma vie ») et qui se promène dans les chemins campagnards de la banlieue, seul ou en compagnie d'un ami choisi, Bernardin de Saint-Pierre. Depuis longtemps, Jean-Jacques sait qu'il a «gagné la bonne santé en marchant », et sa démarche errante favorise le vagabondage de ses pensées. Il revient sur sa vie d'autrefois, et le jour où il quittera Paris pour Ermenonville (la mort l'y surprendra le 2 juillet 1778), il laissera interrompu le manuscrit des Rêveries, et inachevée la dixième Promenade, où le thème de l'enfance perdue trouve son plein épanouissement musical : « Aujourd'hui jour de Pâques fleuries, il y a précisément cinquante ans de ma première connaissance avec Mme de Warens... » 


\section{Lettre 130}

\section{À M. Dusaulx}

Paris, ce 4 de janvier 1771

$\underline{\text { Retour à la table des matières }}$

Si M. Dusaulx faisait quelquefois collation sur le bout du banc, pour être au lit à dix heures, je lui proposerais aujourd'hui un petit souper, non d'Apicius, mais d'Epicure, et tel qu'on n'en fait guère à Paris. Ce souper, j'y ai pourvu, serait animé d'une bouteille de son vin d'Espagne, surtout de sa présence et de son entretien. S'il consent, je lui demande un petit oui, afin que le plaisir de le voir soit précédé de celui de l'attendre, à moins qu'il n'aime mieux croire que ce soit pour faire d'avance les préparatifs du festin.

Les respects de ma femme et les miens à Mme Dusaulx. 


\section{Lettre 131}

\section{À M. [Bernardin de Saint-Pierre]}

Ce vendredi 3 août 1771

Retour à la table des matières

La distraction, Monsieur, de la compagnie qui était chez moi à l'arrivée de votre paquet et la persuasion que c'étaient en effet des mines étrangères m'ont empêché de l'ouvrir, et je me suis contenté de vous en remercier à la hâte. En y regardant j'ai trouvé que c'était du café. Monsieur, nous ne nous sommes jamais vus qu'une fois, et vous commencez déjà par les cadeaux ; c'est être un peu pressé, ce me semble. Comme je ne suis point en état de faire des cadeaux, mon usage est, pour éviter la gêne des sociétés inégales, de ne point voir les gens qui m'en font. Vous êtes le maître de laisser chez moi le café ou de l'envoyer reprendre ; mais dans le premier cas, trouvez bon que je vous en remercie, et que nous en restions là. Je vous prie, Monsieur, d'agréer, mes très humbles salutations. 


\section{Lettre 132}

\section{À M. Linné}

Paris, le 21 septembre 1771

$\underline{\text { Retour à la table des matières }}$

Recevez avec bonté, Monsieur, l'hommage d'un très ignare, mais très zélé disciple de vos disciples; qui doit, en grande partie, à la méditation de vos écrits la tranquillité dont il jouit, au milieu d'une persécution d'autant plus cruelle, qu'elle est plus cachée et qu'elle couvre du masque de la bienveillance et de l'amitié la plus terrible haine que l'enfer excita jamais. Seul, avec la nature et vous, je passe dans mes promenades champêtres des heures délicieuses, et je tire un profit plus réel de votre Philosophie botanique que de tous les livres de morale. J'apprends avec joie que je ne vous suis pas tout à fait inconnu, et que vous voulez bien me destiner quelques-unes de vos productions. Soyez persuadé, Monsieur, qu'elles feront ma lecture chérie, et que ce plaisir deviendra plus vif encore par celui de le tenir de vous. J'amuse une vieille enfance à faire une petite collection de fruits et de graines; si parmi vos trésors en ce genre il se trouvait quelques rebuts dont vous voulussiez faire un heureux, daignez songer à moi. Je les recevrais même avec reconnaissance, seul retour que je puisse vous offrir, mais que le cœur dont elle part ne rend pas indigne de vous.

Adieu, Monsieur ; continuez d'ouvrir et d'interpréter aux hommes le livre de la nature. Pour moi, content d'en déchiffrer quelques mots à votre suite, dans le feuillet du règne végétal, je vous lis, je vous étudie, je vous médite, je vous honore, et je vous aime de tout mon cœur. 


\section{Lettre 133}

\section{À Mme [Delessert, à Lyon]}

À Paris, le 6 décembre 1771

\section{$\underline{\text { Retour à la table des matières }}$}

J'ai reçu, chère cousine, le très petit sac de marrons que vous m'avez envoyé. Il faut qu'il y ait eu quelque quiproquo dans l'envoi, car celui que j'ai reçu est un très grand sac d'une pesanteur énorme. En attendant l'explication, je vais toujours alléger le sac d'une partie de son contenu, en en mangeant autant qu'il me sera possible pour ne pas entasser des indigestions. Je reçois vos cadeaux et ceux de votre bonne maman avec le même cœur que vous mettez à leurs envois, mais il me semble pourtant que, s'ils étaient un peu plus proportionnés à la consommation de mon ménage, ils me feraient encore plus de plaisir.

Je ne comprends pas, chère cousine, ce que $M$. votre beau-frère a pu vous dire de mon logement pour exciter là-dessus votre commisération ; mais je puis vous assurer que ce logement, quoique fort petit et fort haut, est fort gai, fort agréable, qu'il paraît charmant à tous ceux qui me viennent voir, et que je n'en ai jamais occupé aucun qui fût plus de mon goût. Loin d'avoir à me plaindre de la manière dont je vis actuellement, j'en bénis le Ciel chaque jour davantage. Quand j'aurais cent mille livres de rentes, je ne voudrais être ni logé, ni nourri, ni vêtu autrement que je ne suis, et le seul vœu qui me reste à 
faire à cet égard est d'achever mes jours dans la même situation, sans monter ni descendre. C'est à peu près celle où je suis né et pour laquelle j'étais fait ; on ne pourrait m'en assigner aucune autre dans laquelle je ne vécusse beaucoup moins heureux.

Je finis ma lettre en hâte, me réservant de vous écrire plus à mon aise quand j'aurais moins d'embarras. Recevez les tendres salutations de deux cœurs qui vous aiment et faites-les aussi à tout ce qui vous est cher. 


\section{Lettre 134}

\section{À Mme la comtesse d'Egmont}

[Vers 1771]

$\underline{\text { Retour à la table des matières }}$

Agréez, Madame, l'hommage d'une vieille muse, que le désir de vous plaire pouvait seul rajeunir. Dans ces chants, quoique tardifs, il devrait se trouver encore quelques sons touchants et tendres. Modulés par votre ordre, ils vous étaient consacrés : j'en aurais voulu faire des hymnes. 


\section{Lettre 135}

\section{À Mme la marquise de Créqui}

4[Août (?) 1773]

Retour à la table des matières

Je vous entends, Madame, les ouvriers de ténèbres sont arrivés jusqu'à vous. On vous a prouvé généreusement que J.-J. était un méchant ; ce n'est pas à lui que l'on a prouvé cela, c'est à vous, en son absence, à son insu et en grand secret. Ainsi la vérité, escortée de la ruse, de la puissance et de leurs nombreux satellites, se masque, rampe et travaille sous terre, tandis que le mensonge seul, délaissé, trahi, mais intrépide et fier, l'interpelle à grands cris et marche à la face du soleil. Et cela vous paraît assez naturel pour me juger sans vouloir m'entendre, pour ne pas même daigner rompre ouvertement avec moi, pour me déchirer le cœur à loisir par les anxiétés de l'incertitude. Je veux supposer tous les flambeaux de l'évidence réunis pour me convaincre. Je veux qu'un délateur secret ne soit pas toujours un homme vil, qu'un honnête homme puisse en diffamer un autre à son insu, qu'il soit permis de se cacher de l'accusé vivant et présent pour le juger, sans vouloir ni lui parler ni l'écouter ; quelques hommes du moins ont droit d'être exceptés de cette inique règle : J.J. Rousseau pouvait se flatter d'en être un et j'aurais cru qu'une amitié de vingt ans avait quelques droits à réclamer, dans le cœur de Mme de Créqui, pour un homme, fût-il d'ailleurs coupable, mais qu'elle a recherché et qui du moins n'eut jamais aucun tort avec elle. Pensez-y mieux, Madame, je vous en conjure par cet amour de la vérité et de l'équité que j'ai cru voir dans votre âme. Ne 
vous préparez pas des regrets pour le temps où vous connaîtrez trop tard votre erreur et ne pourrez la réparer. Je vous demande une explication : faites percer un rayon de lumière dans cet abîme de noirceur, où ma raison se perd.

Je vous donne ma foi d'homme de bien, qui jamais ne fut violée, que tout ce qui sera dit entre nous à ce sujet, y restera concentré de ma part, et que je n'en ferai jamais aucun usage que de votre consentement. Quoi! Un homme qui passa quarante ans de sa vie aimé de tout le monde et sans avoir un seul ennemi est un monstre! L'auteur de l'Héloïse est un scélérat! S'il est quelque malheureux qui le puisse croire, c'est celui-là qui est un monstre, et c'est lui qu'il faut étouffer. Madame, je fais pour vous ce que je n'ai fait pour personne, je ne cours jamais après ceux qui s'en vont. Les barbares! Ils m'ont bien fait souffrir des maux, mais jamais aucun qui m'ait été plus sensible. 


\section{Lettre 136 [À Glück]}

Paris, le 17 avril 1774

$\underline{\text { Retour à la table des matières }}$

Monsieur le chevalier,

Je rentre chez moi, ravi, de la répétition de votre opéra Iphigénie. Vous avez réalisé ce que j'ai cru impossible jusqu'aujourd'hui. Veuillez recevoir mes félicitations sincères et mes salutations bien dévouées. 


\section{Lettre 137}

\section{À M. le prince Beloselski}

À Paris, le 27 mai 1775

\section{$\underline{\text { Retour à la table des matières }}$}

Je suis vraiment bien aise, Monsieur le Prince, d'avoir votre estime et votre confiance. Les cœurs droits se sentent et se répondent; et j'ai dit en relisant votre lettre de Genève : peu d'hommes m'en inspireront autant.

Vous plaignez mes anciens compatriotes de n'avoir pas pris ma défense, quand leurs ministres assassinaient, pour ainsi dire, mon âme. Les lâches! Je leur pardonne les injustices ; c'est à la postérité peut-être à m'en venger.

À l'heure qu'il est, je suis plus à plaindre qu'eux : ils ont perdu, dites-vous, un citoyen qui faisait leur gloire ; mais qu'est-ce que la perte de ce brillant fantôme, en comparaison de celle qu'ils m'ont forcé de faire? Je pleure quand je pense que je n'ai plus ni parents, ni amis, ni patrie libre et florissante.

O lac sur les bords duquel j'ai passé les douces heures de mon enfance, charmants paysages où j'ai vu pour la première fois le majestueux et touchant lever du soleil, où j'ai senti les premières émotions du cœur, les premiers élans d'un génie devenu depuis trop impérieux et trop célèbre, hélas! je ne vous verrai plus. Ces clochers qui s'élèvent au milieu des chênes et des sapins, ces 
troupeaux bêlants, ces ateliers, ces fabriques, bizarrement épars sur des torrents, dans des précipices, au haut des rochers ; ces arbres vénérables, ces sources, ces prairies, ces montagnes qui m'ont vu naître, elles ne me reverront plus.

Brûlez cette lettre, je vous supplie ; on pourrait encore mal interpréter mes sentiments.

Vous me demandez si je copie encore de la musique. Et pourquoi non? Serait-il honteux de gagner sa vie en travaillant? Vous voulez que j'écrive encore ; non, je ne le ferai plus. J'ai dit des vérités aux hommes ; ils les ont mal prises ; je ne dirai plus rien.

Vous voulez rire en me demandant des nouvelles de Paris. Je ne sors que pour me promener, et toujours du même côté. Quelques beaux esprits me font trop d'honneur en m'envoyant leurs livres : je ne lis plus. On m'a apporté ces jours-ci un nouvel opéra-comique: la musique est de Grétry, que vous aimez tant, et les paroles sont assurément d'un homme d'esprit. Mais c'est encore des grands seigneurs qu'on vient de mettre sur la scène lyrique. Je vous demande pardon, Monsieur le Prince, mais ces gens-là n'ont pas d'accent, et ce sont de bons paysans qu'il faut.

Ma femme est bien sensible à votre souvenir. Mes disgrâces ne lui affectent pas moins le cœur qu'à moi, mais ma tête s'affaiblit davantage. Il ne me reste de vie que pour souffrir, et je n'en ai pas même assez pour sentir vos bontés comme je le dois. Ne m'écrivez donc plus, Monsieur le Prince : il ne me serait pas possible de vous répondre une seconde fois. Quand vous serez de retour à Paris, venez me voir, et nous parlerons. Agréez, Monsieur le Prince, je vous prie, les assurances de mon respect. 


\section{Lettre 138}

\section{À Mme de Corancez}

À Paris, le 9 janvier 1778

$\underline{\text { Retour à la table des matières }}$

J'ai lu, Madame, dans le numéro 5 des feuilles que vous avez la bonté de m'envoyer, que l'un de Messieurs vos correspondants qui se nomme Le Jardinier d'Auteuil avait élevé des hirondelles. Je désirerais fort de savoir comment il s'y est pris, et quelle contenance ces hirondelles qu'il a élevées ont faite chez lui pendant l'hiver. Après des peines infinies, j'étais parvenu à Monquin à en faire nicher dans ma chambre : j'ai même eu souvent le plaisir de les voir s'y tenir, les fenêtres fermées, assez tranquilles pour gazouiller, jouer et folâtrer ensemble à leur aise, en attendant qu'il me plût de leur ouvrir, bien sûres que cela ne tarderait pas d'arriver. En effet, je me levais même pour cela tous les jours avant quatre heures ; mais il ne m'est jamais venu dans l'esprit, je l'avoue, de tenter d'élever aucun de leurs petits, persuadé que la chose était non seulement inutile, mais impossible. Je suis charmé d'apprendre qu'elle ne l'est pas, et je serai très obligé, pour ma part, au jardinier d'Auteuil, s'il veut bien communiquer son secret au public. Agréez, Madame, je vous supplie, mes remerciements et mon respect. 


\section{Lettre 139}

\section{À M. [le comte Duprat]}

À Paris, le 3 février 1778

\section{$\underline{\text { Retour à la table des matières }}$}

Vous rallumez, Monsieur, un lumignon presque éteint ; mais il n'y a plus d'huile à la lampe et le moindre air de vent peut l'éteindre sans retour. Autant que je puis désirer quelque chose encore en ce monde, je désire d'aller finir mes jours dans l'asile aimable que vous voulez bien me destiner, tous les vœux de mon cœur sont pour y être, le mal est qu'il faut s'y transporter. En ce moment, je suis demi-perclus de rhumatismes; ma femme n'est pas en meilleur état que moi, vieux, infirme, je sens à chaque instant le découragement qui me gagne ; tout soin, toute peine à prendre, toute fatigue à soutenir effarouche mon indolence, il faudrait que toutes les choses dont j'ai besoin se rapprochassent; car je ne me sens plus assez de vigueur pour les aller chercher ; et c'est précisément dans cet état d'anéantissement que, privé de tout service et de toute assistance, dans tout ce qui m'entoure, je n'ai plus rien à espérer que de moi. Vous, Monsieur le Comte, le seul qui ne m'ayez pas délaissé dans ma misère, voyez de grâce ce que votre générosité pourra faire pour me rendre l'activité dont j'ai besoin. Vous m'offrez quelqu'un de votre choix pour veiller à mes effets et prendre des soins dont je suis incapable ; oh! je l'accepte, et il n'en faut pas moins pour m'évertuer un peu : car si, par moimême, je puis rassembler deux bonnets de nuit et cinq ou six chemises, ce sera beaucoup. Il n'y a plus que ma femme et mon herbier dans le monde qui puissent me rendre un peu d'activité. Si nous nous embarquons seuls sous 
notre propre conduite, au premier embarras, au moindre obstacle je suis arrêté tout court et je n'arriverai jamais. J'aime à me bercer, dans mes châteaux en Espagne, de l'idée que vous seriez ici, Monsieur, avec M. le Commandeur, que vous daigneriez aiguillonner un peu ma paresse, que mes petits arrangements s'en feraient plus vite et mieux sous vos yeux; que si vous poussiez l'œuvre de miséricorde jusqu'à permettre ensuite que nous fissions route à la suite de l'un ou de l'autre et peut-être de tous les deux; alors, comme tout serait aplani! comme tout irait bien! Mais c'est un château en Espagne et de tous ceux que j'ai faits en ma vie je n'en vis jamais réaliser aucun. Dieu veuille qu'il n'en soit pas ainsi de l'espoir d'arriver au vôtre.

$\mathrm{Au}$ reste, je n'ai nul éloignement pour les précautions qui vous paraissent convenables pour éviter trop de sensation. Je n'ai nulle répugnance à aller à la messe : au contraire, dans quelque religion que ce soit, je me croirai toujours avec mes frères, parmi ceux qui s'assemblent pour servir Dieu. Mais ce n'est pas non plus un devoir que je veuille m'imposer. Encore moins de laisser croire dans le pays que je suis catholique. Je désire assurément fort de ne pas scandaliser les hommes, mais je désire encore plus de ne jamais les tromper. Quant au changement de nom, après avoir repris hautement le mien malgré tout le monde, pour revenir à Paris, et l'y avoir porté huit ans, je puis bien maintenant le quitter pour en sortir, et je ne m'y refuse pas ; mais l'expérience du passé m'apprend que c'est une précaution très inutile et même nuisible, par l'air de mystère qui s'y joint et que le peuple interprète toujours en mal. Vous déciderez de cela connaissant le pays comme vous faites; là-dessus comme sur tout le reste, je m'en remets à votre prudence et à votre amitié. Agréez, Monsieur le Comte, mes très humbles salutations.

Imprimé en Suisse

Fin du texte 